\title{
Optimisation of a transverse flux linear PM generator using 3D Finite Element Analysis
}

\author{
by
}

\author{
Jacques Schutte
}

Thesis presented in partial fulfilment of the requirements for the degree of Master of Science in Engineering at

Stellenbosch University

\author{
Supervisor: Mr. J.M. Strauss \\ Faculty of Engineering \\ Department of Electrical and Electronic Engineering
}

December 2011 


\section{Declaration}

By submitting this thesis electronically, I declare that the entirety of the work contained therein is my own, original work, that I am the sole author thereof (save to the extent explicitly otherwise stated), that reproduction and publication thereof by Stellenbosch University will not infringe any third party rights and that I have not previously in its entirety or in part submitted it for obtaining any qualification.

Date: December 2011

Copyright $(92011$ Stellenbosch University All rights reserved. 


\section{Abstract}

Several transverse flux and longitudinal flux linear generator topologies exist for freepiston Stirling engine applications. In this thesis the transverse flux permanent magnet linear generators are investigated together with a back-to-back converter which can deliver the electrical energy from the linear generator to the electrical network.

The transverse flux permanent magnet linear generator is geometrically optimised with the aim to maximise the power-to-weight ratio while maintaining preset power and efficiency levels. An optimised $3 \mathrm{~kW}$ linear generator is built and the measured results correlate to the simulation results.

A close-loop current control scheme is introduced to control the current of the rectifier, which is part of the back to back converter. The transverse flux permanent magnet linear generator is connected to the input of the rectifier which has the ability to force a specific current from the generator. The measured results of the rectifier correlate to the results of the simulations that were done. The current control present some complications and it is suggested that another control scheme is used.

A close-loop voltage control scheme is introduced for the control of the DC bus voltage. The DC bus is connected between the rectifier and the inverter, which is the other part of the back-to-back converter. A close-loop current control scheme is introduced to control the inverter current that flows from the inverter to the electrical network. The measured results of the inverter and the DC bus correlate to the results of the simulations that were done.

The results of the system, including the generator, rectifier and inverter, tested as a unit is presented and discussed. 


\section{Opsomming}

Verskeie tranverse vloed en longitudinale vloed lineêre generator topologieë bestaan vir vrysuier Stirling enjin toepassings. In hierdie tesis word ' $n$ transverse vloed permanente magneet lineêre generator ondersoek saam met 'n omsetter. Die omsetter dra die elektriese energie van die generator oor aan die elektriese netwerk.

Die transverse vloed permanente magneet lineêre generator word geometries geoptimeer met die doel om die drywing-tot-gewig verhouding te maksimiseer terwyl vasgestelde drywing en effektiwiteit vlakke behou word. 'n Geoptimeerde 3kW lineêre generator prototipe is vervaardig en die gemete resultate is geverifieer met die simulasie resultate.

'n Geslote lus stroombeheer strategie word voorgestel om die stroom te beheer van die gelykrigter, wat deel is van die omsetter. Die transverse vloed permanente magneet lineêre generator word aan die gelykrigter, wat die vermoë het om 'n spesifieke stroom uit die generator te forseer, se intree verbind. Die gemete resultate van die gelykrigter wat gebou is stem goed ooreen met die van die simulasies wat gedoen is. Die stroombeheer hou komplikasies in wat bespreek word. Dus word die gebruik van 'n alternatiewe stroombeheer voorgestel.

'n Geslote lus spannings beheer strategieë word voorgestel om die gs. busspanning te beheer. Die gs. bus is gekonnekteer tussen die gelykrigter en die wisselrigter, wat ook deel uitmaak van die omsetter. 'n Geslote lus stroom beheer word voorgestel om die stroom te beheer wat vanaf die wisselrigter na die elektriese netwerk toe vloei. Die gemete resultate van die wisselrigter en die gs. bus stem goed ooreen met die van die simulasies wat gedoen is.

Die resultate van die hele stelsel, wat die generator, gelykrigter en die wisselrigter insluit, wat as 'n eenheid getoets is word weergegee en bespreek. 


\section{Acknowledgements}

I would like to thank the following people:

- My supervisor, Mr. J.M. Strauss, for the guidance and advice he provided throughout the course of this study.

- South African National Energy Research Institute (SANERI) for providing the financial support to complete the project.

- My family, friends and loved ones, for their support and motivation.

- Mrs. Daleen Kleyn for her reliability and competence with regard to the administrative arrangements throughout this project.

- My colleagues for your never-ending assistance and creating a wonderful atmosphere to work in.

- The members in the SED and SMD groups that was involved in this project, for their assistance and input.

To God be all the Glory 


\section{Contents}

Nomenclature $\quad$ vii

1 Introduction $\quad 1$

1.1 History of Stirling engines . . . . . . . . . . . . . . . . . 1

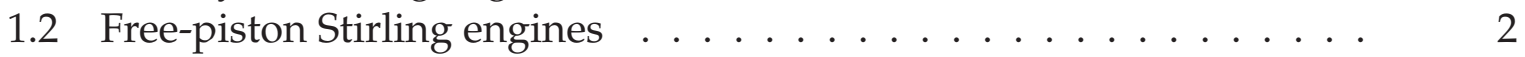

1.3 Power modulation of Stirling engines . . . . . . . . . . . . 4

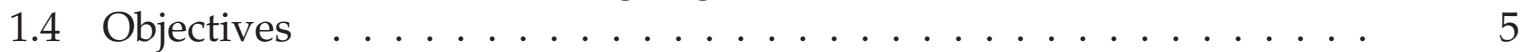

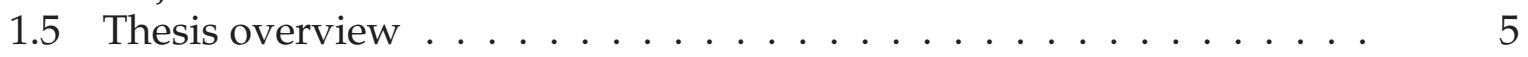

2 Introduction to transverse flux linear generators $\quad 7$

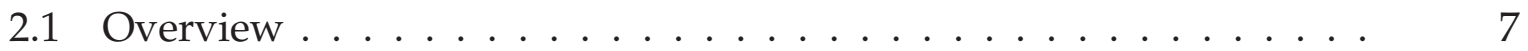

2.2 Suitable linear generator topologies for Stirling engine applications . 8

2.3 Moving iron topologies . . . . . . . . . . . . . . . . 10

2.3.1 An arrangement described by Boldea and Nasar . . . . . . . . 10

2.3.2 Verification of the arrangement described by Boldea and Nasar 10

2.4 Moving magnet topologies . . . . . . . . . . . . . . 12

3 Moving magnet TF linear generator topology 14

3.1 Introduction . . . . . . . . . . . . . . . . . . 14

3.2 Description of topology . . . . . . . . . . . . . . . . . 14

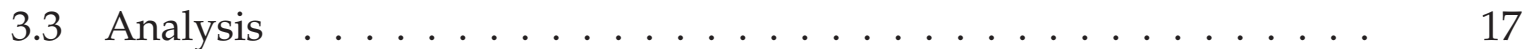

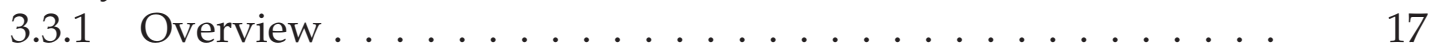

3.3.2 Finite element analysis . . . . . . . . . . . . . . . . . . 17

3.4 Dimensional Optimisation . . . . . . . . . . . . . . . . . . 21

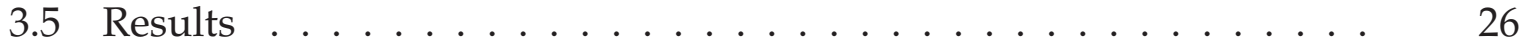

3.5.1 Design and operational spesifications ........... 26

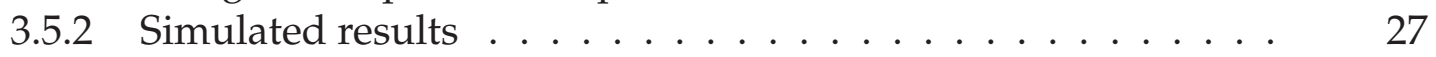

3.5.3 Construction of the $3 \mathrm{~kW}$ prototype . . . . . . . . . . 30

3.5 .4 Measured results . . . . . . . . . . . . . . 33

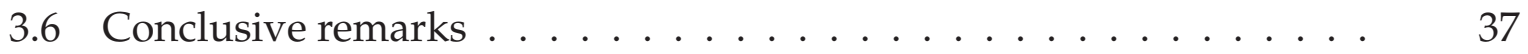

4 Rectifier 38

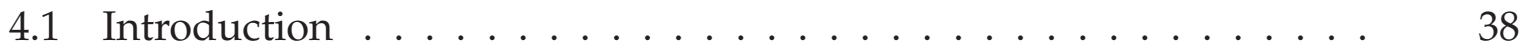

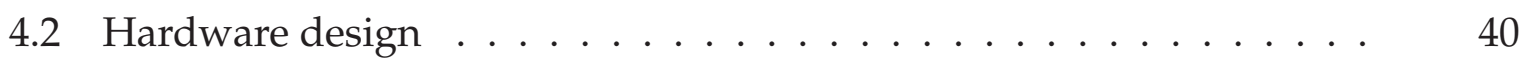

4.2.1 Power electronics and related hardware . . . . . . . . . . . . 40

4.2.2 Digital control hardware . . . . . . . . . . . . . 41 


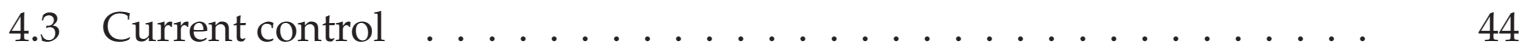

4.3.1 High level overview . . . . . . . . . . . . . . . 44

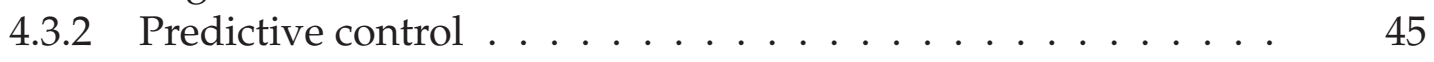

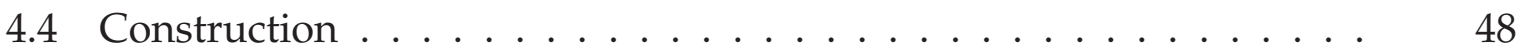

4.5 Results . . . . . . . . . . . . . . . . . . . . 49

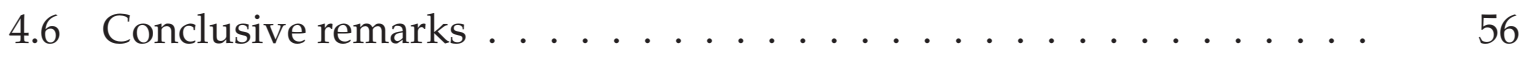

5 Inverter 57

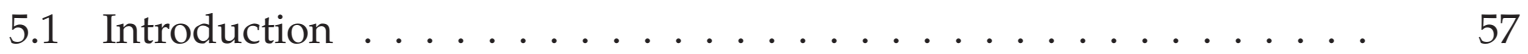

5.2 Hardware design . . . . . . . . . . . . . . . . . . 59

5.2.1 Power electronics and related hardware . . . . . . . . . 59

5.2.2 Digital control hardware . . . . . . . . . . . . . . . . 60

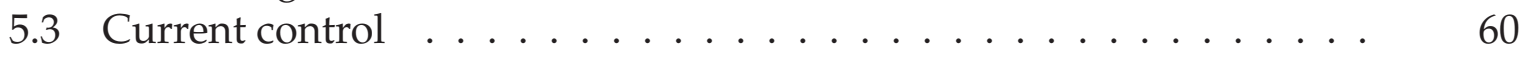

5.3.1 High level description . . . . . . . . . . . . . . 60

5.3.2 The $\alpha \beta$ transformation . . . . . . . . . . . . . 60

5.3.3 Park's transformation . . . . . . . . . . . . . . 62

5.3.4 Space vector pulse width modulation . . . . . . . . . 63

5.3.5 Proportional-Integral (PI) control . . . . . . . . . . . . 67

5.4 DC bus voltage and start-up control $\ldots \ldots \ldots \ldots \ldots$

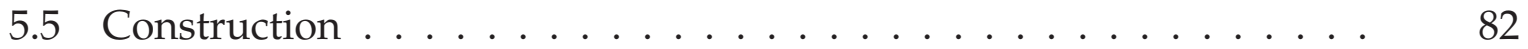

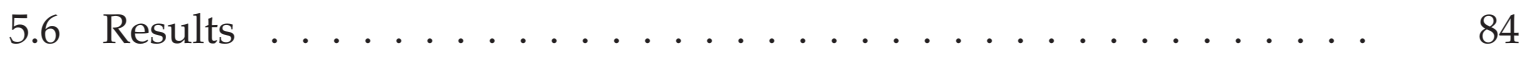

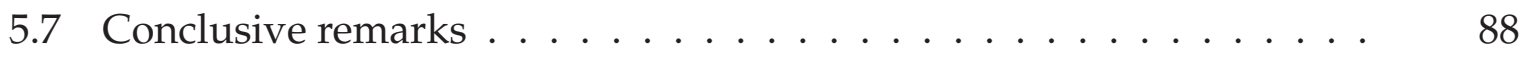

6 Conclusion and recommendations $\quad 90$

$\begin{array}{lr}\text { Bibliography } & 94\end{array}$

A Construction of prototypes $\quad 96$

$\begin{array}{ll}\text { B Sallen-Key Filter } & 100\end{array}$ 


\section{Nomenclature}

$\begin{array}{ll}d & \text { Stator wall thickness } \\ d_{m} & \text { Magnet depth } \\ e \text { or emf } & \text { Electromotive force of the generator } \\ g & \text { Air gap } \\ i_{a, b, c} & \text { Respective currents of the electrical network } \\ i_{d r e f} & \text { Reference d-component current of the inverter } \\ I_{d c i} & \text { The DC current flowing from the rectifier into the DC bus } \\ I_{d c o} & \text { The DC current flowing from the DC bus to the inverter } \\ i_{g} & \text { The current flowing out at the terminals of the generator } \\ i_{r e f} & \text { Reference current of the rectifier } \\ l_{c} & \text { Coil length } \\ l_{p} & \text { Pole length } \\ r_{c h} & \text { Centre hole radius } \\ r_{i s} & \text { Internal stator radius } \\ v_{a g, b g, c g} & \text { Respective voltages of the electrical network at the first measurable point } \\ V_{d c} & \text { The DC bus voltage } \\ v_{f} & \text { Switched voltage of the rectifier } \\ v_{f a} & \text { Filtered voltage between the a-phase-arm of the inverter and the neutral } \\ & \text { of the electrical network } \\ v_{g t} & \text { Terminal voltage of the generator } \\ v_{\lambda} & \text { The voltage induced in the coil by the resultant flux linkage of the coil } \\ w_{c} & \text { Coil width } \\ w_{m} & \text { Magnet width }\end{array}$




\section{Chapter 1}

\section{Introduction}

\subsection{History of Stirling engines}

The Stirling engine was originally called a hot-air engine by Rev. Robert Stirling who invented and patented the engine in 1816. In the search for higher power densities and engine efficiency it was found that gasses with lighter molecular weight such as helium and hydrogen were superior to air and therefore the title Stirling engine was considered more appropriate than hot-air engine.

By the early 1930s the Stirling engine was nearly completely abandoned because vast improvements were made to the internal combustion engine to become the dominant engine of the future. The close-cycle engine was revisited in 1937 in a laboratory of Philips Gloeilampenfabrieken ${ }^{1}$ in the south of Netherlands. Good progress was made with the development of numerous Stirling engines and it was realised that various appliances could be powered by the Stirling engine.

The Stirling engine program progressed steadily during the Second World War and in January 1952 the Engine Division was established at Philips to continue work on Stirling engines. This division was discontinued only two years later in December 1953. This was due to serious problems encountered with Stirling engines which included amongst other the acceptable and uniform heat transfer at high temperature to the working gas, lubrication of the pistons, seals and sealing, and regenerator contamination [1].

After a licence agreement in 1958 and up to 1970 General Motors became involved with the development of Stirling engines. In 1970, General Motors discontinued their

\footnotetext{
${ }^{1}$ Later known as Philips.
} 
Stirling engine project for reasons not directly relating to Stirling engines. From the late 1960s, MAN-MWM² negotiated a licence and cooperation agreement with Philips. Around the same time United Stirling A.B. was formed and became a Philips licence holder shortly afterwards. Various engines were developed until the late 1970s with several applications in mind. A combination of industries and universities became involved and more than one hundred groups were working on Stirling engines by $1978[1,2]$.

\subsection{Free-piston Stirling engines}

William Beale invented the free-piston Stirling engine in the 1950s while he was a professor of mechanical engineering at the University of Ohio. Free-piston engines operate without the pistons being coupled mechanically while mechanical drive mechanisms are employed to rigidly couple the pistons and the output shaft of kinematic type Stirling engines. The displacement of the reciprocating elements are rather coupled gas dynamically in free-piston engines and reciprocation results from resonant interaction between various forces, including gas pressure forces, gas spring forces and damping forces [3]. Of importance here is that reciprocating motion can be converted directly to electrical energy by connecting linear generators directly to the pistons.

It was only in the late 1960s that serious work started on free-piston Stirling engines and serious investment of resources did not begin before the early 1970s. By the late 1970s various groups around the world were working on free-piston Stirling engines [4]. By the beginning of the 1980s Sunpower was the first company in the world to produce free-piston Stirling engines commercially [3].

An artistic rendering illustrates a free-piston Stirling engine with a 4 spoke, 2 pole moving iron linear generator of Stirling Technology Company (STC) in figure 1.1. In the 1980s STC was involved in a project to provide new concepts for Stirling engines. STC is known today as Infinia Corporation and is one of the leaders in the field of free-piston Stirling engines for solar applications.

Kinematic and free-piston Stirling engines were utilized in energy conversion in solar dish and combined heat and power systems since the 1990s. To date, Sunpower and Infinia Corporation includes companies that is seriously involved in free-piston engine development and commercialisation.

\footnotetext{
${ }^{2}$ Mashinenfabrik Augsburg-Nürnberg (MAN) and Motorenwerke Mannheim (MWM) formed the Entwicklungsgruppe Stirlingmotor MAN-MWN.
} 


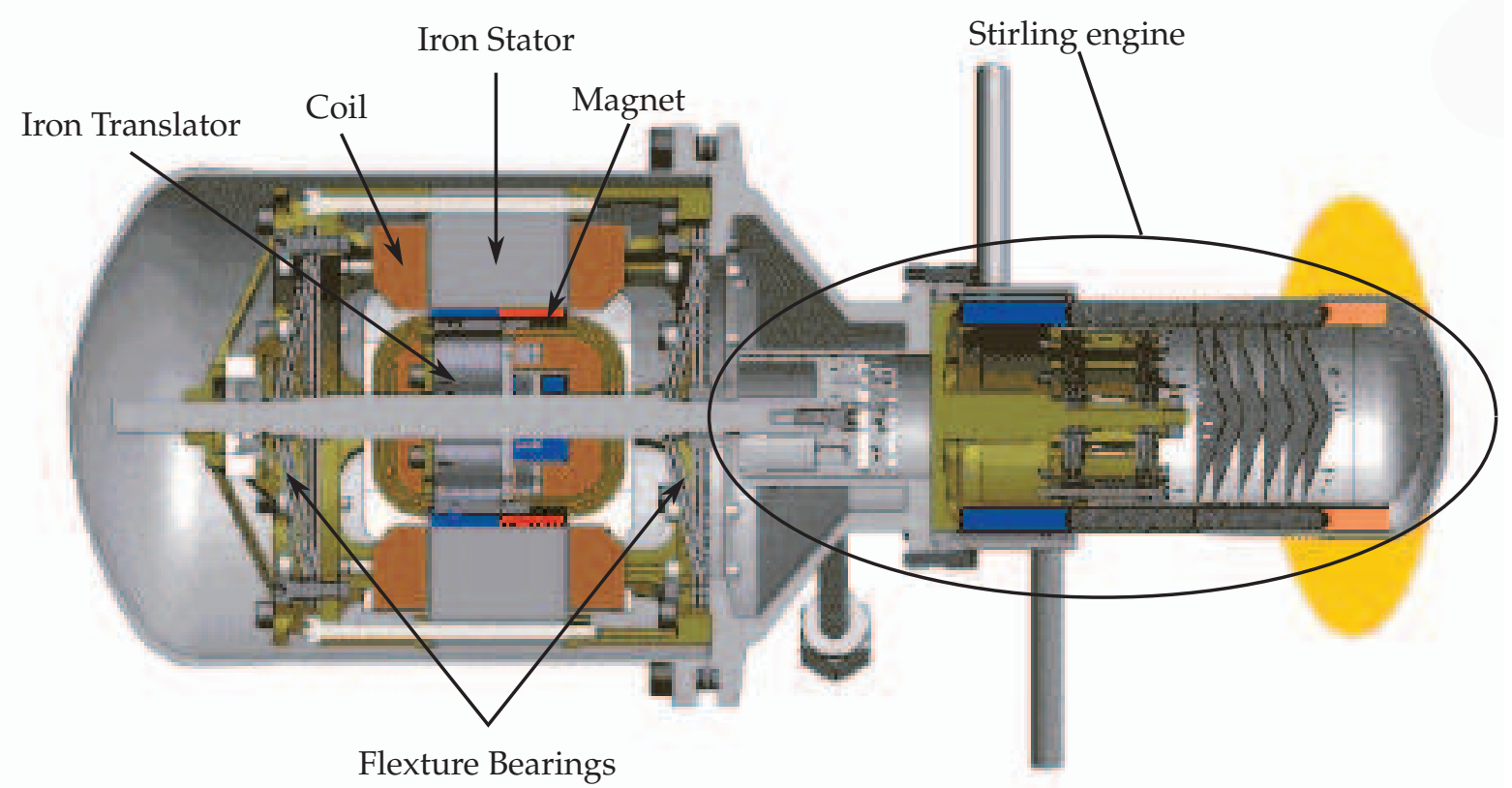

Figure 1.1: Free-piston Stirling engine with moving iron transverse flux linear PM generator [source: Raleigh Myers. Sirling. http://www.raenergy.igc.org/stirling.html] [5].

The number of application fields expanded for Stirling engines due to the advantages the free-piston topology holds with respect to their kinematic counterparts. These include their utilization as deep space power sources heated by isotope heat sources and low maintenance remote power systems. However, the free-piston engines also impose various problems that need to be overcome.

Free-piston Stirling engine advantages include [1,3]:

1. With no crank mechanisms or rotating parts to generate lateral forces and therefore no lubrication is required.

2. Fewer moving parts and dry-running pistons allow lower manufacturing cost and potentially longer periods between maintenance.

3. Free-piston engines can be built as a complete sealed unit, reducing loss of gas virtually to zero and allowing operation in various environments.

Free-piston Stirling engine disadvantages include [1,3]:

1. The oscillations of the moving parts are not set mechanically but are determined by the interactions of the entire system, i.e. engine, generator and applied load. This requires complex calculations to ensure proper reciprocating motion. 
2. As a result of the resonant behaviour of free-piston engines, power modulation might be necessary when driving variable loads. Control techniques are needed to prevent extreme piston displacement which can cause instability and mechanical failure. Techniques that can be used to prevent this include amongst others the alteration of gas springs and damping constants.

3. Piston centering problems emerge due to non-linear flow of gas between the compression and bounce spaces. This resultant gas flow from the compression to the bounce space causes the piston center position to move slowly towards the compression space. Therefore piston position becomes a critical area of control. This could lead to reduced power output or mechanical failure.

\subsection{Power modulation of Stirling engines}

If the disadvantages of free-piston engines can be overcome, then the advantages of the engine would make it a very good candidate for solar thermal to electrical energy conversion. The disadvantages, especially concerning resonant behaviour and piston centering, can be overcome by controlling the energy flow of a free-piston engine. Energy flow control of the Stirling engine can be accomplished by controlling the power output of the linear generator.

Several linear generator topologies, i.e transverse flux (TF) and longitudinal flux (LF) (e.g. [6-11]), can be used for the power modulation of free-piston Stirling engines that convert solar thermal energy to mechanical energy.

Tubular transverse flux permanent magnet linear generators are continuously used with success for mechanical to electrical energy conversion in systems that incorporate a free-piston Stirling engine that convert solar thermal energy to mechanical energy. Due to little information in literature available on performance evaluation of tubular transverse flux permanent magnet linear generators and contradictions in existing literature it was deemed necessary to investigate the matter further.

Free-piston Stirling engines are larger in size for the same power rating than other engines such as the internal combustion engine. While free-piston Stirling engines is the only suitable technology for solar energy to mechanical energy conversion there is a constant effort to improve the power-to-weight ratio of free-piston Stirling engines.

An optimised linear generator with easy manufacturability and power output control is ideal for the mechanical to electrical energy conversion in systems that incorporate a free-piston Stirling engines. In order for free-piston Stirling engines to be a competitive 
technology it must be easy manufacturable and cost effective. This implies that the linear generator used in the system must adhere to these characteristics.

While several methods are used to utilize the electrical output power of the linear generator a back-to-back power electronic converter that is connected to the national grid is favourable. This is because the linear generator acts as a damper on the resonant free-piston Stirling engine which implies that the amplitude of the output current of the linear generator which is controlled by the back-to-back power electronic converter can be seen as a damping coefficient.

\subsection{Objectives}

The main objectives of this thesis include:

- The optimisation and design of a transverse flux permanent magnet linear generator using 3D finite element analysis. For this study the focus on the generator topology of choice lies in the manufacturability while maintaining as good performance as possible.

- The optimised generator must be manufactured and tested to confirm the simulation results.

- The power generated by the linear generator must be delivered to the national grid. Therefore a back-to-back power electronic converter needs to be implemented with all the necessary controls.

\subsection{Thesis overview}

Chapter 2 gives an introduction to transverse flux linear generators. A discussion follows explaining the different transverse flux topologies including the optimisation, investigation and performance evaluation of a moving iron topology.

Chapter 3 further investigates optimisation of transverse flux permanent magnet linear generators. A moving magnet topology is extensively discussed in this chapter.

Chapter 4 describes the design and current control of the rectifier built as part of the back-to-back converter and also includes results of the rectifier unit. 
Chapter 5 describes the design of an inverter with focuses on current control, space vector pulse width modulation and DC bus control. Results of the inverter unit are also included.

Chapter 6 presents test results of the combined system, i.e. generator, rectifier and inverter. 


\section{Chapter 2}

\section{Introduction to transverse flux linear generators}

\subsection{Overview}

Several linear generator topologies, i.e transverse flux (TF) and longitudinal flux (LF) (e.g. [6-11]), exist for free-piston Stirling engine (FPSE) applications. A research program was initiated at the Department of Electrical and Electronic Engineering at the University of Stellenbosch with the objective to evaluate existing generator topologies and to develop new topologies for FPSE applications. In this investigation transverse flux permanent magnet (TFPM) linear generators are under investigation. The study of the TF branch of linear generators was initiated because of limited available literature in the field as well as contradictory information in the available literature.

This chapter provides an introduction to different TFPM linear generator topologies suitable for free-piston Stirling engine (FPSE) applications as discussed in section 1.3. In section 2.2 the requirements of different linear generator topologies are discussed. Sections 2.3 and 2.4 each give a detailed discussion on moving iron and moving magnet linear generators respectively. 


\subsection{Suitable linear generator topologies for Stirling engine applications}

Two of the most important aspects that a linear generator for Stirling engine applications must have are robustness and manufacturability. Tubular TF linear generators are easier to manufacture than the tubular LF generators which require wedge shaped laminations for manufacturing. Soft magnetic composite (SMC) material can be used to overcome the issue of wedged shaped laminations in LF generators but holds some disadvantages as described by [12]. These disadvantages include lower strength than laminate steel and higher losses as low frequencies (i.e fifty to a few hundred Hz).

The shape of tubular TF linear generators correspond better to the shape of free-piston Stirling engines than flat linear generators. This makes the tubular TF linear generator a more desirable option.

In the case of tubular TF linear generators the magnet's face is curved in such a manner that the centre point of the curve lies at the centre of the translator where in the case of a flat plane generator the face of the magnet is flat and face the flat stator. This characteristic enables the translator of the tubular TF linear generator to reach a settling position where no torque acts on the translator due the curved nature of the magnets and the stator spoke. This settling position is where the face of the magnet align with the face of a stator spoke. There is a torque acting on the translator of a flat linear generator due to the attracting force of the magnet to the stator spoke. This implies that it is possible for one side of the magnet to touch the stator spoke which can lead to mechanical damage or failure of the generator.

The advantages and disadvantages listed above is viewed from a physical point of view and a performance evaluation need to be done to further investigate linear generators. In the rest of this chapter only tubular TF linear generator topologies are considered due to the physical advantages it hold over its counterparts in the Stirling engine applications.

Tubular TF linear generators can be divided into several categories, two of which are extensively discussed in this project. The first one is the moving iron TFPM linear generator as seen in figure 2.1 and described by Boldea and Nassar [6]. The second topology discussed in this project is the moving magnet TFPM linear generator as seen in figure 2.2 which is similar to the dual-stator moving magnet topology described by Infinia Corporation [5]. However the Infinia Corporation TFPM linear generator has magnets near the outside radius with two air gaps, hence the dual-stator, while the moving magnet TFPM linear generator described here have magnets mounted on 
the translator iron which results in only one air gap. The magnets of the moving iron TFPM linear generator are mounted on the stator.

The images on the left in figures 2.1 and 2.2 are cross-sectional views of the respective generators that show the flux paths. The images on the right are 3D illustrations with one quarter cut out. All figures of linear generators in this section are scaled to the same proportion with realistic dimensions.
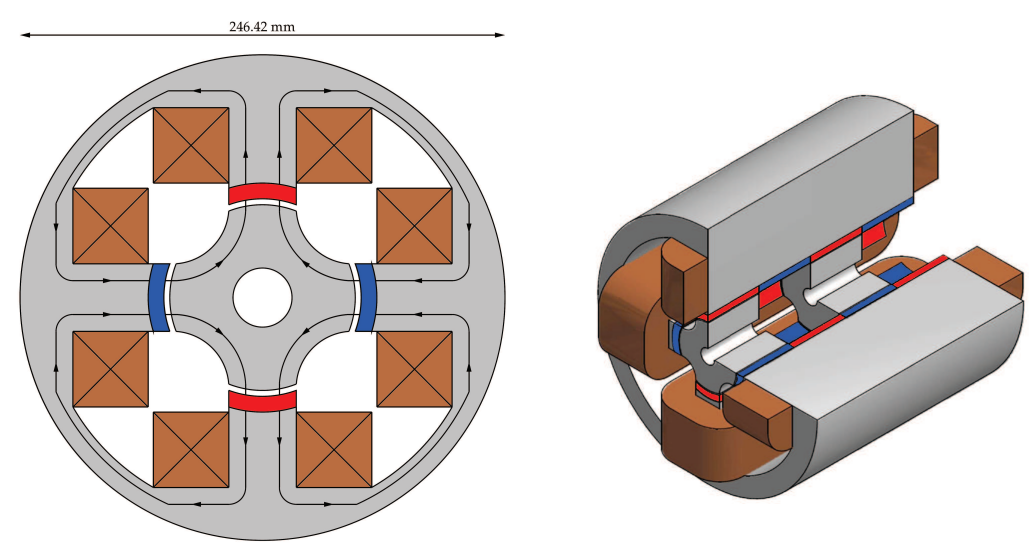

Figure 2.1: Main flux paths and 3D illustration with one quarter cut-out of the Moving Iron TF linear generator
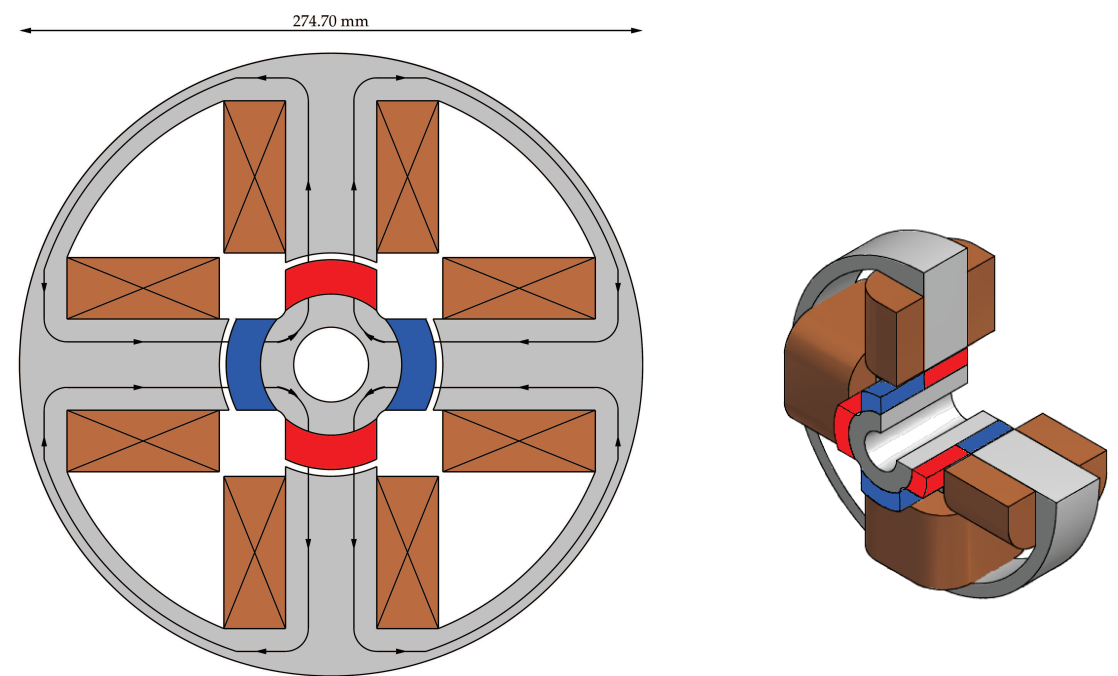

Figure 2.2: Main flux paths and 3D illustration with one quarter cut-out of the Moving Magnet TF linear generator 


\subsection{Moving iron topologies}

\subsubsection{An arrangement described by Boldea and Nasar}

Boldea and Nasar performed an analytical analysis of a 4 spoke, 4 pole, TFPM linear generator as illustated in figure 2.1. According to an example design of this generator by Boldea and Nasar for a $1 \mathrm{~kW}$ generator, the estimated mass (laminations, copper and magnets) is approximately $17 \mathrm{~kg}$. This implies a power-to-weight ratio of 0.058 $\mathrm{kW} / \mathrm{kg}$. The same generator is mentioned by Arshad [7] where he quotes a powerto-weight ratio of approximately $0.1 \mathrm{~kW} / \mathrm{kg}$. This generator topology was only very briefly discussed by Arshad and Boldea and Nasar. In the next section a more detailed analysis done by Schutte and Strauss [8] is discussed.

\subsubsection{Verification of the arrangement described by Boldea and Nasar}

In attempt to clarify contradictions of the two power-to-weight ratio's as listed in the previous section as well as to determine the optimum translator mass, Schutte and Strauss investigated the topology in more depth. This investigation was aimed at the geometric optimisation of the moving iron topology as described by Boldea and Nasar. The goal was to maximise the power-to-weight ratio while maintaining the output power and efficiency at preset levels. This optimisation process by Schutte and Strauss was assisted by a 3D Finite Element Analysis (FEA) using the commercial package MagNet $\AA$ from Infolytica in order to improve the accuracy of results when compared to analytical modelling.

The design optimisation of Schutte and Strauss was performed on a 3kW, 4 spoke, 4 pole TFPM linear generator with specifications listed in table 2.1 below and illustrated in figure 2.1. The cost function was defined as the combined mass of the iron of the stator and the mover segments. The copper and permanent magnets could be included in the cost function but in the design and optimisation of Schutte and Strauss these were not included in the cost function of the optimisation process. If only the mass of the iron is used then the translator's weight would be at an optimal minimum without compromising the proportion of the generator in the optimisation process.

The optimisation results from Schutte and Strauss are listed in table 2.2 below. The total power-to-weight ratio of $0.061 \mathrm{~kW} / \mathrm{kg}$ is not far from to the $0.058 \mathrm{~kW} / \mathrm{kg}$ ratio from the analytical design of Boldea and Nasar. The figure of approximately $0.1 \mathrm{~kW} / \mathrm{kg}$ quoted by Arshad is shown to be optimistic. 
Table 2.1: Design and operational specifications.

\begin{tabular}{|l|l|}
\hline Description & \\
\hline Power & $>3 \mathrm{~kW}$ \\
\hline Efficiency & $>95 \%$ \\
\hline Flux density (stator wall) & $<1.3 \mathrm{~T}$ \\
\hline Flux density (mover) & $<1.3 \mathrm{~T}$ \\
\hline Flux density (spokes) & $<1.3 \mathrm{~T}$ \\
\hline Current density & $<6 \mathrm{~A} / \mathrm{mm}^{2}$ \\
\hline Stroke length & $45 \mathrm{~mm}$ \\
\hline Speed & $3000 \mathrm{reciprocations} / \mathrm{min}$ \\
\hline Stator & Cold rolled $1010 \mathrm{steel} ; 7600 \mathrm{~kg} / \mathrm{m}^{3}$ \\
\hline Mover & Cold rolled $1010 \mathrm{steel} ; 7600 \mathrm{~kg} / \mathrm{m}^{3}$ \\
\hline Magnet & NdFeB: N40; $7500 \mathrm{~kg} / \mathrm{m}^{3} ; \mu_{r}=1.05 ; H_{c}=-936 \mathrm{kA} / \mathrm{m}$ \\
\hline Coil & Copper; $8954 \mathrm{~kg} / \mathrm{m}^{3} ; \sigma=5.77 \times 10^{7} \mathrm{~S} / \mathrm{m}$ \\
\hline
\end{tabular}

Table 2.2: Optimisation results.

\begin{tabular}{|l|c|}
\hline Desciption & Complete generator \\
\hline Cost function mass [kg] & 25.73 \\
\hline Mover mass [kg] & 3.50 \\
\hline Coil mass [kg] & 22.62 \\
\hline Magnet mass [kg] & 0.83 \\
\hline Total generator mass [kg] & 49.18 \\
\hline Power out [W] & 3000 \\
\hline Efficiency & 0.95 \\
\hline Current density & 1.841 \\
\hline Total power-to-weight ratio $[\mathrm{kW} / \mathrm{kg}]$ & 0.061 \\
\hline Resistance [m $\Omega]$ & 84.01 \\
\hline Inductance [mH] & 14.05 \\
\hline Flux density - stator wall [T] & 0.60 \\
\hline Flux density - mover [T] & 0.82 \\
\hline Flux density - spoke [T] & 0.47 \\
\hline
\end{tabular}


A disadvantage of the topology as listed by Schutte and Strauss, apart from the low power-to-weight ratio, is the rather large series inductance. A highly capacitive power factor is therefore required at the terminals in order to have the current in phase with the emf voltage. This is a prerequisite in FPSE's, since it means that the linear generator then acts as a damper of which the coefficient can be adjusted by adjusting the current amplitude. There are several methods to overcome this disadvantage e.g. to install a series capacitor at the terminals of the generator.

This TFPM moving iron generator topology was discarded by Schutte and Strauss as a candidate for the application as listed in section 1.3.

\subsection{Moving magnet topologies}

Infinia Corporation improved the performance of the moving-iron, stationary magnet linear generator by designing a dual-stator, moving magnet linear generator. The dualstator, moving iron generator topology significantly increases specific power according to Infinia Corporation. The dual-stator generator maintains the use of oppositely charged magnets per pole, axially spaced, one with north towards the outer diameter and one with south towards the outer diameter. The magnets are reversed at each adjacent pole, similar to the $1 \mathrm{~kW}$ moving iron type Infinia Corporation built previously. The flux linkage is reversed at each end of the stroke due to opposite polarity magnets in the circuit. Infinia Corporation claim that the dual stator moving magnet generator, which is a $3.1 \mathrm{~kW}$ generator, has a mass of $\pm 13 \mathrm{~kg}$, which is approximately half the mass of the previous $1 \mathrm{~kW}$ moving iron generator [5]. This implies a power-to-weight ratio improvement of approximately six times. Several patents was also registered by Infinia Corporation in this field.

A 2D representation of a 8 spoke, 2 pole dual stator moving magnet generator showing the main flux path is included in figure 2.3.

It can be assumed that the stroke length of the dual stator $3.1 \mathrm{~kW}$ generator ranges from 20-30 $\mathrm{mm}$ because flexures bearings are used. Inifinia Corporation [5] indicated that the diameter of the generator is approximately $250 \mathrm{~mm}$. The eight spoke dual stator moving magnet linear generator of Infinia Corporation [5] seems to have a few advantages. The widened spoke end serve as a guide to direct the magnetic flux along a narrower stator spoke. Thus simultaneously increasing the effective copper area of the winding and the magnet width while decreasing the mass of the outer stator. The magnets that are moved to the outer diameter allow the possibility for more that 4 spokes without a significant increase in the stator mass. When more poles are added in a in- 

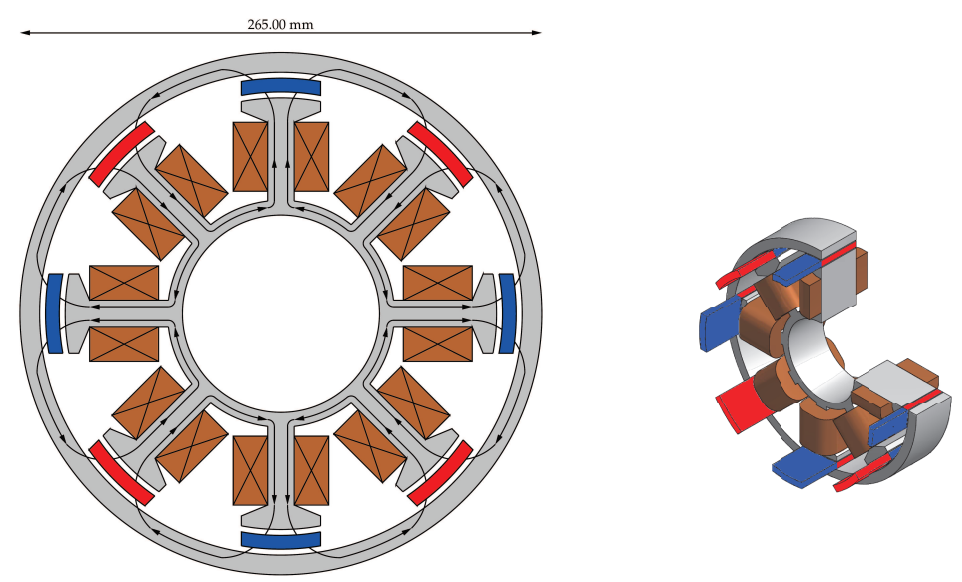

Figure 2.3: Main flux path of the 8 spoke, 2 pole moving magnet topology described by Infinia [5].

side magnet topology an increase in the inside diameter occurs due to the increase of parasitic reluctance paths between adjacent magnets in close vicinity. An increased inside diameter will significantly increase the total mass which is a disadvantage. When more poles are implemented in an outside magnet topology then the space between the poles can be better filled with windings.

Several disadvantages can also be identified in the dual stator, outside magnet topology. The carrier in which the magnets are seated presents problems in manufacturability. The windings can not be slid over the spoke from the end due to the widened spoke ends. Therefore each winding must be wound directly onto its spoke which implies that the entire generator needs to be dissembled should one winding need replacement. More manufacturability problems occur due to each spoke being separate for winding purposes as stated above.

There is little information disclosed regarding efficiency, power density and dimensions of the 8 spoke, 2 pole dual stator moving magnet topology. Therefore it was decided to investigate the performance of this topology. However it was chosen to first do an analysis of a moving magnet linear generator with one stator and the magnets fixed to the translator. This altered topology in discussed in detail in the next chapter. 


\section{Chapter 3}

\section{Moving magnet TF linear generator topology}

\subsection{Introduction}

It was decided to investigate the moving magnet topology described in this chapter because of a combination of advantages from the moving iron topology described by Boldea and Nasar [6] and the dual-stator moving magnet generator described by Infinia Corporation [5]. These advantages include the manufacturability of the moving iron topology and the increased performance of the dual-stator moving magnet topology. This makes the investigation into the moving magnet topology described here worth while as part of the bigger ongoing investigation of TF tubular linear generator topologies for free-piston Stirling engine applications.

In section 3.2 the geometry of the moving magnet topology is described. The analysis and optimisation of the topology is discussed in sections 3.3 and 3.4 respectively. The simulated and measured results is presented in section 3.5 and finally a concluding discussion is presented in section 3.6.

\subsection{Description of topology}

A 2D representation of one quarter of the moving magnet transverse flux linear generator topology showing the various dimensions that describe the topology is shown in figure 3.1. The description of the dimensions shown in figure 3.1 is listed in table 3.1. A $3 \mathrm{D}$ representation with one quarter cut-out can be seen in figure 2.2. The generator is 
essentially a combination of four different parts as indicated in figure 3.1. These parts include the stator, mover, coils and magnets.

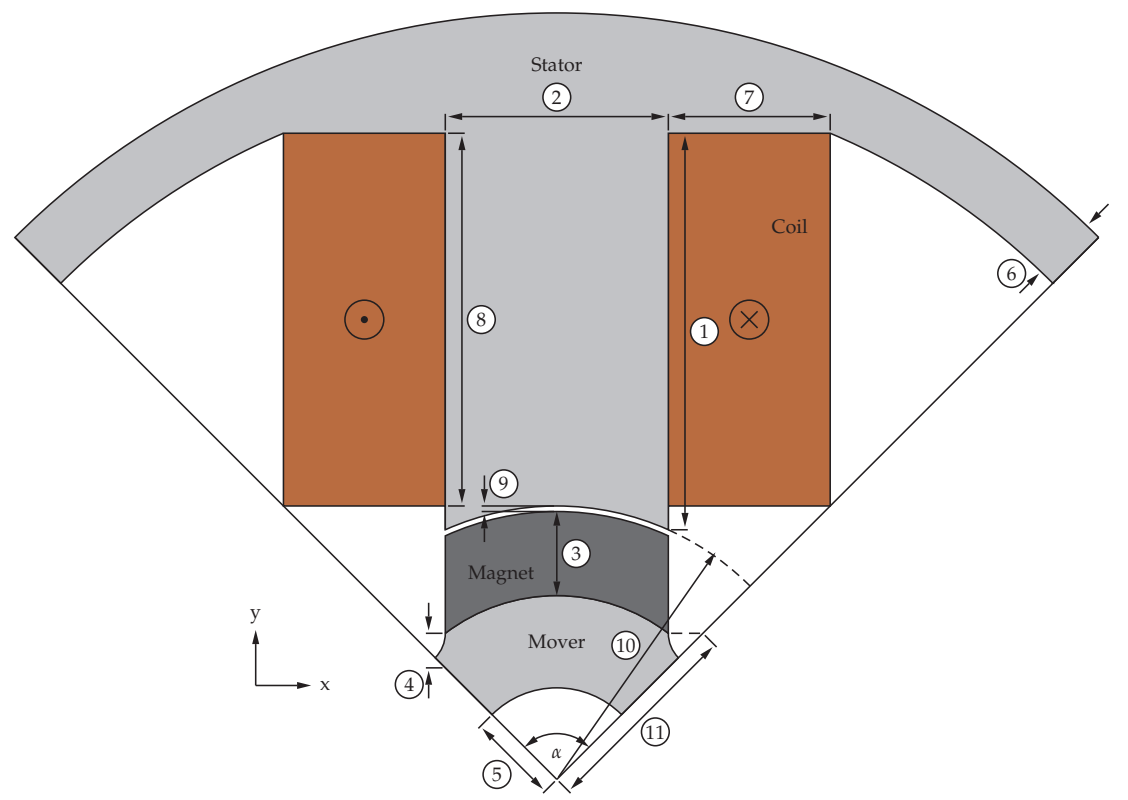

Figure 3.1: Dimensions that describe the TF linear moving magnet generator.

Table 3.1: Dimension descriptions and symbols.

\begin{tabular}{|c|l|c|}
\hline Number & Description & Symbol \\
\hline 1 & Pole length & $l_{p}$ \\
\hline 2 & Magnet width & $w_{m}$ \\
\hline 3 & Magnet depth & $d_{m}$ \\
\hline 4 & Mover corner to $45^{\circ}$ & $m_{c l}$ \\
\hline 5 & Centre hole radius & $r_{c h}$ \\
\hline 6 & Stator wall thickness & $d$ \\
\hline 7 & Coil width & $w_{c}$ \\
\hline 8 & Coil length & $l_{c}$ \\
\hline 9 & Air gap & $g$ \\
\hline 10 & Internal stator radius & $r_{i s}$ \\
\hline 11 & Mover arc cut-out centre distance & $A_{c c d}$ \\
\hline
\end{tabular}

The stator and mover are made from non-orientated, laminate silicon steel. The topology has four coils and eight magnets as seen in the image on the right in figure 2.2. Each coil is wound around the part of the stator which will be referred to as a spoke. The four coils can be connected in series or parallel depending on the application. In this case the coils are connected in series to ensure a higher voltage which is needed by the power electronic converter to connect to a $400 \mathrm{~V}$ three phase grid. 
The magnets are mounted on the mover so that the mover, magnets and axle translates together as a unit. Two oppositely polarised magnets per spoke of the generator are axially spaced, one with north towards the outer diameter of the generator and one with south towards the outer diameter of the generator. The magnet polarisation is reversed at each adjacent spoke as shown in figure 2.2, where black and dark grey colours are used to indicate oppositely polarised magnets.

Figure 3.2 shows the left view of half of the quarter generator shown in figure 3.1. Dimension $l_{m}$ is the magnet length and is equal to the stroke length, the stroke length being the distance of translation of the mover.

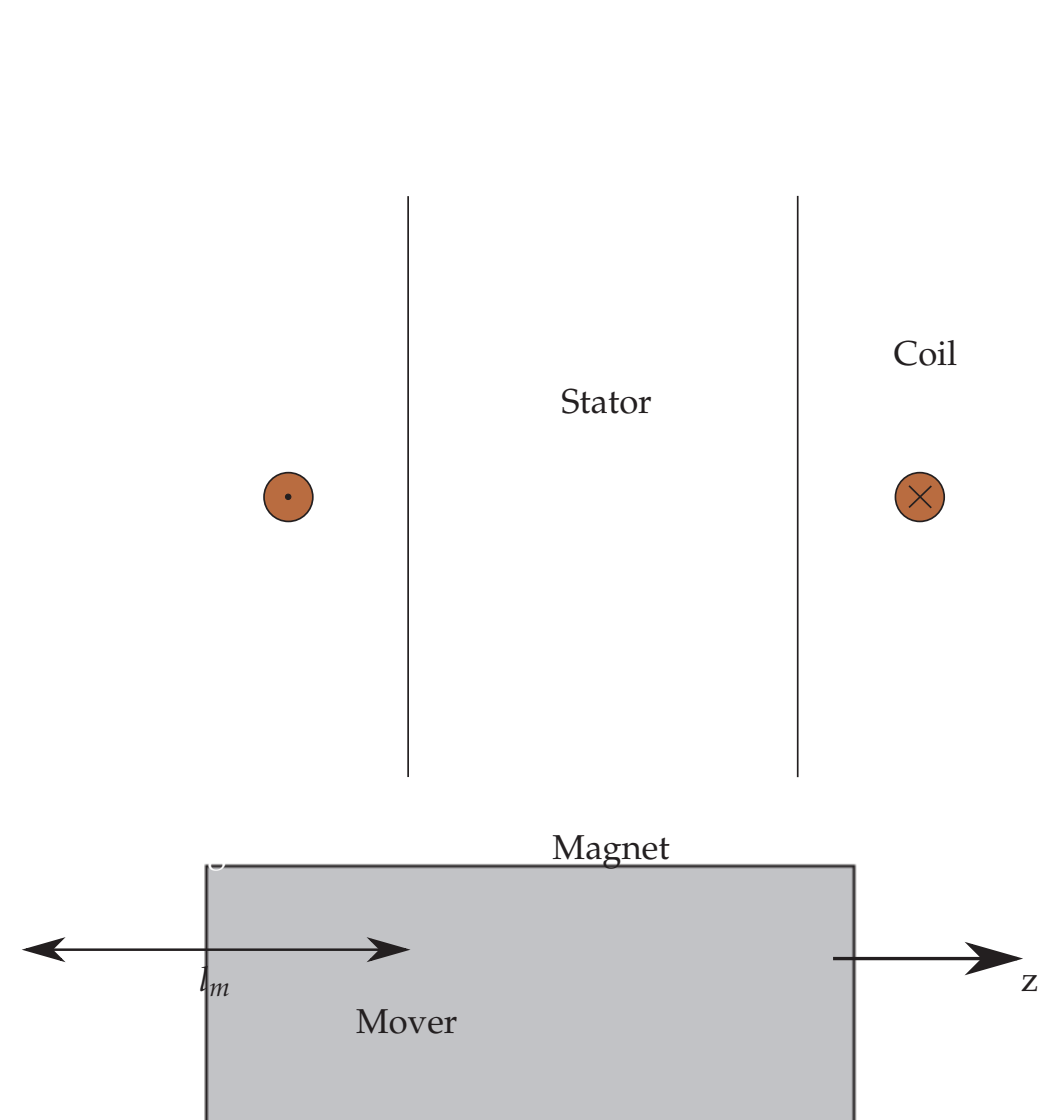

Figure 3.2: z-direction view of the generator.

The image on the left side of figure 2.2 indicate the directions of the flux paths with arrows. When the translator move so that the oppositely polarised magnets move to face the spoke of the stator then the flux paths change direction. This variation of resultant flux induces a voltage in the coils. 


\subsection{Analysis}

\subsubsection{Overview}

Two major flux paths, apart from the main flux path, are identified by Boldea and Nasar [6]. These two flux paths influence the total flux linkage and can be described in terms of their reluctances enabling the determination of the total flux linkage of the coils.

Schutte and Strauss [8] identified a third flux path that is not taken into account by Boldea and Nasar and for which no proper analytical description exists. Although it is possible to still simulate this generator analytically to a fair degree of accuracy under certain conditions, it was found in the early stages of this investigation that optimisation of the generator topology using the analytical model without taking the third path into consideration yielded poor results. Finite element analysis is therefore the only option for analysing and optimisation of the generator.

\subsubsection{Finite element analysis}

2D FE simulation is not sufficient due to the transverse flux topology of this linear generator. Therefore static 3D simulations are performed in the commercial FE package MagNet. Transient 3D analysis would be a better option since core losses could have been better accounted for but was not chosen due to licence limitations and especially longer simulation time and increased simulation difficulties. One of the ongoing issues with 3D simulations is that it takes significantly more time to complete a simulation. This is a disadvantage especially when performing iterative optimisation. Great care should therefore be taken in setting up the simulation model to be as time effective as possible while maintaining accuracy.

Only one eighth of the four stroke generator (one half of the section shown in figure 3.1) needs to be simulated due to its symmetrical nature. This ensures a significant reduction in the simulation time. The results from the simulation of an eighth of the generator is scaled to represent a full generator.

The simulation of the linear generator is done in MagNet via a Visual Basic (VB) script. The VB script initializes a COM interface with MagNet and effectively passes all the necessary commands to MagNet for a successful execution of a specific simulation. The required parameters of the generator are read from a text file by the VB script. A flow diagram of the sequence in which the VB script creates and simulates the generator in 


\section{MagNet via the COM interface is shown in figure 3.3.}
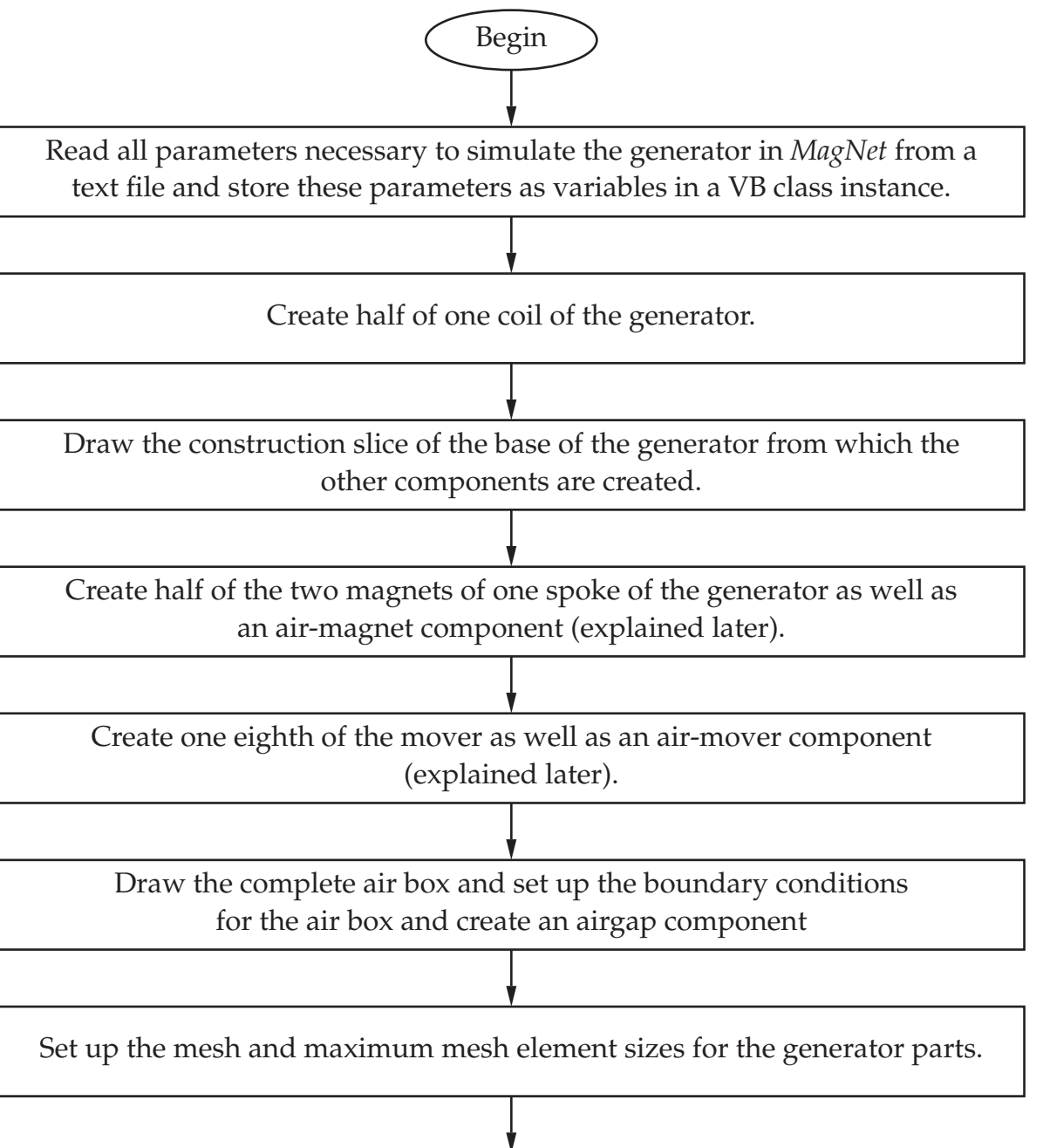

Set the shift vector for the moving parts i.e. the mover and the magnets.

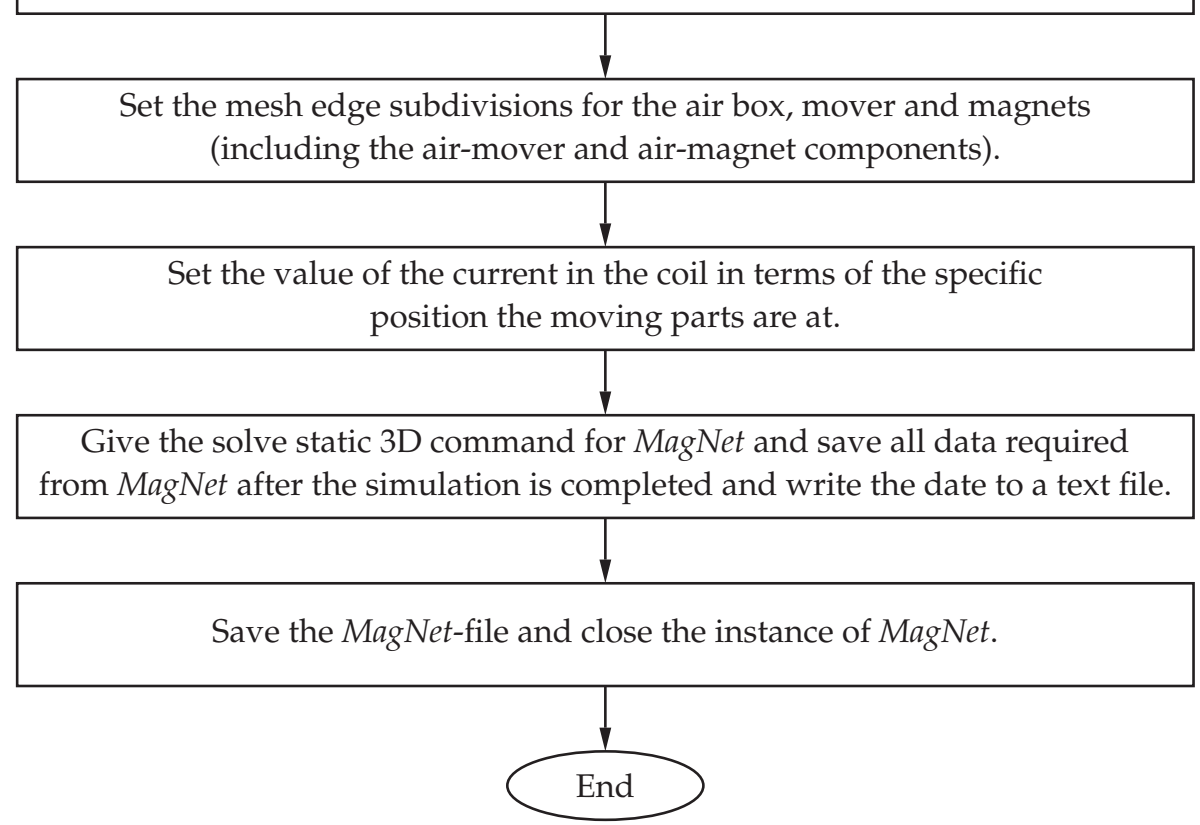

Figure 3.3: Flow diagram representation of the VB script. 
The part of the coil that is created is extruded orthogonal to the rest of the components in order to create what is called a simple coil in MagNet. The current through the coil must be set in terms of the position of the moving parts and therefore is calculated using

$$
i_{n}=A \sin \left(2 \pi f t_{n}+\phi\right)
$$

where $i_{n}$ is the current at position $n, A$ is the amplitude of the current, $f$ is the frequency, $\phi$ is the phase shift and $t_{n}$ is the time at position $n$ given by

$$
t_{n}=\frac{1}{2 \pi f} \arccos \left(1-\frac{2 n}{N}\right), \quad 0 \leq n \leq N, \quad \forall n \in \mathbb{Z}
$$

where $n$ is the current position and $\mathrm{N}$ is the total number of steps.

Two boundaries rendered by MagNet are shown in figure 3.4, where boundary condition number one is set to constrain the normal component of the magnetic flux density to zero, i.e. the flux is made to flow tangential to the boundary. Boundary condition number two is set to constrain the tangential component of the field to zero, i.e. the field is made normal to the boundary.

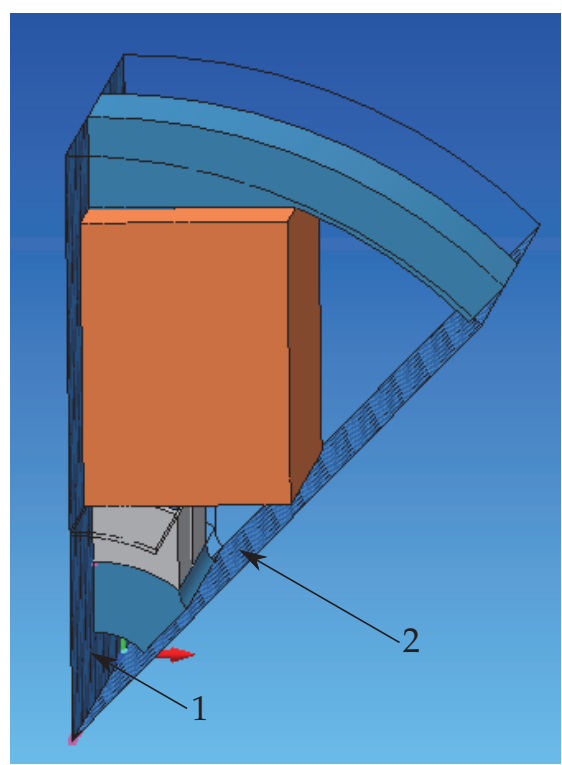

Figure 3.4: Two boundaries in MagNet model

Mesh edge subdivisions are added along the z-direction in order to refine the mesh in that direction. These subdivisions are indicated by pink dots on the edge of the air box and are depicted in the images in figure 3.5. Two control components made out of air, shaped into a magnet and a mover, and touching the base plane of the air box are added to the model and indicated by the red highlighted parts in figures $3.5 \mathrm{a}$ and $3.5 \mathrm{~b}$ respectively. These control component are added to the model so that their maximum element sizes can be set and propagated along the $\mathrm{z}$ extent and thus refining the mesh 
throughout the length of the air box. Edge subdivisions are also added to the edge between the magnet and mover control components touching boundary number one. This is because edges that have binary (or periodicity) constraints are not refined and are skipped during the $2 \mathrm{D}$ base plane meshing phase. A binary constraint is used to express a relationship between the field values either side of a boundary condition.

The control component made out of air to simulate the air gap is made for the same reason as the other two control components and is shown in figure 3.5c. This control component simulating the air gap is also subdivided on the edge touching the flux tangential boundary. The maximum element sizes of the magnets, mover and three control components as discussed above are set to one millimeter. Figure 3.6 depicts the 3D model and 3D mesh as simulated in MagNet.

In order to simulate the movement of the magnets and the mover using 3D static solving in MagNet a shift vector is required. This vector is an array of the different positions where the moving parts must be simulated. The size of each step in the array is equal to the length of translation divided by the number of steps that are simulated.

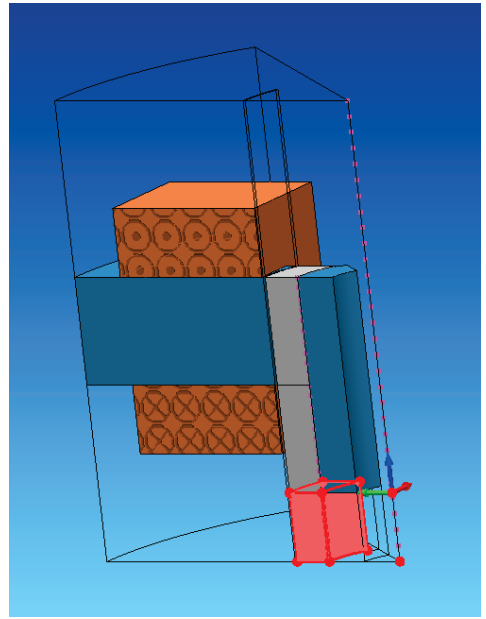

(a) Magnet

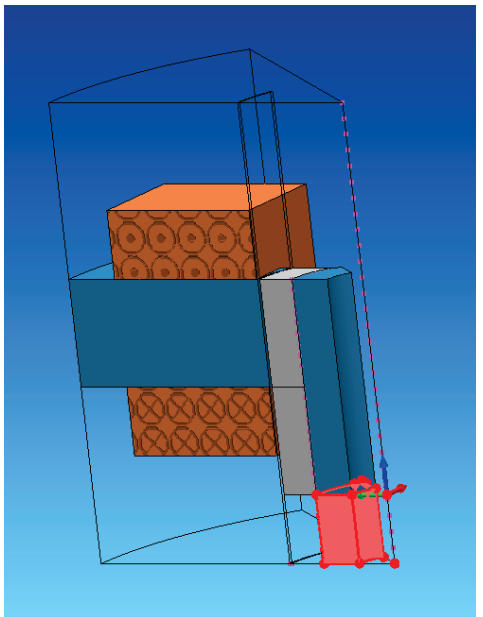

(b) Mover

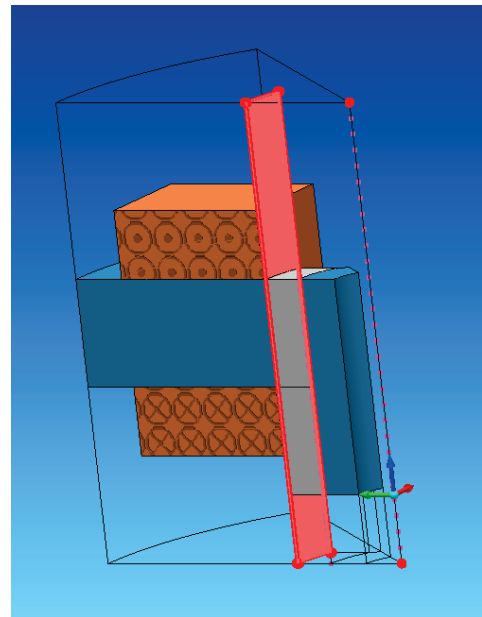

(c) Air gap

Figure 3.5: Control components made out of air in MagNet 


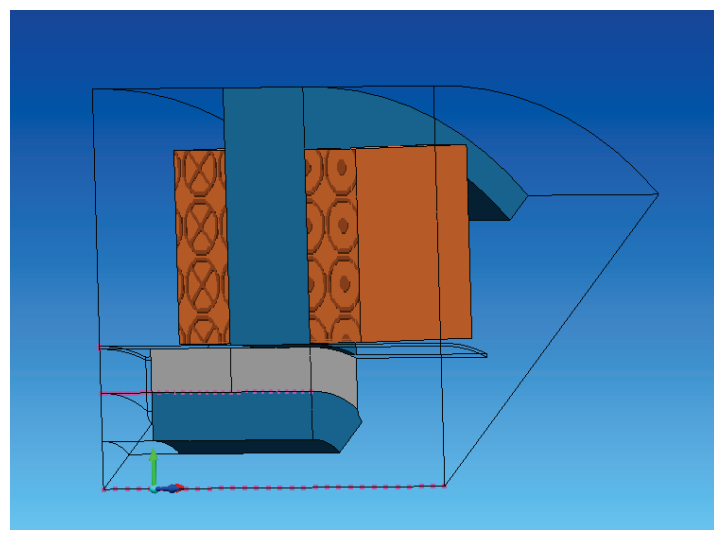

(a) 3D model

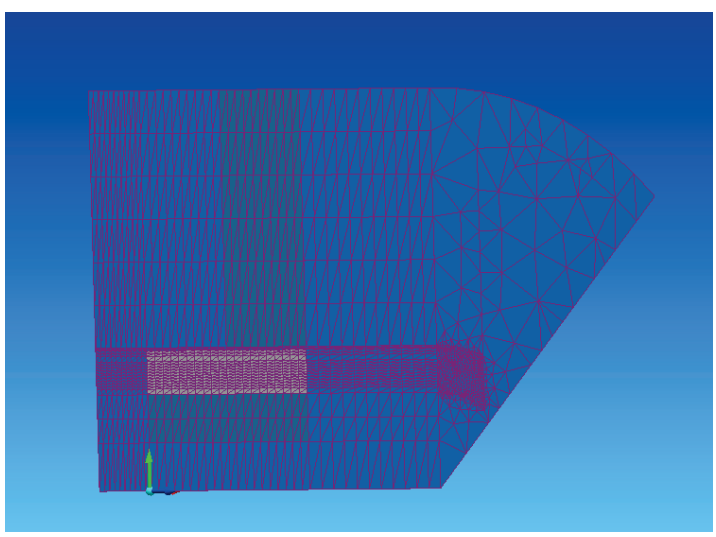

(b) Initial 3D mesh

Figure 3.6: MagNet FEM images

\subsection{Dimensional Optimisation}

The aim of this section is to describe the optimisation process with a goal to maximise the power-to-weight ratio while maintaining pre-set power and efficiency levels. Several parameters are chosen to define the generator. These parameters are then optimised using numerical approximation. As stated in the previous section, finite element analysis (FEA) is used to simulate the generator and to obtain the results for a specific set of parameters.

The r-algorithm (ralg) solver, from the open source optimisation framework OpenOpt implemented in the open source scripting language Python, was chosen as the optimisation algorithm. The implementation of r-algorithm, originally developed by N.Z. Shor, is discussed by Kappel et al. [13]. The r-algorithm solver is suitable for medium scaled, non-linear problems with various different constraints and can reportedly handle ill-conditioned, piecewise linear and polynomial, non-smooth and noisy problems rather good. The solver can handle user-provided first derivatives for the cost function and constraint functions, or may approximate these by finite differences approximation. Figure 3.7 shows a high-level block diagram representation of the OpenOpt optimisation framework.

The optimisation algorithm is provided with initial values for the parameter vector as indicated by $\mathbf{X}(0)$. The parameters are then optimised iteratively using the cost function which returns the mass, $\mathrm{m}$, while continuously evaluating the constraint functions which return the constraint evaluations, indicated by $c_{1}$ to $c_{N}$, to ensure an optimal solution within the given constraints. The total mass, $\mathrm{m}$, consisting of the stator and mover mass, is calculated using the xy-plane surface areas and the lengths of the specific components together with the density of the steel. Various other optimisation scenarios are also possible, e.g. it is possible to add the mass of the magnets and coils 


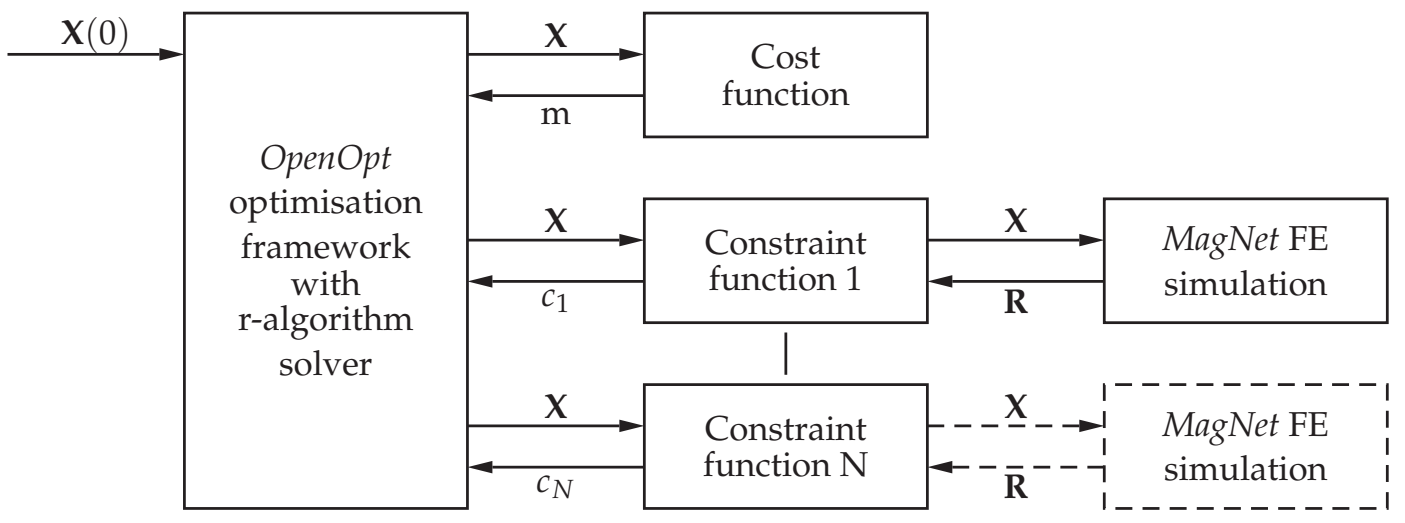

Figure 3.7: Block diagram representation of the OpenOpt optimisation framework.

to that of the stator and the mover. These masses can be weighed by their monetary cost to optimise cost of manufacturing.

Several constraint functions are used to ensure that the initial generator design adhere to design specifications. The constraints may be categorised into two categories, namely dimensional constraints and performance constraints. The dimensional constraints help to ensure the integrity of the dimensions in the MagNet environment, while the performance constraints help to ensure that generator specifications are adhered to. The various performance constraints are listed below:

- Power:

$P_{\text {out }} \geq P_{\min }$

- Efficiency:

$E f f \geq E f f_{\min }$

- Flux Density:

$B \leq B_{\max }$ at 3 locations, namely in the stator back wall, in the mover segments and in the spokes.

- Current density in coil:

$J \leq J_{\max }$

To determine the various performance parameters above, FEA is necessary. The relevant constraint functions therefore firstly perform a finite element analysis by passing the dimensions and other parameters to MagNet. Results indicated as $\mathbf{R}$ are obtained from MagNet and are processed to determine the relevant constraint value.

Figure 3.8 shows a detailed flow diagram representation of the FEA assisted determination of the performance constraint values in the relevant constraint functions. The 
set-up and initialisation of the simulation and post-processing of results gained from the FE simulation in MagNet are done in Python. There was difficulty establishing a COM interface directly between Python and MagNet which led to the use of VB as a communication medium between the Python scripts and the MagNet simulations. The parameter vector $\mathbf{X}$ and other geometric parameters are passed to the VB script described previously using a text file. Python executes the VB script by calling an executable file generated by VB. VB then initializes the COM interface to MagNet and sets up all the necessary settings as described in section 3.3.2. If the geometric model needs alterations or one would like to optimise another topology the necessary changes would be made in VB.

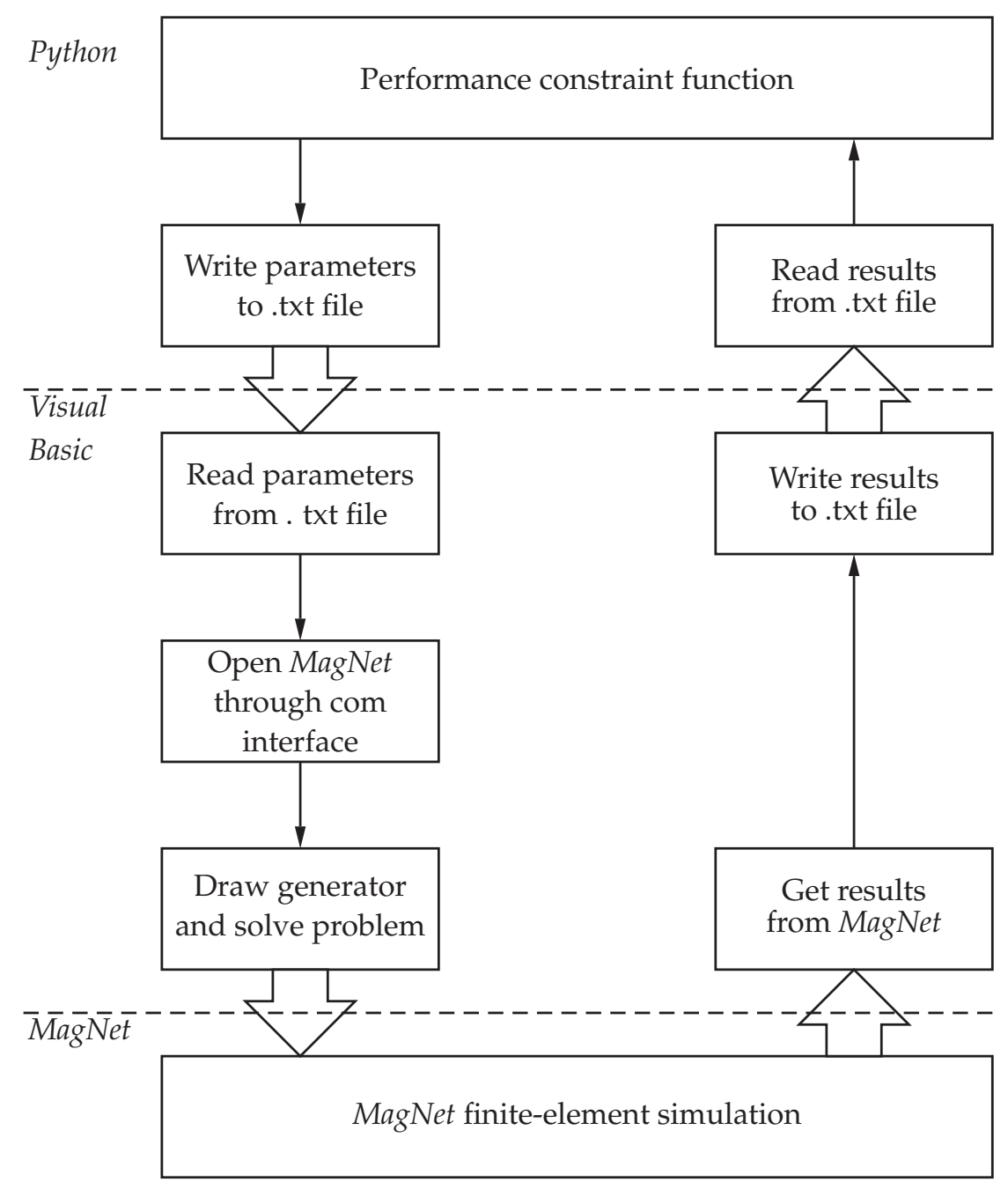

Figure 3.8: Flow diagram of the FEA assisted determination of constraint values.

Two simulations are performed in the MagNet FE package. The first simulation is done where the mover is shifted over 10 steps from one end to the other. The derivative of the flux linkage at each step was calculated using splines to obtain the induced voltage accurately at each step. Verification using more steps showed that no significant 
improvement in the accuracy was achieved. What did improve accuracy considerably however was to ensure that the flux linkage is calculated accurately at each step. The second simulation is performed without current and with the mover at only one position, namely at half a stroke length. The purpose of the two simulations is to determine the inductance of the coil by obtaining the difference in flux linkage due to the current flowing in the coil. The inductance may then be calculated using

$$
L=\frac{\lambda}{i}
$$

This approach to calculate the inductance was found viable, since low levels of flux density is achieved in the iron, with effectively no saturation occurring. An approach where the inductance was calculated at all steps was also evaluated, but was found unnecessary for this particular case, since the same level of accuracy was obtained. It is expected that if iron saturation becomes more pronounced, that this approach would yield more accurate results.

The VB script then retrieves the simulation results from MagNet and writes it in a text file that allows the Python script to access the results and to perform post processing. Since only one eighth of the generator is simulated, the power, mass, total inductance, total resistance and simulated output voltage need to be scaled accordingly.

Restrictions have been placed on the dimensions to simplify the optimisation process. The dimensions $w_{c}$ and $l_{c}$ define the copper area and are calculated to utilise as much of the area around the spoke available for the copper coil, while maintaining easy manufacturability. There is also a restriction placed on the mover arc cut-out centre distance $A_{c c d}$ to have the same y-coordinate as the corner of the mover at the air gap, indicated by the dashed straight line in figure 3.1 .

The air gap was chosen to be $1 \mathrm{~mm}$. The dimensions in the z-direction, as shown in figure 3.2, were chosen as constant and were not part of the optimisation process. The inner stator radius $r_{i s}$, as indicated in figure 3.1, can be derived using some of the other dimensions listed in table 3.1. The dimensional parameters used in the optimisation algorithm are therefore dimensions 1 to 6 as listed in table 3.1. Two additional parameters are added to the parameter vector $\mathbf{X}$, namely the RMS value of the sinusoidal current in the coil as well as the phase shift of the current waveform. Dimensions like $w_{c}$ and $l_{c}$ could be added to the parameter vector $\mathbf{X}$ to allow more freedom and to possibly improve the outcome of the optimisation process in future.

A simplified electrical model that describes the generator is shown in figure 3.9.

The voltage, $v_{\lambda}$, represents the voltage induced in the coil by the resultant flux linkage 


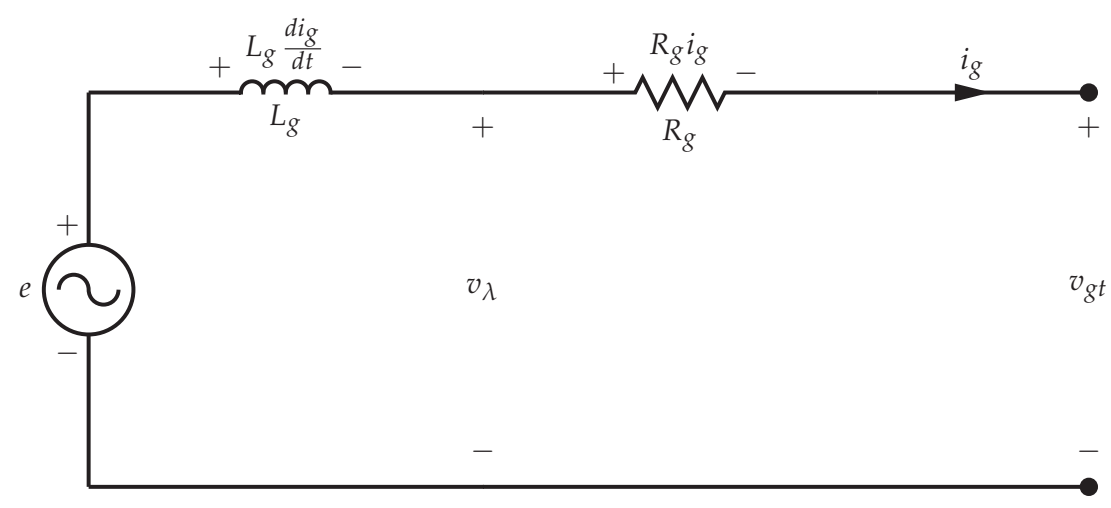

Figure 3.9: Equivalent electrical model of the TF linear moving magnet generator.

of the coil. It is calculated using

$$
v_{\lambda}=\frac{\mathrm{d} \lambda}{\mathrm{d} t}
$$

The terminal voltage, $v_{g t}$, is calculated using

$$
v_{g t}=v_{\lambda}-R_{g} i_{g}
$$

The input and output power can then be calculated from

$$
P_{\text {in }}=\frac{1}{T} \int_{0}^{T} i_{g}(t) v_{\lambda}(t) \mathrm{d} t
$$

and

$$
P_{\text {out }}=\frac{1}{T} \int_{0}^{T} i_{g}(t) v_{g t}(t) \mathrm{d} t
$$

The efficiency, $\eta$, is derived from 3.4.4 and 3.4.5 by

$$
\eta=\frac{P_{\text {out }}}{P_{\text {in }}}
$$

The current density necessary for the current density constraint during optimisation is calculated from

$$
J=\frac{I}{A_{c}}
$$

where $A_{c}$ denotes the effective copper area and is calculated using

$$
A_{c}=\frac{A_{w}}{k_{f i l l}}
$$

$A_{c}$ and $k_{\text {fill }}$ denote the copper window area and the fill factor respectively. The copper window area is equal to the area enclosed by dimensions 7 and 8 listed in table 3.1, while the fill factor can be chosen to accurately represents a manufactured coil. 


\subsection{Results}

\subsubsection{Design and operational spesifications}

A design optimisation was performed on a 4 spoke, 2 pole TF linear PM generator as described in the previous sections of this chapter with specifications as listed in table 3.2. An active power electronic load was assumed with the ability to force a sinusoidal current irrespective of the voltage waveforms. This simplified the simulation process. If a variable passive load was assumed, a more complex approach would have been necessary.

The question could be raised if one should rather design the generator for a specific voltage. In this case we decided that the output voltage in not of big importance for the design because a back-to-back converter is connected to the output of the generator. It also avoided complications in the simulation process in MagNet.

Table 3.2: Design and operational specifications.

\begin{tabular}{|l|l|}
\hline Description & \\
\hline Power & $>3 \mathrm{~kW}$ \\
\hline Efficiency & $>96 \%$ \\
\hline Flux density (stator wall) & $<1.3 \mathrm{~T}$ \\
\hline Flux density (mover) & $<1.3 \mathrm{~T}$ \\
\hline Flux density (spoke) & $<1.3 \mathrm{~T}$ \\
\hline Current density & $<6 \mathrm{~A} / \mathrm{mm}^{2}$ \\
\hline Stroke length & $45 \mathrm{~mm}$ \\
\hline Speed & $3000 \mathrm{reciprocations} / \mathrm{min}$ \\
\hline Stator & Cold rolled $1010 \mathrm{steel} ; 7600 \mathrm{~kg} / \mathrm{m}^{3}$ \\
\hline Mover & Cold rolled $1010 \mathrm{steel} ; 7600 \mathrm{~kg} / \mathrm{m}^{3}$ \\
\hline Magnet & NdFeB: N40; $7500 \mathrm{~kg} / \mathrm{m}^{3} ; \mu_{r}=1.05 ; H_{c}=-936 \mathrm{kA} / \mathrm{m}$ \\
\hline Coil & Copper; $8954 \mathrm{~kg} / \mathrm{m}^{3} ; \sigma=5.77 \times 10^{7} \mathrm{~S} / \mathrm{m}$ \\
\hline
\end{tabular}

Core losses cannot be determined without transient analysis which is not available as described in section 3.3.2. Order of magnitude calculation showed that the core losses will degrade the efficiency by approximately $1 \%$. To compensate for core losses not taken into consideration in the calculation of the efficiency the optimisation is done with efficiency approximately $1 \%$ higher than required. The required efficiency is 95 $\%$, therefore the optimisation was done for $96 \%$ efficiency. 


\subsubsection{Simulated results}

Only one eighth of the generator is optimised as stated in section 3.4. Table 3.3 shows the results for an one turn winding equivalent, i.e. one eigth of the generator with one turn per coil as optimised and simulated denoted by 1 turn equiv., and a complete generator with 164 turns per coil with four coils switched in series denoted by 164 turns. The results for a complete generator with specifically 164 turns per coil is shown because the maximum number of turns that could be fitted on each coil of the prototype generator (explained in the next section) is 164. The cost function was defined as the combined mass of the stator and the mover, referred to as the cost function mass in table 3.3.

Table 3.3: Optimisation results.

\begin{tabular}{|l|r|r|}
\hline Description & 1 turn equiv. & 164 turns \\
\hline Cost function mass [kg] & 1.545 & 12.36 \\
\hline Mover mass [kg] & 0.515 & 4.12 \\
\hline Coil mass [kg] & 1.255 & 10.04 \\
\hline Magnet mass [kg] & 0.223 & 1.78 \\
\hline Total generator mass [kg] & 3.023 & 24.18 \\
\hline Power out [W] & 375 & 3000 \\
\hline Efficiency & \multicolumn{2}{|c|}{0.96} \\
\hline Current density [A/mm $\left.{ }^{2}\right]$ & 0.243 & 0.243 \\
\hline MagNet power-to-weight ratio [kW/kg] & 0.124 & 0.124 \\
\hline Total power-to-weight ratio [kW/kg] & $2.351 \times 10^{-3}$ & 505.8 \\
\hline Resistance [m $\Omega]$ & $0.225 \times 10^{-3}$ & 48.37 \\
\hline Inductance [mH] & \multicolumn{2}{|c|}{0.9098} \\
\hline Maximum flux density - stator wall [T] & \multicolumn{2}{|c|}{1.139} \\
\hline Maximum flux density - mover [T] & \multicolumn{2}{|c|}{0.6370} \\
\hline Maximum flux density - spoke [T] & \multicolumn{2}{|c|}{} \\
\hline
\end{tabular}

The power and efficiency constraints were reached, but the current density and flux densities (as indicated in table 3.3) were found to be particularly low compared to the performance contraint values of the design specifications. Low flux density implies that more turns are necessary to obtain a specified voltage. This again requires thicker copper conductors to maintain a certain efficiency. The current density is therefore also lower. For this generator topology, sufficient efficiency levels can only be reached at the expense of the current density. The inductance, as shown in table 3.3, is calculated as described in section 3.4.

The optimised geometric dimensions of the 4 spoke, 2 pole TF linear PM generator are listed in table 3.4. The dimensions in table 3.4 are rounded to manufacturing toler- 
ances. The centre hole radius, $r_{c h}$, was optimised to be $22.03 \mathrm{~mm}$ but because it is not a practical size for a axle it was decided to use an axle with a $16.5 \mathrm{~mm}$ radius. This increased the weight of the mover which negatively effects the power-to-weight ratio but the performance parameters were not effected negatively. The illustration in figure 3.1 is proportional to the dimensions listed in table 3.4. The number of turns per coil is practically determined by the number of turns that can be fitted into the copper window with copper wire that was available. The RMS current and its phase shift $(\phi)$ are optimised to be 2523.2 A and -0.116 radians respectively.

Table 3.4: Optimised dimensions.

\begin{tabular}{|c|l|l|}
\hline Number & Description & Dimensions (mm) \\
\hline 1 & Pole length & 98.54 \\
\hline 2 & Magnet width & 40.2 \\
\hline 3 & Magnet depth & 15.2 \\
\hline 4 & Mover corner to 45 & 5.23 \\
\hline 5 & Centre hole radius & 16.5 \\
\hline 6 & Stator wall thickness & 11.68 \\
\hline 7 & Coil width & 28.7 \\
\hline 8 & Coil length & 66.6 \\
\hline 9 & Air gap & 1.0 \\
\hline 10 & Internal stator radius & 98.54 \\
\hline 11 & Mover arc cut-out centre distance & 37.23 \\
\hline
\end{tabular}

The results shown in figure 3.10 to 3.14 are all normalised with the values listed in table 3.5. The normalised values are derived from the simulated generator results (i.e. only one eighth of the generator).

Table 3.5: Normalised values.

\begin{tabular}{|l|l|l|}
\hline Quantity & Unit Symbol & Value \\
\hline Flux & $\mathrm{mWb}$ & 0.9943 \\
\hline Voltage & $\mathrm{mV}$ & 260.83 \\
\hline Current & $\mathrm{A}$ & 3555.4 \\
\hline Force & $\mathrm{N}$ & 144.0 \\
\hline
\end{tabular}

The flux linkage vs. position and time for the optimised generator geometry for a coil with one winding is shown in figures 3.10 and 3.11 respectively. The flux linkage vs. position graph is only shown for half a cycle $(-22.5 \mathrm{~mm}$ to $22.5 \mathrm{~mm})$ while the flux linkage vs. time graph is shown for an entire cycle. The forces (with no load and with load) acting on the mover vs. position (also from $-22.5 \mathrm{~mm}$ to $22.5 \mathrm{~mm}$ ) are shown in the figure 3.12. Figure 3.13 depicts the forces with no load and with load vs. time. 


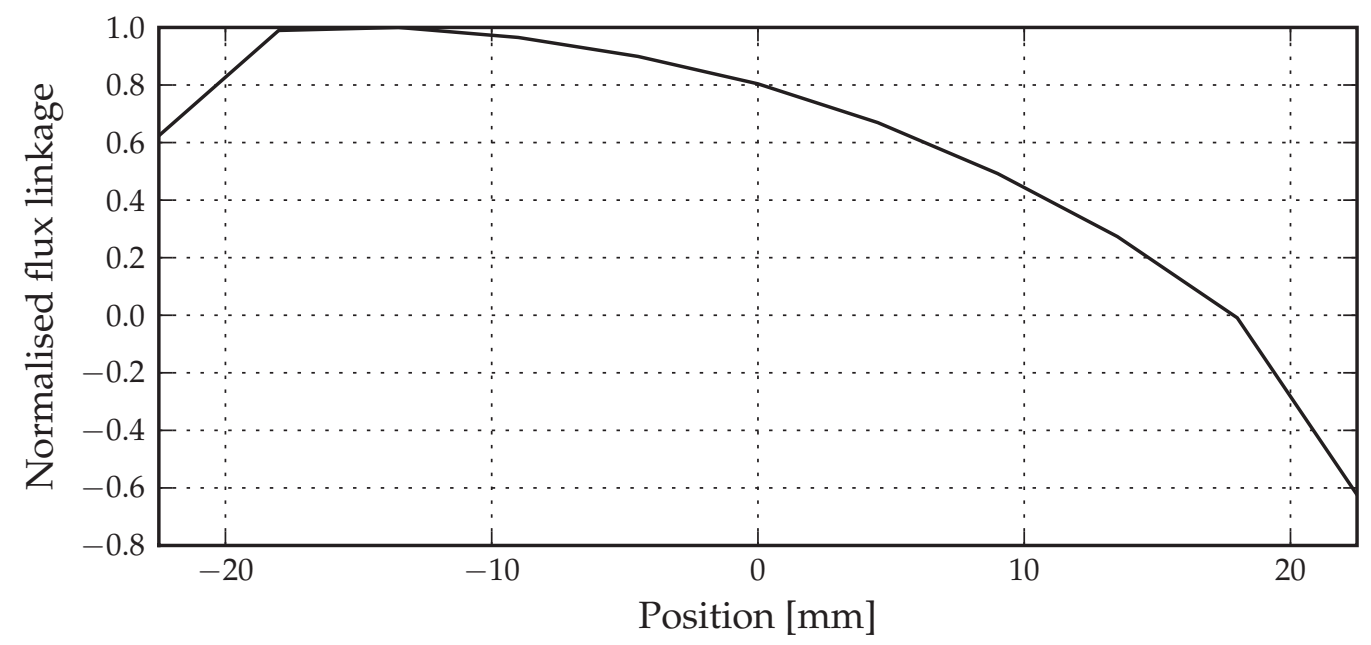

Figure 3.10: Flux linkage vs. position.

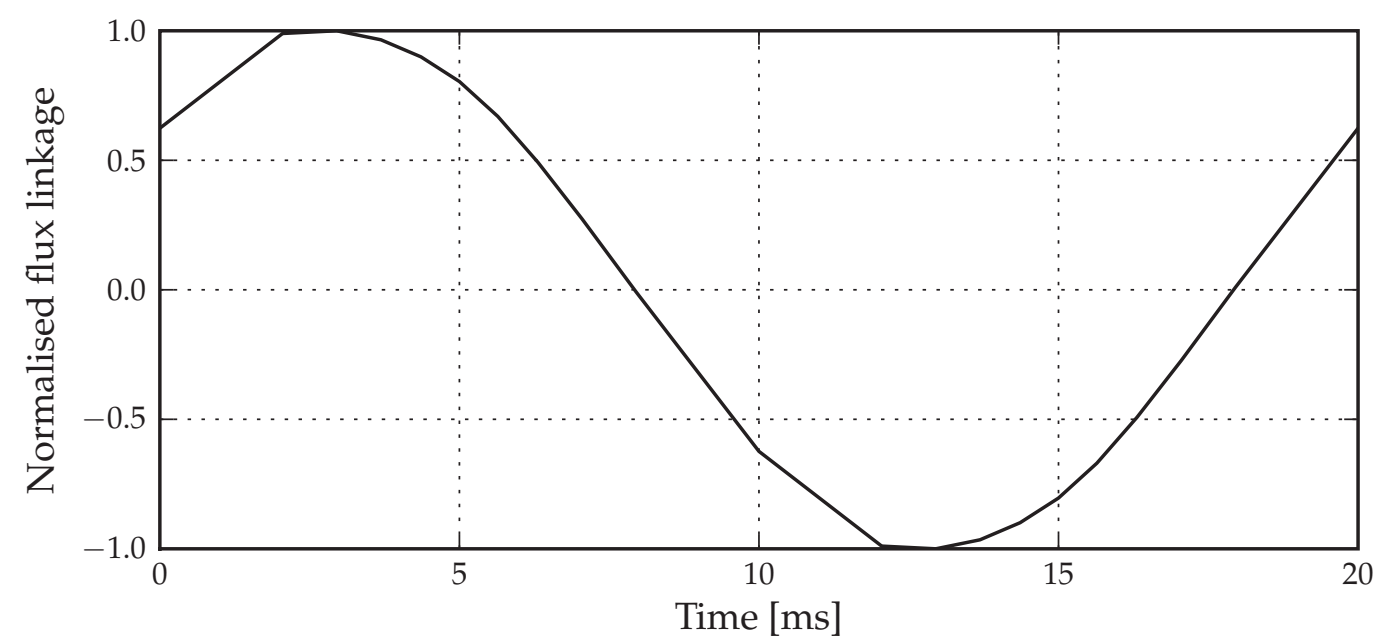

Figure 3.11: Resultant flux linkage vs. time.

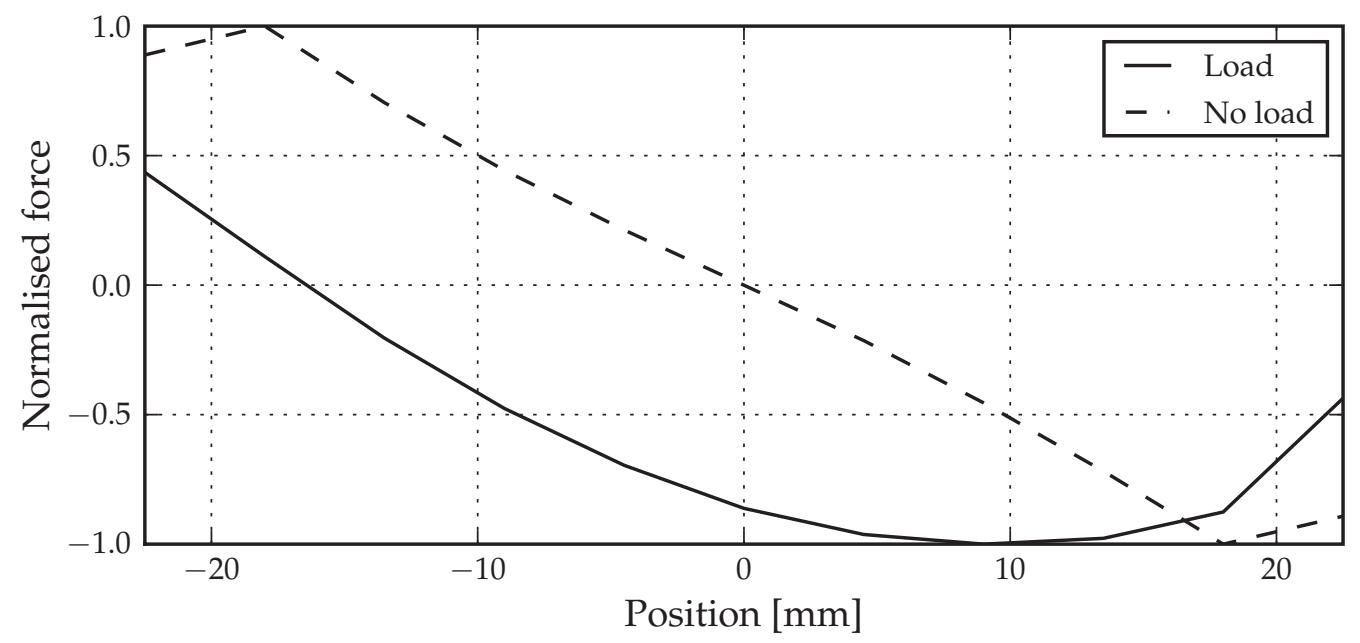

Figure 3.12: Forces vs. position. 


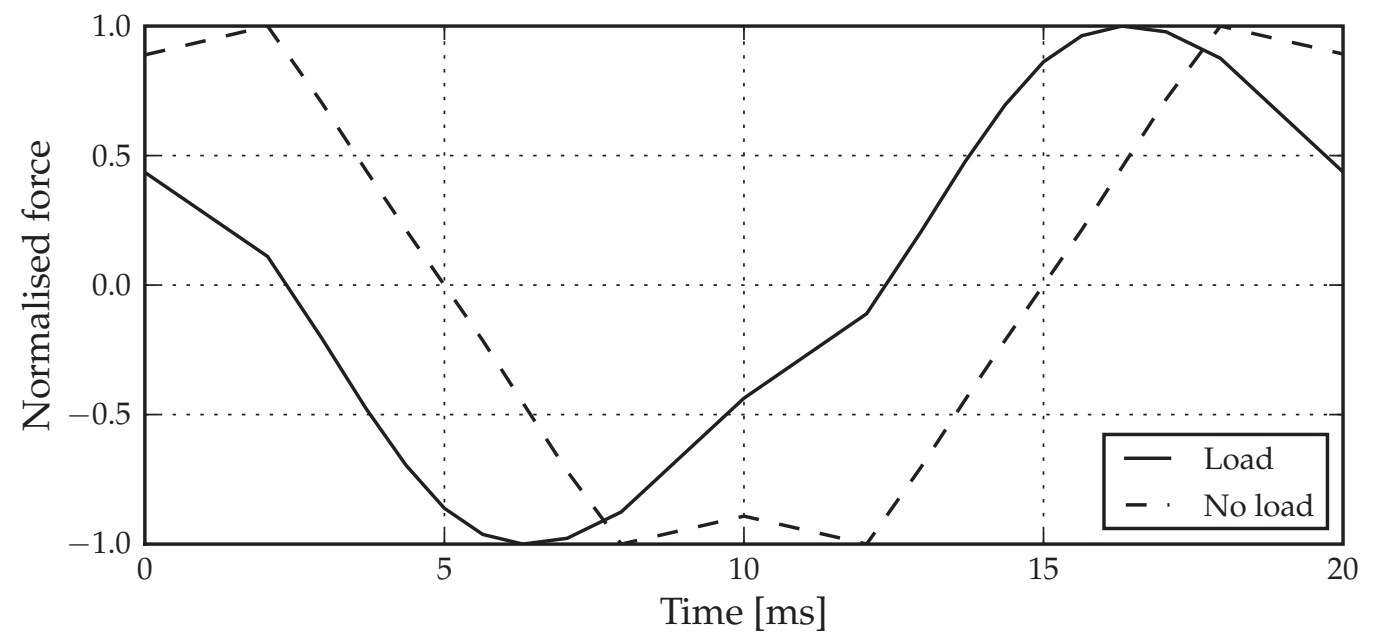

Figure 3.13: Forces vs. time.

The per turn per coil terminal voltage $\left(v_{g t}\right)$ and the emf, $(e)$, as well as the current $\left(i_{g}\right)$ through the coil are shown in figure 3.14. The simulation was done with one turn per coil which occupies all the copper area. Thus, a low voltage and a high current are obtained as seen from the normalisation values in table 3.5. Post-processing that take the actual number of turns per coil into account will ensure more realistic voltage and current levels.

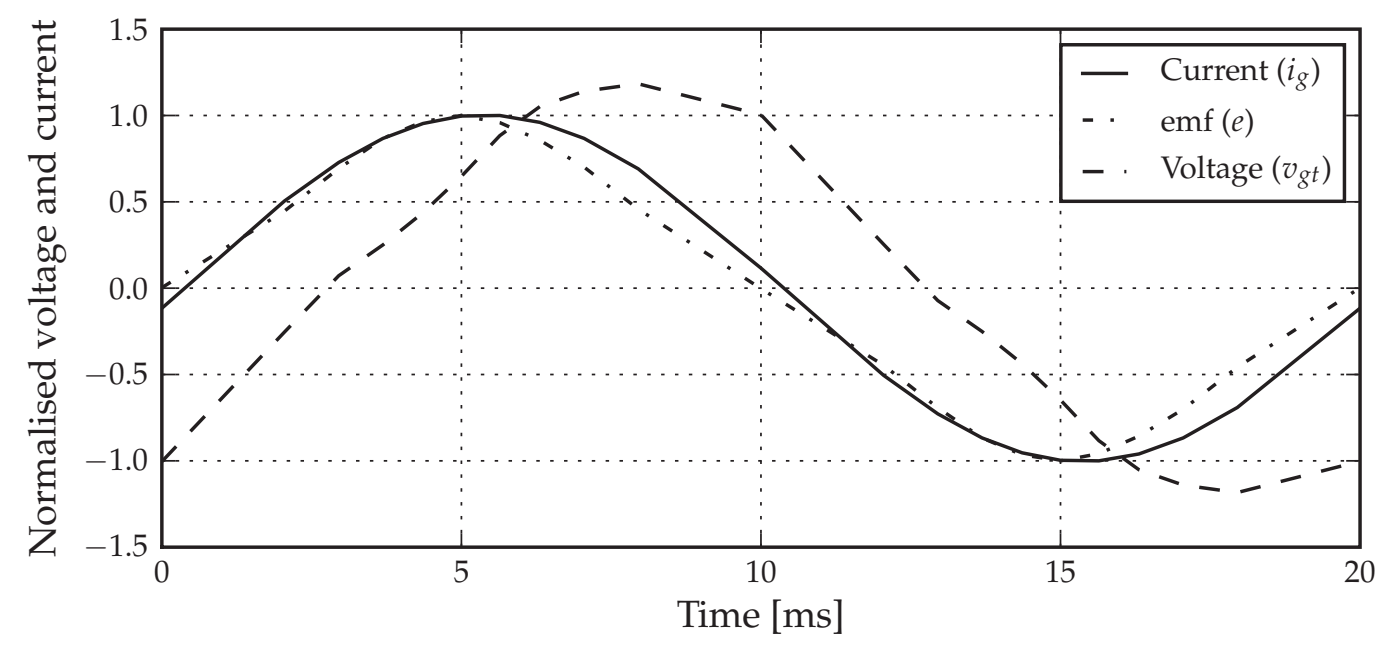

Figure 3.14: Current, emf and terminal voltage.

\subsubsection{Construction of the $3 \mathrm{~kW}$ prototype}

The stator and mover are constructed from $0.5 \mathrm{~mm}$ non-orientated silicon steel laminations that are stacked to the desired height. In the case of the stator the stack height is $45 \mathrm{~mm}$ (equal to the stroke length) and in the case of the mover the stack height is $90 \mathrm{~mm}$ to accommodate two magnets that is axially spaced. The stator laminations are 
geometrically located by four dowels and the mover lamination make use of a key to locate correctly on the axle. Both stator and mover laminations are held together by circlips.

The magnets are located onto the four sides of the mover with industrial strength adhesive. Figure 3.15 shows a photo of the mover with the magnets just after the final magnet is fixed to the mover.

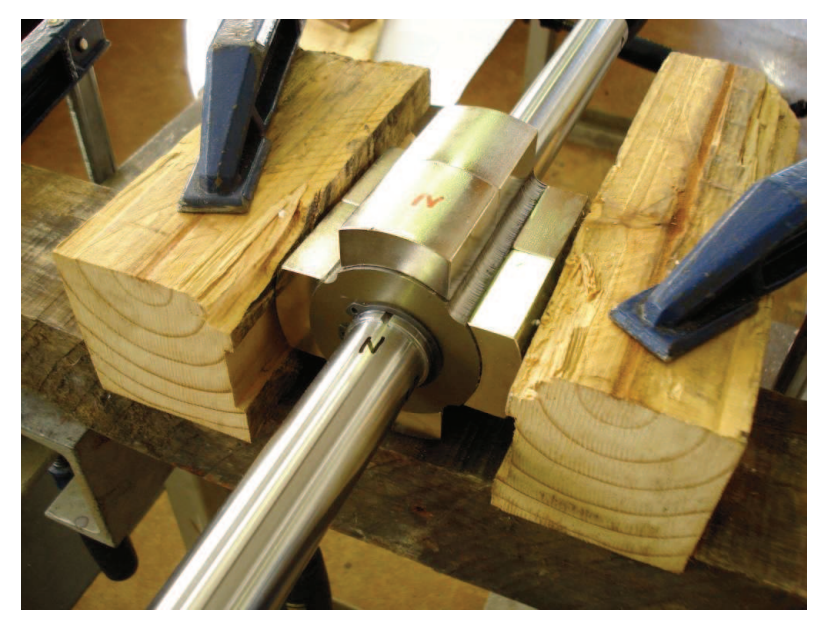

Figure 3.15: Mover with magnets.

The four coils were wound with $4 \times 1.5 \mathrm{~mm}$ rectangular copper wire. There were 164 turns fitted on each coil. This give a fill factor, $\left(k_{f i l l}\right)$, of approximately 0.52. Epoxy resin is used between the turns of the coil and taped with glass tape to keep the coil more compact as a unit. Epoxy resin is also used to fix the coils to the stator. Figure 3.16a and 3.16b show an individual coil and the stator (with three coils already located) respectively. Isolation paper is used between the stator and the coils to ensure that an electrical short does not occur.

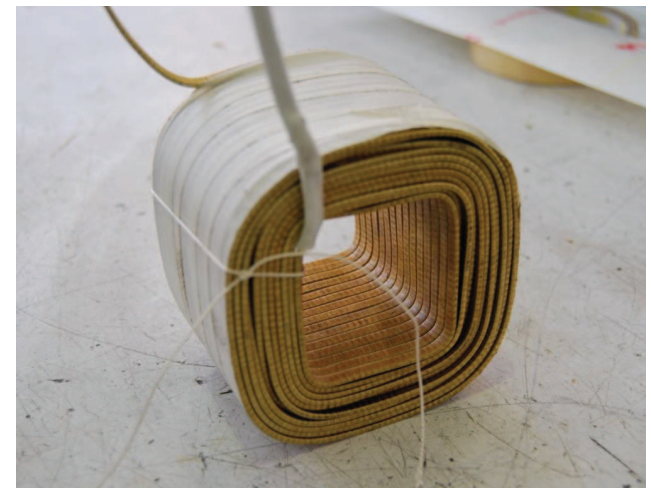

(a) One coil

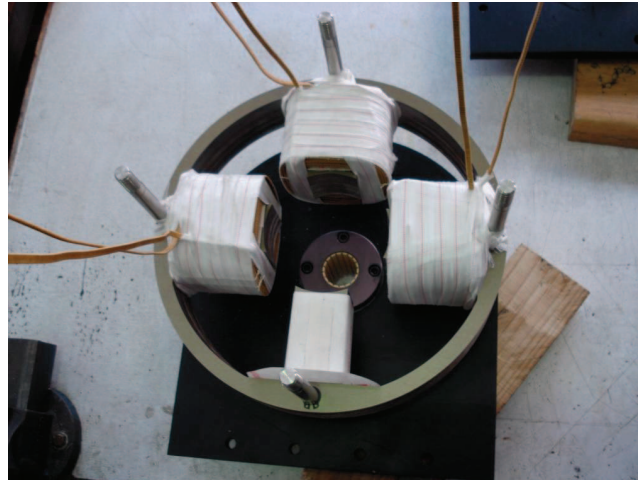

(b) Stator with coils

Figure 3.16: Stator and coils. 
With a stroke length of $45 \mathrm{~mm}$ it was not possible to use flexure bearings. Conventional linear ball bearings cannot handle the force, velocity and acceleration magnitudes. Linear bearings made from engineering plastics were used (shown in figure 3.16b) and were mounted on the side plates which is part of the mechanical construction. It was designed for $50 \mathrm{~Hz}$ operation with a safety factor of 5, except for the axle which was designed with a fatigue safety factor of 1.3. Due to the extreme forces and velocities acting on the axle it was difficult to increase the fatigue safety factor. The safety factor was chosen to be 5 , because the aim was to manufacture and test the optimised electrical design of the generator and not the entire design which include the mechanical construction.

A picture of the complete assembled generator is shown in figure 3.17. Figure 3.18 shows a picture of the test bench with the generator mounted on it. Figure A.1 shows an image of the complete generator while figure A.2 shows an image of only the stator and coils with the dowels to align the stator laminations. An image of the axle with the magnets are shown in figure A.3. Figures A.1 to A.3 are all Inventor rendered images.

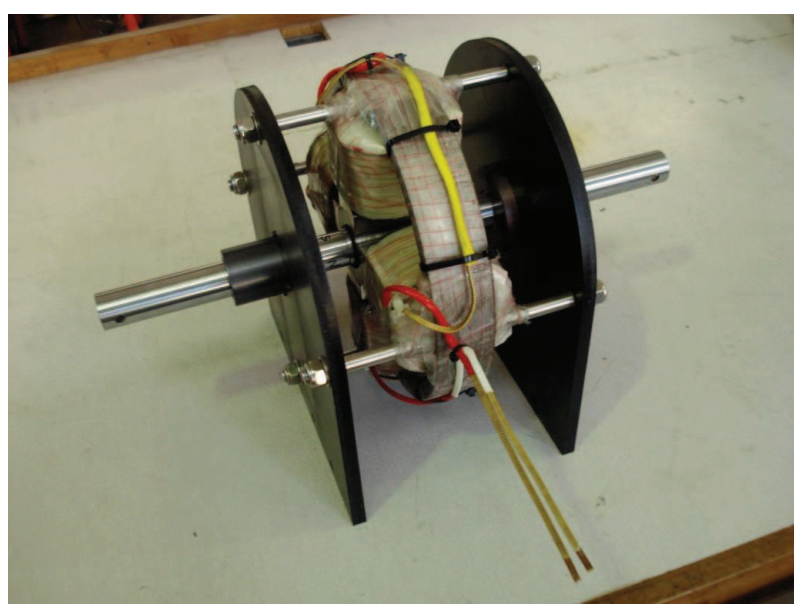

Figure 3.17: Complete generator.

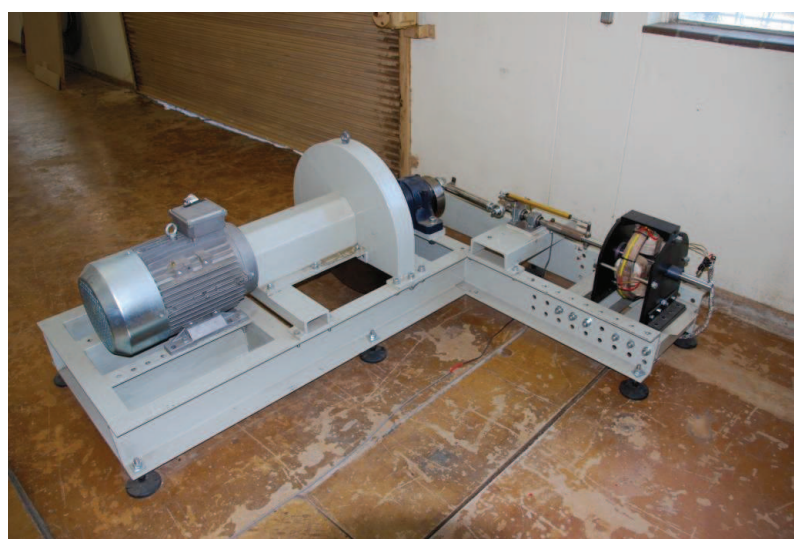

Figure 3.18: Test bench with mounted generator. 
There was difficulty aligning the generator axle with the test bench. Mainly because the linear engineering plastic bearings are very sensitive to misalignment and the fact that there were too many fixed points on the drive shaft did not make the task any easier. The initial misalignment caused the temperature of the engineering plastic bearings to rise and eventually melt. The alignment was fine-tuned with great effort to overcome this problem. The counterweight on crank was not correctly balanced which contributed to the alignment issues. Therefore it is recommended to rather use a linear test bench in the future.

\subsubsection{Measured results}

The test bench was not stable enough to test the generator at $50 \mathrm{~Hz}$ so all the tests was done at $10 \mathrm{~Hz}$. By doing this the results is a scaled version of the optimised $50 \mathrm{~Hz}$ results. The measured signals (at $10 \mathrm{~Hz}$ ) were very noisy at first due to the drive that was used for the speed control on the induction motor on the test bench. Most of the electromagnetic coupled noise was decoupled from the measured signals by improving the way of measurement. This included using coaxial wire and using the oscilloscope in a shielding box which is connected to ground. The measured signals improved drastically but was still too noisy. Therefore a second order low pass analogue Bessel filter from the scipy package in Python at $1 \mathrm{kHz}$ was used to filter the signals. This filtering did not compromise the accuracy of the measurements whatsoever. Python is used to do all the post processing and the plotting of the graphs.

Three sets of measurements were taken, one with no load to get the emf and two with different current values, namely at 2A RMS and at 6A RMS. The measurement at 2A RMS was done to enable us to compare the $10 \mathrm{~Hz}$ measured results with the $50 \mathrm{~Hz}$ simulated results. The current of the $10 \mathrm{~Hz}$ measured results must be five times smaller than the current of the $50 \mathrm{~Hz}$ simulation results to obtain the same phase shift between the current and the terminal voltage for both the $10 \mathrm{~Hz}$ measured results and the 50 $\mathrm{Hz}$ simulated results. This cause the output power to be 25 times smaller at the 10 $\mathrm{Hz}$ measurement than at the design specification at $50 \mathrm{~Hz}$. This is the reason why the measurement at approximately 2A RMS was done at $10 \mathrm{~Hz}$. The measurement at 6A RMS was done only to gain insight at a higher current.

A MagNet simulation is done for each set of measurements and the simulation results is compared to the measured results. Table 3.6 shows the values of each set of the measured and simulated results. The percentage difference between the measured value and the simulated value is shown in brackets after the simulated value. 
Table 3.6: Measured and simulated values.

\begin{tabular}{|c|c|c|}
\hline Quantity & Measured value & Simulated value (\% diff.) \\
\hline \multicolumn{3}{|l|}{ No load: } \\
\hline $\mathrm{E}\left[\mathrm{V}_{R M S}\right]$ & 45.4 & $43.9(3.42)$ \\
\hline \multicolumn{3}{|l|}{ 2A RMS: } \\
\hline $\mathrm{I}_{g}\left[\mathrm{~A}_{R M S}\right]$ & 2.17 & $2.17(0)$ \\
\hline $\mathrm{V}_{\lambda}\left[\mathrm{V}_{R M S}\right]$ & - & $42.2(-)$ \\
\hline $\mathrm{V}_{g t}\left[\mathrm{~V}_{R M S}\right]$ & 42.6 & $40.8(4.41)$ \\
\hline $\mathrm{P}_{\text {out }}[W]$ & 92.4 & $87.5(5.60)$ \\
\hline \multicolumn{3}{|l|}{ 6A RMS: } \\
\hline $\mathrm{I}_{g}\left[\mathrm{~A}_{R M S}\right]$ & 6.09 & $6.09(0)$ \\
\hline$\stackrel{\circ}{\mathrm{V}}_{\lambda}\left[\mathrm{V}_{R M S}\right]$ & - & $32.6(-)$ \\
\hline $\mathrm{V}_{g t}\left[\mathrm{~V}_{R M S}\right]$ & 28.0 & $28.9(3.21)$ \\
\hline $\mathrm{P}_{\text {out }}[W]$ & 169 & $162(4.32)$ \\
\hline
\end{tabular}

Figure 3.19 shows the comparison between the measured and the simulated emf under no-load. It is seen that the measured emf is generally close to the simulated emf, but with noticeable difference at the zero crossings and peaks. This thought to be a result of a difference between the simulated flux linkage and the actual flux linkage due to build imperfections.

Simulations was done with current waveforms as close as possible to the measured current waveforms, for both the 2A RMS and 6A RMS tests, in order to compare the measured and simulated terminal voltages. A comparison between the measured and simulated current for the 2A RMS and 6A RMS test are shown in figures 3.20 and 3.22 respectively.

Figure 3.21 shows the measured and simulated results of the terminal voltages for the 2A RMS test. It is seen that the measured terminal voltage for the 2A RMS test is generally close to the simulated terminal voltage with a percentage difference of 4.41 as listed in table 3.6. A comparison between the measured and simulated results of the terminal voltage for the 6A RMS test is shown in figure 3.23.

It is seen that the phase shift between the measured terminal voltage and the simulated terminal voltage for the 6A RMS test is larger that that of the 2A test while the percentage difference between the measured and simulated RMS values remain approximately the same for both tests. Unfortunately the 6A RMS test does not tell us much about the design of the generator. 


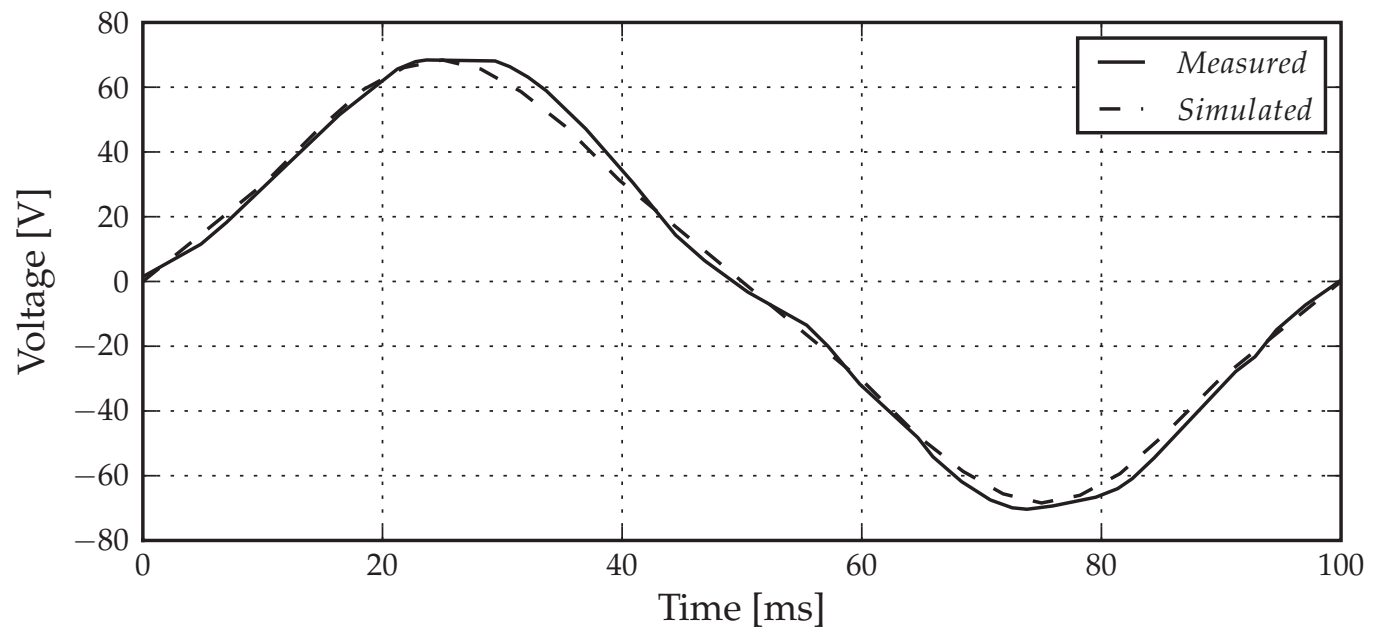

Figure 3.19: Measured and simulated emf compared (No load).

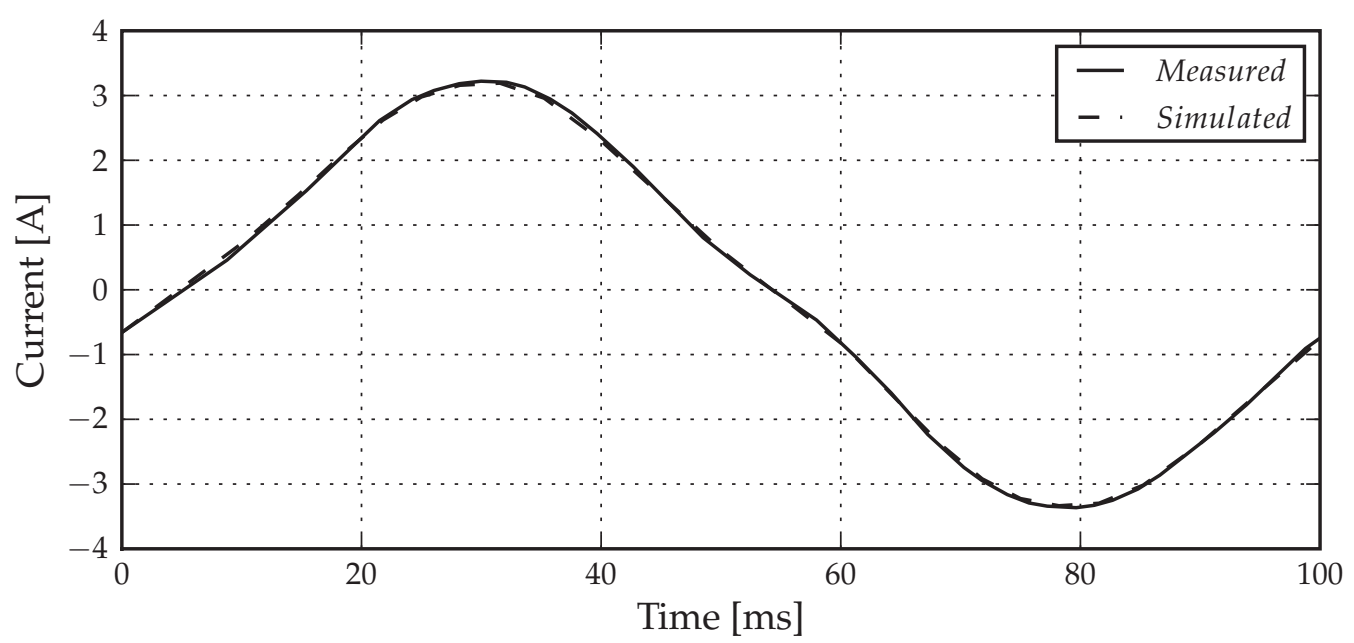

Figure 3.20: Measured and simulated current compared (2A RMS).

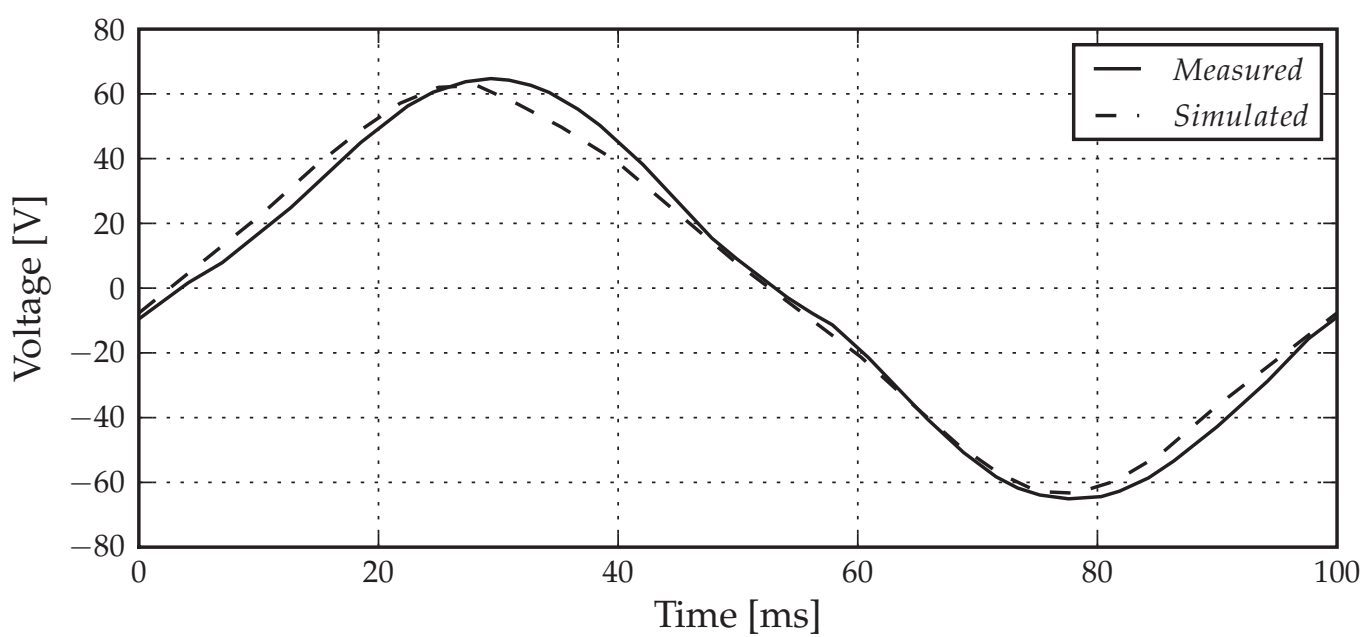

Figure 3.21: Measured and simulated terminal voltage compared (2A RMS). 


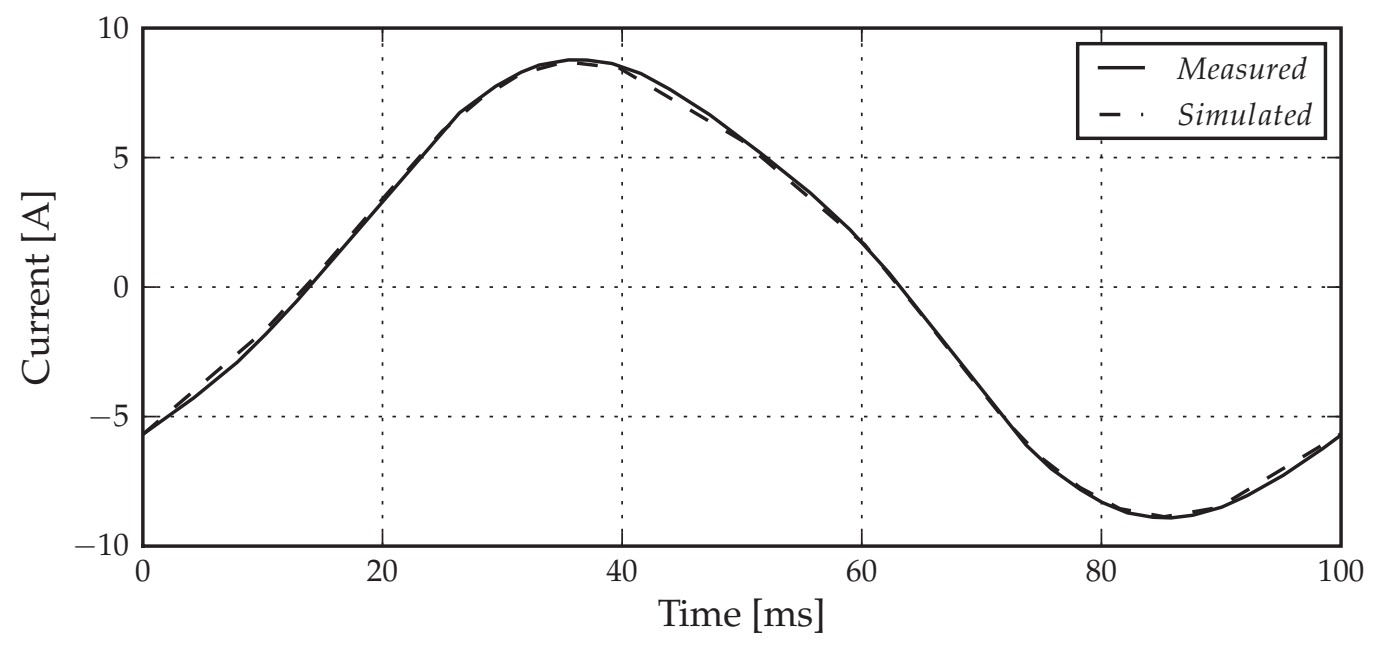

Figure 3.22: Measured and simulated current compared (6A RMS).

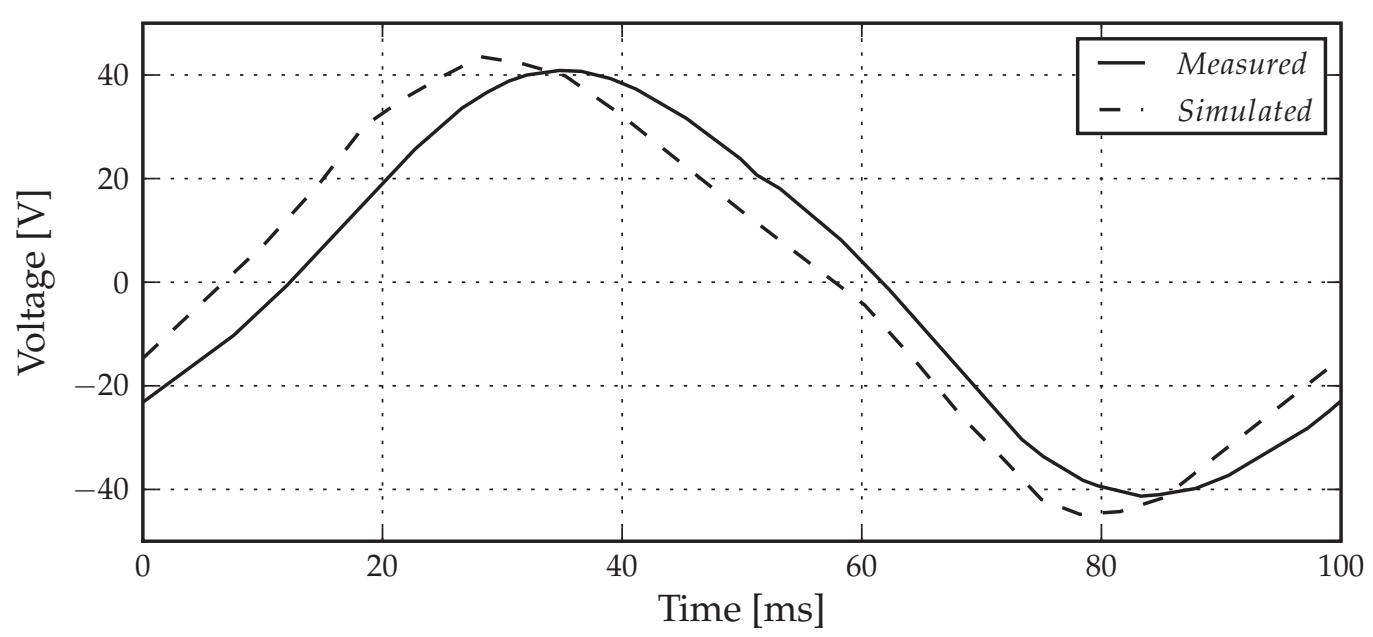

Figure 3.23: Measured and simulated terminal voltage compared (6A RMS).

The inductance of the generator was calculated using

$$
L_{g}=\frac{v_{\lambda}-e}{\frac{d i}{d t}}
$$

The inductance $\left(L_{g}\right)$ is undefined where the denominator, i.e. $\frac{d i}{d t}$, is zero and inaccurate for where $\frac{d i}{d t}$ approaches zero. Therefore is was decided to calculate the average inductance for only a piece of the current $(i)$ waveform where $\frac{d i}{d t}$ is not close to zero. The interval between $50 \mathrm{~ms}$ and $70 \mathrm{~ms}$ was chosen as $\frac{d i}{d t}$ for both the 2A RMS and 6A RMS test is not close to zero as seen in figures 3.20 and 3.22 respectively. This gives an approximate average inductance value of $69.7 \mathrm{mH}$ and $71.2 \mathrm{mH}$ for the 2A RMS and 6A RMS measured results respectively. This method was also used to calculate the average inductance of the generator using the results from the simulations. The average inductance of the generator using the results of the 2A RMS and 6A RMS simulations was $51.5 \mathrm{mH}$ and $54 \mathrm{mH}$ respectively. 
The inductance values calculated from the simulations compare well to the calculated inductance of $48.4 \mathrm{mH}$ for the $50 \mathrm{~Hz}$ optimised simulation. However, the inductance values calculated from the measured results is approximately $36 \%$ higher than that of the simulated inductances.

The efficiency could not be measured due to the lack of measurement equipment and proper measurement techniques.

\subsection{Conclusive remarks}

A 3D finite element analysis assisted optimisation strategy for a moving magnet TF linear generator topology has been implemented successfully. Geometric optimisation for a $3 \mathrm{~kW}$ version with the aim to maximise the power-to-weight ratio could be performed successfully. The optimised generator was successfully built and tested to confirm optimisation and design results.

The obtained total power-to-weight ratio of the moving magnet topology is approximately $0.124 \mathrm{~kW} / \mathrm{kg}$. This value is a significant improvement on the previous optimisation performed by Schutte and Strauss [8] on the moving iron topology described by Boldea and Nasar [6]. The total power-to-weight ratio for the moving iron topology was $0.058 \mathrm{~kW} / \mathrm{kg}$ as stated in section 2.3.1.

The investigation into the TF linear PM generator family showed great improvement, but it is believed that there is still work to be done to further improve the results of the TF linear PM generator topologies for free-piston Stirling engine applications. Changes to improve the geometric optimisation without compromising the manufacturability of the generator can be implemented. Optimisation parameters in the z-direction can be added. These parameters include the magnet length and stator length which are not necessarily the same length. This will give the optimisation algorithm more freedom to improve the generator topology. Freedom can also be added by making the magnet width and spoke width independent of each other.

There are some other variations of the topology that can be investigated, unfortunately these change have an effect on the manufacturability. The magnets can be separated from the stator and the mover introducing a dual stator dual air gap moving magnet generator. This however presents problems such as the manufacturing of a magnet carrier. The magnet carrier act as a housing for the magnets so that the magnets can translate as a unit. 


\section{Chapter 4}

\section{Rectifier}

\subsection{Introduction}

This chapter discusses the design and control of a single phase rectifier which is part of the back to back converter. The schematic diagram of the entire system, which includes the generator, rectifier, capacitor bank, inverter and network, is shown in figure 4.1. The rectifier and capacitor bank are highlighted in the figure for clarity. It is necessary to build a power electronic converter to transfer the energy from the generator, as discussed in chapter 3 , to the electricity network. The rectifier has the ability to force a current from the generator. This is especially needed to ensure the correct phase angles between the current $\left(i_{g}\right)$ and the voltages $\left(e\right.$ and $\left.v_{g t}\right)$. The phase angle between $e$ and $v_{g t}$ varies according to the inductance of the generator and the generator current $i_{g}$.

The hardware design of the rectifier is discussed in section 4.2 and the current control is discussed in section 4.3. Section 4.4 elaborate on the construction process of the rectifier. In section 4.5 the results of the tested rectifier (without the generator connected) are given and discussed. Finally a concluding discussion is presented in section 4.6. 


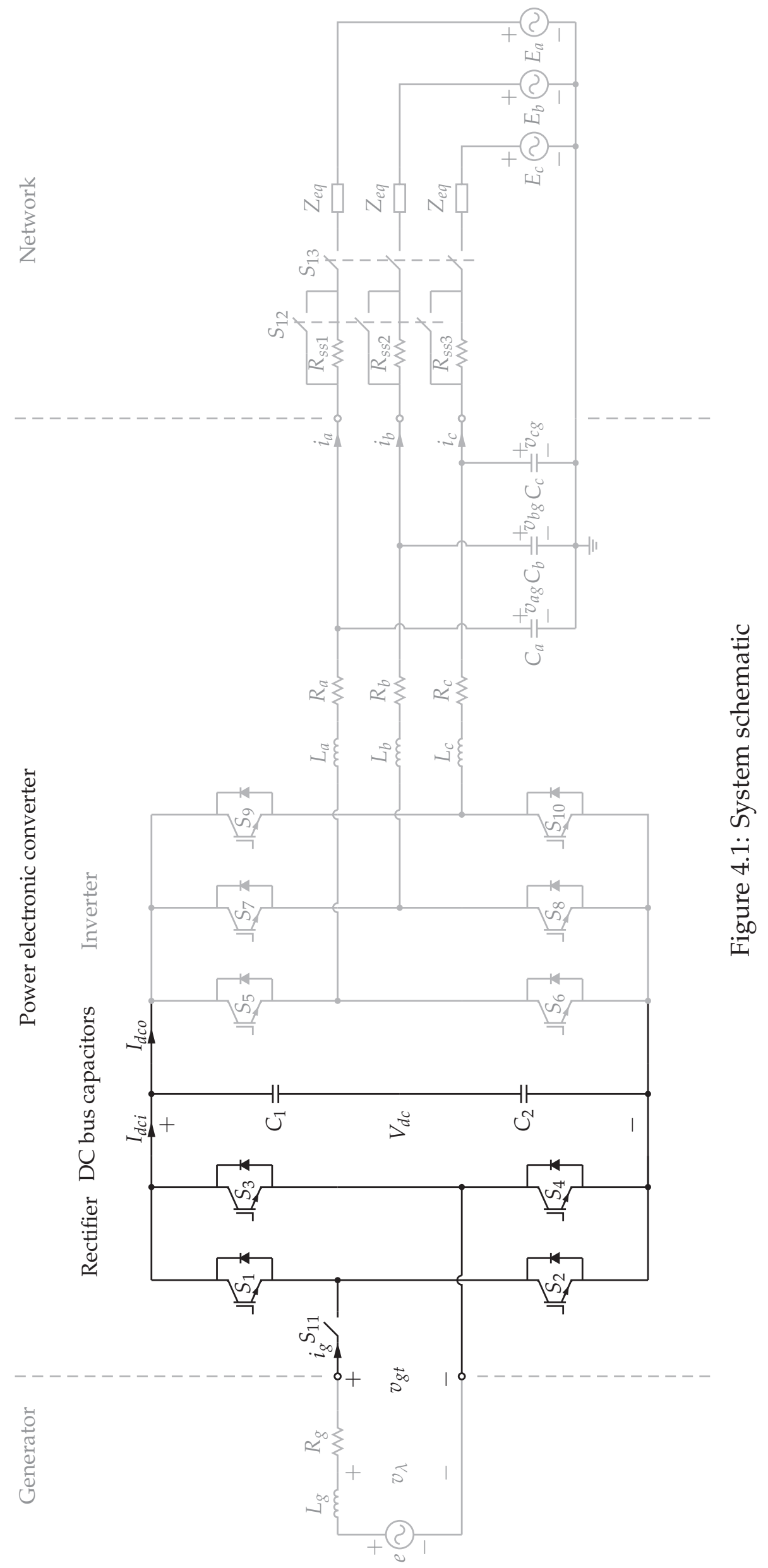




\subsection{Hardware design}

\subsubsection{Power electronics and related hardware}

A $20 \mathrm{~kW}$ rectifier was designed so that it can be used for this project as well as in future for various other generators. It is not expected that future generators will exceed rated capacity of $10 \mathrm{~kW}$. Therefore, a $20 \mathrm{~kW}$ rectifier is regarded to be sufficient for the testing of these generators. However, if the inductance value $(\mathrm{L})$ of the generator becomes to high, then the input voltage limit of the rectifier is reached due to $v_{g t}$ that becomes to high in order to force the rated current. There is a limit on the voltage $\left(v_{g t}\right)$ that the rectifier can obtain with a certain bus voltage and if this limit is reached due to a large inductance value of the generator, the rectifier will not be able to effectively control the current $\left(i_{g}\right)$.

The intelligent power module (IPM) (PM100RL1A120) from Mitsubishi is used which is a six pack Insulated-Gate Bipolar Transistor (IGBT) module. The six IGBTs is rated at $1200 \mathrm{~V}$ and $100 \mathrm{~A}$. This IPM module was chosen because of the built in driver for the IGBTs. The three phase IPM module is used although a single phase rectifier is implemented. A single phase rectifier is needed for this application but in the future one may need a three phase rectifier. Therefore the hardware is designed for the full three phase rectifier, although only four of the six IGBTs will be used for the single phase rectifier discussed in this chapter.

Figure 4.2 shows a flow diagram for the hardware designed. The pulse width modulation (PWM) signals come in from the PWM-module, described in section 4.2.2, via fiber optics to an interface printed circuit board (PCB). These signals are then passed via a ribbon cable to a PCB which is directly connected to the pins of the IPM module. The PWM signals are then optically decoupled from the rest of the system and connected to the IPM. Error signals from the IPM are send back to the digital control hardware the same way the PWM signals was sent to the IPM. Two extra fibre optic signals from the digital control hardware are used to switch contactors. One of these signals are used to control contactor $S_{11}$, as shown in figure 4.1, which connect the rectifier to the generator. The other signal is not currently used and was only implemented for future use.

The interface PCB is supplied with $5 \mathrm{~V}_{\mathrm{dc}}$ from a regulator with a $220 \mathrm{~V}_{\mathrm{ac}}$ input. The signals from the opto-couplers are supplied with $15 \mathrm{~V}_{\mathrm{dc}}$ from a regulator with a $5 \mathrm{~V}_{\mathrm{dc}}$ input to ensure rated PWM signals to the IPM.

In the capacitor bank shown in figure $4.2, C_{1}$ and $C_{2}$ both represent four $450 \mathrm{~V}, 4700$ 


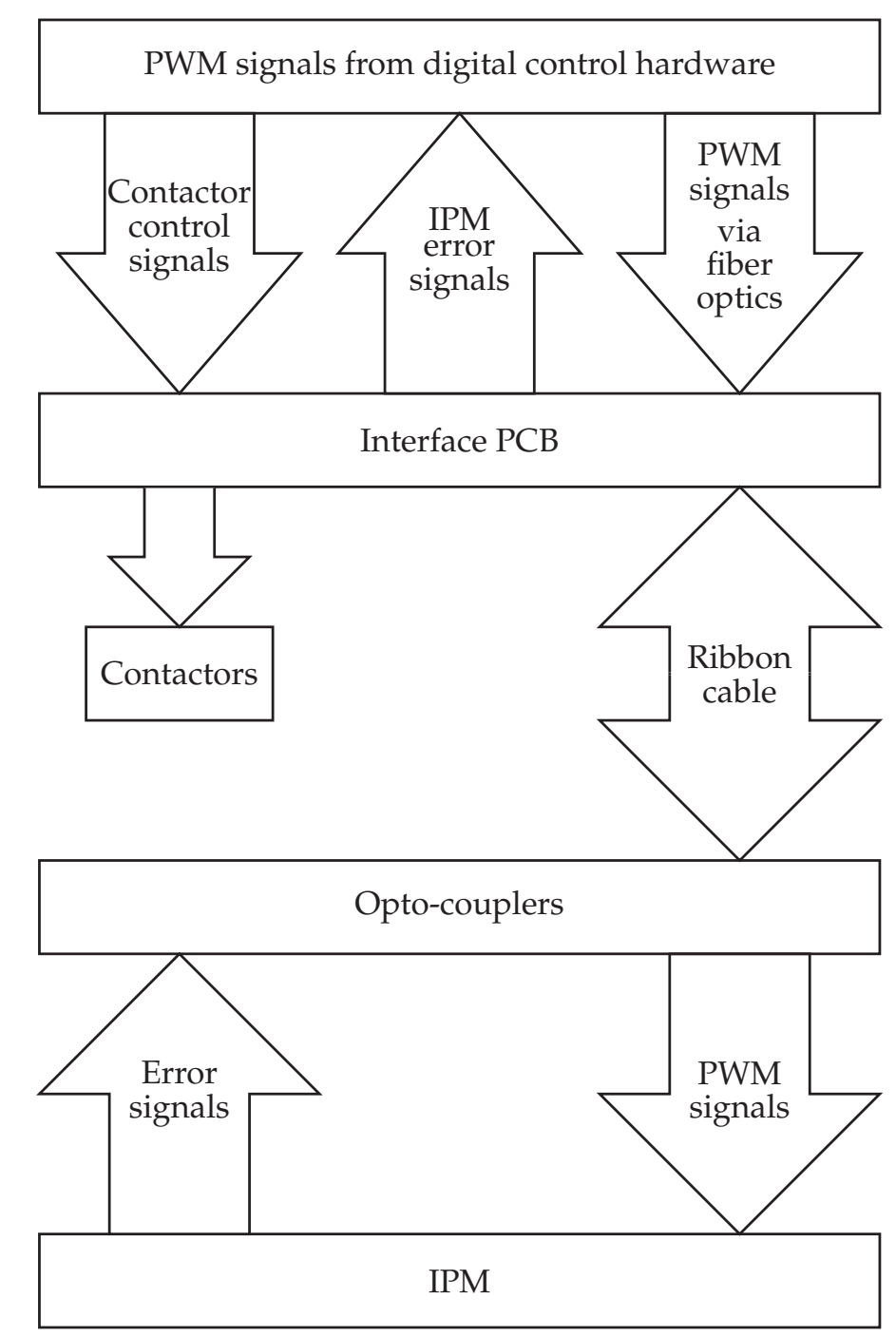

Figure 4.2: Flow diagram of power electronic hardware

$\mu \mathrm{F}$ capacitors connected in parallel. The total bus capacitance is $9400 \mu \mathrm{F}$ with a rated voltage of $900 \mathrm{~V}$. Each capacitor has a $33 \mathrm{k} \Omega$ bleeding resistance with a power rating of $10 \mathrm{~W}$ connected between its positive and negative terminal to ensure that the capacitors discharge completely.

\subsubsection{Digital control hardware}

Digital implementation of controllers have several advantages over analogue controllers. These advantages, as discussed by Wolf [14], include:

- The control characteristics of analogue systems change over time because the values of analogue components change in changes in temperature and age. However, digital systems are insensitive to environmental changes. 
- Improving or adding functionality to digital controllers does not necessarily increase the physical size of the hardware.

- Digital controllers can be re-programmed and therefore algorithms can be upgraded or reconfigured at no additional cost. This also reduces the design time.

- Insensitivity to component tolerances implies that two different digital controllers will give identical results. Production costs are thus lowered because no components need to be tweaked.

To do the calculation for the current control, a digital signal processor (DSP) is used. The DSP is part of a generic control system that was previously developed. The system was incomplete in the beginning of this project but the missing components was acquired and the PCBs were populated to the point where a functional system was obtained for the project. Figure 4.3 shows a diagram of the digital control.

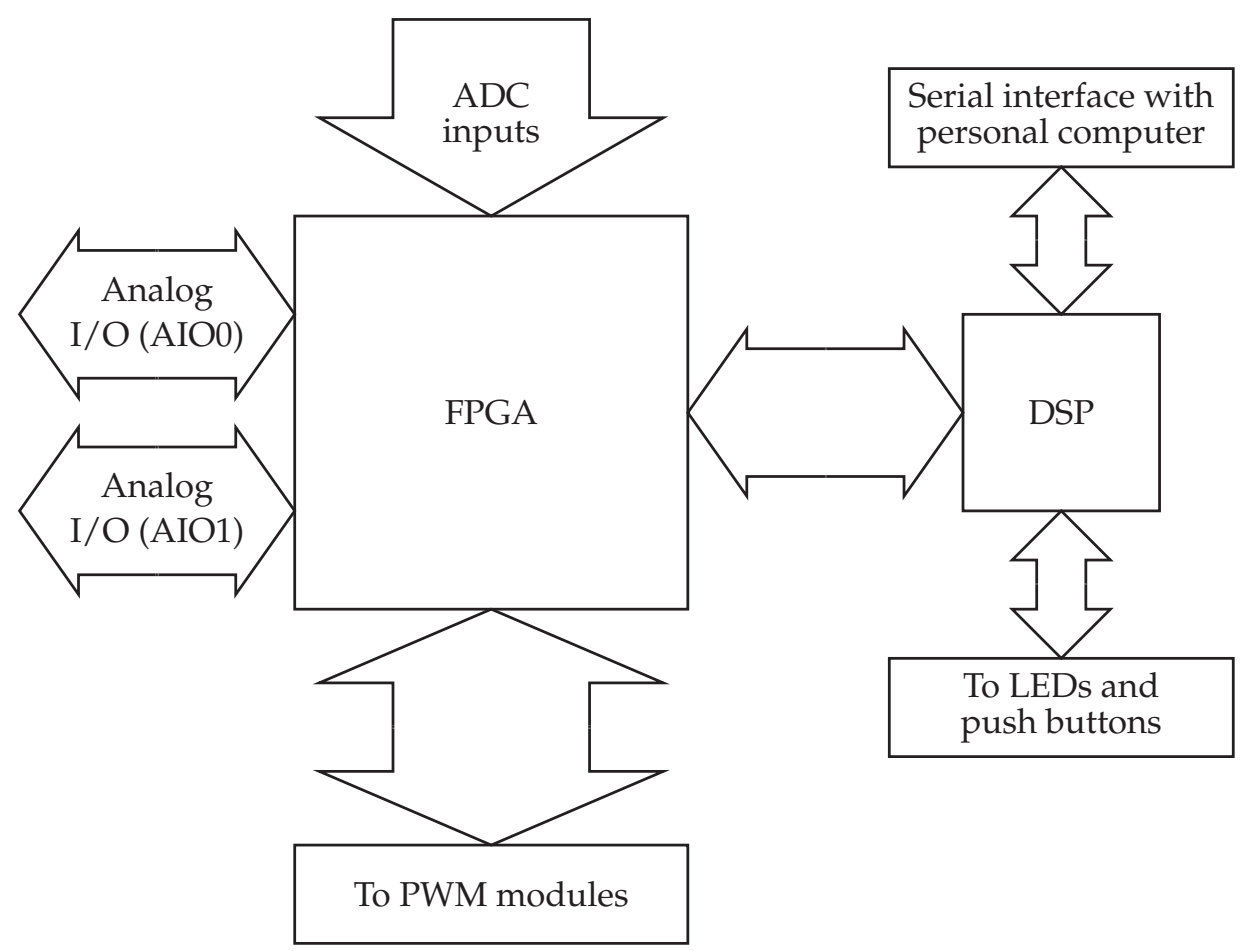

Figure 4.3: Diagram of the digital control hardware

A Texas Instruments DSP chip (part number TMS320VC33) is used together with a number of modules and components for proper functioning of the system. The DSP has a serial interface with a personal computer for programming purposes. LEDs and push buttons are connected to the DSP for debugging purposes. The DSP communicates mainly with an Altera Cyclone field-programmable gate array (FPGA) (part number EP1C6Q240C8) which gather data from most of the peripherals and send the 
required data, when needed, to the DSP for processing. The two input/output (I/O) ports connected to the FPGA is used for debugging purposes.

The FPGA communicates to PWM modules via small complex programmable logic devices (CPLDs). The PWM modules send and receive data via fiber optic cables. One PWM module is used for the rectifier and a second is used for the inverter, there is place for two more PWM modules in the system but that is not needed for this project. 12-bit analogue to digital converters (ADCs) from Analog Devices are used to sample measured voltages and currents required for calculations in the DSP.

The LA50-S and LA100-S are closed loop Hall effect current transducers from LEM. The LA100-S are used to measure current $I_{d c i}$ and $I_{d c o}$ while the LA50-S is used to measure current $i_{g}$. The only difference between the LA50-S and the LA100-S is that their primary nominal RMS current are $50 \mathrm{~A}$ and $100 \mathrm{~A}$ respectively. All the voltages are differentially measured and filtered with an analogue Low Pass Filter (LPF) at 1 $\mathrm{kHz}$.

Voltages $e$ and $v_{g t}$ are not measured from the generator for testing purposes of the rectifier. Voltage $e$ indicate a supply voltage that is connected to the input of the rectifier and voltage $v_{g t}$ is the switched voltage generated by the rectifier. The voltages measured for rectifier control include $e$, which can be measured because it is a supply voltage and not the emf of the generator, and the DC bus voltage $\left(V_{d c}\right)$. In a later stage in this chapter the results is discussed when the generator is connected to the input of the rectifier, where these voltage symbols indicate the voltages of the generator.

The measured voltages are 459.5 times greater than the input voltage to the ADCs. The measured currents are 20 times greater than the input voltage to the ADCs. This results from a 1:1000 scale of the current transducers and a $50 \Omega$ measuring resistance. An offset of $2.5 \mathrm{~V}$ are added to these ADCs input voltages to ensure a 0 - $5 \mathrm{~V}$ input to the ADC chip self. This enable us to measure alternating waveforms. The maximum and minimum voltage that can be measures are:

$$
v_{\text {meas }}= \pm 2.5 \mathrm{~V} \times 459.5= \pm 1148.75 \mathrm{~V}
$$

The maximum and minimum current that can be measures are:

$$
i_{\text {meas }}= \pm 2.5 \mathrm{~V} \times 1000 / 50 \Omega= \pm 50 \mathrm{~A}
$$




\subsection{Current control}

\subsubsection{High level overview}

A significant amount of literature is available on different current control strategies. This section will discuss a few current control options together with their advantages and disadvantages.

Linear controllers, e.g. the stationary controller and the synchronous vector controller described by Kazmierkowski and Malesani [15], have dynamic properties that is inferior to those of bang-bang controllers.

Excellent results can be obtained with state-space observers but their control algorithms are complex. Ryan et. al. [16] give a full discussion of the state space controller amongst others.

Variable and constant switching frequency hysteresis current control schemes are discussed by Kazmierkowski and Malesani [15]. Hysteresis current control with a variable switching frequency have advantages which include robustness, simplicity, independence of load parameter changes, lack of tracking errors and extremely good dynamics limited only by switching speed and load time constant. One of the main disadvantages of hysteresis current control with variable switching frequency is that the switching frequency depends on the load parameters and varies with the AC voltage. Hysteresis control with constant switching frequency is more complex than the variable frequency option but guarantee very fast response together with limited tracking error and are therefore suited for high-performance high-speed applications.

A low computational predictive control strategy was presented by Bester [17]. Predictive current controllers have a good dynamic performance but steady state tracking errors can occur if there is no integration term present in the control equation. Use of a proportional-integral (PI) controller can minimize this error. With predictive controllers the zero states of the inverter can be used in order to reduce the switching frequency at low back emf voltages.

Due to the advantages and disadvantages as discussed above it was decided to use the predictive current controller as described by Bester [17] for the rectifier current control in this project. 


\subsubsection{Predictive control}

Unipolar switching is used in stead of bipolar switching because unipolar switching uses the two zero states of a single phase converter. This is the main advantage of unipolar switching above bipolar switching. The zero state occur when both phase arms are either on or off. Figure 4.4 shows the single phase full bridge rectifier with the unipolar switching states. The zero states (indicated as $S_{0}$ ) enable $-e$ to be used as forcing voltage over the inductor which is not possible when using bipolar switching with consists only of active switching states $S_{1}$ and $S_{2}$.
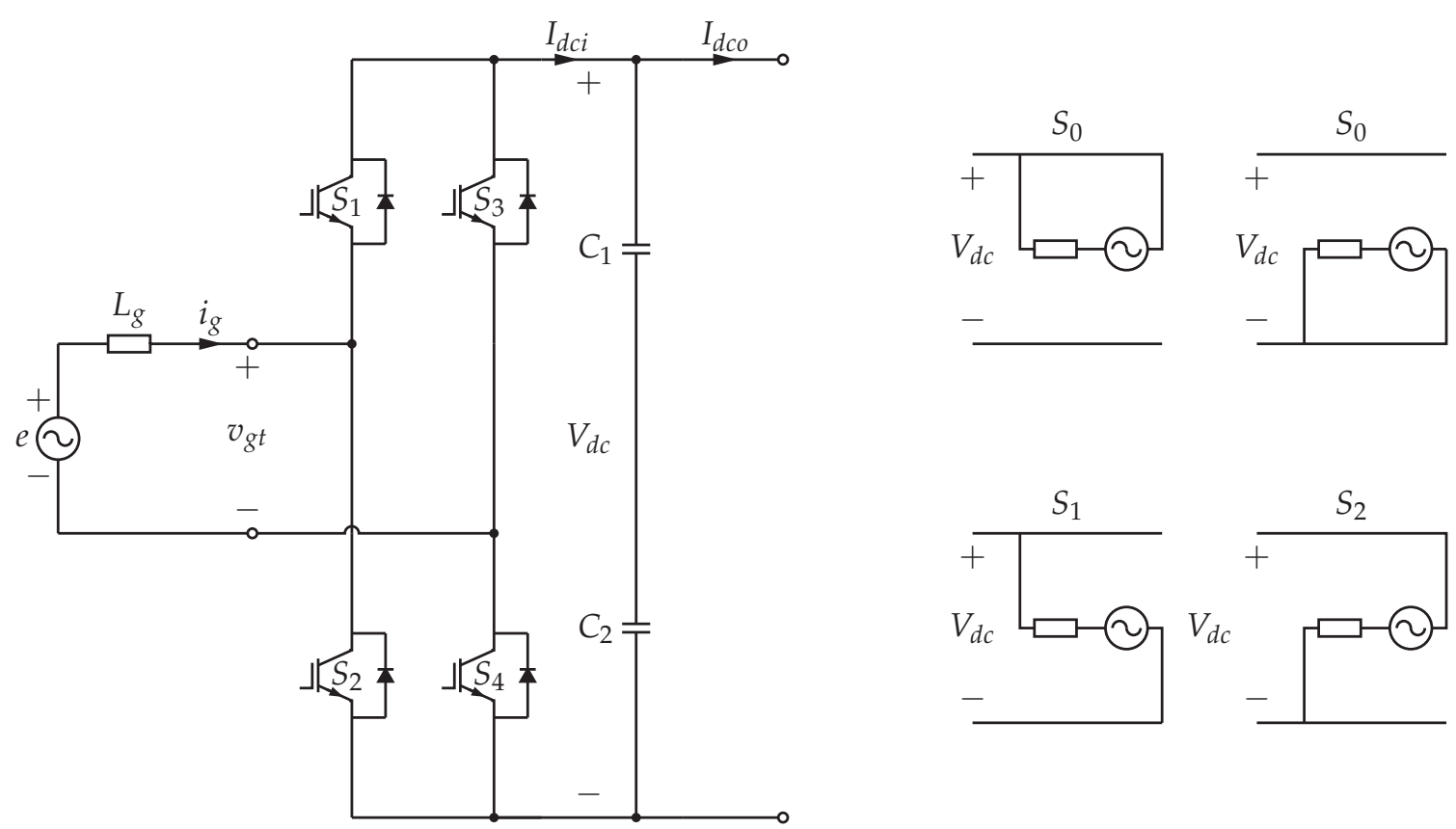

Figure 4.4: Single phase full bridge rectifier with unipolar switching definitions.

An example of a typical switching waveform is shown in figure 4.5 where it can be seen that the difference between the duty cycles of phase arm 1 and phase arm 2 is equal to the time that is spent in an active state. This leads to the rectifier duty cycle,

$$
d_{r}=d_{1}-d_{2} \quad\left(-1<d_{r}<1\right)
$$

where $d_{1}$ and $d_{2}$ are the duty cycles of phase arm 1 and phase arm 2 respectively. A balanced switching waveform, as shown in figure 4.5 , ensure a minimum current ripple.

The two phase arm duty cycles can be calculated from the rectifier duty cycle, for the switching period $t_{k}$ to $t_{k+1}$ as shown in figure 4.5. In the case of creating a balanced switching waveform $d_{1}$ and $d_{2}$ can be derived as

$$
d_{1}=0.5+\frac{d_{r}}{2}
$$




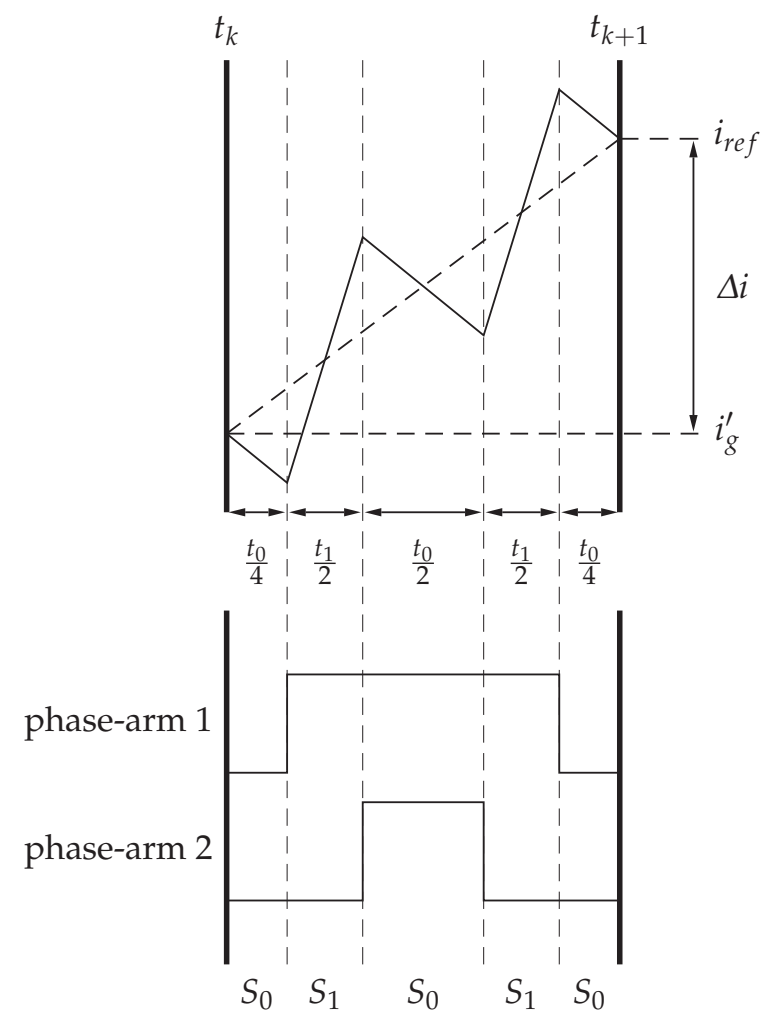

Figure 4.5: An example of an ideal switching waveform.

and

$$
d_{2}=0.5-\frac{d_{r}}{2}
$$

The derivation of the rectifier duty cycle is shown by Bester [17] and boils down to

$$
d_{r}=\frac{L_{g} \frac{\Delta i}{T_{s}}+e}{V_{d c}}
$$

where $T_{s}$ is the sampling period, which is $100 \mu$ s for the $10 \mathrm{kHz}$ switching frequency implemented, and

$$
\Delta i=i_{r e f}-i_{g}^{\prime}
$$

where $i_{\text {ref }}$ is the reference current that must be obtained and $i_{g}^{\prime}$ the measured value of the current $\left(i_{g}\right)$ shown in figure 4.4 .

The control strategy was tested with the commercial package Simplorer. However, the control was implemented in the continuous time domain in the simulations. This was first done to confirm that the control work effectively. Digital control was never implemented in Simplorer simulations, therefore the simulation results shown for the rectifier as well as the inverter discussed in chapter 5 is for the continuous time domain. This poses no issues because the continuous time domain results should correspond with the digital time domain results.

It is shown in Figure 4.6 that the measured current $\left(i_{g}\right)$ follows the reference current $\left(i_{\text {ref }}\right)$ closely. Figure 4.7 depicts the supply voltage $e$ and the switched voltage $v_{g t}$ gen- 
erated by the rectifier. The switched voltage waveform as shown in Figure 4.7 is filtered at $1 \mathrm{kHz}$ with a RC low pass filter (LPF) in Simplorer.

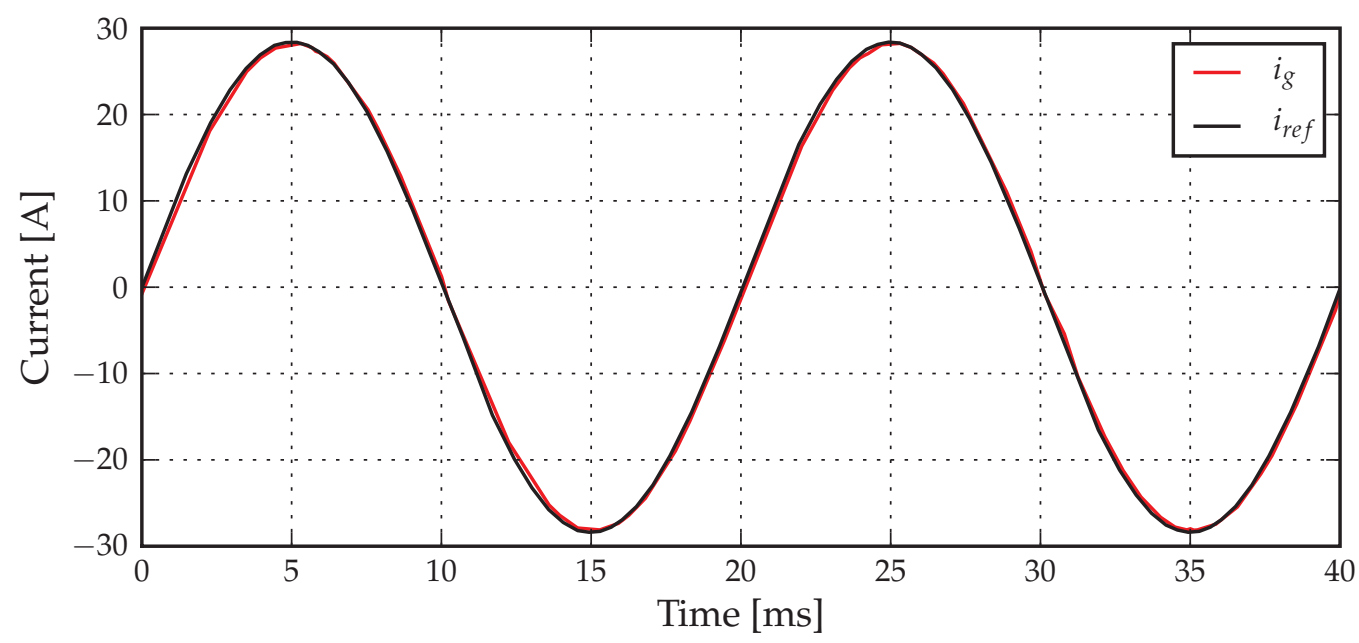

Figure 4.6: Measured and reference currents as simulated in Simplorer.

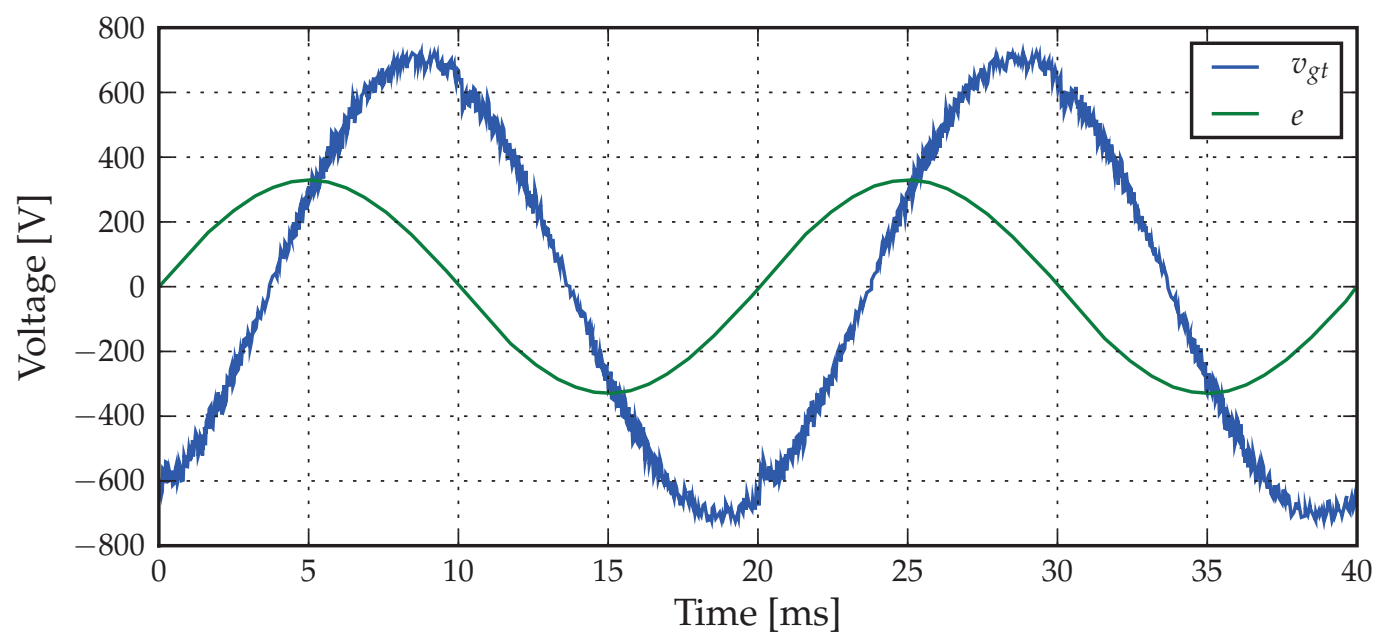

Figure 4.7: Supply voltage and filtered switched voltage as simulated in Simplorer.

The simulation was done with an inductance value $\left(L_{g}\right)$ of $72 \mathrm{mH}$. This value was chosen to represent the inductance value of the generator that was tested in chapter 3. The simulation values of $230 V_{r m s}$ and $20 A_{r m s}$ was chosen for $e$ and $i_{g}$ respectively. This represents a $4.6 \mathrm{~kW}$ generator.

The limiting factor for the size of generator that can be tested with the rectifier is the inductance $\left(L_{g}\right)$. In this case the switched voltage $\left(v_{g t}\right)$ of the rectifier must be $717 V_{\text {peak }}$, which is close to the maximum available switched voltage keeping in mind the a 750 $\mathrm{V}$ DC bus voltage is used, to force a $20 A_{\text {rms }}$ current through the inductor. Therefore the chosen simulation values as stated above is the maximum the rectifier can handle with a $750 \mathrm{~V}$ bus voltage. The bus voltage control is described in chapter 5 and it will be assumed in this chapter that the bus voltage is controlled by the inverter at $750 \mathrm{~V}$. 


\subsection{Construction}

This section discusses the construction phase of the rectifier and shows some images of the final product. The duct for the fan as well as the stand for the bus capacitors was cut out of sheet metal by laser cutting and then folded as desired. The positive and negative DC bus plates was also cut out of aluminium using the same process. Figure A.4 shows an Inventor rendered image of the back-to-back converter while figure A.5 shows the folded sheet metal unit which includes the part that is the fan duct as well as the part to mount the heat sink on.

Figure 4.8 shows an image of the power electronic converter where the rectifier IPM's and relevant PCB's are indicated. Figure 4.9 also depicts the power electronic converter but from another view in order to indicate contactor $S_{11}$ and inductor $L_{g}$ also indicated in figure 4.1. The LEM transducer used for the measurement of current $i_{g}$ is also indicated in figure 4.9 .

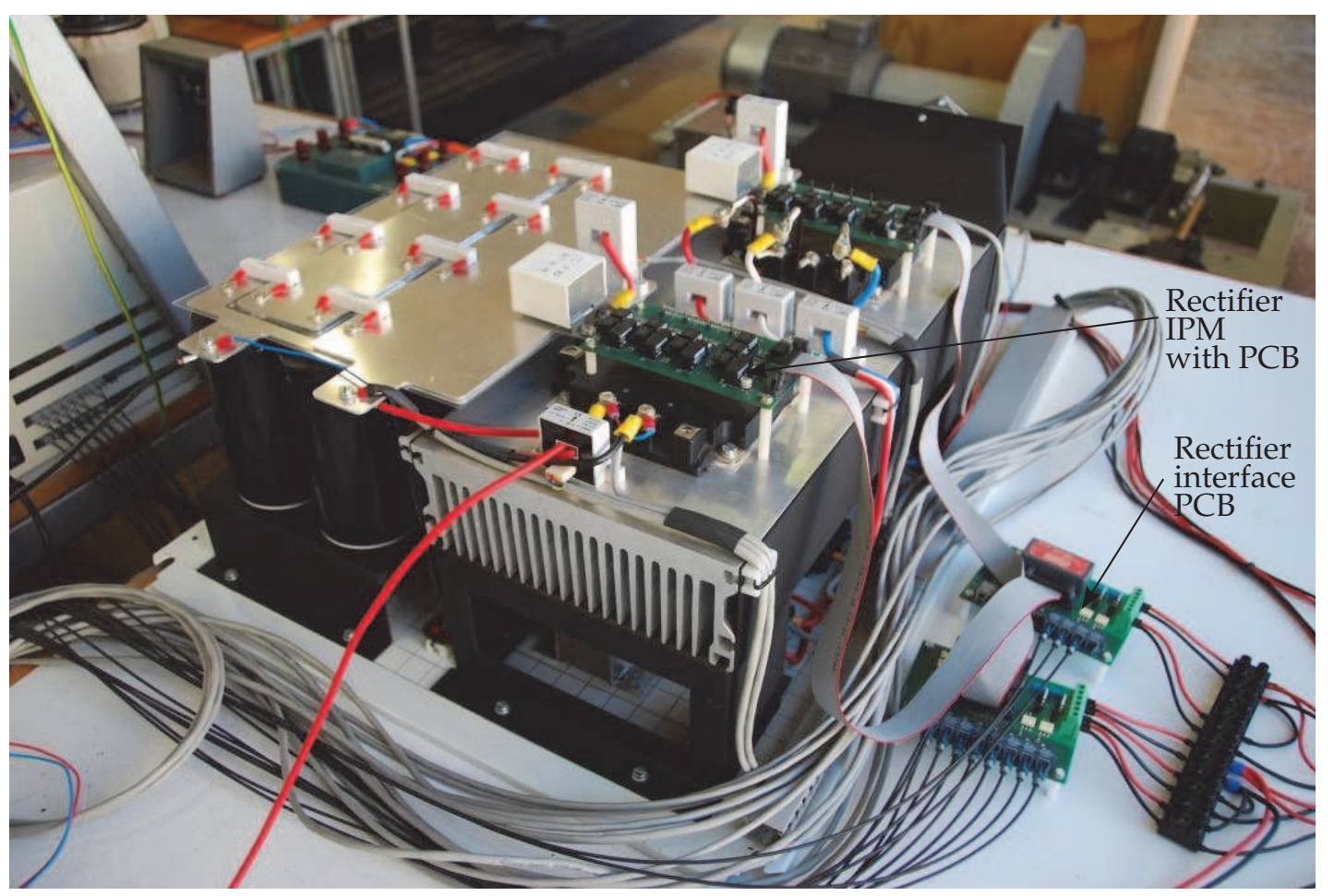

Figure 4.8: Power electronic converter showing the bus capacitors on the left and the IGBT modules for the rectifier and inverter on the heat sink on the right. 


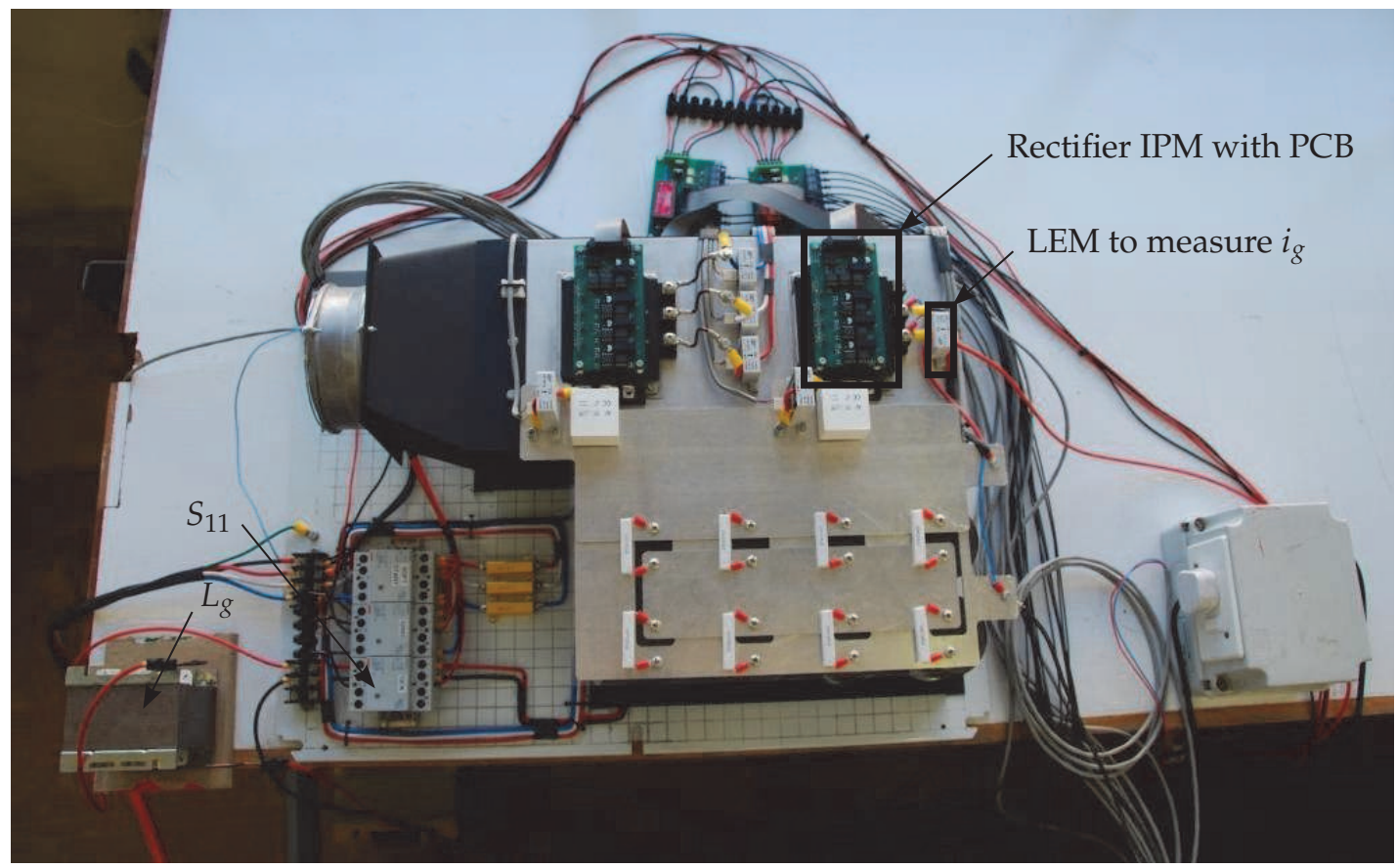

Figure 4.9: Top view of the power electronic converter showing relevant components of the rectifier.

\subsection{Results}

The rectifier was first tested at approximately three times lower than rated values to ensure proper functioning of the control implemented. Later when the higher value measurement was done the anti-parallel diodes failed due to the issues with soft-start resistors on the inverter side of the back-to-back converter. This matter is further discussed in chapter 5 . Therefore test results are only shown at the lower scaled values.

Figure 4.10 shows the measured current $\left(i_{g}\right)$ through the inductor $(\mathrm{L})$ as well as the reference current $\left(i_{r e f}\right)$ and voltages $e$ and $v_{g t}$ as they were measured. Current $i_{g}$ was measured with a TCP current probe and $i_{\text {ref }}$ was measured from the digital to analogue converter (DAC) output of the digital system. Voltage $e$ was measured with a differential voltage probe and $v_{g t}$ was also measured with a differential voltage probe and was filtered at $1 \mathrm{kHz}$ with a low pass RC-filter.

Figure 4.11 shows all the signals in figure 4.10 but filtered at $1 \mathrm{kHz}$ with a second order digital Bessel-Thompson low pass filter. The filtering is done from left to right and again from right to left for zero phase shift. All the post process digital filtering mentioned in this section refer to this filtering method.

Figure 4.12 shows the measured current $\left(i_{g}\right)$ through the inductor $(\mathrm{L})$ as well as the reference current $\left(i_{\text {ref }}\right)$ and voltages $e$ and $v_{g t}$ as simulated in Simplorer. The measured 


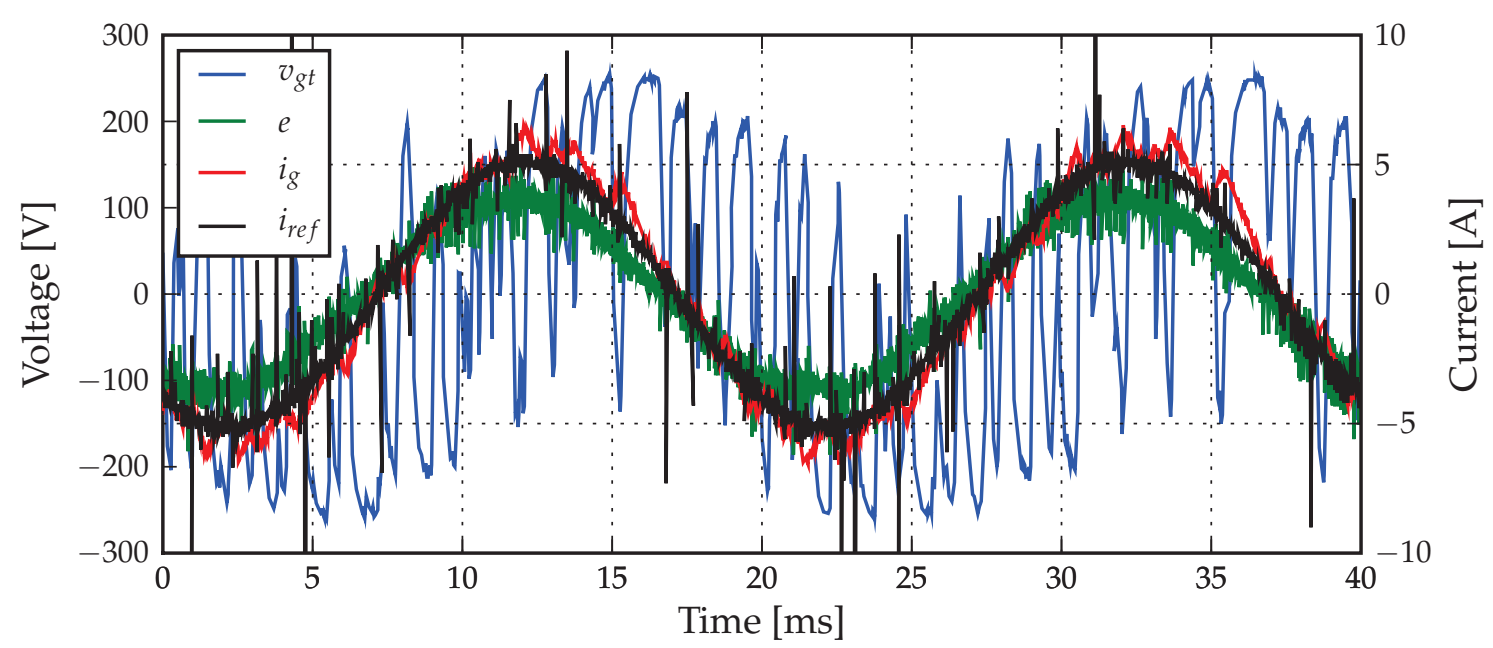

Figure 4.10: Current and corresponding reference current with the voltages $e$ and $v_{g t}$.

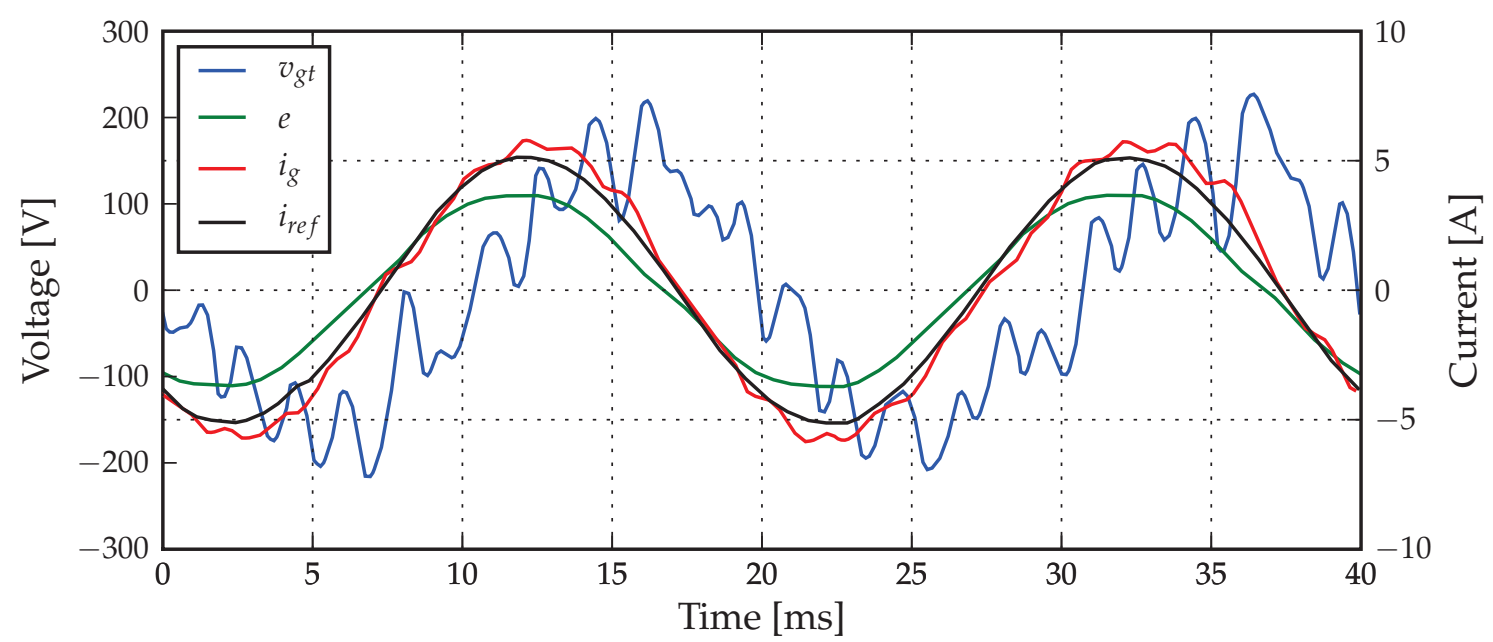

Figure 4.11: Filtered current and corresponding reference current with the voltages $e$ and $v_{g t}$.

signals of the tested system correspond to the simulation results when compared. The big difference between the two is that the switched rectifier voltage $\left(v_{g t}\right)$ has a higher frequency signal superimposed on the fundamental. This appearance of the higher frequency can not be declared. Further investigation is necessary to resolve this issue, but was not attended to due to time restriction.

Figures 4.13 and 4.14 depict the input and output DC currents $\left(I_{d c i}\right.$ and $\left.I_{d c o}\right)$ for the practical test and the Simplorer simulation respectively. Where figures 4.15 and 4.16 shows the same signal but digitally filtered at $1 \mathrm{kHz}$ with the same second order BesselThompson filter mentioned earlier. The Simplorer simulation shows more ideal signal but the comparison between the practically measured signals still correspond well to the simulated signals.

The bus voltage is controlled by the inverter at $250 \mathrm{~V}$ and is discussed in chapter 5 . 


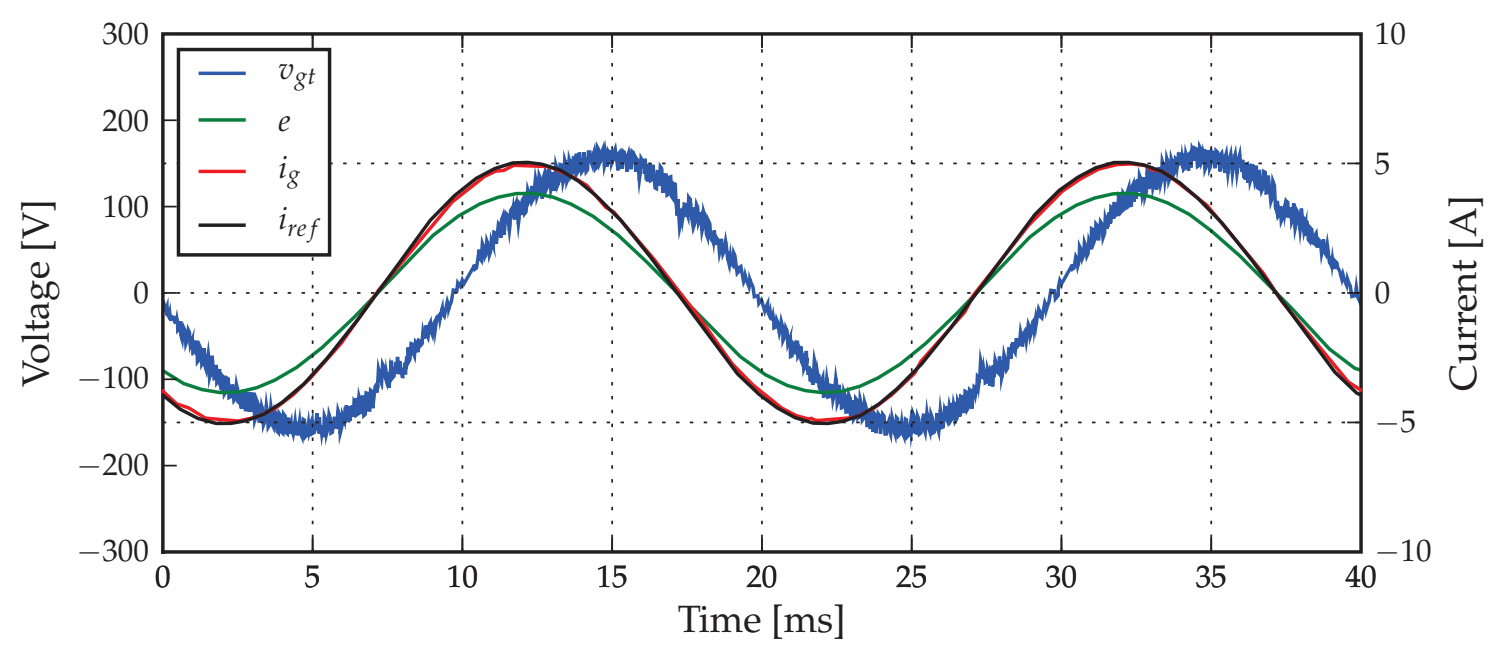

Figure 4.12: Simulated current and corresponding reference current with the voltages $e$ and $v_{g t}$.

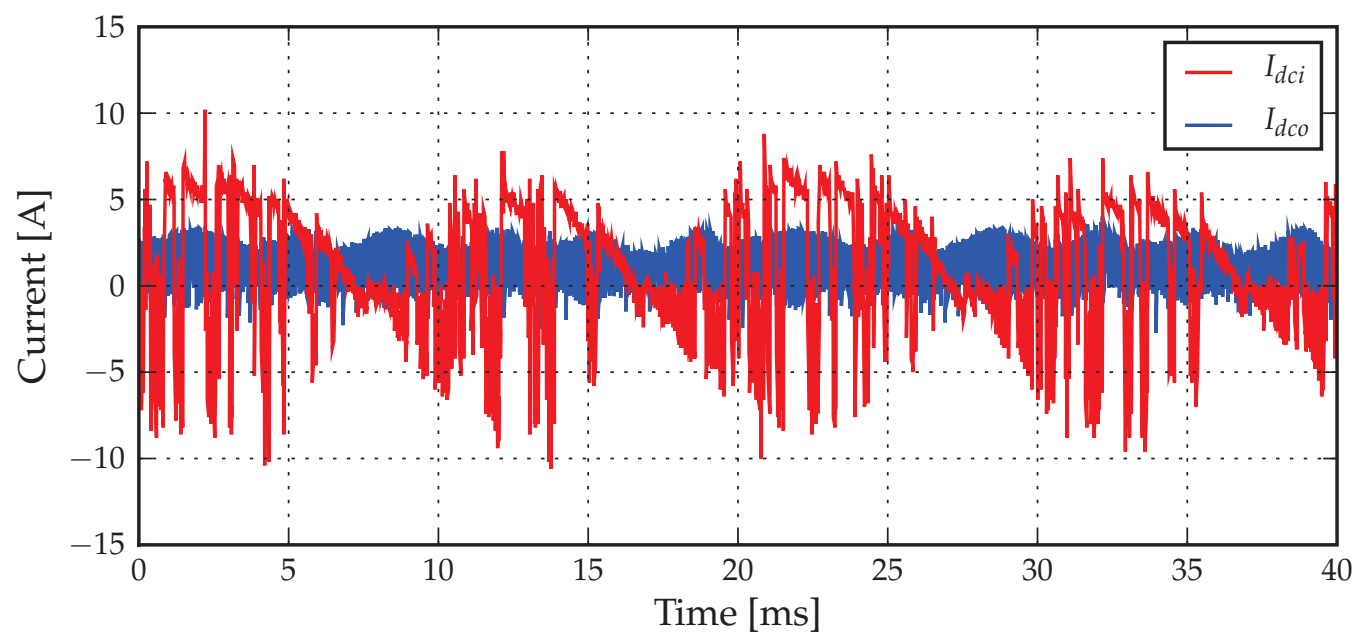

Figure 4.13: Input and output DC currents.

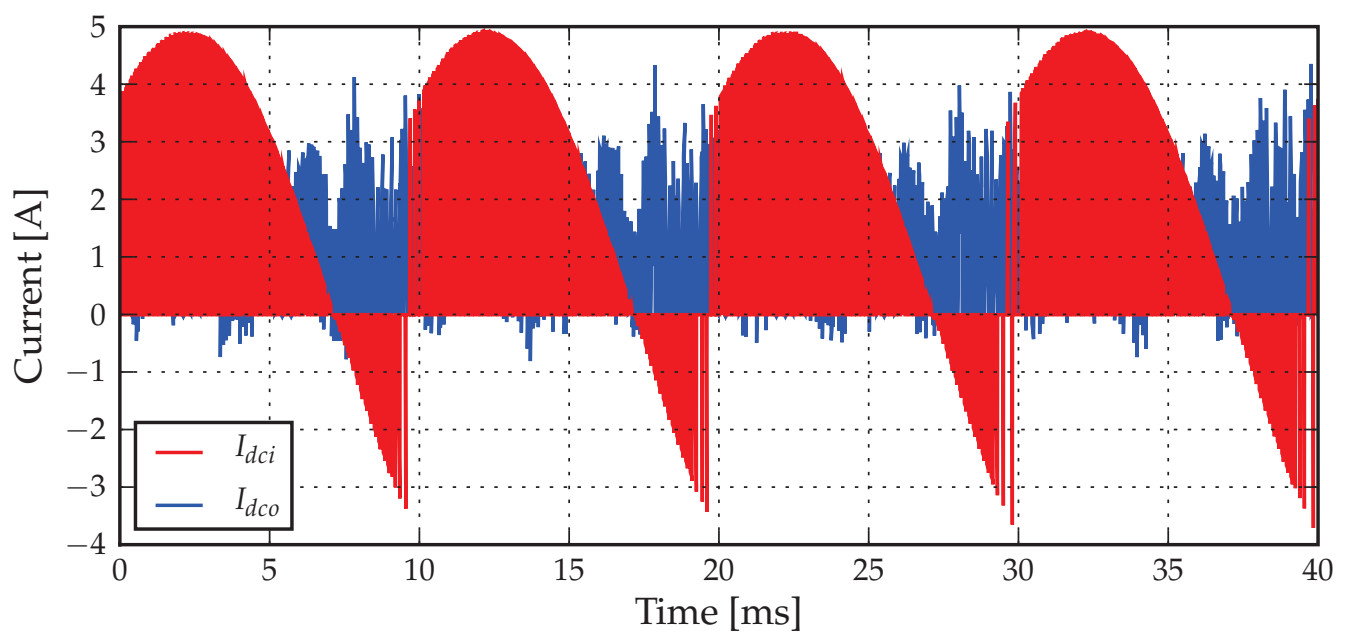

Figure 4.14: Simulated input and output DC currents. 


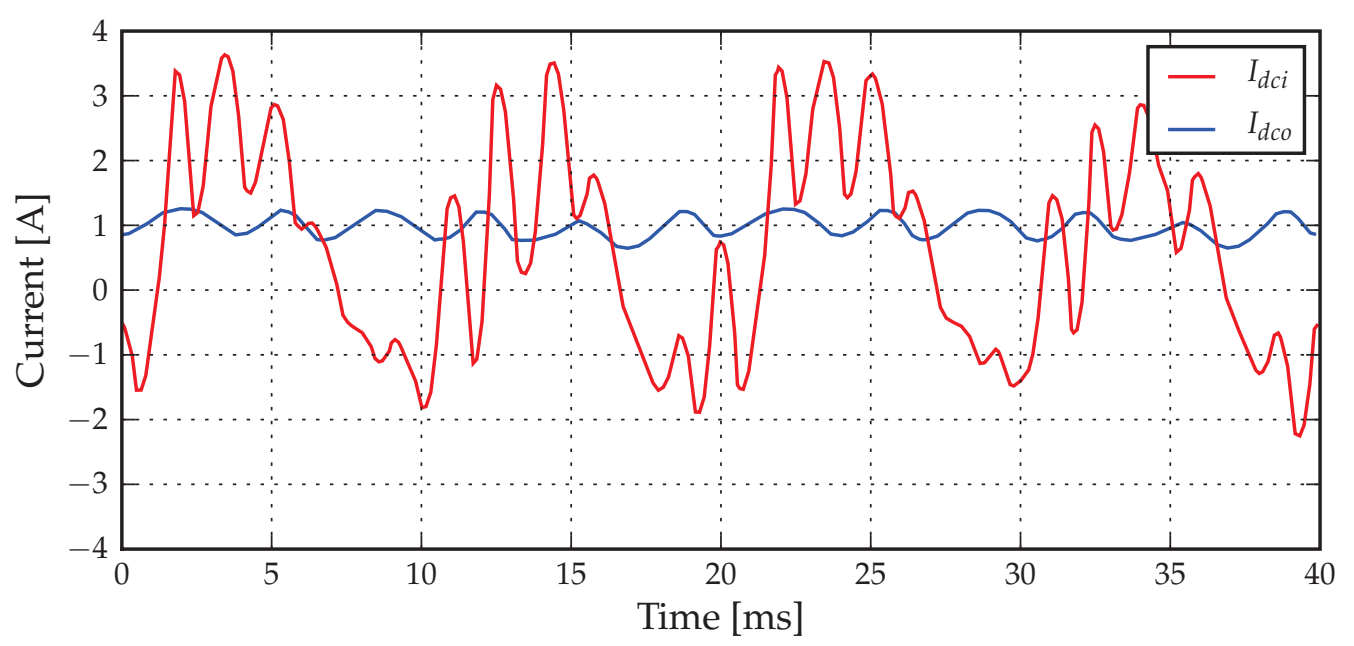

Figure 4.15: Filtered input and output DC currents.

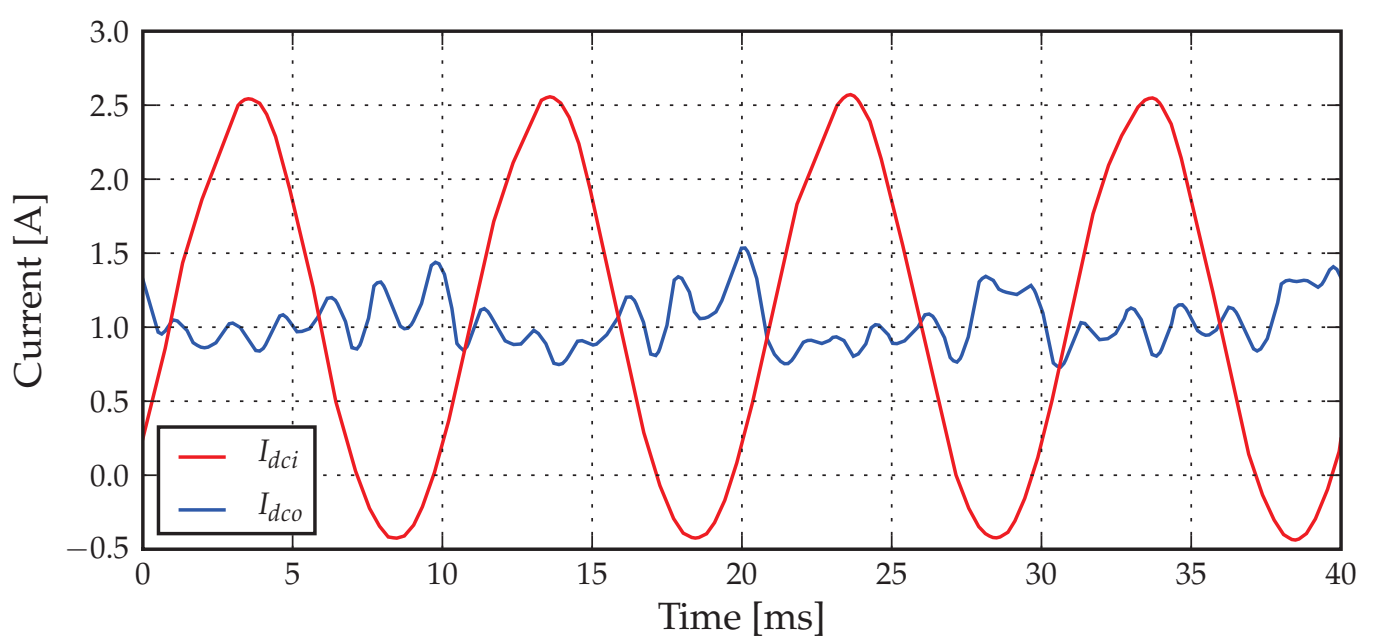

Figure 4.16: Simulated filtered input and output DC currents.

Figure 4.17 shows the DC bus voltage with some measurement noise. In figure 4.18 the bus voltage is filtered with a Bessel-Thompson low pass filter at $1 \mathrm{kHz}$ and makes it more clear that the bus voltage $V_{d c}$ is closely controlled at $250 \mathrm{~V}$. The simulated bus voltage confirm the measured results and is depicted in figure 4.19. 


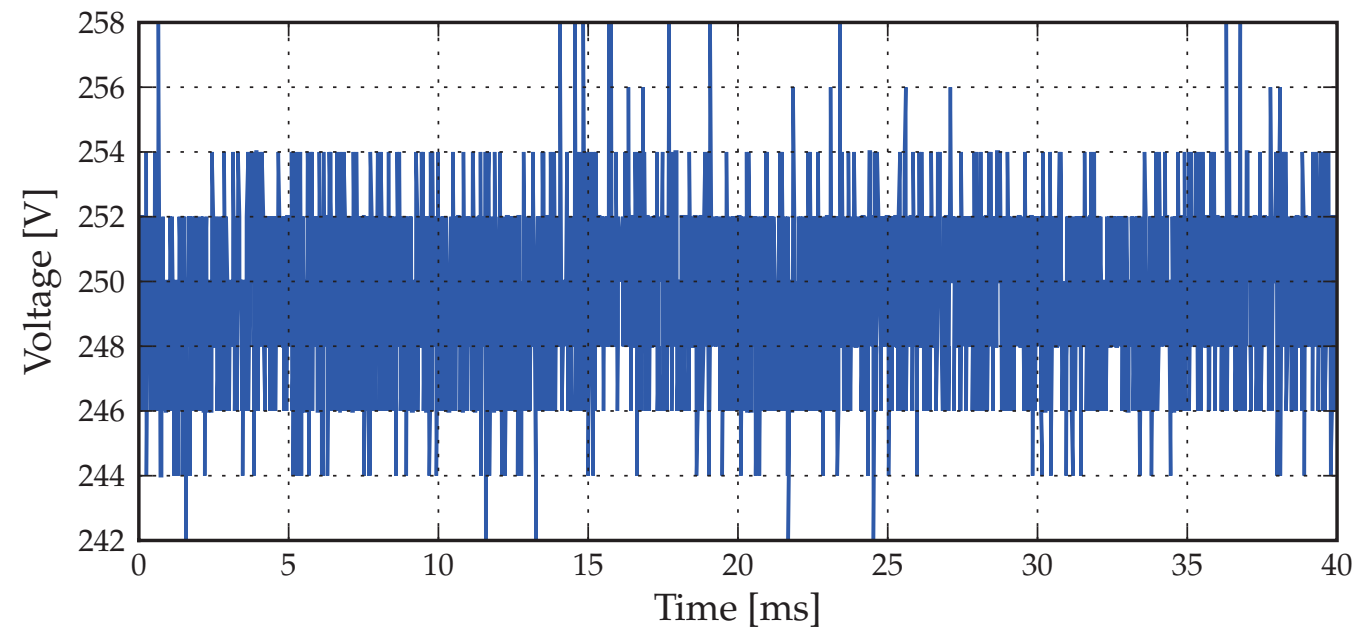

Figure 4.17: DC bus voltage.

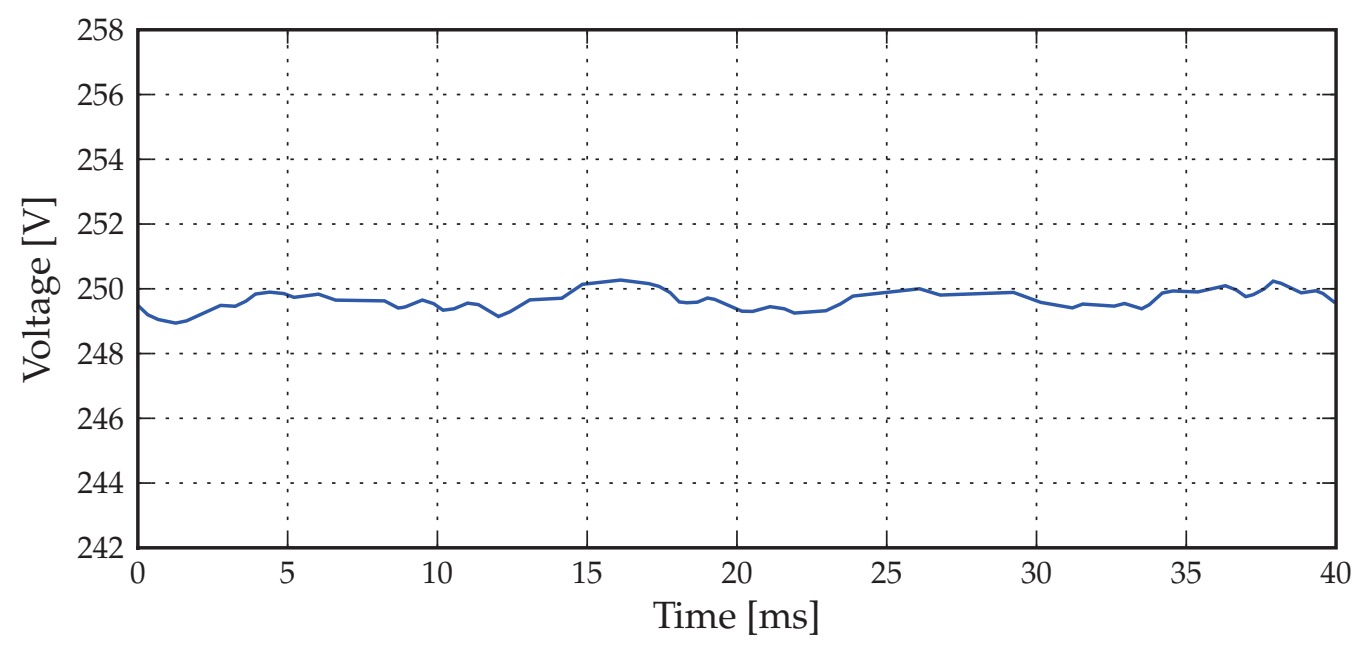

Figure 4.18: Filtered DC bus voltage.

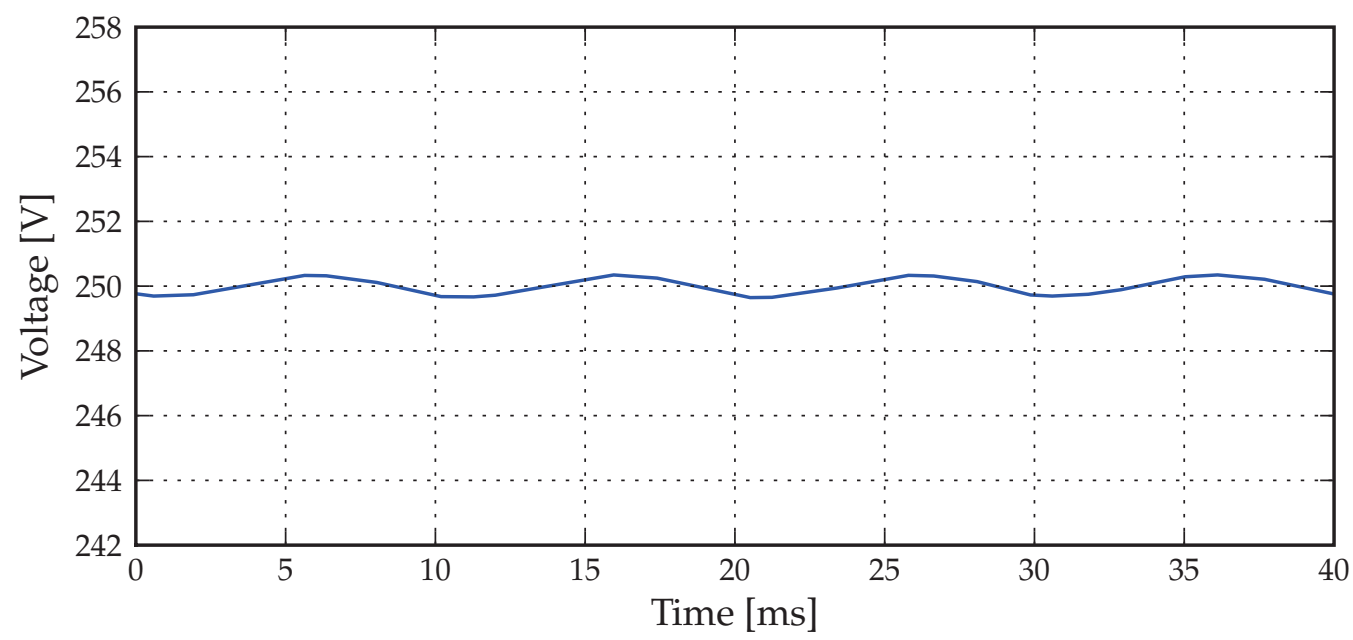

Figure 4.19: Simlulated DC bus voltage. 
The remainder of this chapter discusses the rectifier current control with the generator connected to the input of the rectifier. It is assumed that the inverter, as discussed in chapter 5, will control the DC bus voltage at $250 \mathrm{~V}$ and deliver the electrical energy from the generator to the electrical network.

The emf (e) of the generator is needed for the rectifier control equation (4.3.4) but it cannot be measured. Therefore an external inductor $\left(L_{\text {ext }}\right)$ is inserted between the terminals $\left(v_{g t}\right)$ of the generator and the input to the rectifier $\left(v_{f}\right)$. Now $v_{g t}$ and $L_{\text {ext }}$ replace $e$ and $L_{g}$ respectively in equation 4.3.4. A second order Sallen-Key LPF (see appendix B) was designed to filter voltage $\left(v_{g t}\right)$ at $1 \mathrm{kHz}$ to enable the digital control system to effective control of the current $\left(i_{g}\right)$. Other methods that could be used to control the current $i_{g}$ of the generator is discussed in chapter 6 .

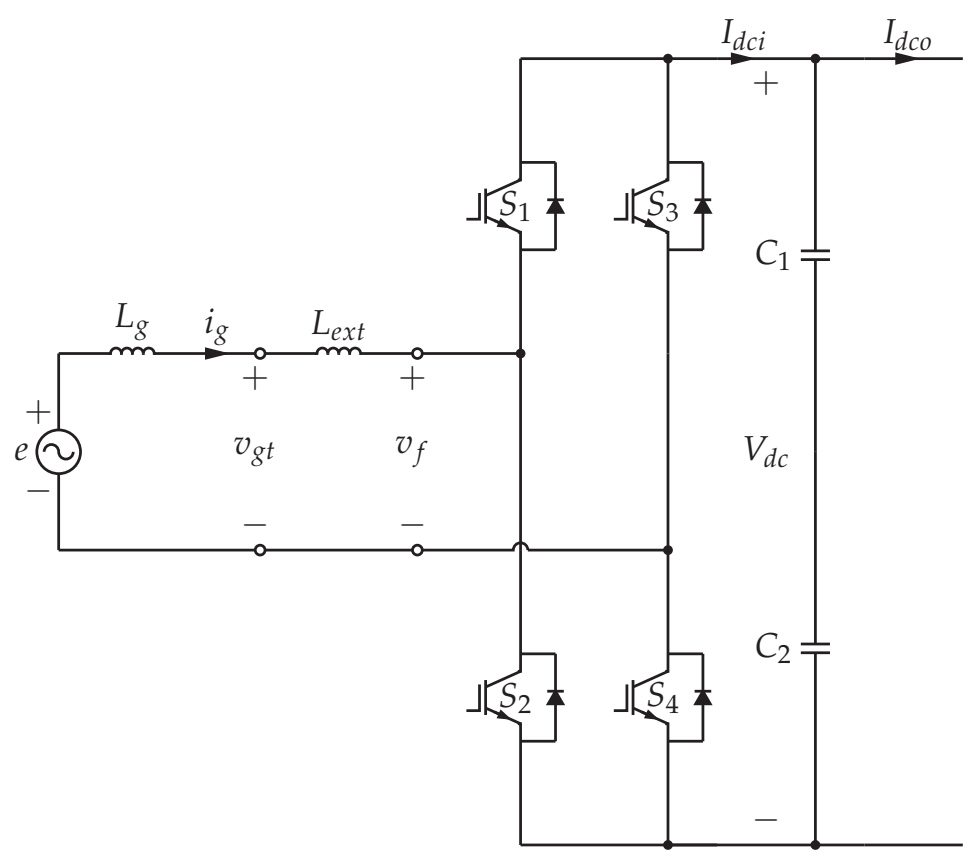

Figure 4.20: Circuit used to test rectifier-generator combination.

The reference current was generated to be in phase with the emf of the generator. This was done using a positional transducer to measure the translation of the mover of the generator. The first derivative of the translation of the mover of the generator is equal the the velocity of the mover. The velocity is in phase with the emf $(e)$ of the generator. Two external knobs on the digital control system was used to set the phase and amplitude of the reference current to the desired values. The value of inductor $L_{e x t}$ was chosen to be $5.8 \mathrm{mH}$.

The emf $(e)$ of the generator was measured during a test with no load connectd to the terminals of the generator. A test was then done to control the current $\left(i_{g}\right)$ to be in phase with the emf using the posisional transducer. Figure 4.21 indicates that the 
current $\left(i_{g}\right)$ of the generator was indeed controlled to be in phase with the emf $(e)$. $i_{g}$ and $e$ was plotted on the same graph using the posisional transducer signal as a reference to obtain a accurate phase indication between $i_{g}$ and $e$.

The two voltages $v_{g t}$ and $v_{f}$ are measured through a $1 \mathrm{kHz}$ low pass RC-filter with differential probes and are shown in figure 4.22. Figures 4.23 and 4.24 shows the same signals as in figures 4.21 and 4.22 respectively but only digitally filtered at $100 \mathrm{~Hz}$ to see the phase and amplitudes of the signals more clearly. The filtering was done from left to right and from right to left with a second order Bessel-Thompson filter to ensure that there is no phase shift as explained earlier in this section.

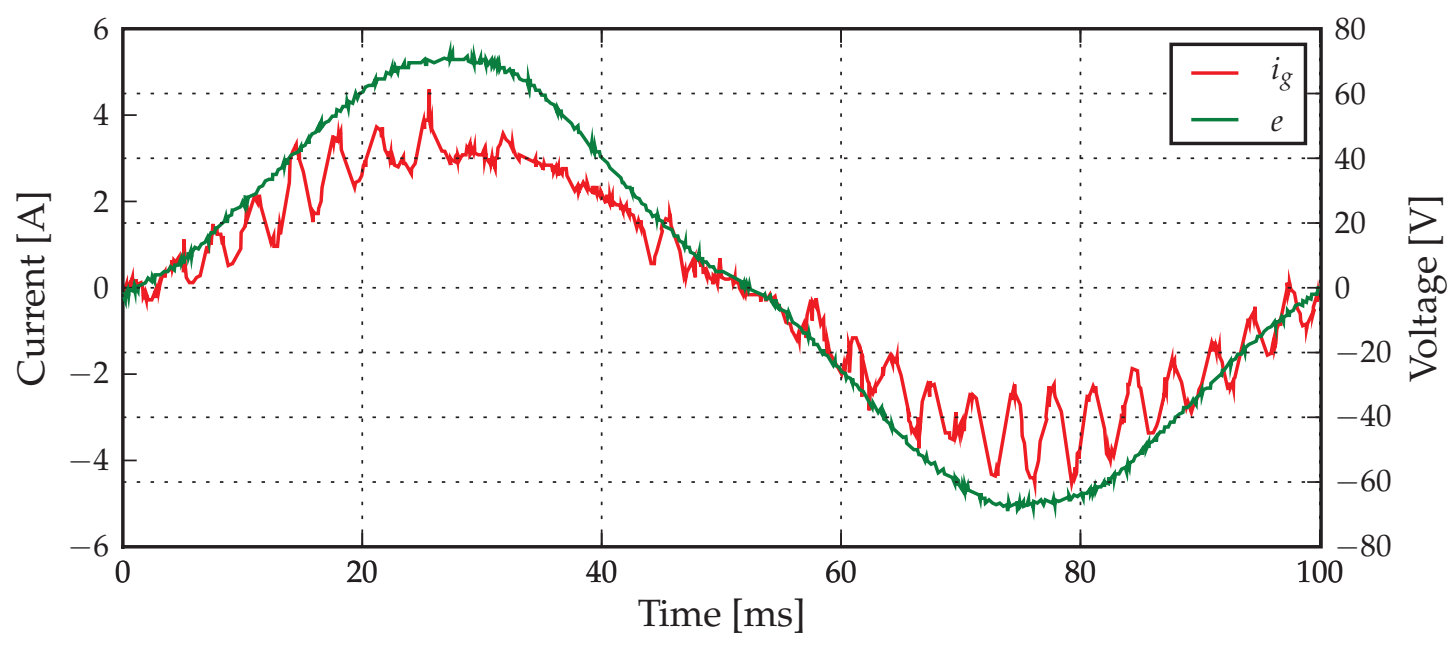

Figure 4.21: The emf and current of the generator.

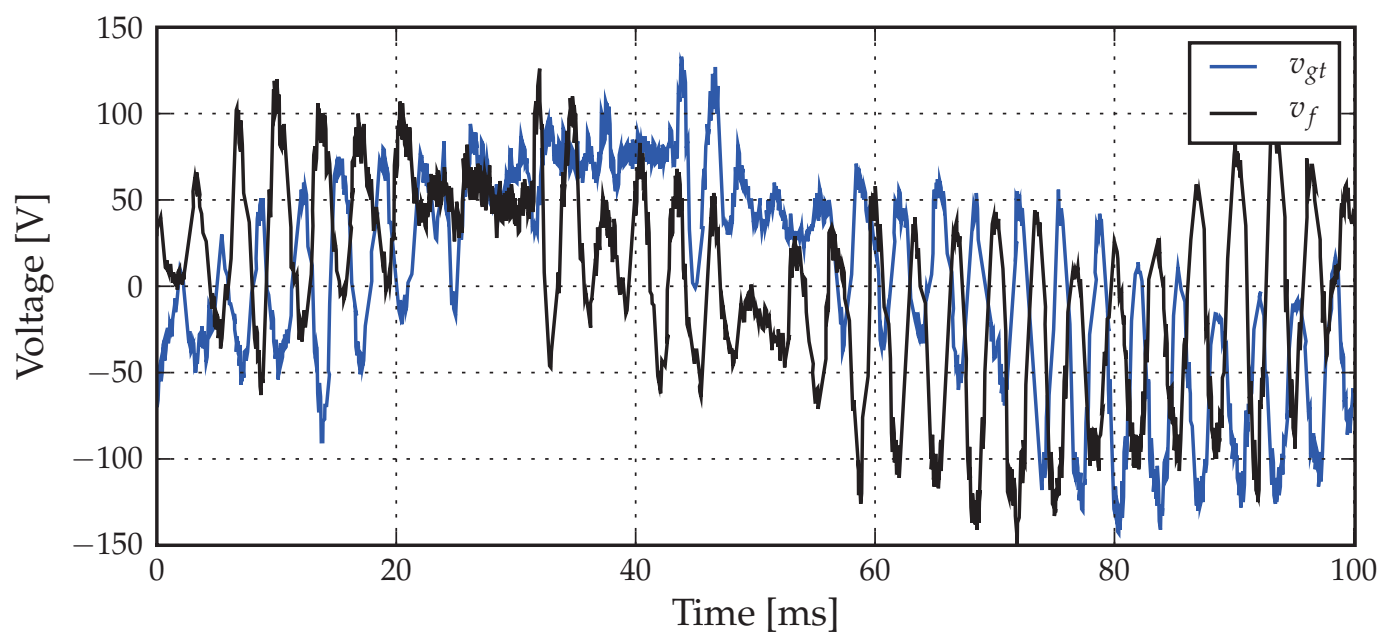

Figure 4.22: Terminal voltage of the generator and the rectifier switching voltage. 


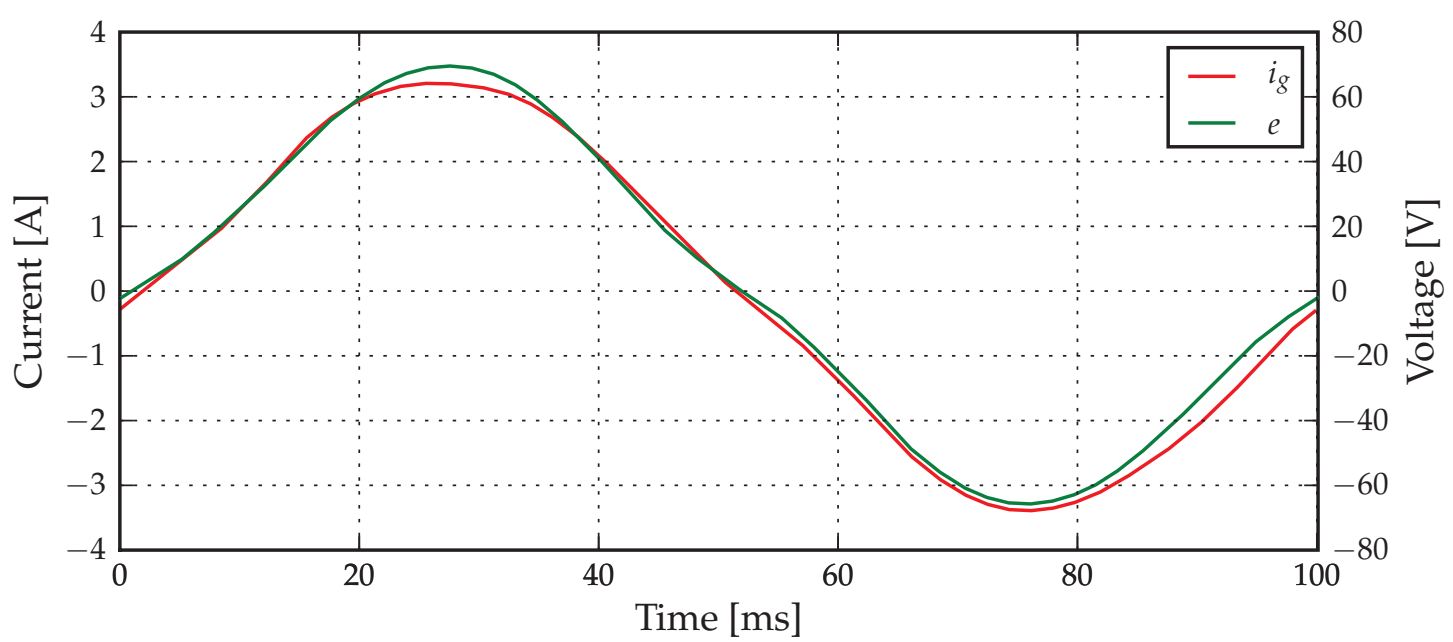

Figure 4.23: The emf and current of the generator digitally filtered at $100 \mathrm{~Hz}$.

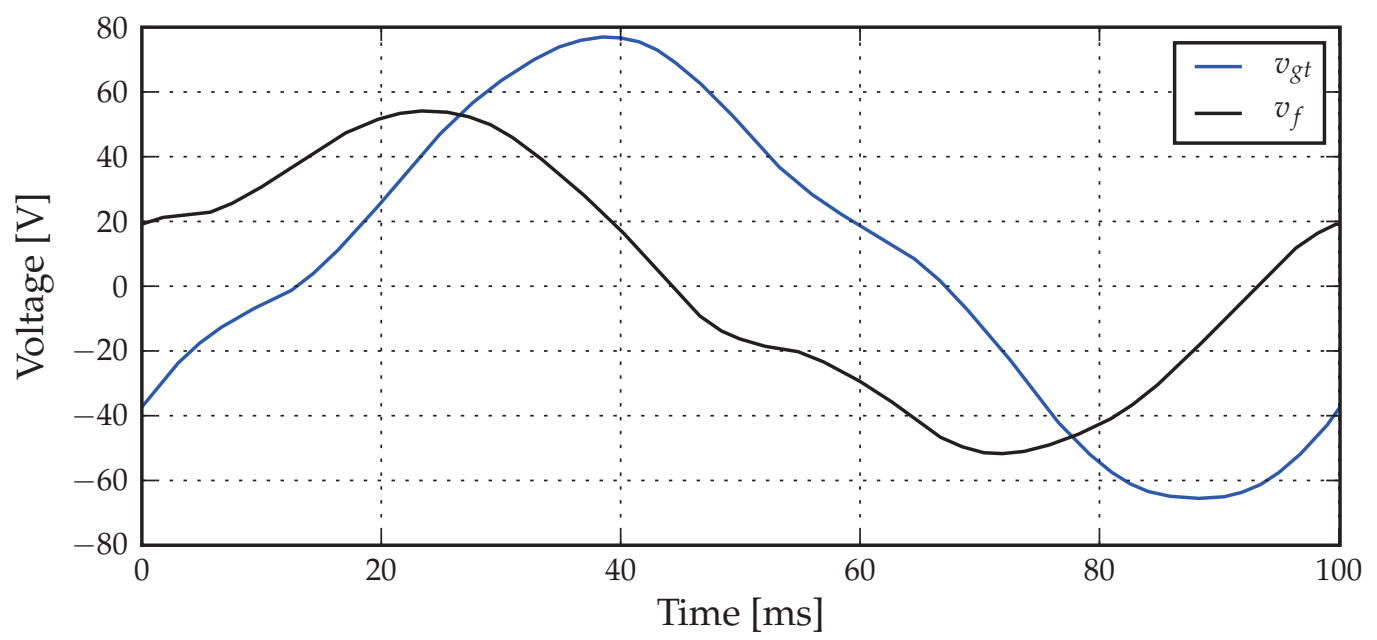

Figure 4.24: Terminal voltage of the generator and the rectifier switching voltage digitally filtered at $100 \mathrm{~Hz}$.

\subsection{Conclusive remarks}

In this chapter a three-phase $20 \mathrm{~kW}$ rectifier was designed and implemented. Only two of the phase arms were used because the single phase moving magnet transverse flux linear generator topology was connected to the input of the rectifier. Predictive current control was successfully implemented and tested with a voltage supply connected to the input of the rectifier. A test was also done with the generator connected to the rectifier in order to evaluate the practical case. There was difficulty determining the emf of the generator operating under load conditions due to limited measuring techniques available. All the tests were done at one third of the rated values due to issues with the soft-start resistors that connected the inverter to the electrical network. The measuring of the emf of the generator should be improved in future research of this specific generator topology. 


\section{Chapter 5}

\section{Inverter}

\subsection{Introduction}

This chapter discusses the design and control of the three phase inverter which is part of the back-to-back converter. The schematic diagram of the entire system, which include the generator, rectifier, capacitor bank, inverter and network, is shown in figure 5.1. The inverter and network are highlighted in the figure for clarity. The inverter must control the bus voltage $\left(V_{d c}\right)$ at a predetermined value by controlling the current flow to and from the electrical network. This enables the system to transfer energy to and from the electrical network.

The hardware design of the inverter is discussed in section 5.2 and the current control is discussed in section 5.3. The control of the DC bus voltage is discussed in section 5.4. Sections 5.5 and 5.6 discuss the construction and results of the inverter respectively and finally a concluding discussion is presented in section 5.7 . 


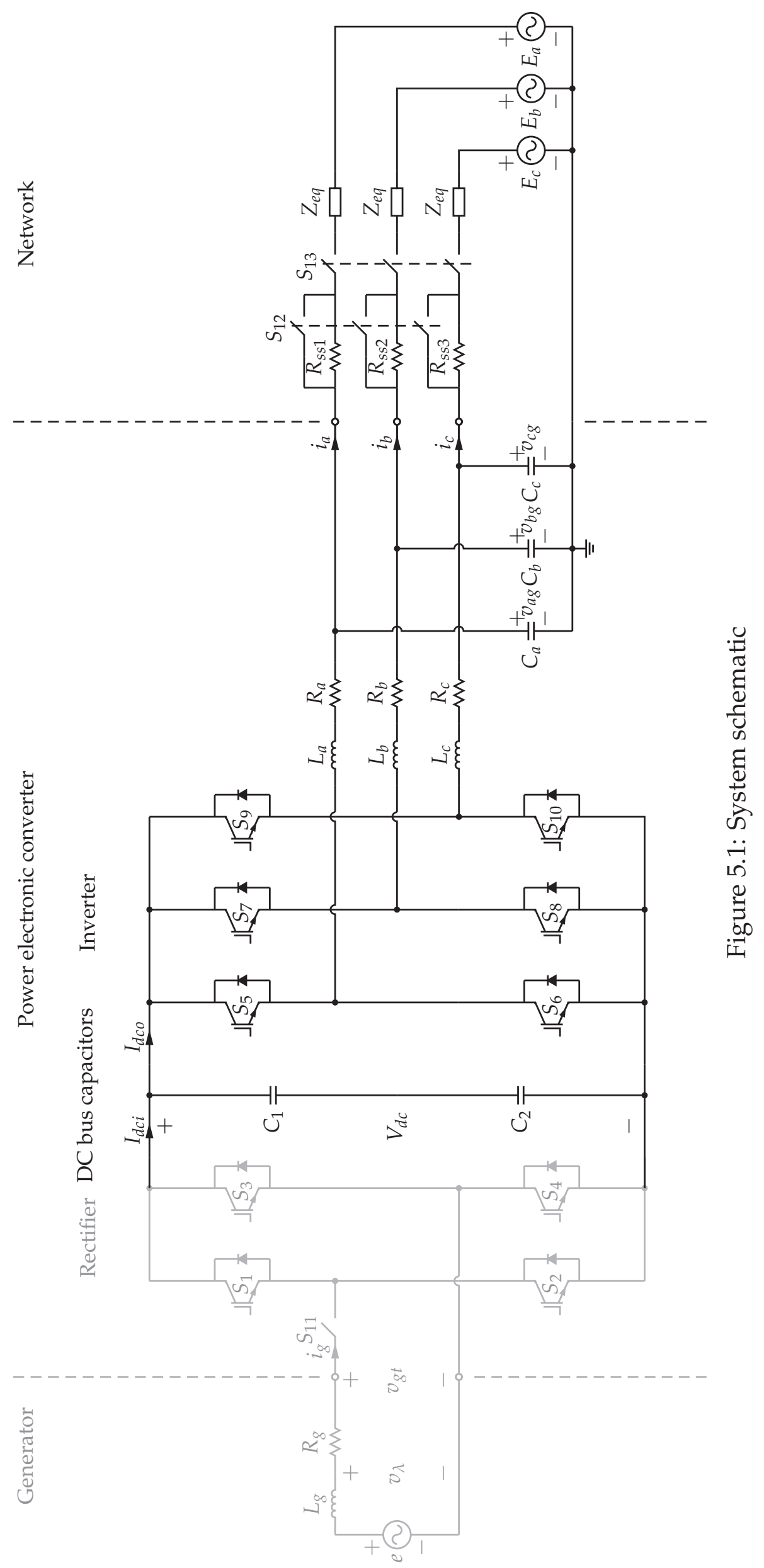




\subsection{Hardware design}

\subsubsection{Power electronics and related hardware}

A $20 \mathrm{~kW}$ three-phase inverter was designed because it is sufficient to test generator prototypes that will be designed in the ongoing research as discussed in section 4.2.

The same power electronic hardware is used for the inverter as for the rectifier, discussed in chapter 4, where the only difference is that all six Insulated-Gate Bipolar Transistor (IGBTs) is used because this is a three phase inverter. Therefore the same hardware is used to control the power electronics. Only this time all the channels is populated with electronics to accommodate all three phases.

Figure 4.2 in chapter 4 shows a flow diagram for the hardware designed. The pulse width modulation (PWM) signals for the inverter follow an identical route as in the case of the rectifier. Two extra fibre optic signals from the digital control hardware that are used to switch contactors are used to control $S_{12}$ and $S_{13}$ as shown in figure 5.1. $S_{12}$ is used to switch the soft-start resistors $\left(R_{S S}\right)$ in or out of the circuit while $S_{13}$ is used to connect the inverter to the electrical network.

An LC-filter is used on each output phase of the inverter to filter out the switching harmonics. The LC-filters was designed to have a cut-off frequency of approximately one fifth the switching frequency. The switching frequency was chosen to be $10 \mathrm{kHz}$ (the same as for the rectifier). The cut-off frequency of the low pass LC-filter can be calculated as follows:

$$
f_{0}=\frac{1}{2 \pi \sqrt{L C}}
$$

The value of $L$ was chosen to be $830 \mu \mathrm{H}$ and the capacitor was chosen to be $10 \mu \mathrm{F}$ which results in a cut-off frequency of $1.75 \mathrm{kHz}$. The value of the inductor influences the ripple current. The maximum ripple current, stated by Hobbs [18], is given by

$$
\Delta i_{\text {Lmax }}=\frac{V_{d}}{8 L f_{s}}
$$

where $V_{d}$ is the bus voltage, $L$ the inductance and $f_{s}$ the sample frequency. With the chosen value of $830 \mu \mathrm{H}$ and a bus voltage of $750 \mathrm{~V}$ the maximum ripple current $\left(i_{\text {Lmax }}\right)$ is $11.3 \mathrm{~A}$, which is approximately one quarter of the rated current.

$R_{a}, R_{b}$ and $R_{c}$ in figure 5.1 represent the resistance of each of the inductors. $R_{s s 1}, R_{s s 2}$ and $R_{s s 3}$ are soft start resistors that are used for initially loading the bus voltage $\left(V_{d c}\right)$. $Z_{\text {eq }}$ represents the equivalent line impedance of the network for each phase. 


\subsubsection{Digital control hardware}

The advantages of digital controllers over analogue controllers is discussed in section 4.2.2. The same digital hardware used for the rectifier control was used for the current and bus voltage control of the inverter. In section 4.2.2 a description of the hardware is given.

The LA50-S closed loop Hall effect current transducers are used to measure currents $i_{a}, i_{b}$ and $i_{c}$. All the voltages are differentially measured and filtered with an analogue Low Pass Filter (LPF) at $1 \mathrm{kHz}$. The voltages measured for inverter control include the network voltages $\left(v_{a g}, v_{b g}, v_{c g}\right)$ and the DC bus voltage $\left(V_{d c}\right)$ as shown in figure 5.1.

\subsection{Current control}

\subsubsection{High level description}

Two main closed loop strategies exist for controlling an inverter. The first method uses only a single outer voltage control loop which is a simple design but with slow response. The second method is a double loop strategy which consists of the outer voltage control loop and incorporates an inner current control loop. The double loop control strategy is used as control strategy in this case.

\subsubsection{The $\alpha \beta$ transformation}

The $\alpha \beta$ transformation is used to reduce a three-phase linear electrical model to a twophase electrical model as discussed by Buso and Mattavelli [19]. This two-phase system can be represented in the $\alpha \beta$ plane without any loss of information, assuming that the three-phase system is balanced. The transformation, $\mathbf{T}_{\alpha \beta \gamma}$

$$
\left[\begin{array}{l}
x_{\alpha} \\
x_{\beta} \\
x_{\gamma}
\end{array}\right]=\mathbf{T}_{\alpha \beta \gamma}\left[\begin{array}{l}
x_{a} \\
x_{b} \\
x_{c}
\end{array}\right]=\sqrt{\frac{2}{3}}\left[\begin{array}{ccc}
1 & -\frac{1}{2} & -\frac{1}{2} \\
0 & \frac{\sqrt{3}}{2} & -\frac{\sqrt{3}}{2} \\
\frac{1}{\sqrt{2}} & \frac{1}{\sqrt{2}} & \frac{1}{\sqrt{2}}
\end{array}\right]\left[\begin{array}{l}
x_{a} \\
x_{b} \\
x_{c}
\end{array}\right]
$$

allows us to describe $a b c$-plane electrical variables (voltage or current) in the $\alpha \beta \gamma$ plane. If the property

$$
x_{a}+x_{b}+x_{c}=0
$$

then

$$
x_{\gamma}=0
$$




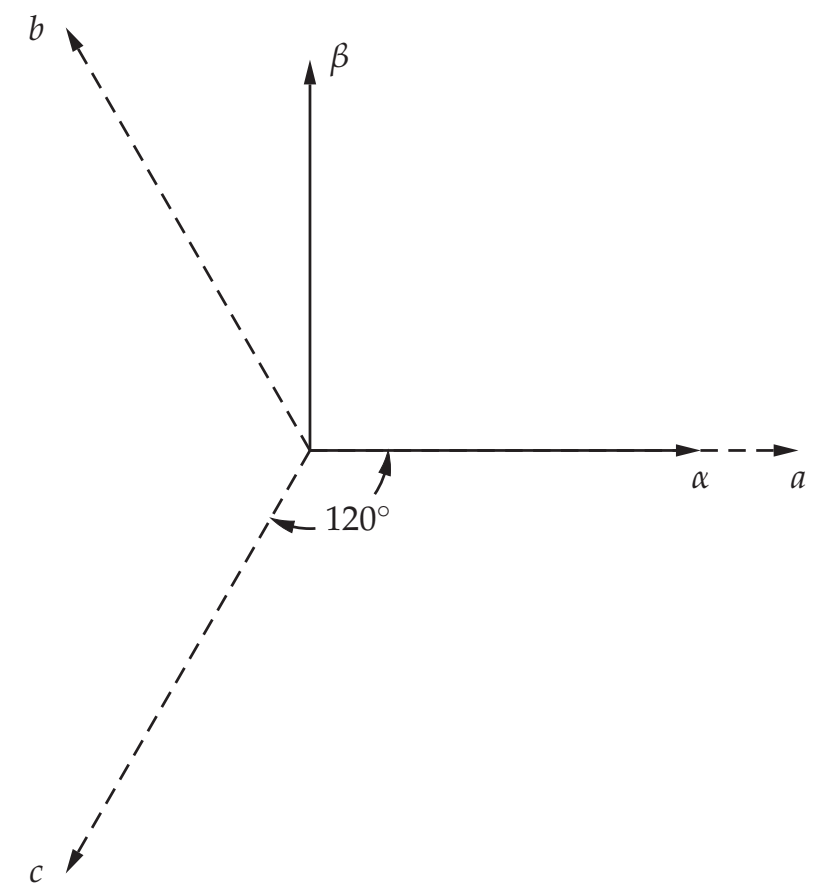

Figure 5.2: Graphical representation of the $a b c$-plane and the $\alpha \beta$-plane.

of the $\mathbf{T}_{\alpha \beta \gamma}$ transformation holds, the $\alpha \beta$ transformation can be represented as follows

$$
\left[\begin{array}{l}
x_{\alpha} \\
x_{\beta}
\end{array}\right]=\mathbf{T}_{\alpha \beta}\left[\begin{array}{l}
x_{a} \\
x_{b} \\
x_{c}
\end{array}\right]=\sqrt{\frac{2}{3}}\left[\begin{array}{ccc}
1 & -\frac{1}{2} & -\frac{1}{2} \\
0 & \frac{\sqrt{3}}{2} & -\frac{\sqrt{3}}{2}
\end{array}\right]\left[\begin{array}{l}
x_{a} \\
x_{b} \\
x_{c}
\end{array}\right]
$$

and its inverse as

$$
\left[\begin{array}{l}
x_{a} \\
x_{b} \\
x_{c}
\end{array}\right]=\mathbf{T}_{\alpha \beta}^{T}\left[\begin{array}{c}
x_{\alpha} \\
x_{\beta} \\
0
\end{array}\right]=\sqrt{\frac{2}{3}}\left[\begin{array}{cc}
1 & 0 \\
-\frac{1}{2} & \frac{\sqrt{3}}{2} \\
-\frac{1}{2} & -\frac{\sqrt{3}}{2}
\end{array}\right]\left[\begin{array}{l}
x_{\alpha} \\
x_{\beta}
\end{array}\right]
$$

The graphical representation between the $a b c$-plane and the $\alpha \beta$-plane are shown in figure 5.2 .

If the $a b c$-voltages of a three-phase system are assumed to be balanced then the following represents the instantaneous sinusoidal signals

$$
\begin{aligned}
& v_{a}(t)=A \sin (\omega t) \\
& v_{b}(t)=A \sin \left(\omega t-\frac{2 \pi}{3}\right) \\
& v_{c}(t)=A \sin \left(\omega t+\frac{2 \pi}{3}\right)
\end{aligned}
$$




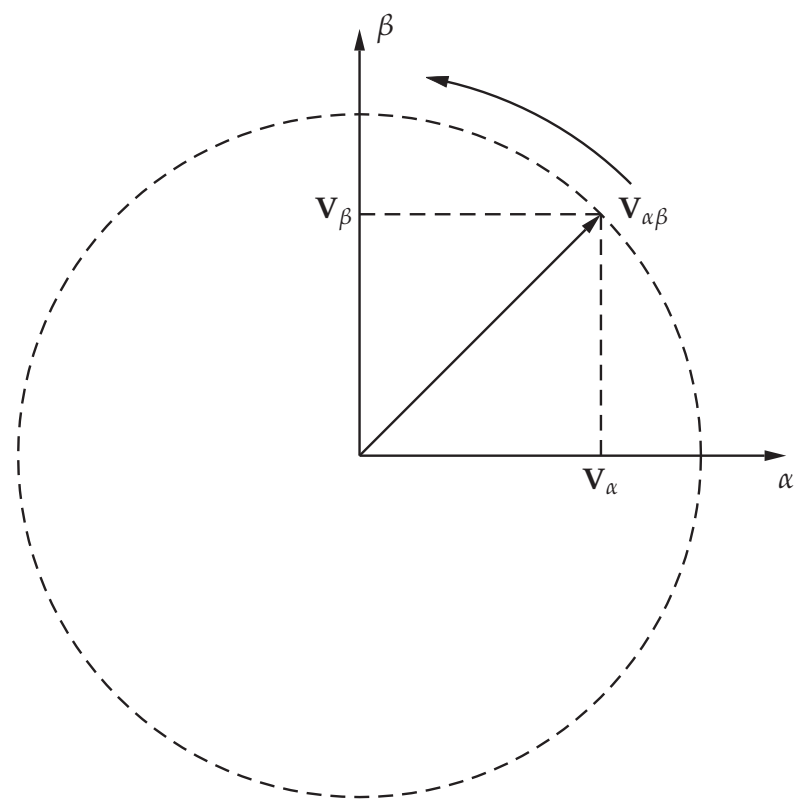

Figure 5.3: Rotating $\alpha \beta$ space vector representation.

The corresponding $\alpha \beta$-voltages are then written as:

$$
\begin{aligned}
& v_{\alpha}(t)=\sqrt{\frac{3}{2}} \mathrm{~A} \sin (\omega t) \\
& v_{\beta}(t)=\sqrt{\frac{3}{2}} \mathrm{~A} \cos (\omega t)
\end{aligned}
$$

If the $\alpha \beta$ transformation is done on the instantaneous values of a three-phase system (Eqn. 5.3.6), it translates to an instantaneous space vector with components $v_{\alpha}(t)$ and $v_{\beta}(t)$. This space vector $\mathbf{V}_{\alpha \beta}$ rotates anti-clockwise at an angular velocity of $\omega$ as shown in figure 5.3.

\subsubsection{Park's transformation}

The Park transformation maps the three-phase signals of the inverter, voltages or currents, onto a two-axis synchronous rotating reference frame instead of onto a fixed two-axis reference frame like the $\alpha \beta$ transformation. This is extensively discussed by Buso and Mattavelli [19]. The transformation defines a new reference frame, called the $d$ and $q$ axes, which rotate around the static $\alpha \beta$ reference frame at a constant angular velocity $\omega$. In figure 5.4 the vector diagrams are shown, where $\theta=\omega t$.

In section 5.3.2 it is shown that the $\alpha \beta$ transformation reduces balanced three-phase sinusoidal signals to two sinusoidal signals, shifted by $90^{\circ}$, that can be interpreted as a rotating vector $\mathbf{V}_{\alpha \beta}$. The rotating vector angular speed can be considered equal to the angular velocity of the original three-phase signals, which is the fundamental 

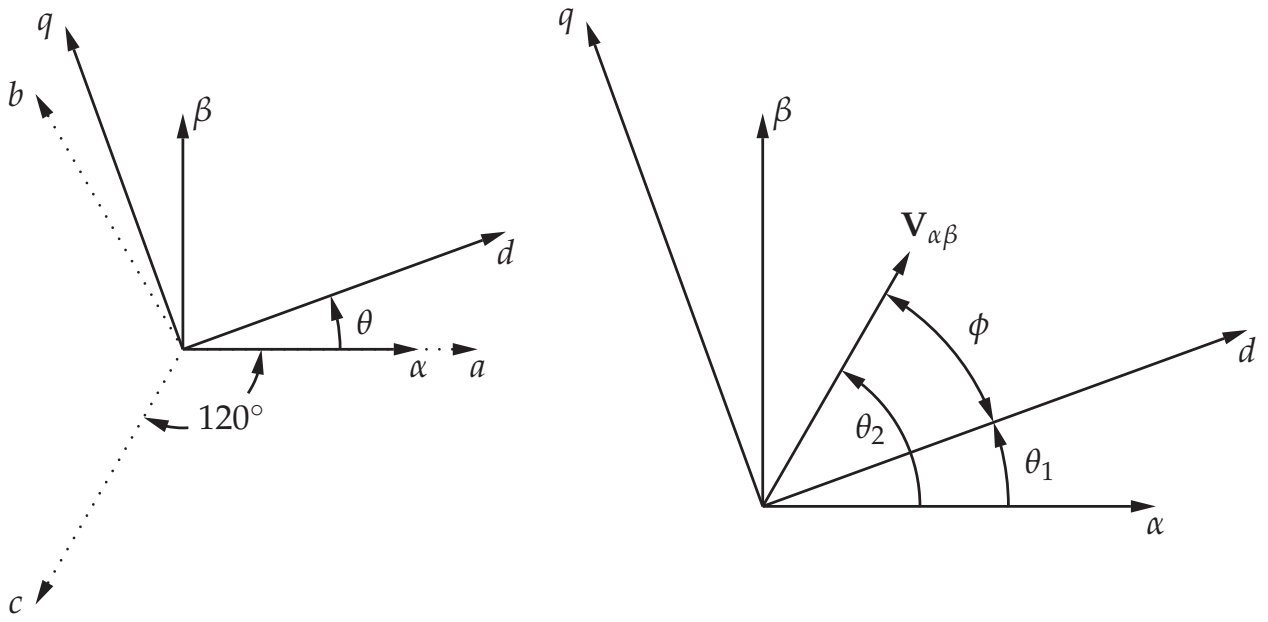

Figure 5.4: Vector diagrams for Park's transformation.

frequency of the three-phase system. Therefore, if the angular velocity of the rotating vector equals $\omega$ then the rotating vector is not moving in the $d q$ reference frame. This implies that $\theta_{1}$ and $\theta_{2}$ as seen in figure 5.4 will both increase with angular velocity $\omega$, while angle $\phi$ will be constant and therefore the lengths of the projections of vector $\mathbf{V}_{\alpha \beta}$ on the $d$ and $q$ axes will also be constant.

The fact that sinusoidal signals with angular frequency $\omega$ will be seen as constant signals in the $d q$ reference frame is the advantage of using the Park's transformation. This is especially useful when a PI controller is implemented in the $d q$ reference frame because the tracking error with respect to the sinusoidal signals having an angular frequency $\omega$, which is equal to that of the Park's transformation, will be equal to zero. The reason for the tracking error equal to zero is because the PI controller guarantee a zero tracking error on constant signals, thanks to the integral component.

The transformation, $\mathbf{T}_{d q}$

$$
\left[\begin{array}{l}
x_{d} \\
x_{q}
\end{array}\right]=\mathbf{T}_{d q}\left[\begin{array}{l}
x_{\alpha} \\
x_{\beta}
\end{array}\right]=\left[\begin{array}{cc}
\cos \theta & \sin \theta \\
-\sin \theta & \cos \theta
\end{array}\right]\left[\begin{array}{l}
x_{\alpha} \\
x_{\beta}
\end{array}\right]
$$

transforms signals in the $\alpha \beta$ reference frame to signals in the $d q$ rotating reference frame, where $\theta=\omega t$. The inverse of $\mathbf{T}_{d q}$ is easily derived so that

$$
\left[\begin{array}{l}
x_{\alpha} \\
x_{\beta}
\end{array}\right]=\mathbf{T}_{d q}^{T}\left[\begin{array}{l}
x_{d} \\
x_{q}
\end{array}\right]=\left[\begin{array}{cc}
\cos \theta & -\sin \theta \\
-\sin \theta & \cos \theta
\end{array}\right]\left[\begin{array}{l}
x_{d} \\
x_{q}
\end{array}\right]
$$

\subsubsection{Space vector pulse width modulation}

Space vector pulse width modulation (SVPWM) is inherently a voltage control scheme that makes it possible to simplify the control organization used in three-phase inverters 
with an insulated neutral. With a known reference voltage in the $\alpha \beta$-plane, the SVPWM technique calculates the optimum switching pattern for the three-phase inverter so ensure the desired voltage is obtained. SVPWM explained in this section is discussed in great detail by Buso and Mattavelli [19].

A three-phase inverter has only eight possible switching combinations. The idea behind the implementation of SVPWM is to generate a desired output voltage, on average, at the end of each modulation period, represented in the $\alpha \beta$-plane from the superposition of the inverter output vectors. Therefore the instantaneous inverter output needs to be converted to the $\alpha \beta$-plane by using the transformation as explained by equation 5.3.4. Figure 5.5 shows the eight different states as well as the inverter output vector associated with that state. Each of the inverter outputs is referred to node G. There are six state vectors of the same size and two zero state vectors. The size of the six non-zero vectors are:

$$
\left|\mathbf{V}_{001}\right|=\left|\mathbf{V}_{010}\right|=\left|\mathbf{V}_{011}\right|=\left|\mathbf{V}_{100}\right|=\left|\mathbf{V}_{101}\right|=\left|\mathbf{V}_{110}\right|=\sqrt{\frac{2}{3}} V_{d c}
$$

To obtain the inverter duty cycles the desired output reference voltage, $\mathbf{V}_{\alpha \beta}$, of the inverter in the $\alpha \beta$ reference frame, can be projected on the two closest inverter output state vectors, i.e., $\mathbf{V}_{100}$ and $\mathbf{V}_{110}$ as shown in figure 5.6. The position of $\mathbf{V}_{\alpha \beta}$ in figure 5.6 is arbitrary chosen but the same reasoning apply to any position. The length of each projection, $\mathbf{V}_{\mathbf{1}}$ and $\mathbf{V}_{\mathbf{2}}$, determines the fraction $\delta$ of the modulation period that will be occupied by each output vector, according to the relation

$$
\delta_{a}=\frac{\left|\mathbf{V}_{\mathbf{1}}\right|}{\left|\mathbf{V}_{\mathbf{1 0 0}}\right|} \quad \text { and } \quad \delta_{b}=\frac{\left|\mathbf{V}_{\mathbf{2}}\right|}{\left|\mathbf{V}_{\mathbf{1 1 0}}\right|}
$$

The application of the zero vector for a fraction $\delta_{c}$ of the modulation period is usually required to satisfy the following condition:

$$
\delta_{a}+\delta_{b}+\delta_{c}=1
$$

This expresses the fact that the modulation period must be fully occupied by output voltage vectors. This means that the average output voltage of the inverter can be given by

$$
\mathbf{V}_{o}=\delta_{a} \mathbf{V}_{\mathbf{1 0 0}}+\delta_{b} \mathbf{V}_{\mathbf{1 1 0}}+\delta_{c} \mathbf{V}_{\mathbf{0 0 0}}=\mathbf{V}_{\alpha \beta}
$$

The voltage vector $\mathbf{V}_{\mathbf{0 0 0}}$ indicated in the equation above can be either $\mathbf{V}_{\mathbf{0 0 0}}$ or, equivalently, $\mathbf{V}_{\mathbf{1 1 1}}$. Some amount of computation, as listed below, is needed to obtain the values of the duty cycles $\left(\delta_{a}, \delta_{b}\right.$ and $\left.\delta_{c}\right)$. Given the $\alpha \beta$ components of the reference vector, one has to 
Vector 100: $V_{a}=V_{d c} \quad V_{b}=0 \quad V_{c}=0$

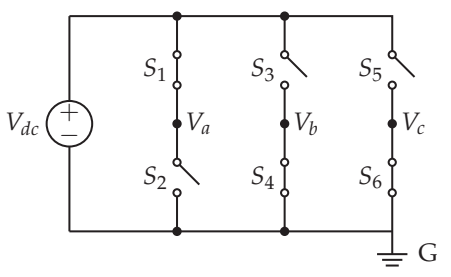

Vector 010: $V_{a}=0 \quad V_{b}=V_{d c} \quad V_{c}=0$

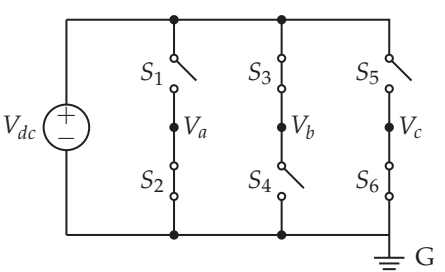

Vector 001: $\quad V_{a}=0 \quad V_{b}=0 \quad V_{c}=V_{d c}$
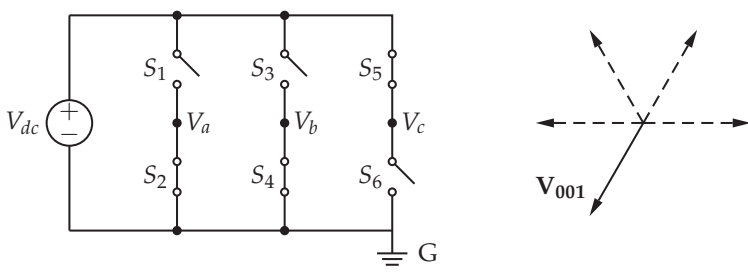

Vector 111: $V_{a}=V_{d c} \quad V_{b}=V_{d c} \quad V_{c}=V_{d c}$
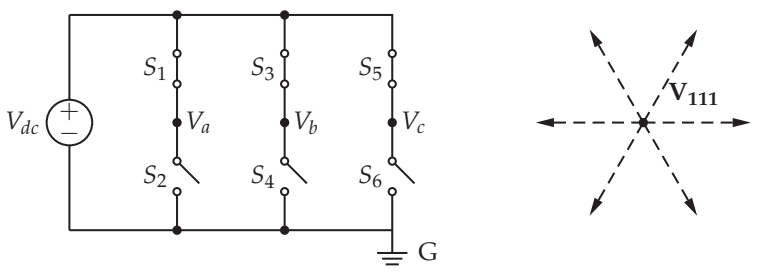

Figure 5.5: Three-phase inverter output voltage vectors and the representation in the $\alpha \beta$-plane.

- locate the two closest inverter output vector or in other words, the hexagon sector where $\mathbf{V}_{\alpha \beta}$ is lying,

- determine the amplitude of $\mathbf{V}_{\mathbf{1}}$ and $\mathbf{V}_{\mathbf{2}}$,

- and calculate the values of $\delta_{a}, \delta_{b}$ and $\delta_{c}$.

Vectors that lies outside the dotted circle indicated in figure 5.6 cannot be generated by the inverter due to the sum of the corresponding $\delta_{a}, \delta_{b}$ and $\delta_{c}$ that becomes greater than unity. This situation is called inverter saturation and generally causes output voltage distortion [19]. As mentioned by T.L. Skvarenina [20], one of the advantages of SVPWM is that it utilizes $15 \%$ more of the DC bus. This is due to third harmonics 


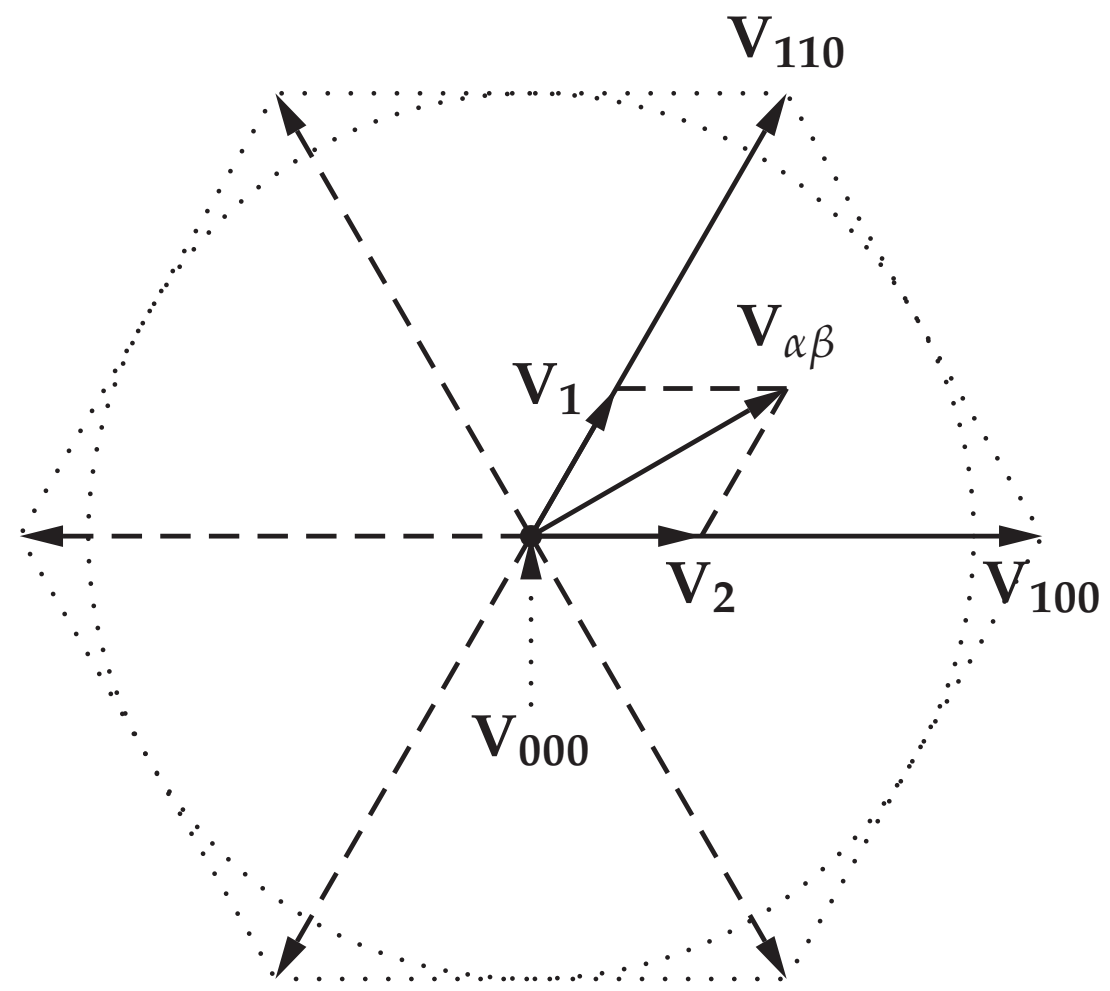

Figure 5.6: Generation of voltage reference vector by superposition of inverter output vectors.

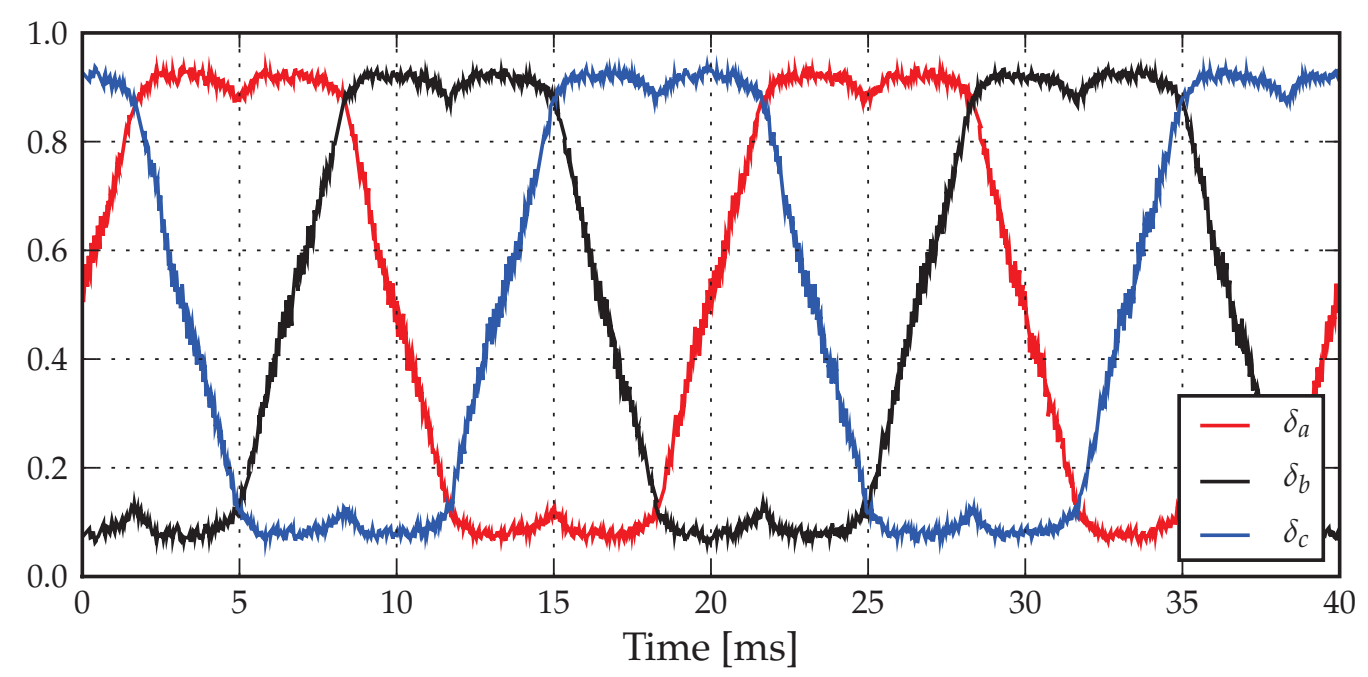

Figure 5.7: Three duty cycles of inverter generated using SVPWM.

that is generated and results in flattening of the peaks. This effect can be seen in the duty cycles shown in figure 5.7, which is from a simulation that was done in Simplorer. Another advantage of using SVPWM is that the center node of the DC bus is floating which ensures that the inverter has an insulated neutral. 


\subsubsection{Proportional-Integral (PI) control}

Various current controllers was considered as discussed in section 4.3 .1 but a PI controller is chosen as the inner current loop controller for the inverter because it is simple to implement and due to the $d q$ transformation there will be no tracking error for sinusoidal signals with angular frequency $\omega[19]$.

The diagram that describe the current control in figure 5.8 is in the continuous time as it was simulated in the commercial package Simplorer. The quantities in the diagram in figure 5.8 are indicated as vectors. The currents $i_{a}^{\prime}, i_{b}^{\prime}$ and $i_{c}^{\prime}$ represents the measured currents $i_{a}, i_{b}$ and $i_{c}$ as shown in figure 5.1. $D_{a b c}$ represents the three duty cycles of the inverter generator by SVPWM as discussed in section 5.3.4.

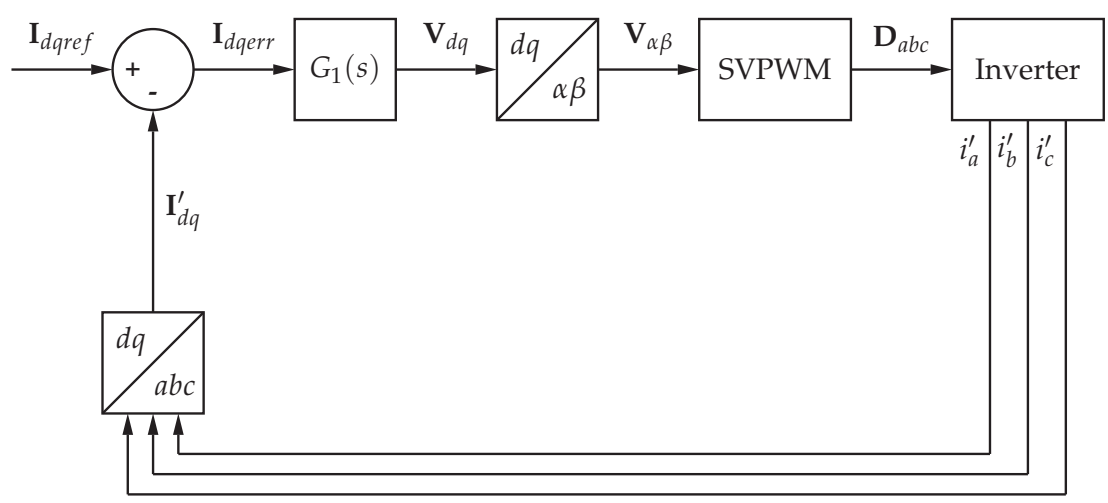

Figure 5.8: Current control loop for the inverter.

$G_{1}(s)$ represents the PI controller with its proportional and integral parts. The PI controller, $G_{1}(s)$, can be written as,

$$
G_{1}(s)=K_{p}+\frac{K_{i}}{s}
$$

The delay effect of the SVPWM can be approximated by the first order Padé approximation, as stated by Buso and Mattavelli [19], which can be considered equal to half of the modulation period. Therefore the SVPWM-block can be modelled as $F(s)$, where

$$
F(s)=\frac{1-s \frac{T_{s}}{4}}{1+s \frac{T_{s}}{4}}
$$

The Inverter-block resembles the inverter gain and the transfer function of the load admittance. Therefore the Inverter-block can be modelled as $H(s)$, where

$$
H(s)=\frac{V_{d c}}{R_{s}} \frac{1}{1+s \frac{L_{s}}{R_{s}}}
$$


and $L_{S}$ and $R_{S}$ represents the series inductor value and its resistance respectively for each phase depending of the component of the vector used in the diagram in figure 5.8 .

The entire transfer function of the control loop can be obtained using the individual blocks as described above. The only unknowns are the $K_{i}$ and $K_{p}$ values of the PI controller. The closed loop current bandwidth was chosen to be one-twentieth of the switching frequency, i.e. $\omega_{C L}=0.05 \omega_{S}$ and the phase margin $\left(p h_{m}\right)$ was chosen at $60^{\circ}$. Using the magnitude and phase equation of the total transfer function of the system, the equations for the $K_{p}$ and $K_{i}$ values can be determined as

$$
K_{p}=\frac{R_{s}}{V_{d c}} \sqrt{1+\left(\omega_{C L} \frac{L_{s}}{R_{s}}\right)^{2}}
$$

and

$$
K_{i}=\frac{\omega_{C L} K_{p}}{\tan \left(-90^{\circ}+p h_{m}+2 \tan ^{-1}\left(\omega_{C L} \frac{T_{s}}{4}\right)+\tan ^{-1}\left(\omega_{C L} \frac{L_{s}}{R_{s}}\right)\right)}
$$

When these two equations are solved the values of $K_{p}$ and $K_{i}$ are calculated to be 2.36 and 3524 respectively. The control was digitally implemented in the digital signal processor (DSP) using the backward Euler discretization method, namely

$$
s=\frac{z-1}{z T_{s}}
$$

and results in a discrete PI controller, $D_{1}(z)$

$$
D_{1}(z)=K_{p}+\frac{K_{i} T_{s} z}{z-1}
$$

Therefore $\mathbf{V}_{d q} I$ is given by

$$
\mathbf{V}_{d q} I(k)=\mathbf{V}_{d q} I(k-1) K_{p}+K_{i} T_{s} \mathbf{I}_{d q e r r}
$$

which is the integral part of the PI controller, where $k$ represents the value in the current time step while $k-1$ represents the previous time step value. The proportional part of the PI controller is given by

$$
\mathbf{V}_{d q} P(k)=K_{p} \mathbf{I}_{d q e r r}
$$

Vector $\mathbf{V}_{d q}$ as shown in figure 5.8 is then equal to

$$
\mathbf{V}_{d q}(k)=\mathbf{V}_{d q} P(k)+\mathbf{V}_{d q} I(k)
$$

Two simulations was done in Simplorer. The first one was with an ideal DC current source connected to the input of the DC bus. This simulation will be further referred to as simulation 1 . The second simulation was done with the active rectifier connected to the input of the DC bus, which will be further referred to as simulation 2. Simulation 
2 has a current limit on $i_{\text {dref }}$ of $\pm 30 \mathrm{~A}$, to demonstrate more realistic values as it would be in practice, while simulation 1 is done with no limits and an ideal current source.

Both simulations was done over a five second time period where the bus is loaded, from zero at time equals to zero, to a certain voltage. The bus is then maintained at this level until either the ideal DC current source or the rectifier, in cases of simulation 1 and 2 respectively, is connected to the DC bus at time equal to two seconds. This acts as a power input step to the system. There after the system is in steady state until the simulation is finished at time equal to five seconds. The amplitude of the ideal DC current source is set to the average of the DC current $\left(I_{d c i}\right)$ supplied by the rectifier for an input reference current $\left(i_{g}\right)$ of $20 A_{r m s}$ and a DC bus voltage of $750 \mathrm{~V}$ as discussed in section 4.3.2.

In figure 5.9, the voltage and current for the a-phase of the inverter are shown. It is clearly visible that higher order harmonics is present in the current signal. Further investigation was done and it was found that the SVPWM inject seventh order harmonics into the system. The fast Fourier transform (FFT) of the a-phase current signal showed that the amplitude at $50 \mathrm{~Hz}$ is 5.19 A while the amplitude at $350 \mathrm{~Hz}$ (the seventh harmonic) is approximately $1.14 \mathrm{~A}$. Similar results were obtained for simulation 2 , where the active rectifier was connected to the bus instead of the DC current source. Figure 5.10 shows the a-phase current and voltage of the inverter for simulation 2.

A simulation was done where the value of the DC current source connected to the bus was increased. This ensured that the inverter output phase current increases. Figure 5.11 shows the results for the higher DC current source simulation. One can clearly see that the seventh order harmonics do not distort the signal as much as it did with the lower current simulation. This is because the amplitude of the harmonics stayed the same while the amplitude of the fundamental increased significantly.

The d-component of $\mathbf{I}_{\text {dqref }}$ is generated by the bus voltage control explained in section 5.4, while the q-component reference is set to zero. Figures 5.12 and 5.14 depict the measured d- and q-component of the current indicated as $\mathbf{I}_{d q}^{\prime}$ in the current control loop diagram for simulations one and two respectively. Figures 5.13 and 5.15 show the two components of $\mathbf{I}_{d q e r r}$ for simulations one and two repectively.

It is noted that the average of the error signals is zero as expected. The ripple seen on these signals is a effect of the seventh order harmonics as explained earlier. All the $\mathbf{I}_{d q}$ error signals and measured signals shown in graphs in this section is digitally filtered with a second order Bessel-Thompson low pass filter (LPF) at $1 \mathrm{kHz}$ from left to right and again from right to left to ensure that there is no phase shift. 


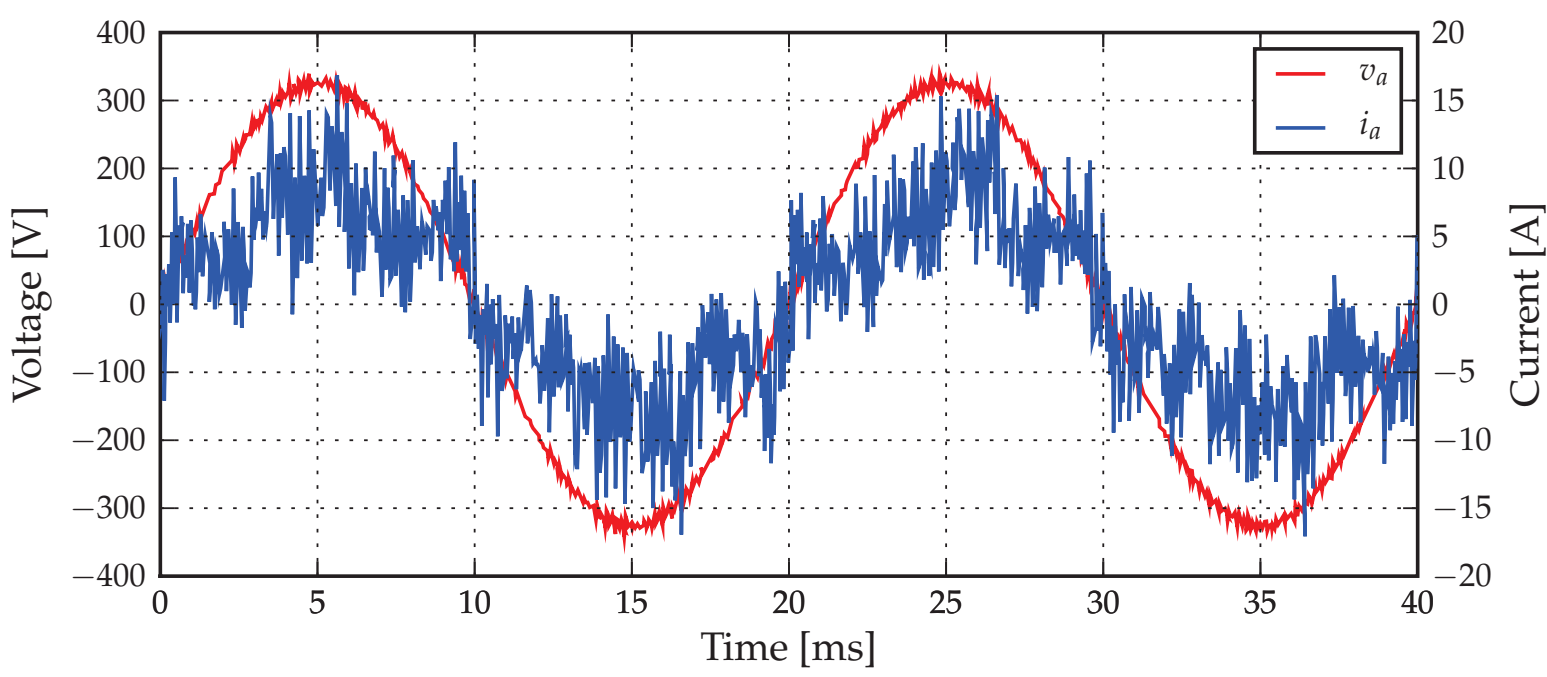

Figure 5.9: Output a-phase voltage and current with DC current source connected to the bus.

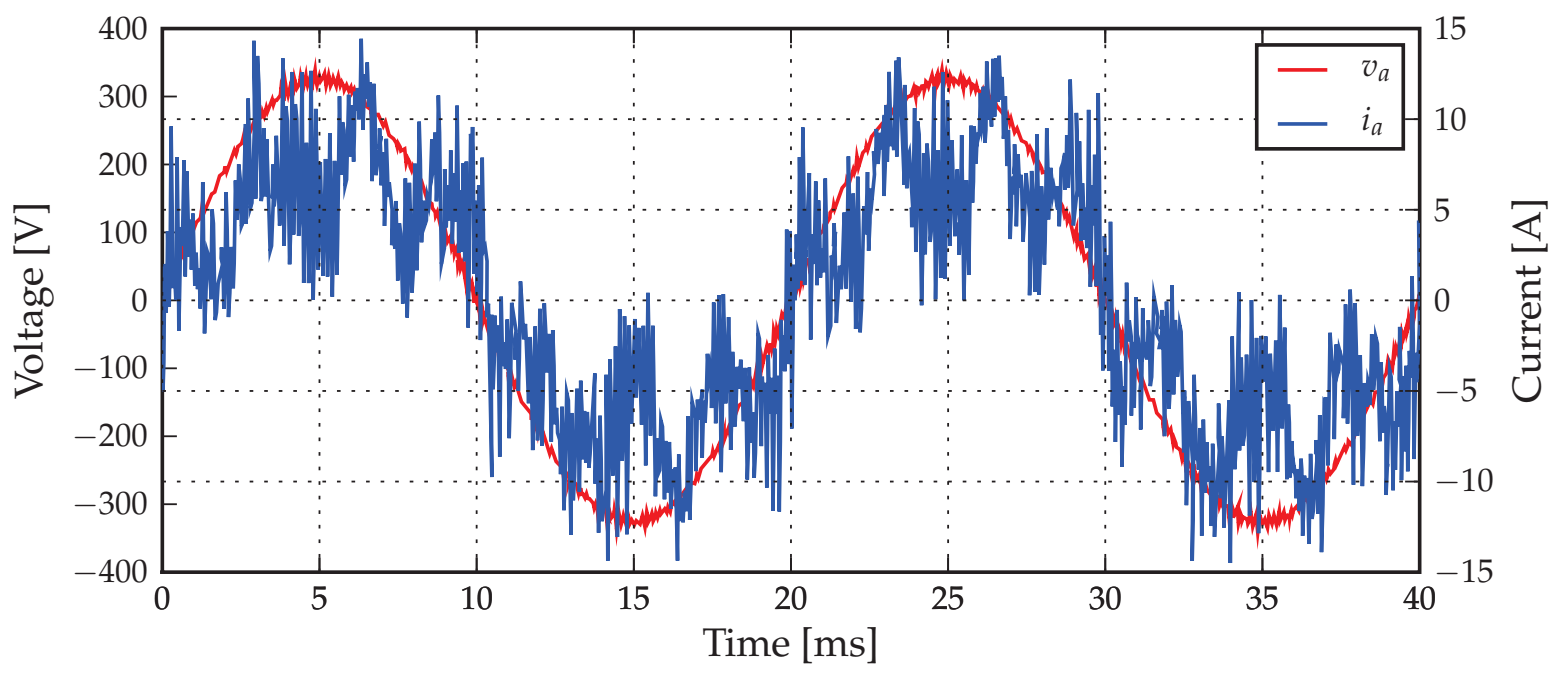

Figure 5.10: Output a-phase voltage and current with the rectifier connected to the DC bus.

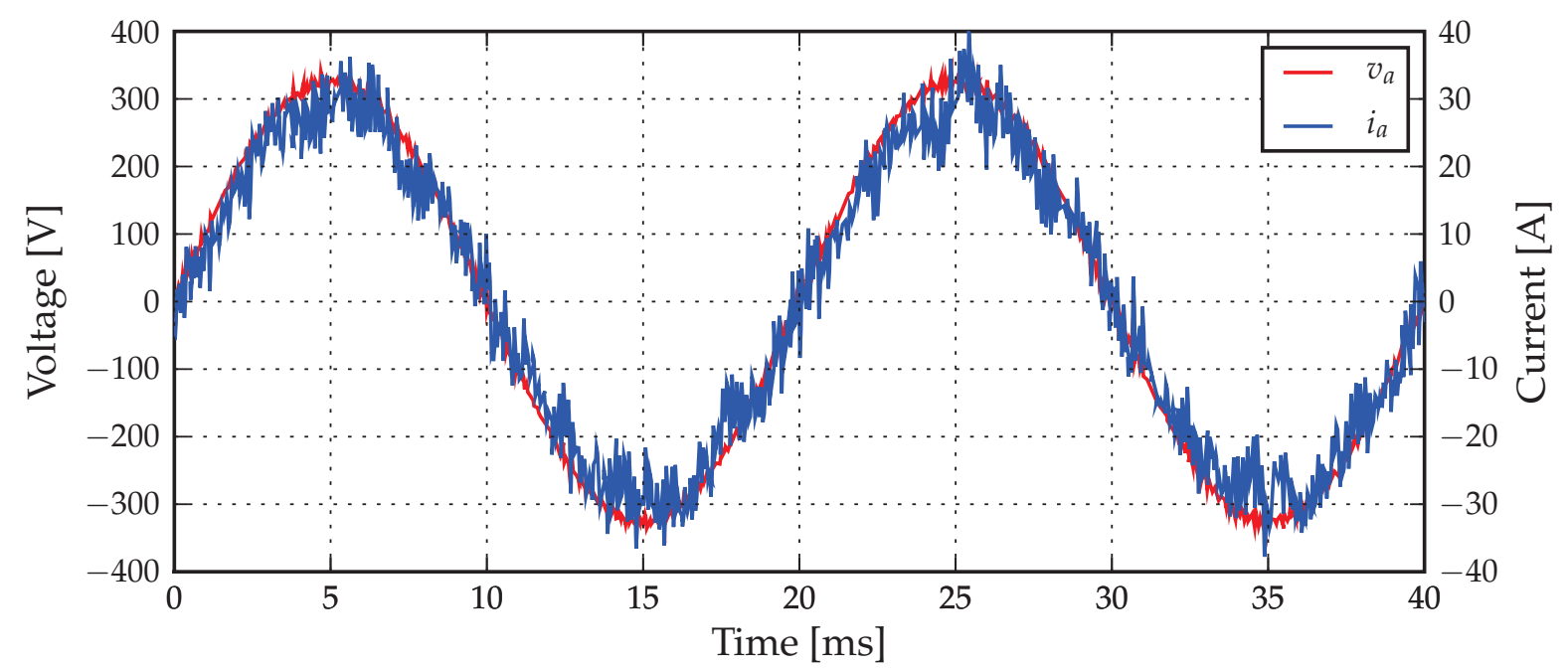

Figure 5.11: Output a-phase voltage and current with DC current source connected to the bus (with a higher DC input current). 


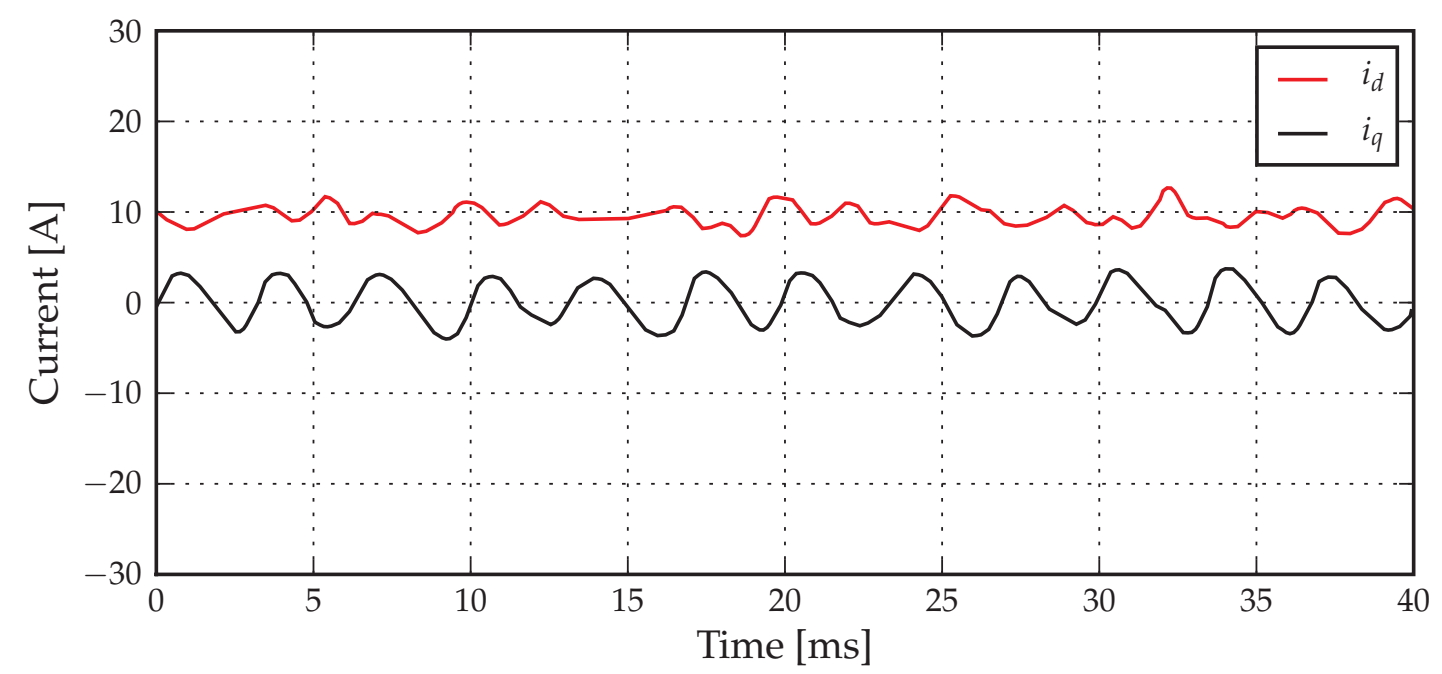

Figure 5.12: The d- and q- components of the measured current with the DC current source connected to the bus.

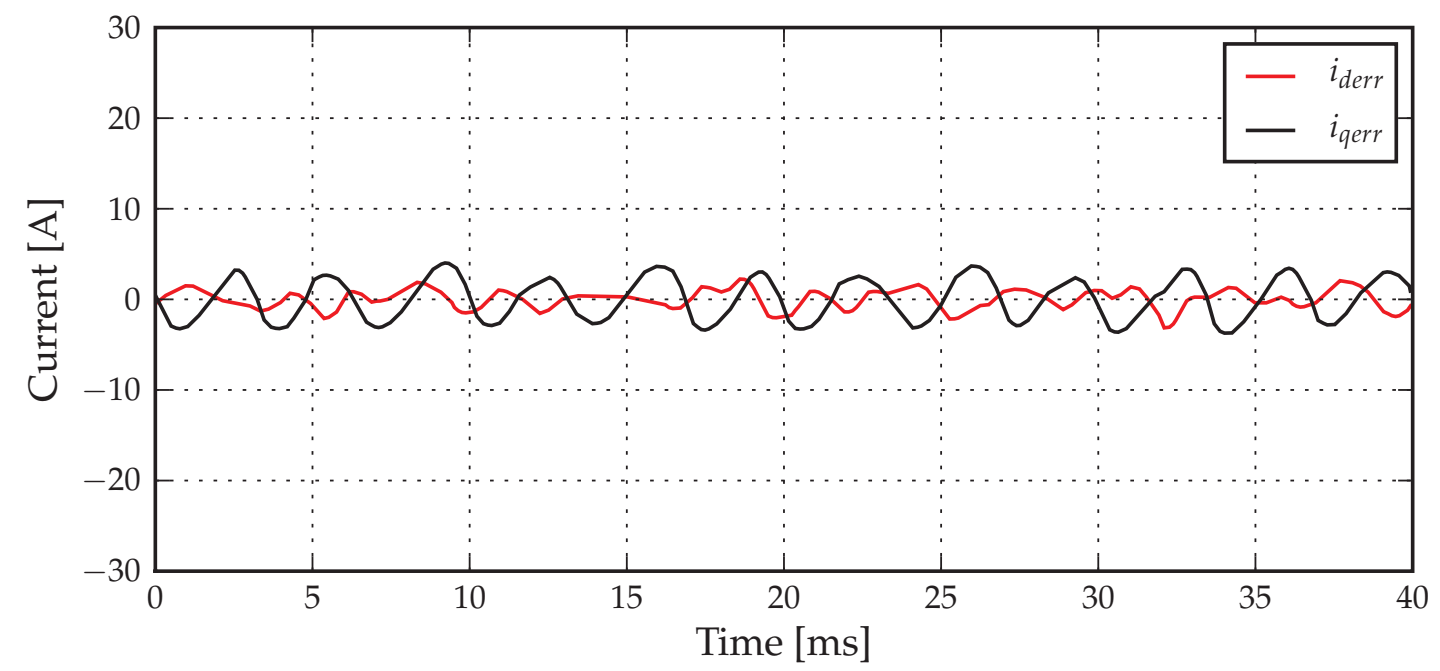

Figure 5.13: The d- and q-components of the error signal with the DC current source connected to the bus.

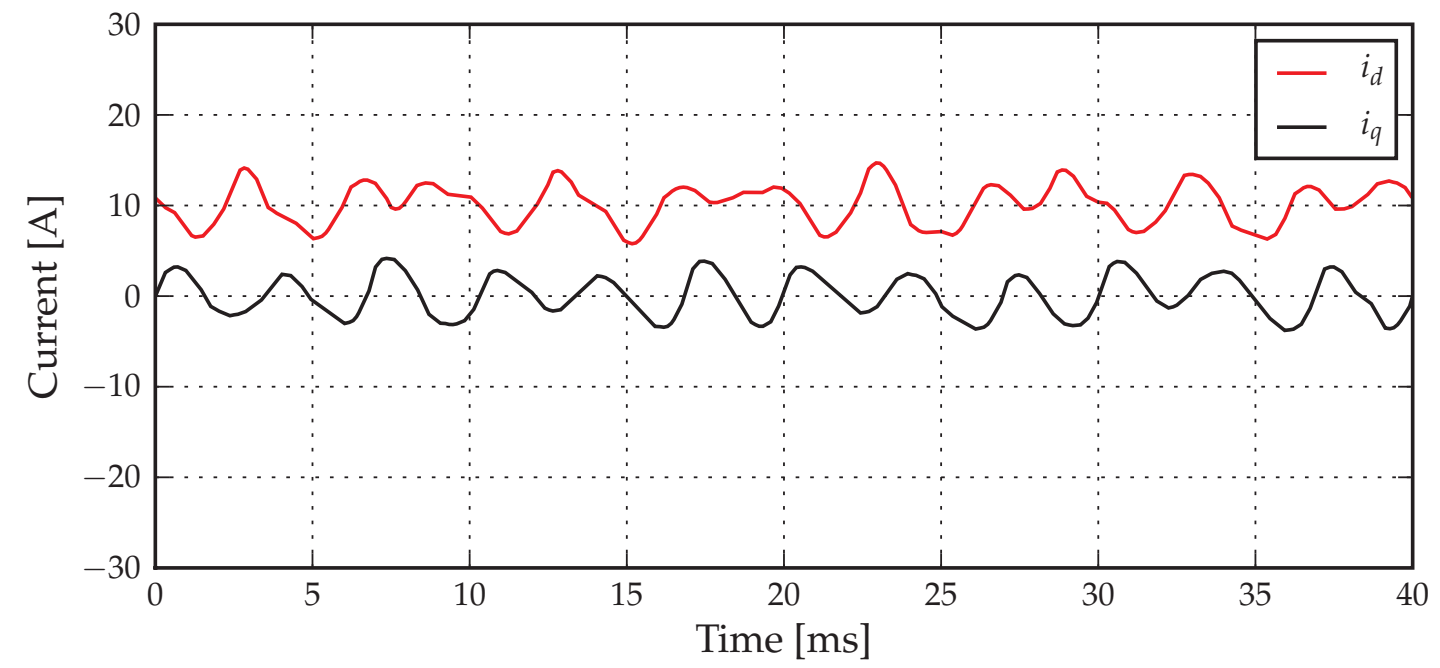

Figure 5.14: The d- and q- components of the measured current with the rectifier connected to the bus. 


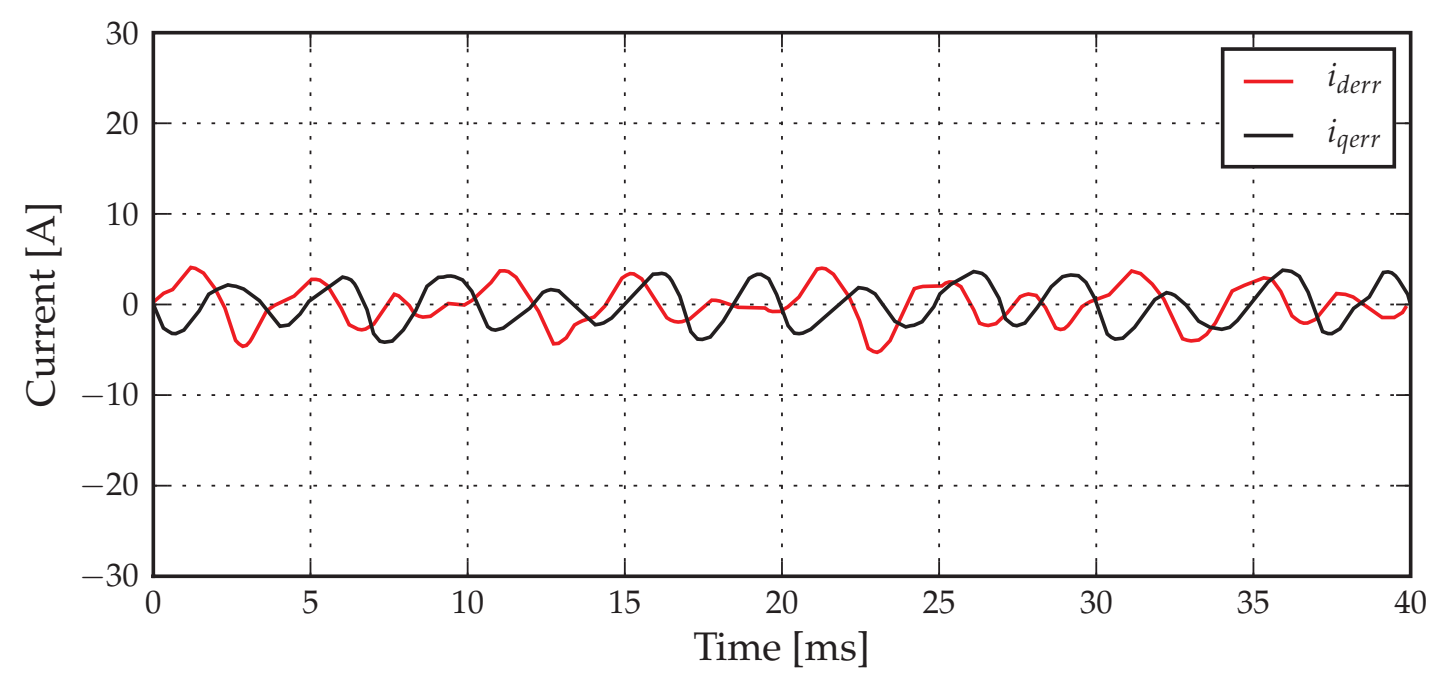

Figure 5.15: The d-and q-components of the error signal with the rectifier connected to the bus.

The $\alpha$ and $\beta$ components used by the SVPWM algorithms to generate the duty cycles are shown in figures 5.16 and 5.17 for simulations one and two respectively. These two figures for the two different simulations match closely. Figures 5.9 to 5.17 are all under steady state conditions, where the rectifier or DC current source force a current into the bus and the inverter transfer the energy to the electrical network.

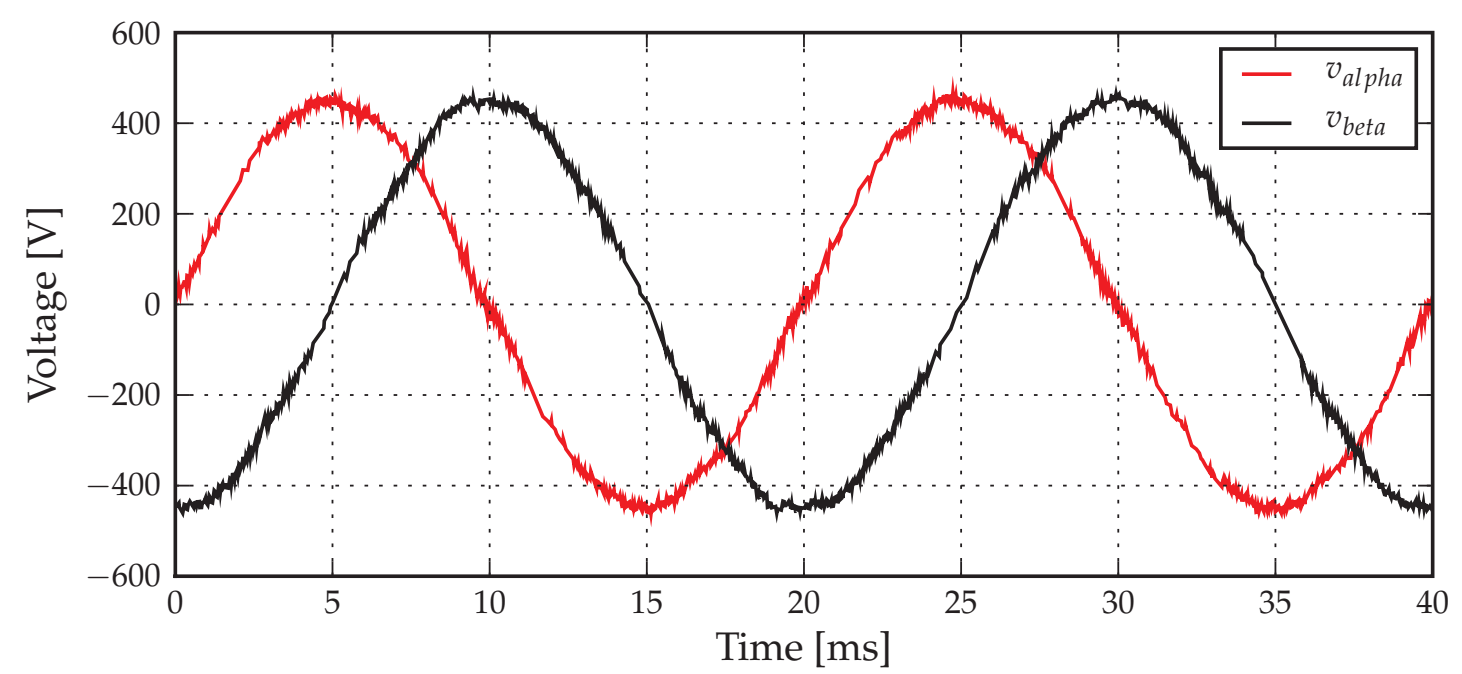

Figure 5.16: The $\alpha$ and $\beta$ input signal to SVPWM block when the DC current source is connected to the bus.

Figures 5.18 to 5.25 are all results for the step response as described earlier in this section. The step occurs at time equals to two seconds in the simulation but the graphs show the parts of the signals from just before the step occur. In the graphs the step occur at time equal to $100 \mathrm{~ms}$.

Figures 5.18 and 5.19 show the d-and q-components of the measured current- and the error-signal respectively with the DC current source connected to the bus. In order to 


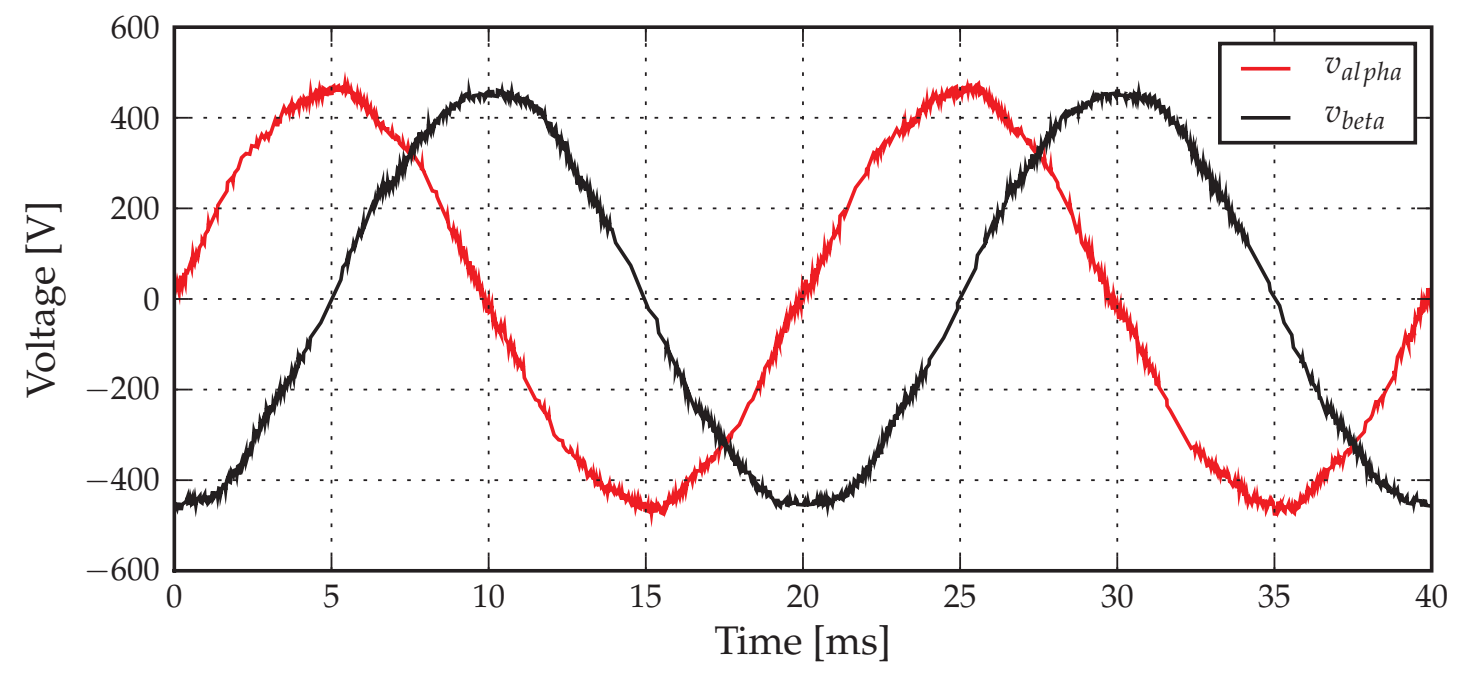

Figure 5.17: The $\alpha$ and $\beta$ input signal to SVPWM block when the rectifier is connected to the bus.

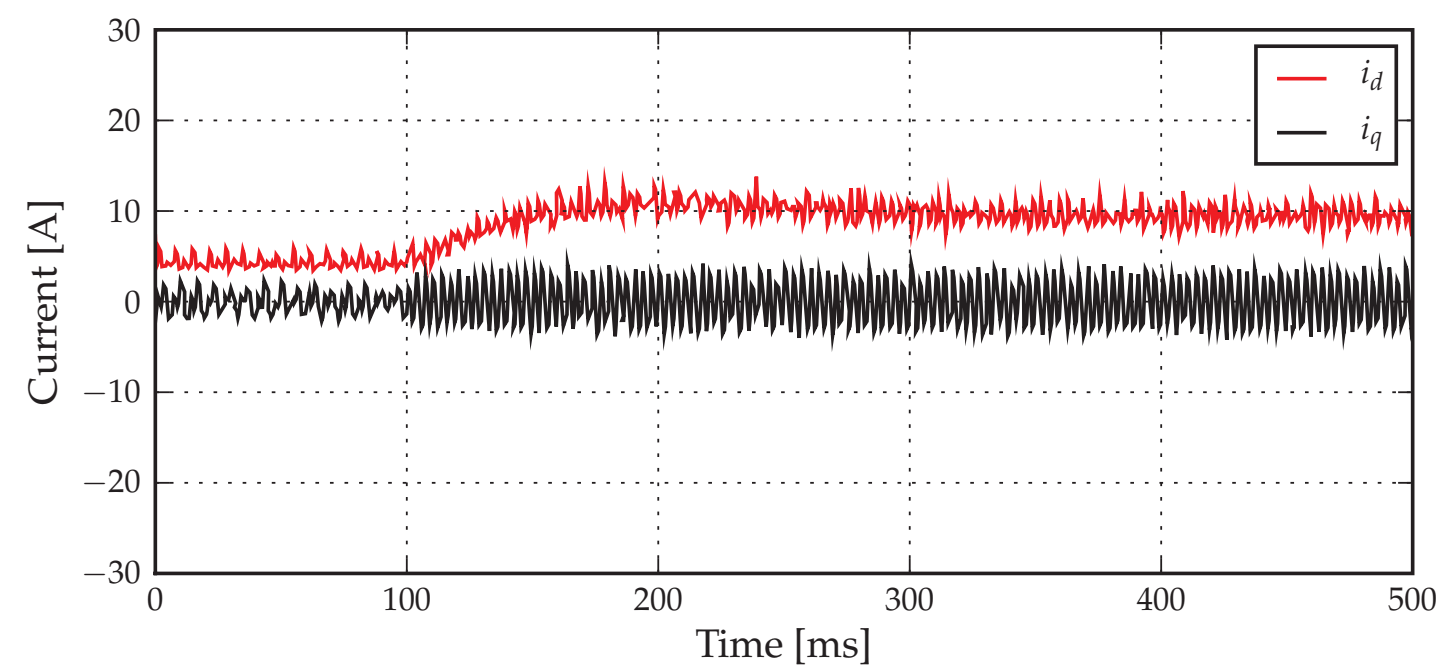

Figure 5.18: Step response of the measured d-and q-components of the current with the DC current source connected to the bus.

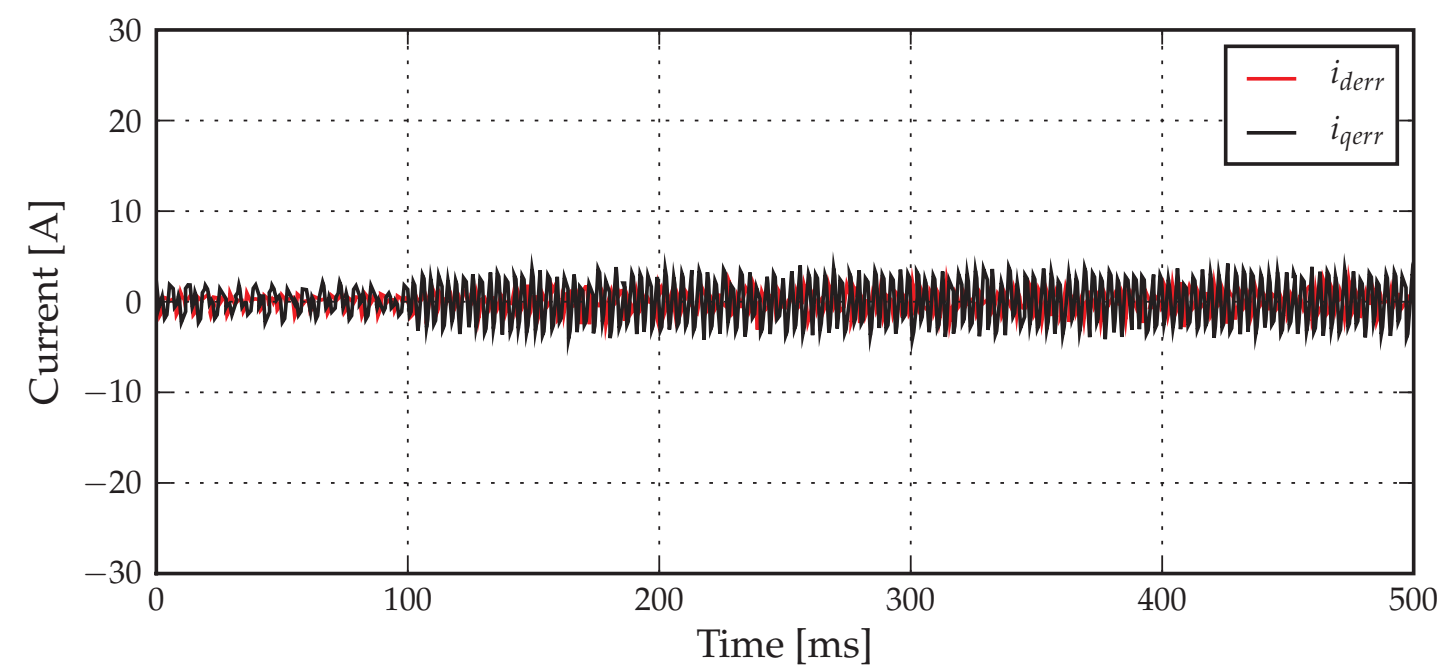

Figure 5.19: Step response of the d- and q-components error signal with the DC current source connected to the bus. 
maintain the DC bus voltage the d-component of the current is not zero before the step occurs as seen in figure 5.18 .

Figures 5.20 and 5.21 show the same signals as figures 5.18 and 5.19, but with the rectifier connected to the bus. The d-component of the measured current does not have much overshoot and settles within $200 \mathrm{~ms}$ after the step occurred.

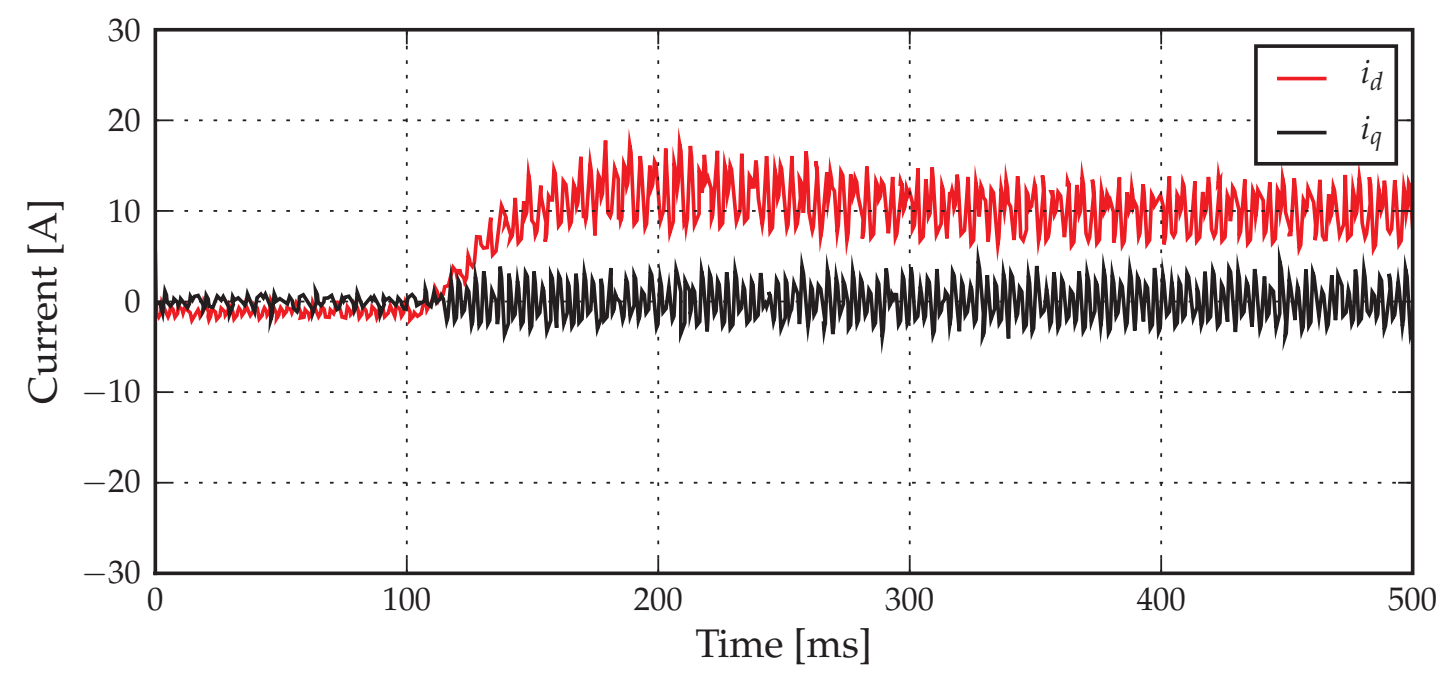

Figure 5.20: Step response of the measured d- and q-components of the current with the rectifier connected to the bus.

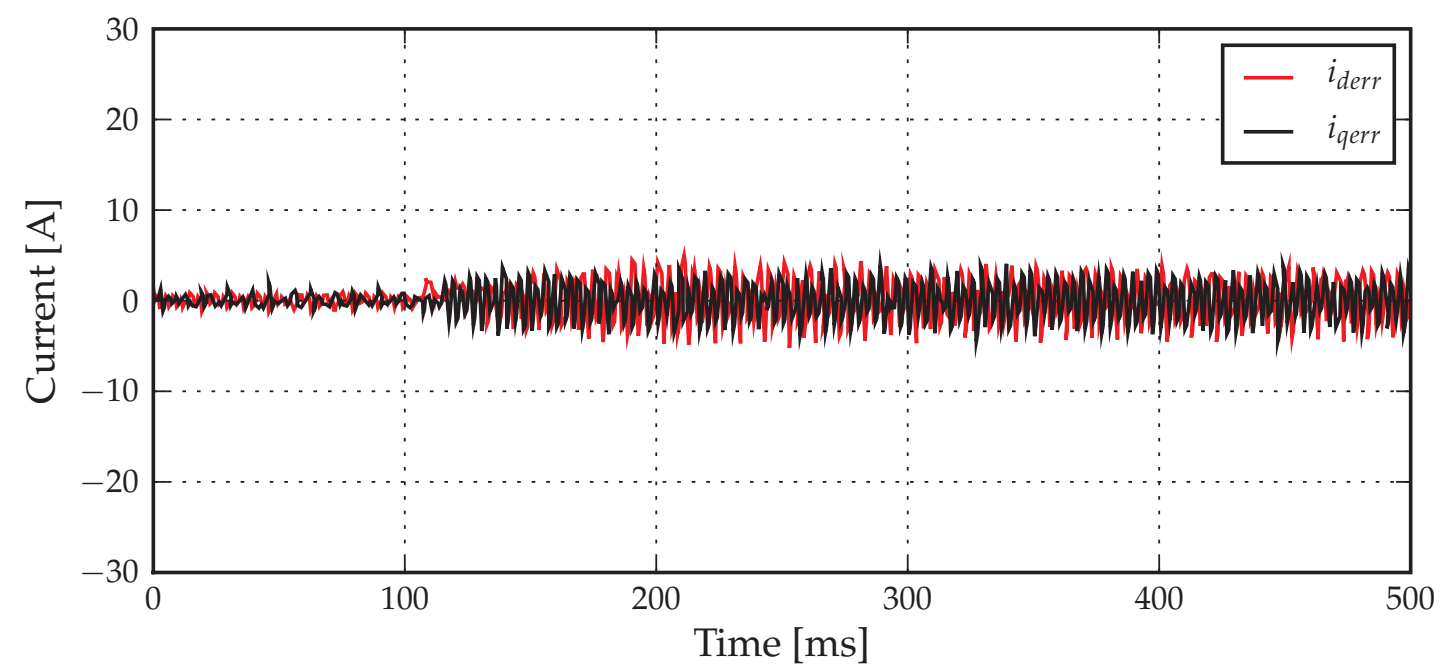

Figure 5.21: Step response of the d- and q-components error signal with the rectifier connected to the bus.

Figure 5.22 depicts the $\alpha$ and $\beta$ input signals to the SVPWM and figure 5.23 show the a-phase voltage and corresponding current of the output at the inverter. Both figure 5.22 and 5.23 are results from the simulation with the DC source current connected to the bus. Figures 5.24 and 5.25 show the same signals as in figures 5.22 and 5.23 respectively but with the rectifier connected to the bus. 


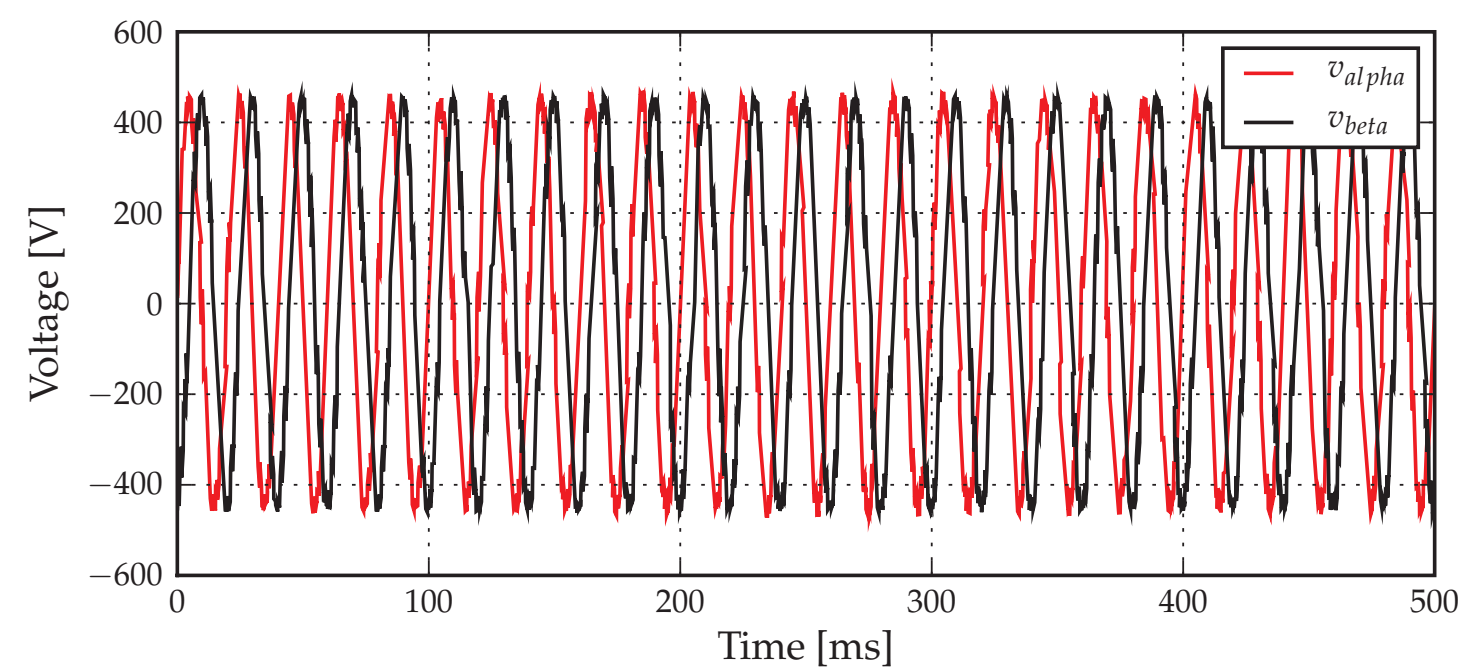

Figure 5.22: Step response of the $\alpha$ and $\beta$ input signal to SVPWM block with the DC current source connected to the bus.

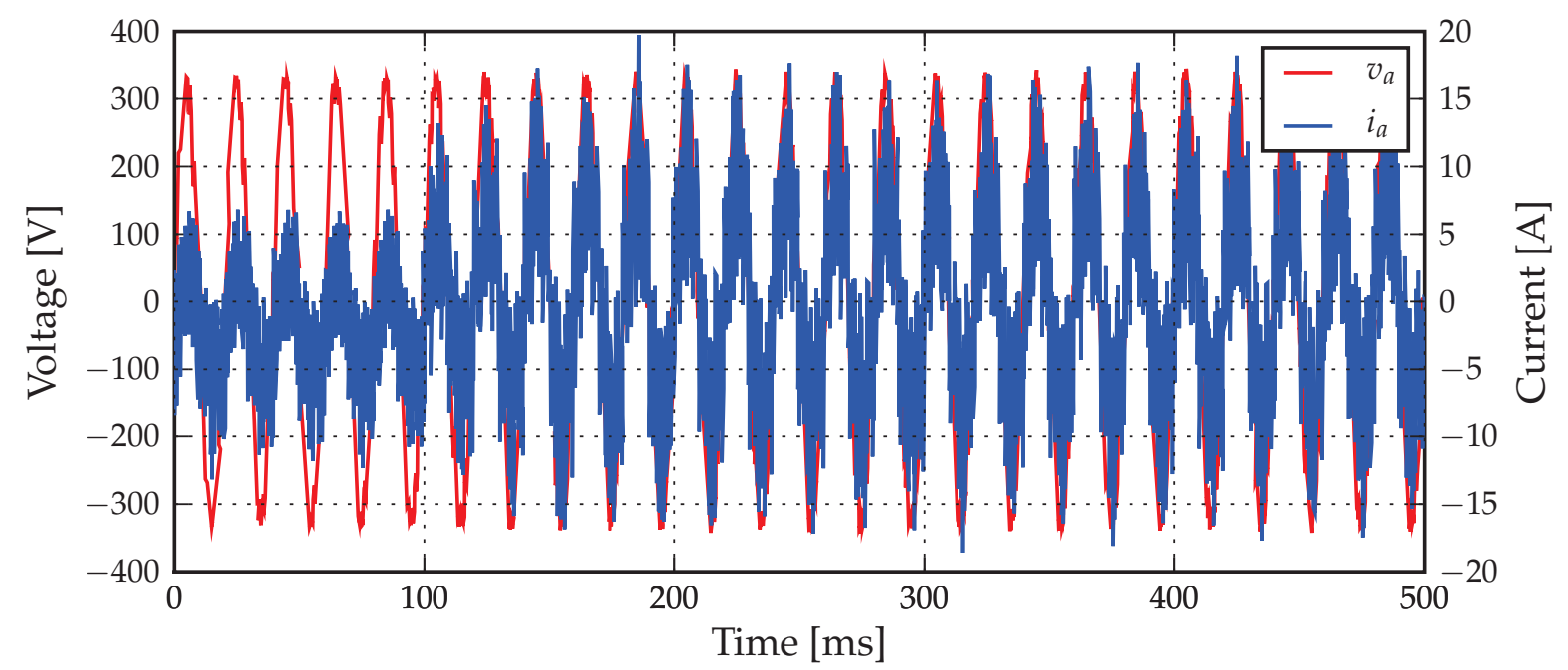

Figure 5.23: Step response of the output a-phase voltage and current with DC current source connected to the bus.

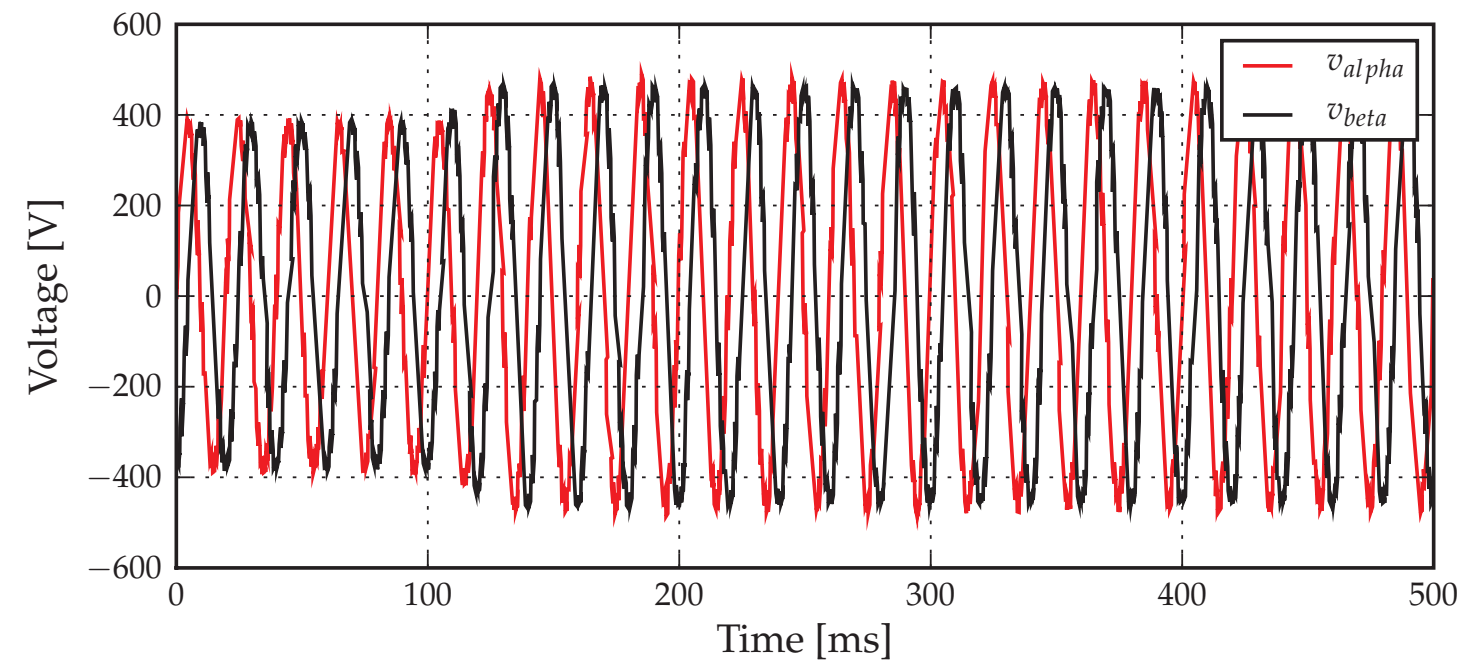

Figure 5.24: Step response of the $\alpha$ and $\beta$ input signal to SVPWM block with the rectifier connected to the bus. 


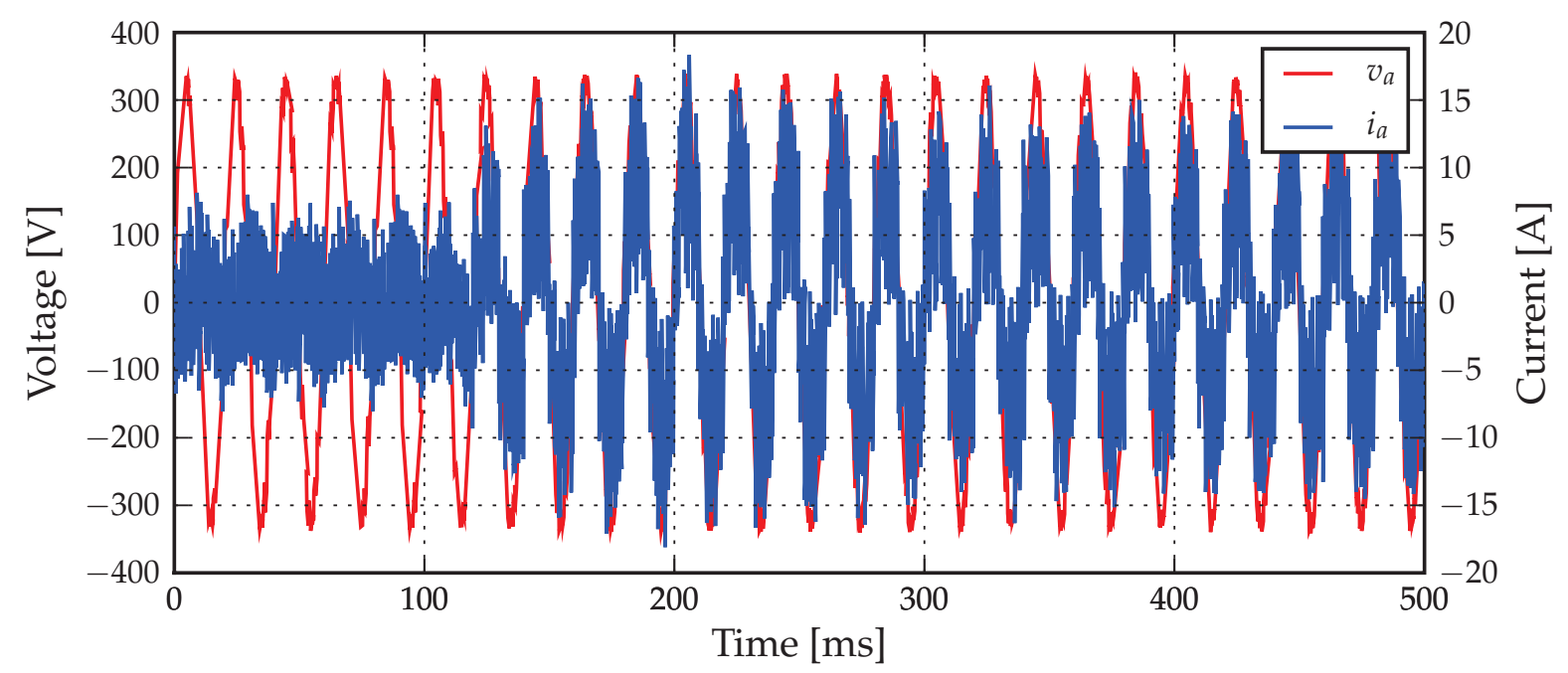

Figure 5.25: Step response of the output a-phase voltage and current with rectifier connected to the bus.

\subsection{DC bus voltage and start-up control}

The outer voltage control loop must have a much lower bandwidth than the inner current control loop in order for the system to function effectively. The bus voltage control (outer voltage control loop) is designed using the sisotool in Matlab. A PI controller is used to control the bus voltage because its easy to implement and due to the bus voltage being a DC value no constant tracking errors will occur.

The inner current control loop described in section 5.3 as well as the outer voltage control loop is shown in figure 5.26. The inner current loop is approximated by

$$
G_{I}(s)=\frac{1}{1+s \tau_{C C}}
$$

where

$$
\tau_{C C}=\frac{1}{2 \pi f_{C L}}
$$

as discussed by Buso and Mattavelli [19]. The new diagram of only the outer voltage loop, where the inner current loop is replaced by the approximation as stated above, is shown in figure 5.27. $V_{d c}^{\prime}$ represents the measured DC voltage while $V_{\text {dcref }}$ is the reference voltage that must be obtained. The PI controller, $G_{2}(s)$, can be written as

$$
G_{2}(s)=K_{p}+\frac{K_{i}}{s}
$$

where $K_{p}$ and $K_{i}$ is equal to 0.257 and 4.552 respectively. The values for the proportional $\left(K_{p}\right)$ and integral $\left(K_{i}\right)$ constants of the controller are obtained from the sisotool in Matlab. The closed loop bandwidth of the voltage control is chosen to be $43.3 \mathrm{rad} / \mathrm{s}$ with a phase margin of $60^{\circ}$. The DC voltage control was implemented on the same digital system as the current control in a similar fashion. 
The output of $G_{2}(s)$ is multiplied with a gain $K$ in order to obtain $i_{d r e f}$, the necessary input for the current controller. $K$ is given by,

$$
K=-\frac{V_{d c}}{V_{s v}}
$$

where

$$
V_{s v}=\sqrt{V_{\alpha}^{2}+V_{\beta}^{2}}
$$

$G_{3}(s)$ represents the transfer function for the capacitor bank and is given by

$$
G_{3}(s)=\frac{16.5 \times 10^{3}}{1+155.1 s}
$$

which results from the $C_{1}$ and $C_{2}$ and their bleeding resistances as discussed in section 4.2.1.

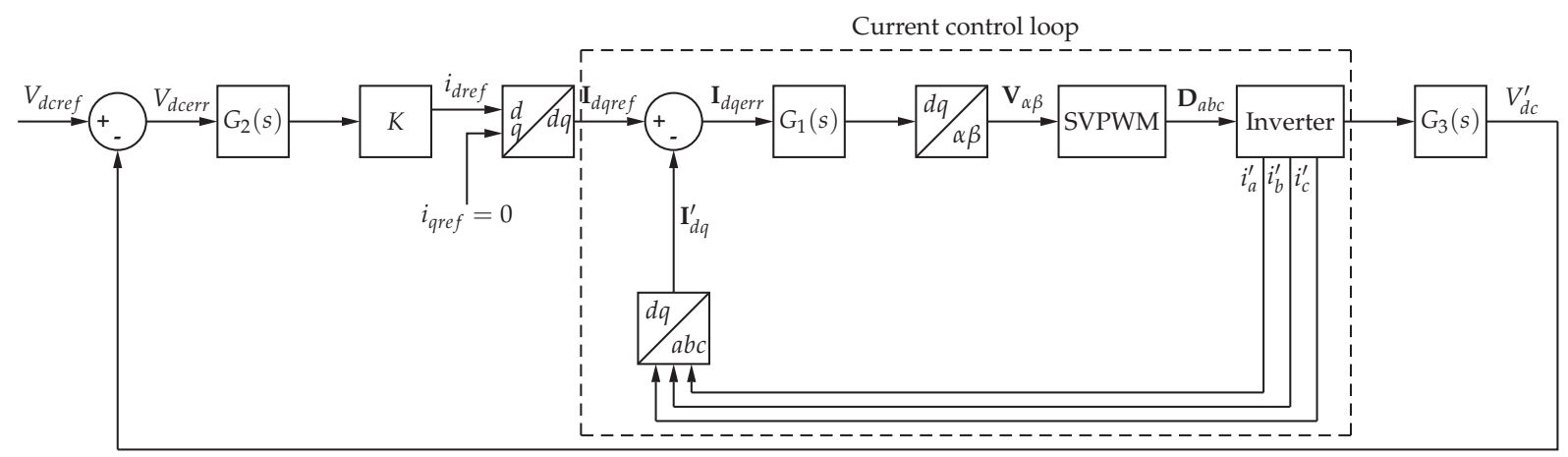

Figure 5.26: Double loop control strategy.

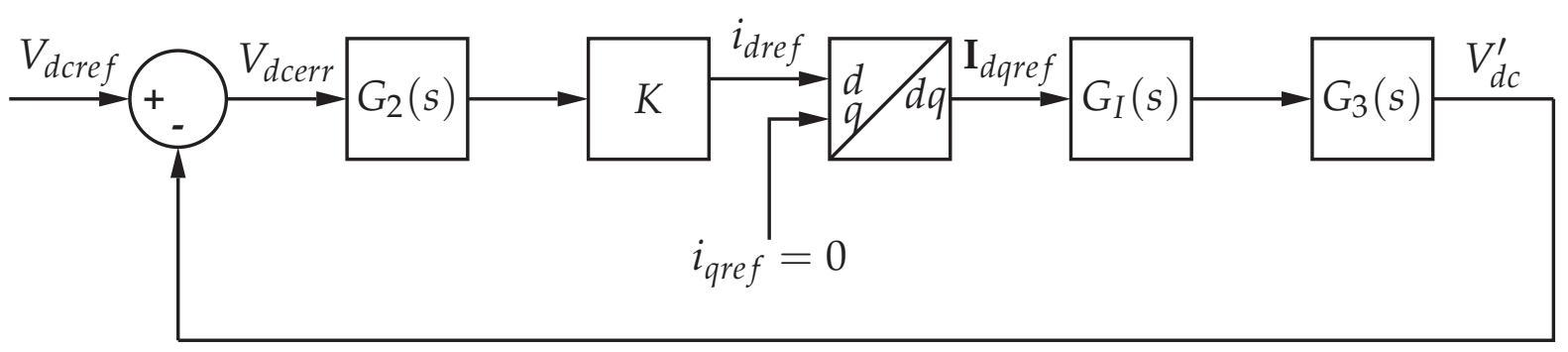

Figure 5.27: Simplified voltage control loop.

$V_{d c}$ was set to be $750 \mathrm{~V}$ and figure 5.28 shows that the measured value $V_{d c}^{\prime}$ follow this closely. The graph shown is for steady state conditions with a DC current source connected to the bus. Figure 5.28 also depicts the reference current $i_{d r e f}$, the input to the current controller. Figure 5.29 shows the same signals as figure 5.28 but only for the rectifier connected to the bus.

It is clearly visible how the $V_{d c}^{\prime}$ and $i_{d r e f}$ signals with the rectifier connected to the bus has a much larger ripple if compared to when the DC current source is connected to the bus. This is because the input current that the DC current source supply to the 
bus is much smoother than the input current that the rectifier supply to the bus. The input and output currents of the DC bus for when the DC current source is connected to the bus is shown in figure 5.30 while the same signals with the rectifier connected to the DC bus is shown in figure 5.31. The ripple on the input DC current $\left(I_{d c i}\right)$ is clearly visible when the rectifier is connected to the DC bus.

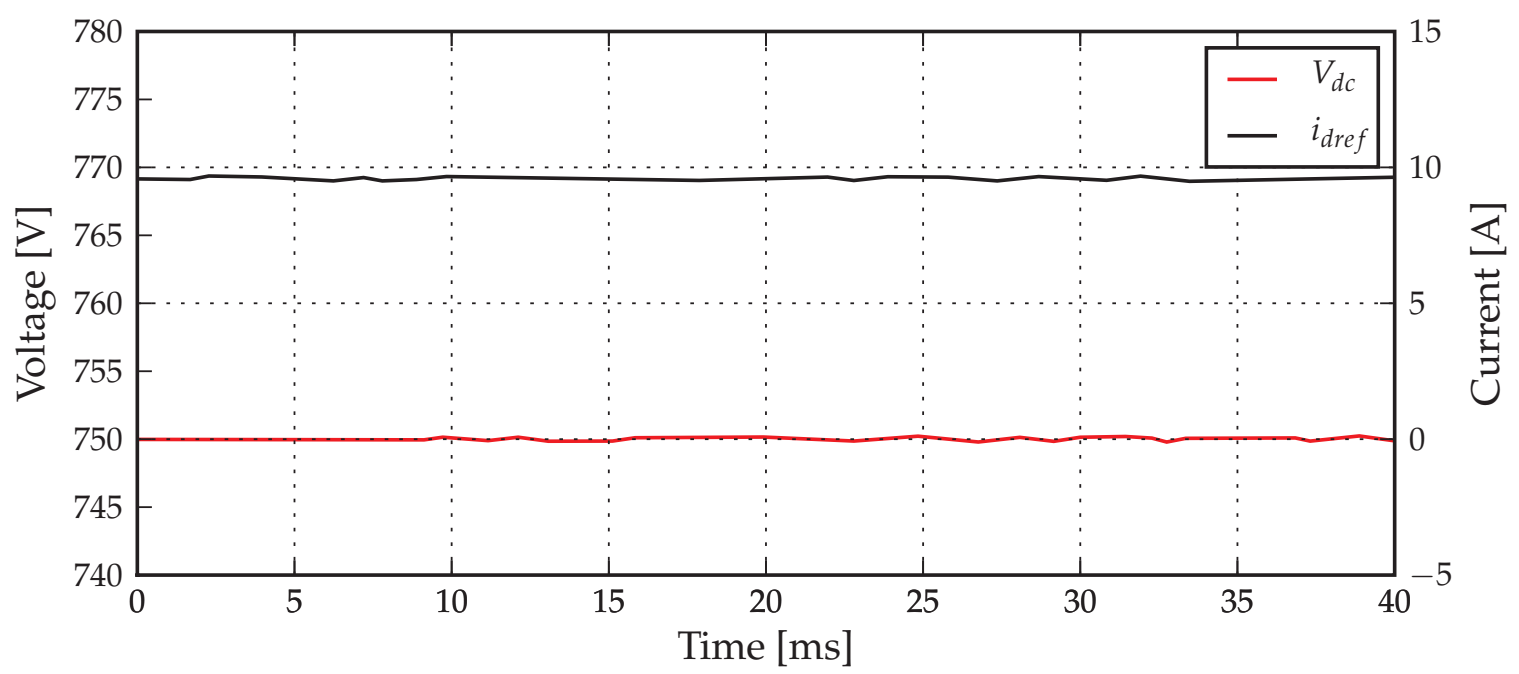

Figure 5.28: Bus voltage and the d-component reference current with a DC current source connected to the bus.

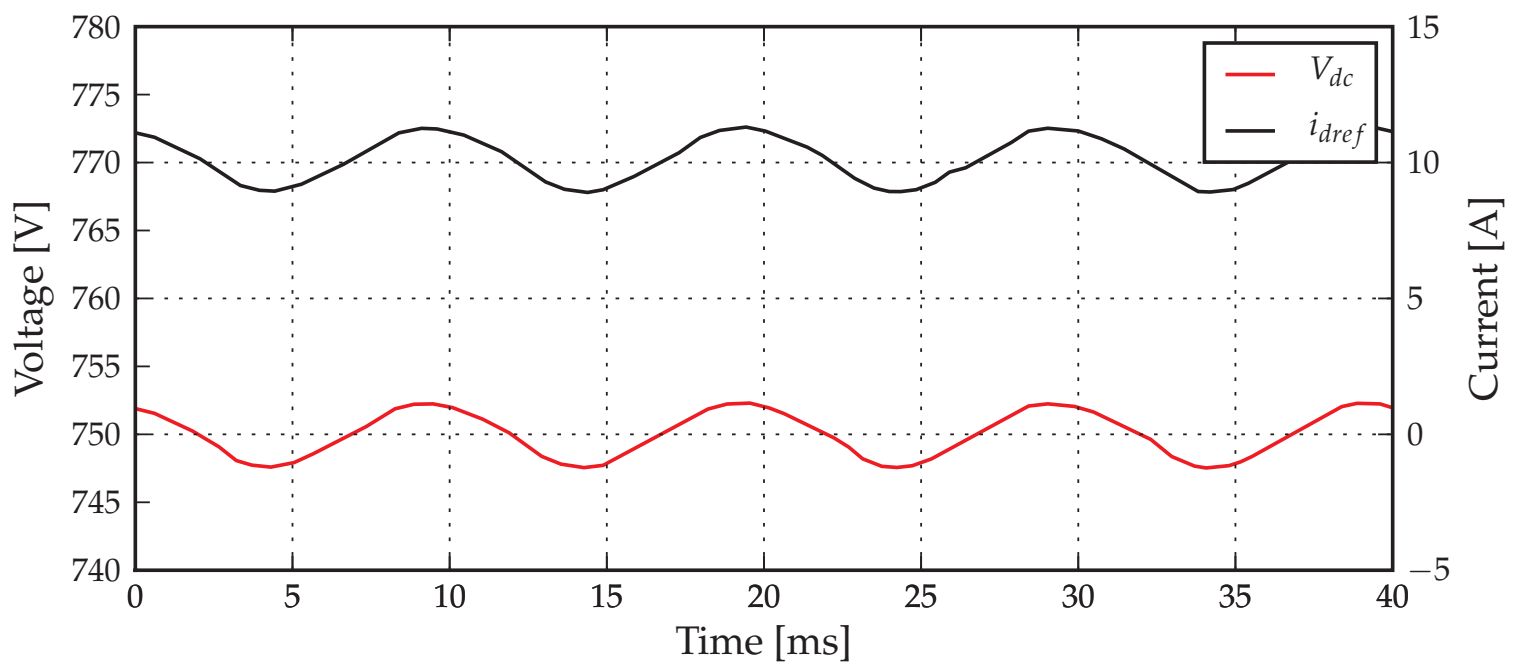

Figure 5.29: Bus voltage and the d-component reference current with a rectifier connected to the bus.

Figure 5.32 shows the step response of the bus voltage and the $\mathrm{d}$-component of the reference current with a DC current source connected to the bus while figure 5.33 shows the same signals but with the rectifier connected to the bus. The effect of the DC current ripple due to the rectifier connected to the bus can be seen if figures 5.32 and 5.33 are compared. 


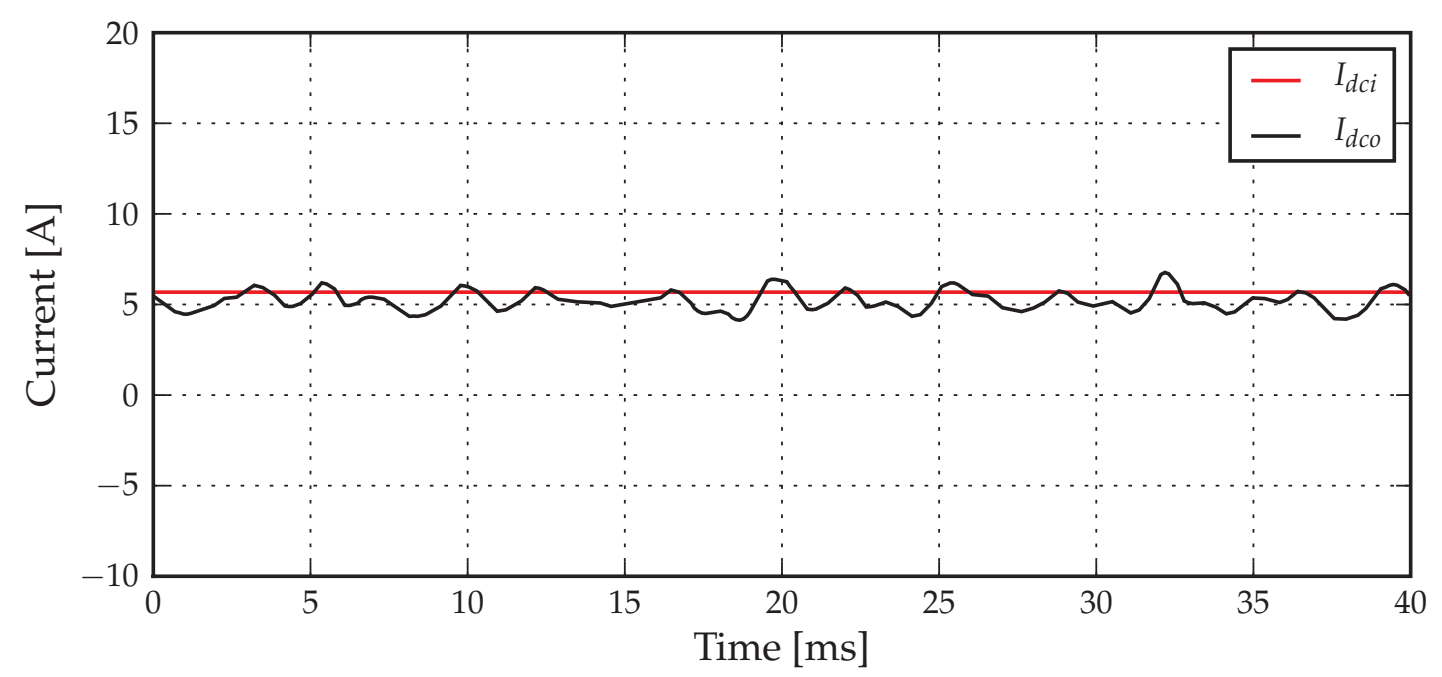

Figure 5.30: Input and output current to the DC bus with a DC current source connected to the bus.

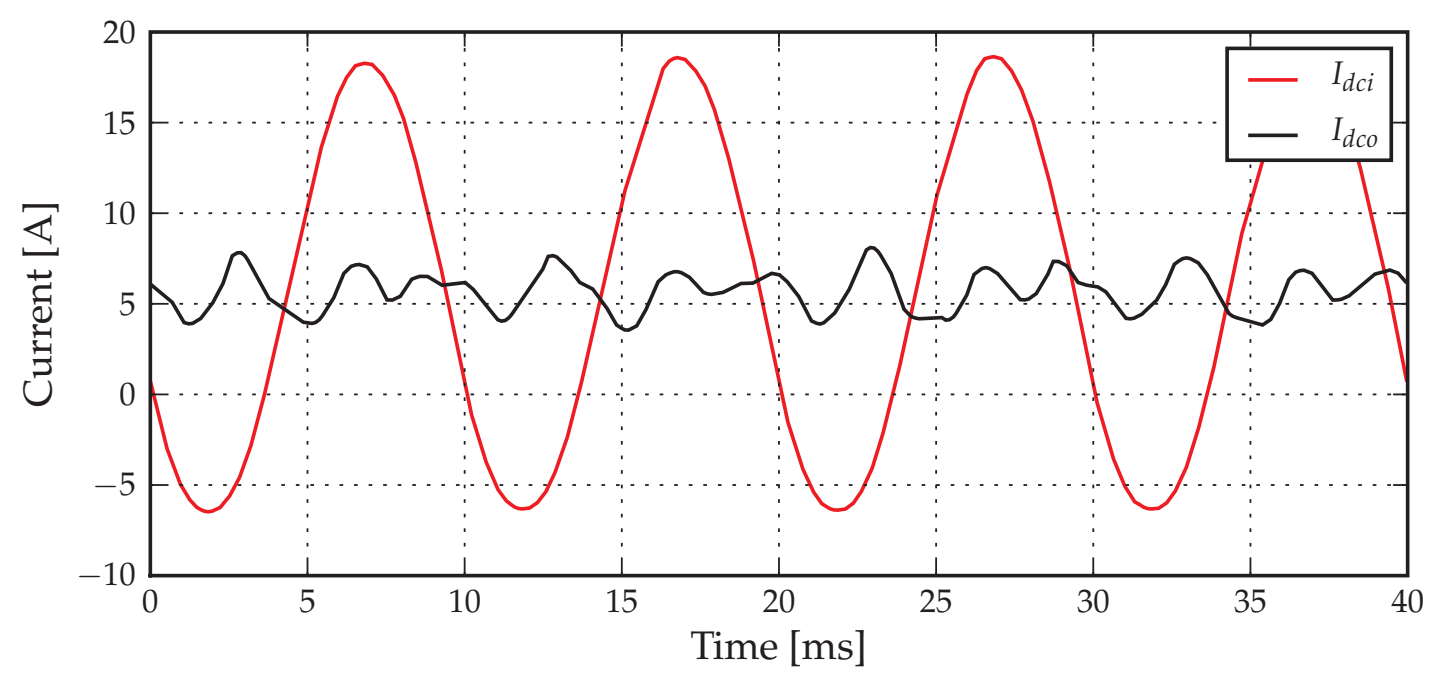

Figure 5.31: Input and output current to the DC bus with a rectifier connected to the bus.

The step response of the input and output DC currents for when the DC current source and the rectifier is connected to the bus is shown in figures 5.34 and 5.35 respectively. All the $I_{d c i}$ and $I_{d c o}$ signals shown in graphs in this section is digitally filtered with a second order Bessel-Thompson low pass filter (LPF) at $1 \mathrm{kHz}$ from left to right and again from right to left to ensure that there is no phase shift.

$R_{s S 1}, R_{s S 2}$ and $R_{s s 3}$ was set to different values and simulated for each value in Simplorer to gather information regarding the ripple current through the filter capacitor as well as the peak diode currents of the inverter bridge. The value for these soft start resistors was chosen to be $6.8 \Omega$ with a power rating of $50 \mathrm{~W}$. There resistors was used to start up the inverter by loading the bus voltage to a certain value. This was done by closing contactor $S_{13}$ while contactor $S_{12}$ is still open. When the bus reach a certain voltage contactor $S_{12}$ closes and switch the soft start resistors out of the circuit. The inverter control then take over to control the bus voltage. 


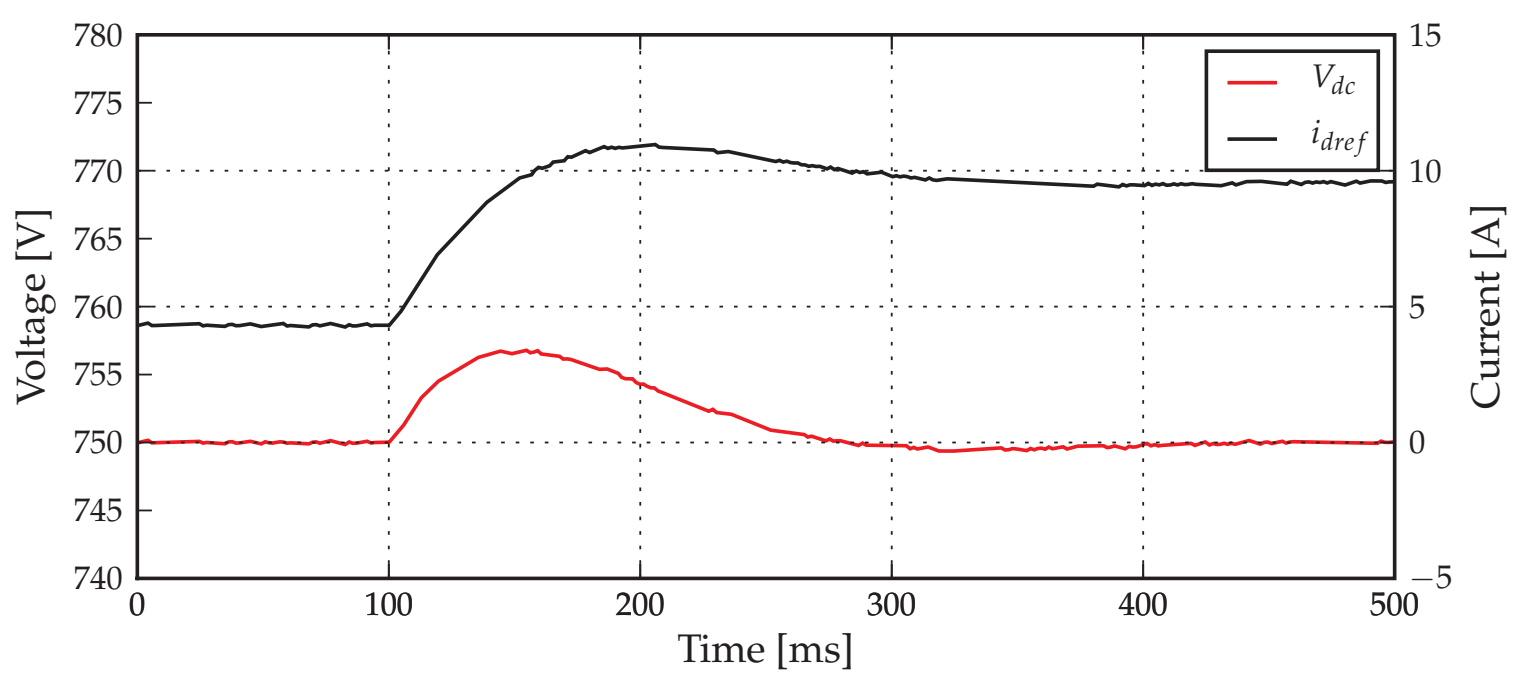

Figure 5.32: Step response for the bus voltage and the d-component reference current with a DC current source connected to the bus.

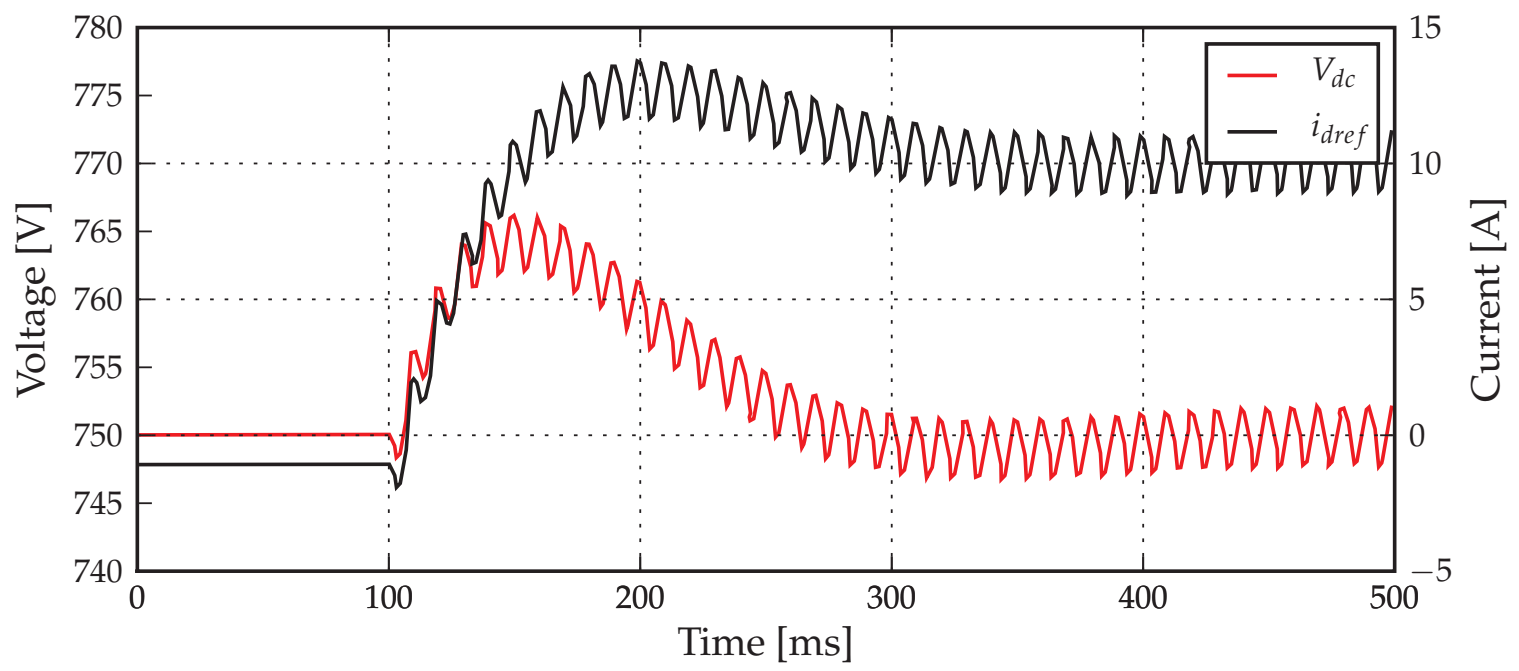

Figure 5.33: Step response for the bus voltage and the d-component reference current with a rectifier connected to the bus.

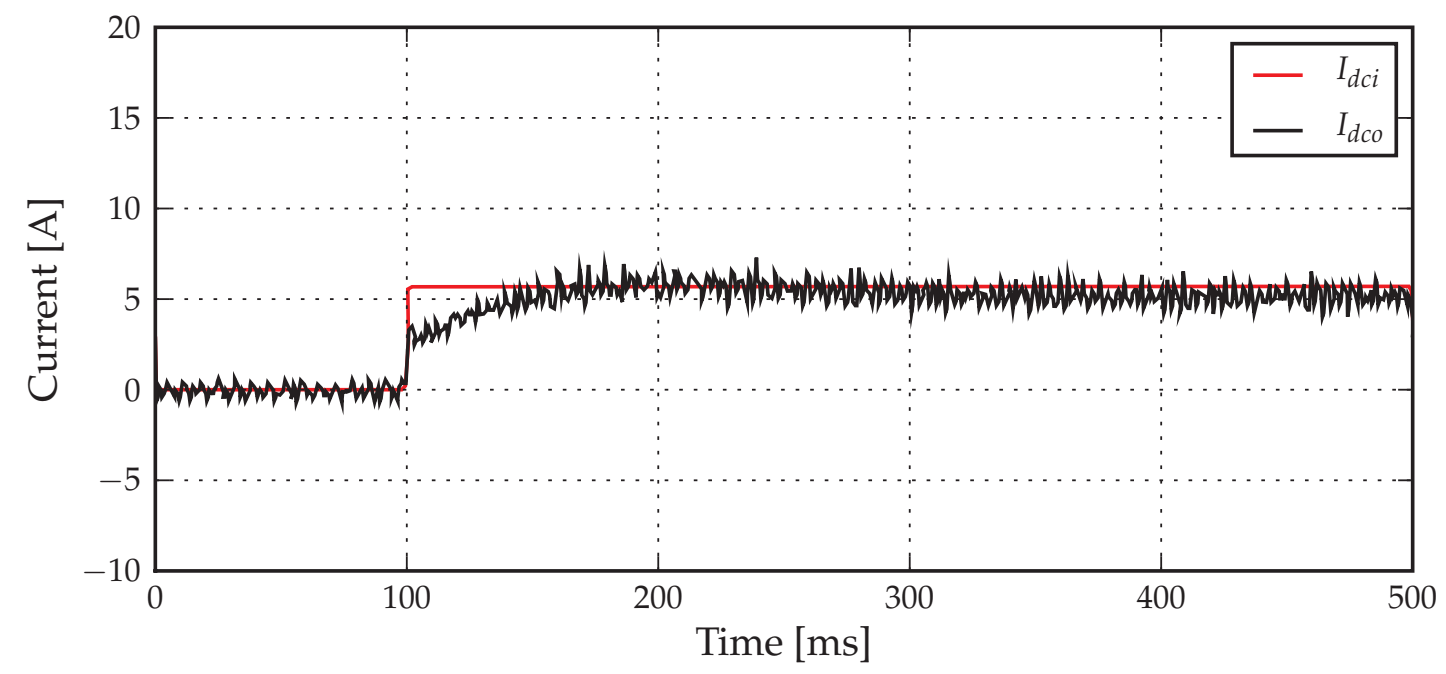

Figure 5.34: Step response for the input and output current to the DC bus with a DC current source connected to the bus. 


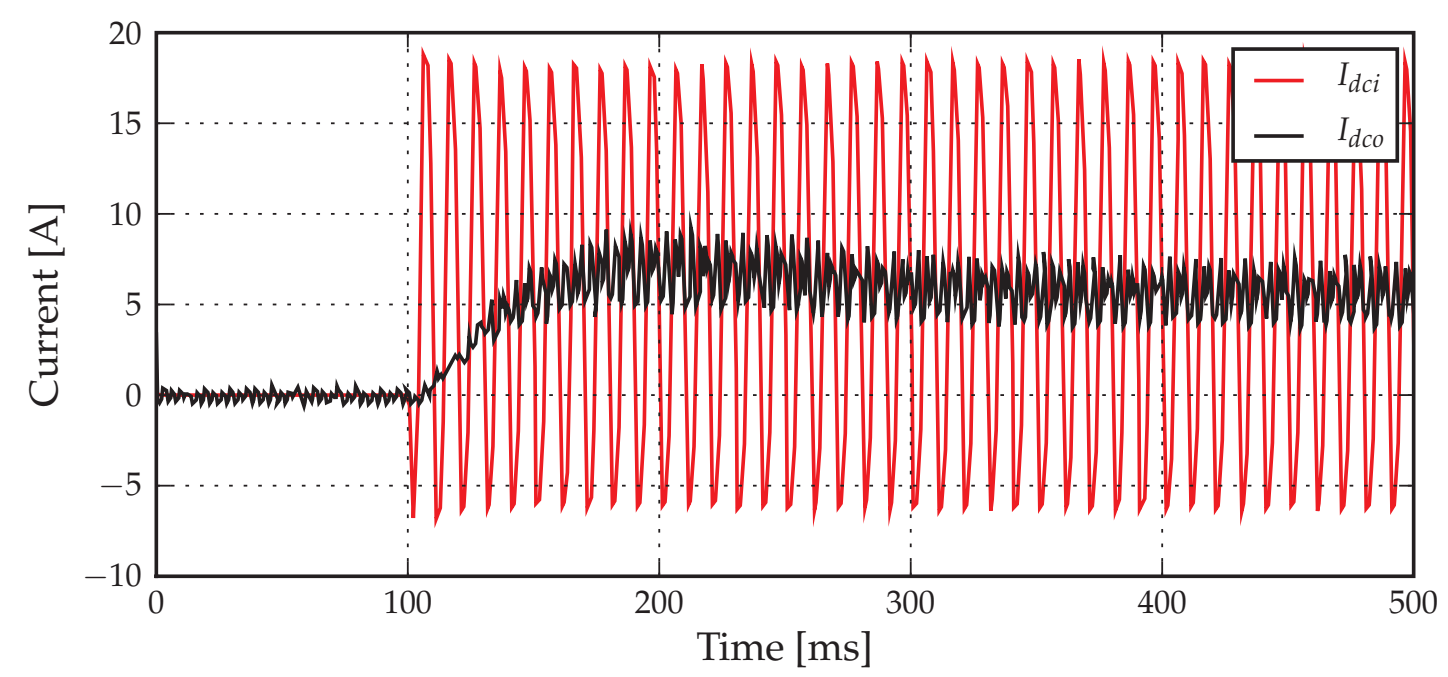

Figure 5.35: Step response for the input and output current to the DC bus with a rectifier connected to the bus.

Figure 5.36 show the DC bus voltage during the start up procedure as well as the DC current and the d-component current reference. The current reference was limited at $\pm 30 \mathrm{~A}$ to ensure that maximum ratings of the components would not be exceeded. Figure 5.37 show the a-phase current and corresponding voltage for the same period. The resemblance between the $i_{\text {dref }}$ signal in figure 5.36 and the $i_{a}$ signal in figure 5.37 is clearly visible.

The soft start resistors are taken out of the circuit when the bus voltage reaches a value of $500 \mathrm{~V}$. This is where the DC current $\left(I_{d c o}\right)$ spike appears in figure 5.36 . The duration of the spike is very short. The inverter control then takes over and control the bus voltage from this point on. There is an overshoot on the bus voltage, but its still within the capability of the bus capacitors. The bus settles at the desired value in just under one second. 


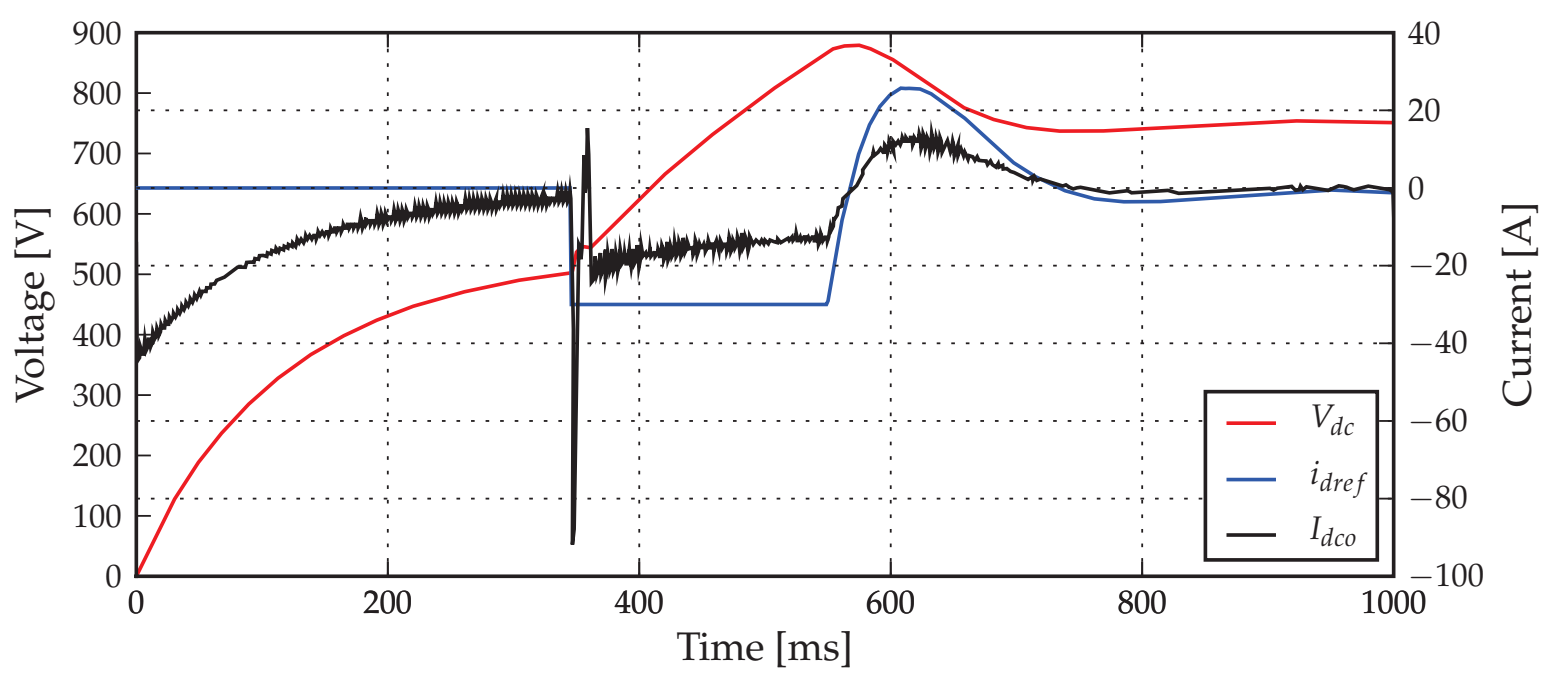

Figure 5.36: Transient response at start up for bus voltage and current, as well as the d-component current reference.

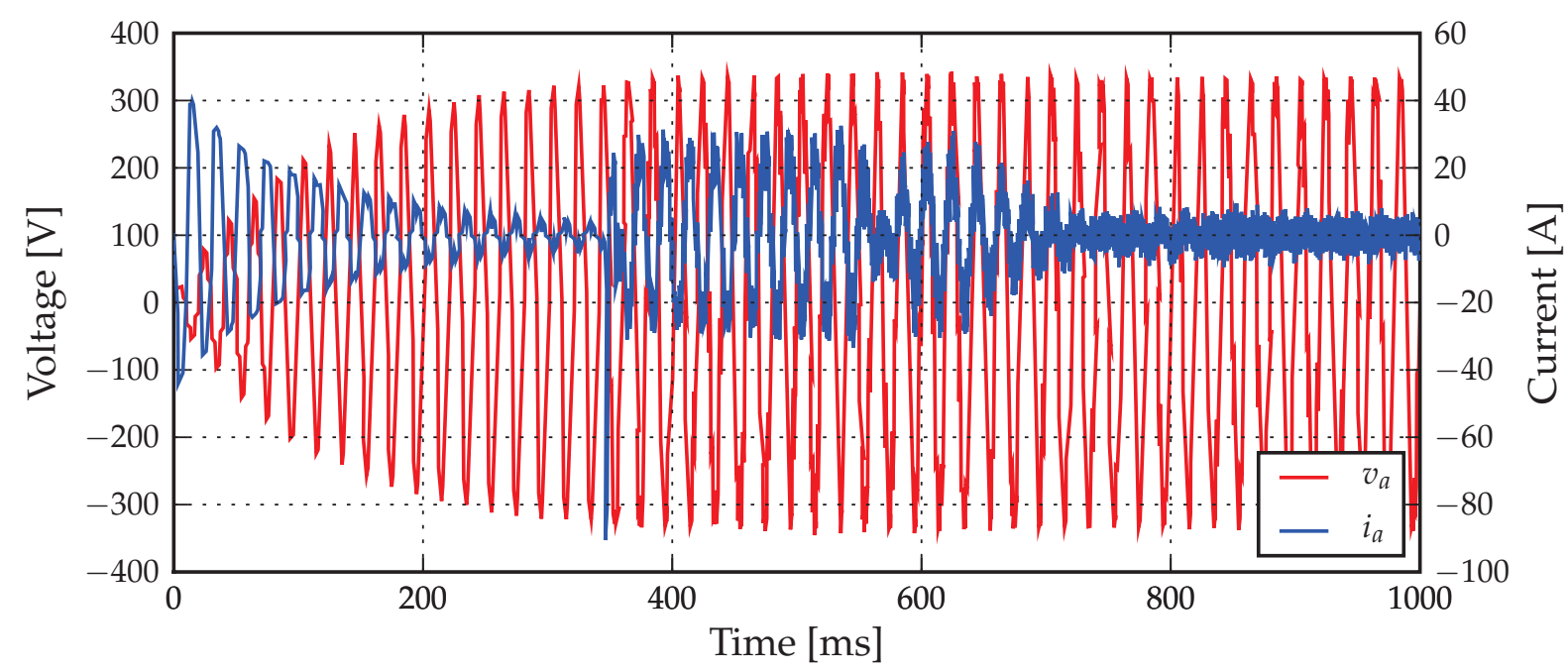

Figure 5.37: Transient response at start up for the a-phase current and corresponding voltage.

\subsection{Construction}

This section discusses the construction phase of the inverter and shows some images of the final product. Figure 5.38 shows an image of the power electronic converter where the inverter IPM's and relevant PCB's are indicated. Figure 5.39 also shows the power electronic converter but from another angle in order to indicate contactors $S_{12}$ and $S_{13}$ as well as the soft start resistors, also indicated in figure 5.1. The LEM transducer used for the measurement of the three phase currents are also indicated in figure 5.39.

Figure A.6 depicts an image of the power electronic converter, switch gear, digital control hardware and measurement setup. Figure A.7 shows another view of the power electronic converter where part of the inductors and filter capacitors can be seen under the heat sink. Each $10 \mu \mathrm{F}$ filter capacitor consists of ten $1 \mu \mathrm{F}$ capacitors connected in 


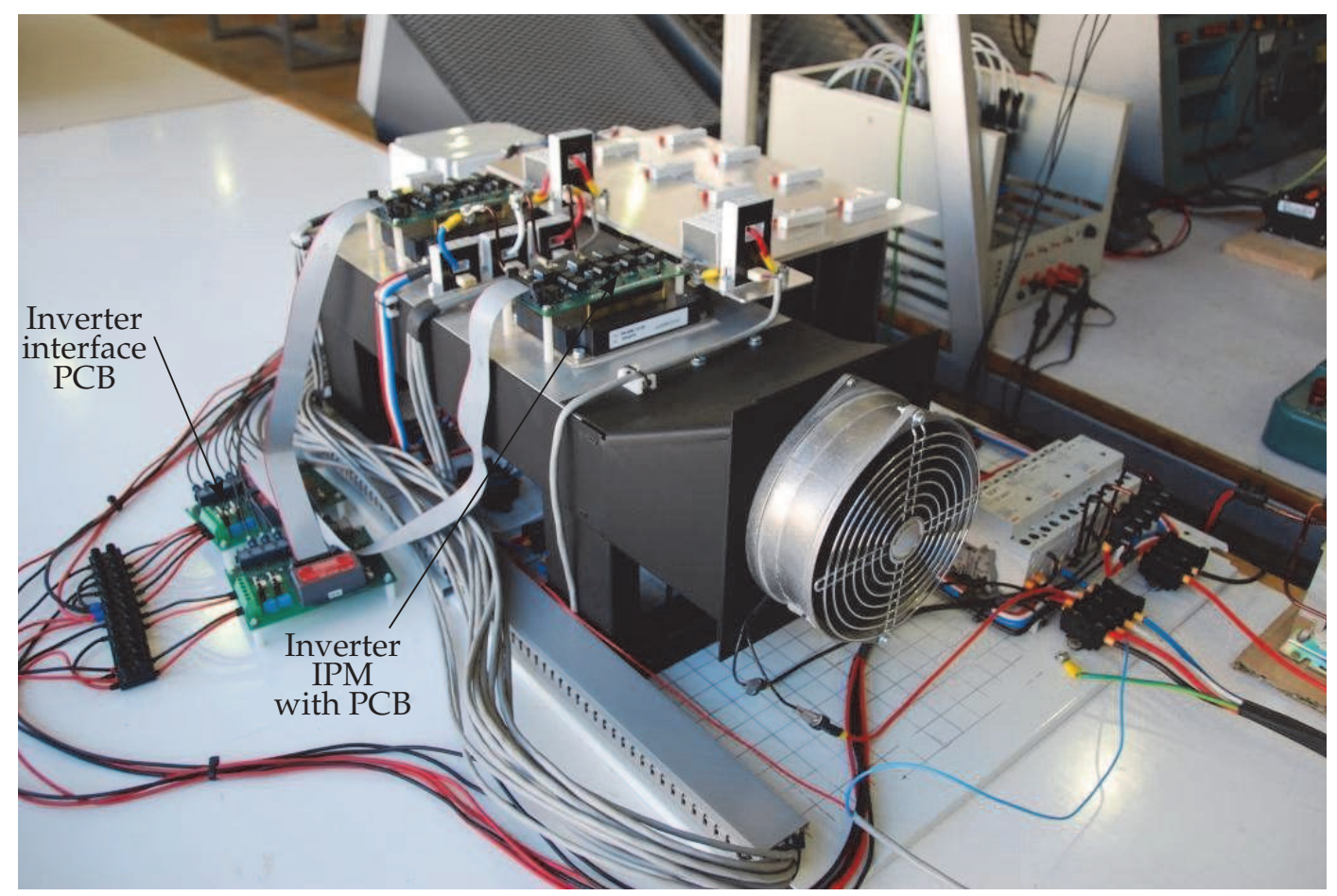

Figure 5.38: Power electronic converter showing the fan and duct in front, the bus capacitors at the back and the IGBT modules for the rectifier and inverter on the heat sink on the left.

parallel on a PCB. Each $830 \mu \mathrm{H}$ inductor consists of two $415 \mu \mathrm{H}$ inductors connected in series.

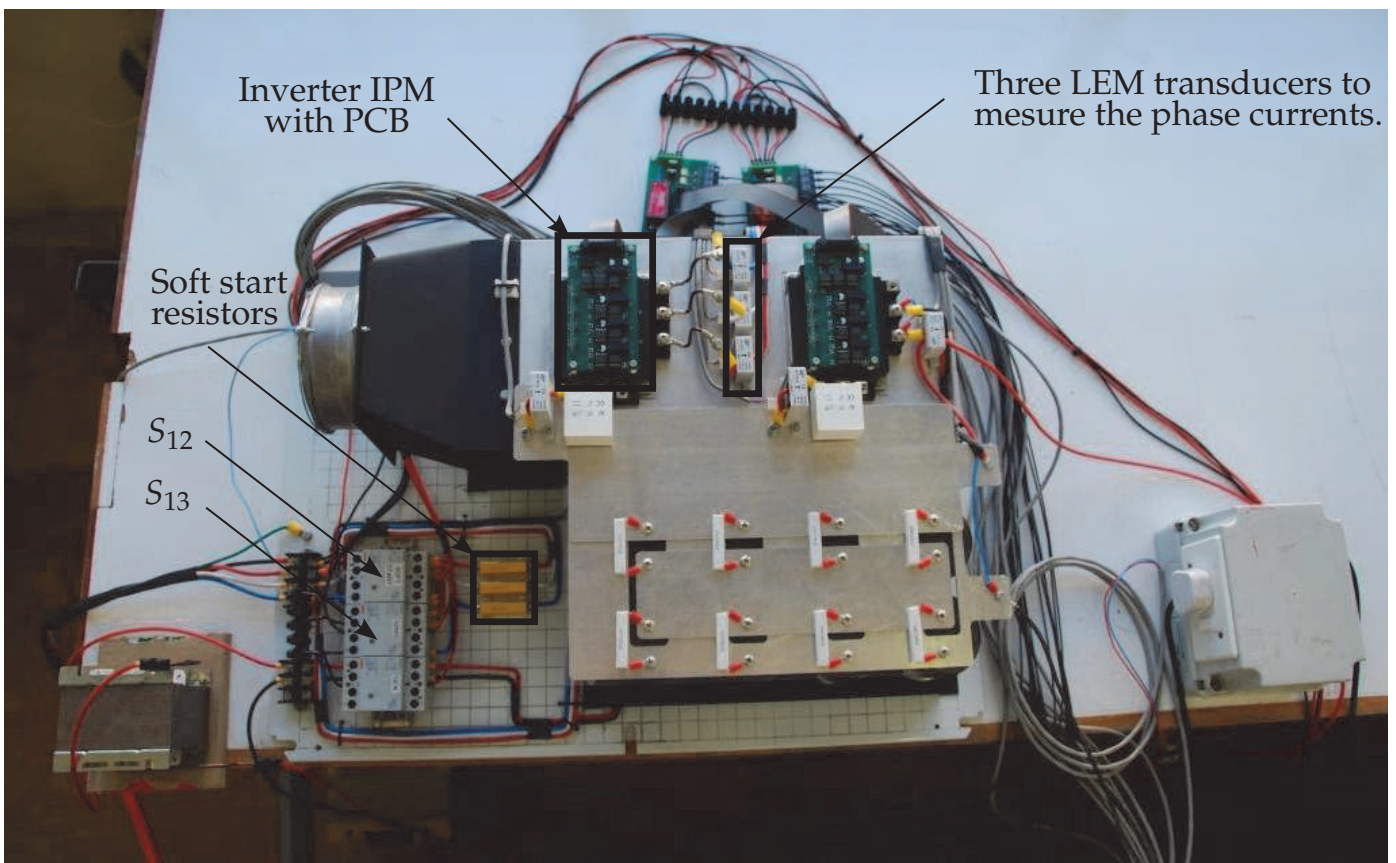

Figure 5.39: Top view of the power electronic converter indicating relevant components of the inverter. 


\subsection{Results}

As mentioned in section 4.5, the back-to-back converter was first tested at approximately three times lower than rated values to ensure proper functioning of the control implemented and later when the higher value measurement was done the anti-parallel diodes failed due the issues regarding the soft-start resistors. Therefore, test results of the inverter are, like the rectifier, only shown at the lower scaled values. The reference value for the DC bus voltage was $250 \mathrm{~V}$ for all the results shown in this section.

Figure 5.40 shows the voltages and current on the a-phase as well as the d-component of the reference current. The q-component is zero. $V_{f a}$ is the voltage measured between the point where the a-phase connects to the IGBT's and the ground connected to the filter capacitors as shown in figure 5.1.

The harmonics as discussed in the previous sections of this chapter are also visible on the current $i_{a}$. All the signals in figure 5.40 are digitally filtered at $10 \mathrm{kHz}$ with a second order digital Bessel-Thompson low pass filter. The filtering is done from left to right and again from right to left so that no phase shift occurs. All the post process digital filtering mentioned in this section refer to this filtering method.

Figure 5.41 depicts the same signals as shown in figure 5.40, but for the Simplorer simulation, also filtered at $10 \mathrm{kHz}$. One can see that the measured results correlate to the simulation results.

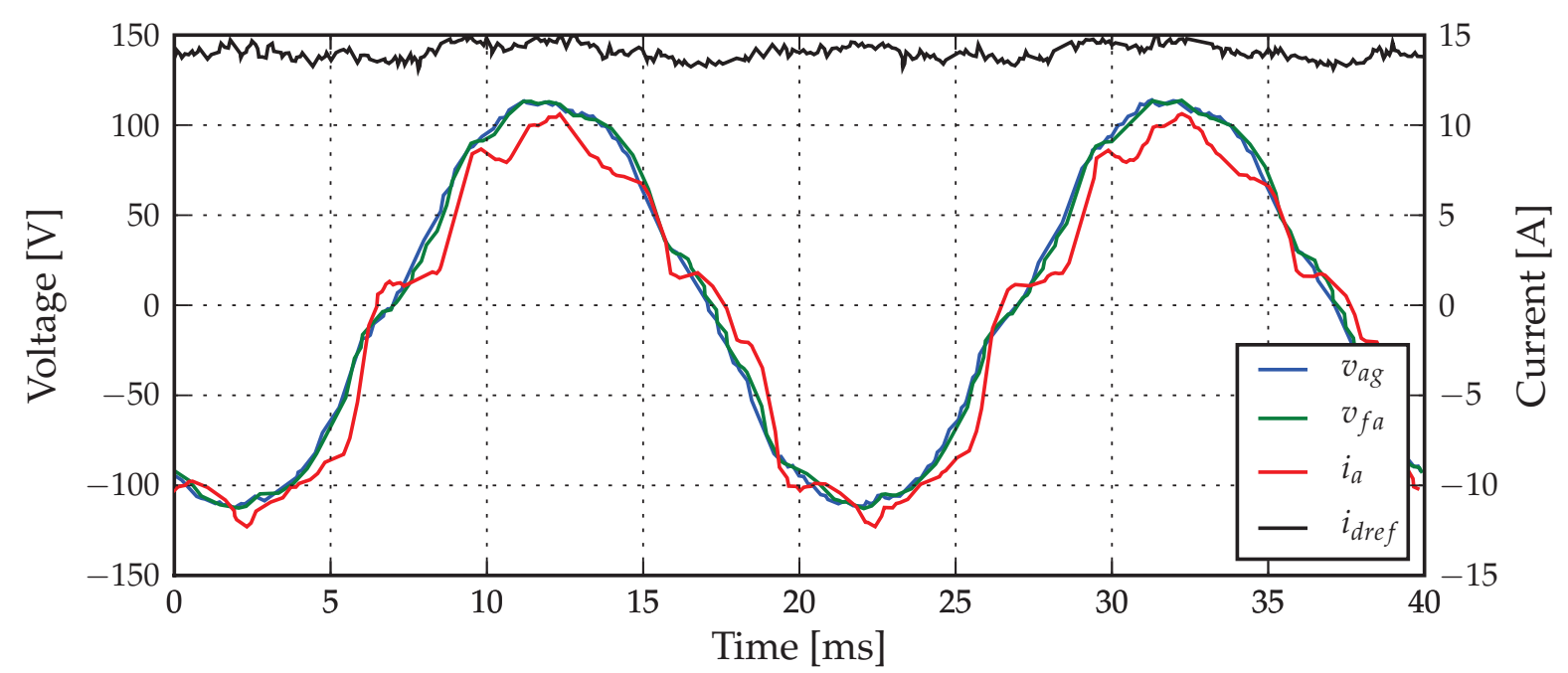

Figure 5.40: Measured a-phase voltages with the a-phase current and the reference current.

The DC current into the bus $\left(I_{d c i}\right)$ was supplied with a passive three-phase rectifier during the practical test. The ripple due to the passive rectifier as well as the output 


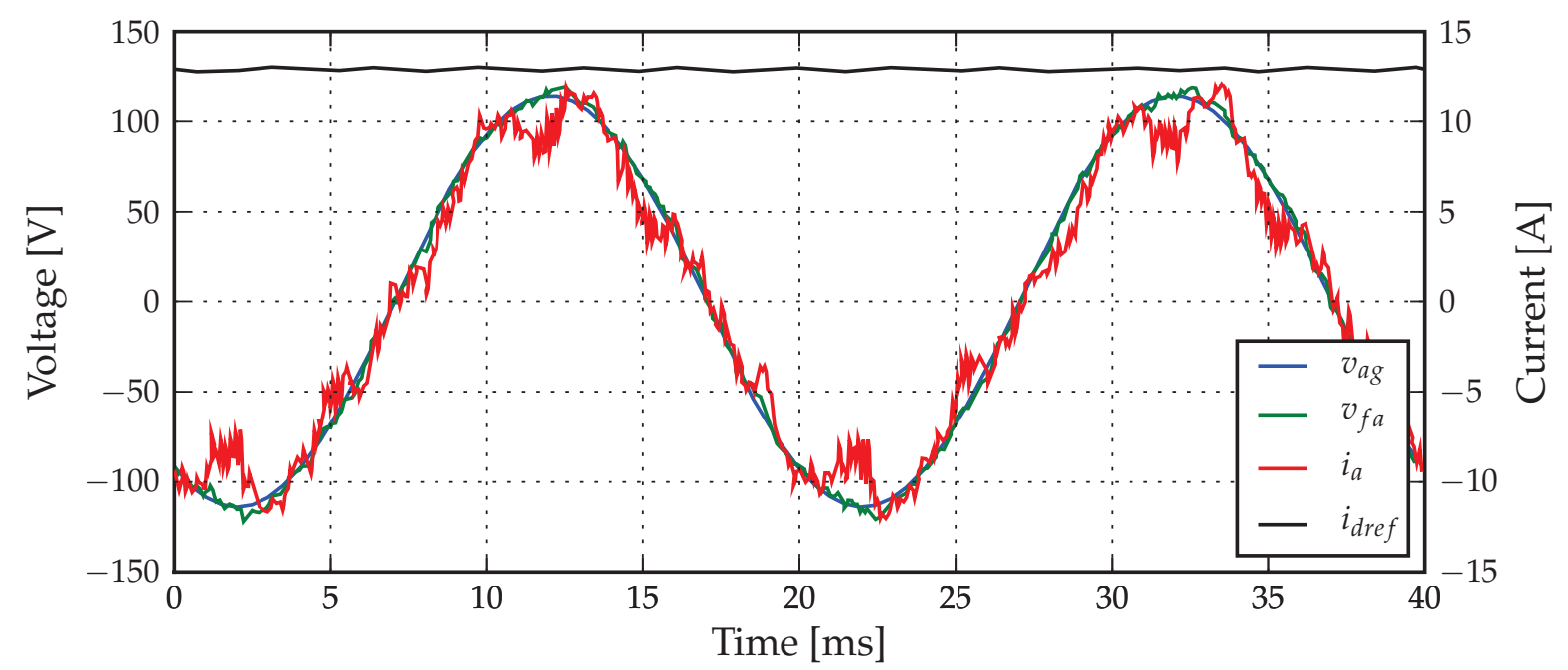

Figure 5.41: Simulated a-phase voltages with the a-phase current and the reference current.

DC current $\left(I_{d c o}\right)$ of the bus is depicted in figure 5.42. Figure 5.43 shows $I_{d c i}$ and $I_{d c o}$ as simulated in Simplorer with a DC current into the bus. The signals in figures 5.42 and 5.43 are also digitally filter at a frequency of $10 \mathrm{kHz}$.

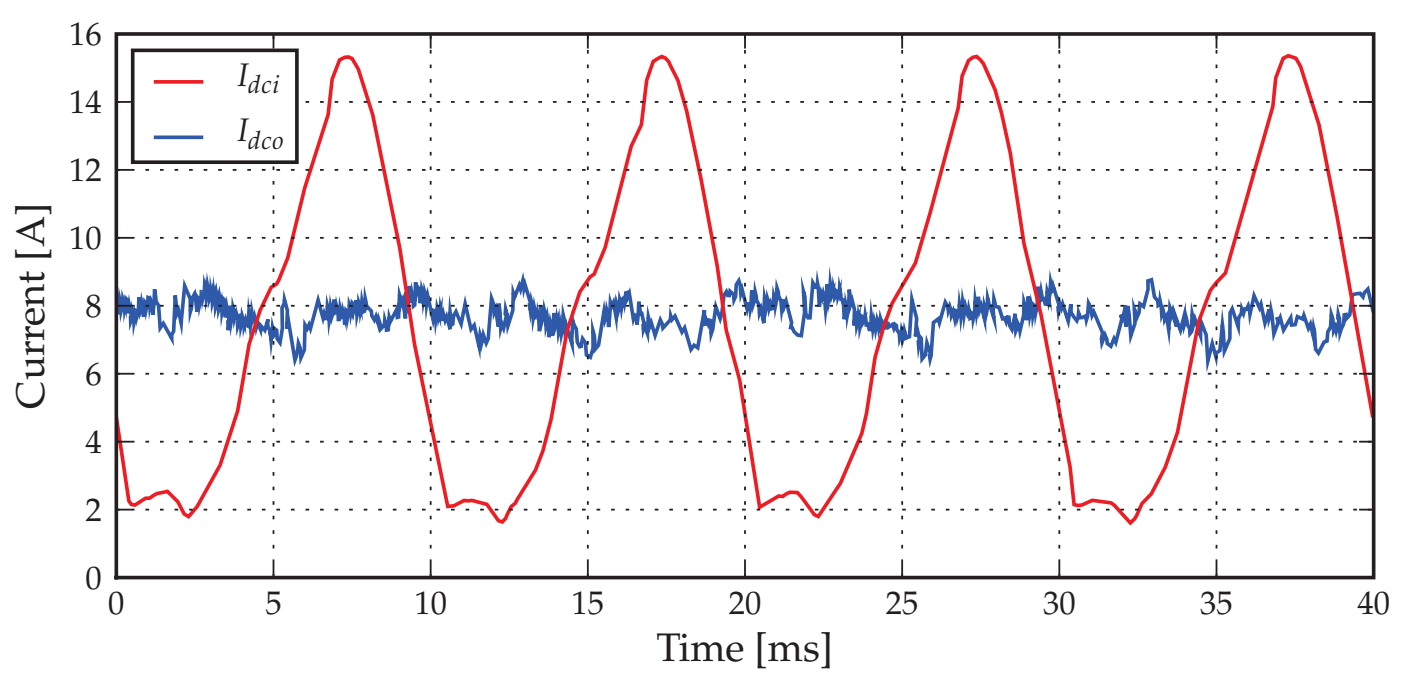

Figure 5.42: Measured input and output DC bus current.

The measured bus voltage shown in figure 5.44 are also digitally filtered, but at 500 Hz. The ripple seen on the bus voltage is due to the current ripple from the passive rectifier. Figure 5.45 shows the bus voltage as simulated. The ripple is significantly less due to a DC current supply to the DC bus.

A simulation was done in Simplorer to simulate the DC current with the large ripple as supplied by the passive rectifier. Figure 5.46 shows the input and output DC current for the simulated passive rectifier current. Figure 5.47 shows the simulated bus voltage with the DC input current that resembles the ripple current of the passive rectifier. This 


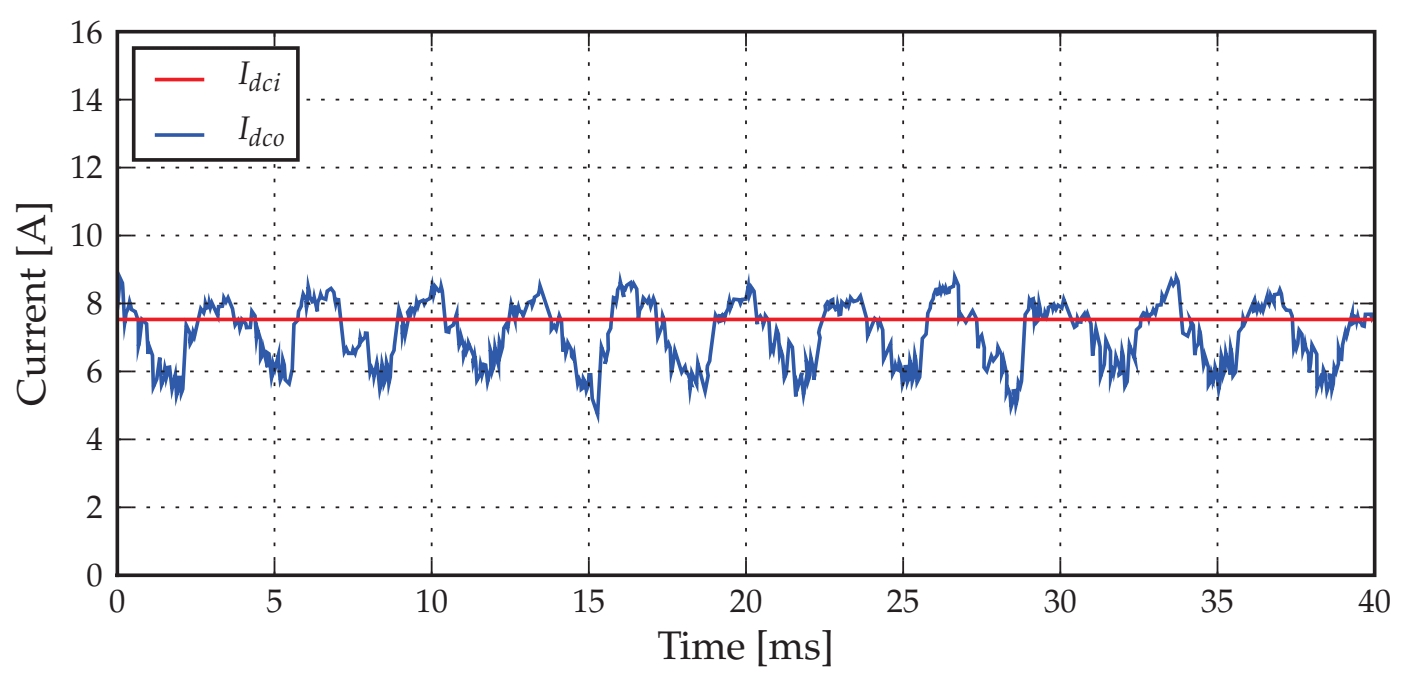

Figure 5.43: Simulated input and output DC bus current.

verify that the ripple on the measured bus voltage is due to the passive rectifier used to supply the input DC current to the bus.

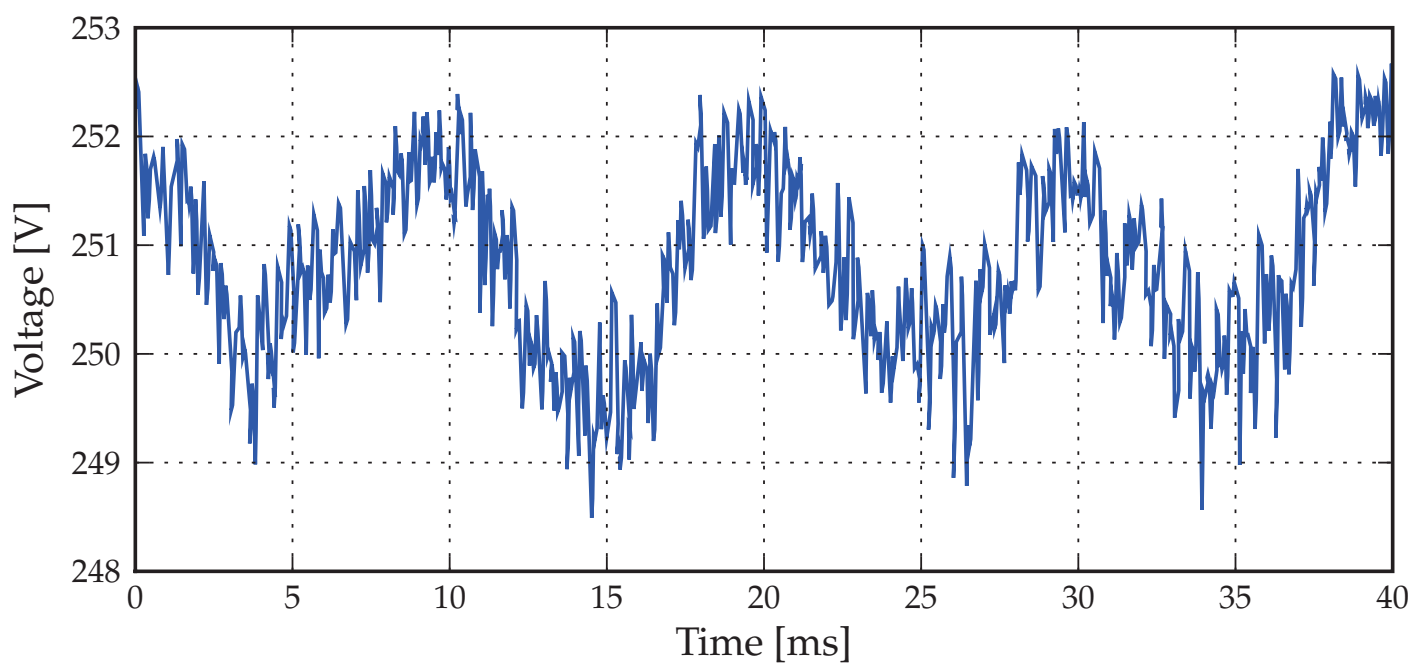

Figure 5.44: Measured DC bus voltage.

Figures 5.48 and 5.49 shows the transient response during the start up procedure for the measured values and the simulated values respectively. The figures show the relevant DC current and the DC bus voltage as well as the d-component of the current reference.

The $i_{\text {dref }}$ signal in figure 5.48 is equal to -25 A for approximately $150 \mathrm{~ms}$. $i_{\text {dref }}$ should have been equal to zero for this time period, as confirmed by the simulation in figure 5.49. This is due to the digital to analogue converter (DAC) of the digital system that gave an output equal to the negative rail of the DAC. The DAC gave this output because the inverter control start only when the bus voltage is equal to $125 \mathrm{~V}$ and there- 


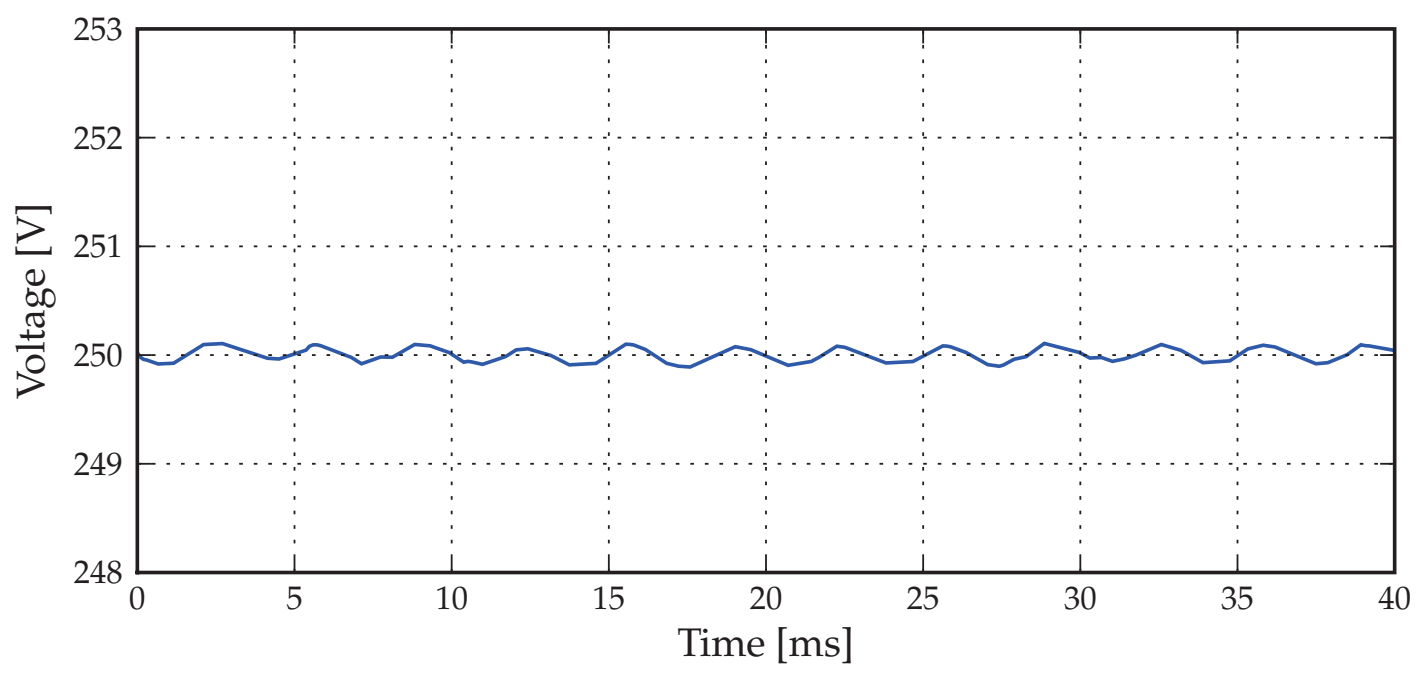

Figure 5.45: Simulated DC bus voltage.

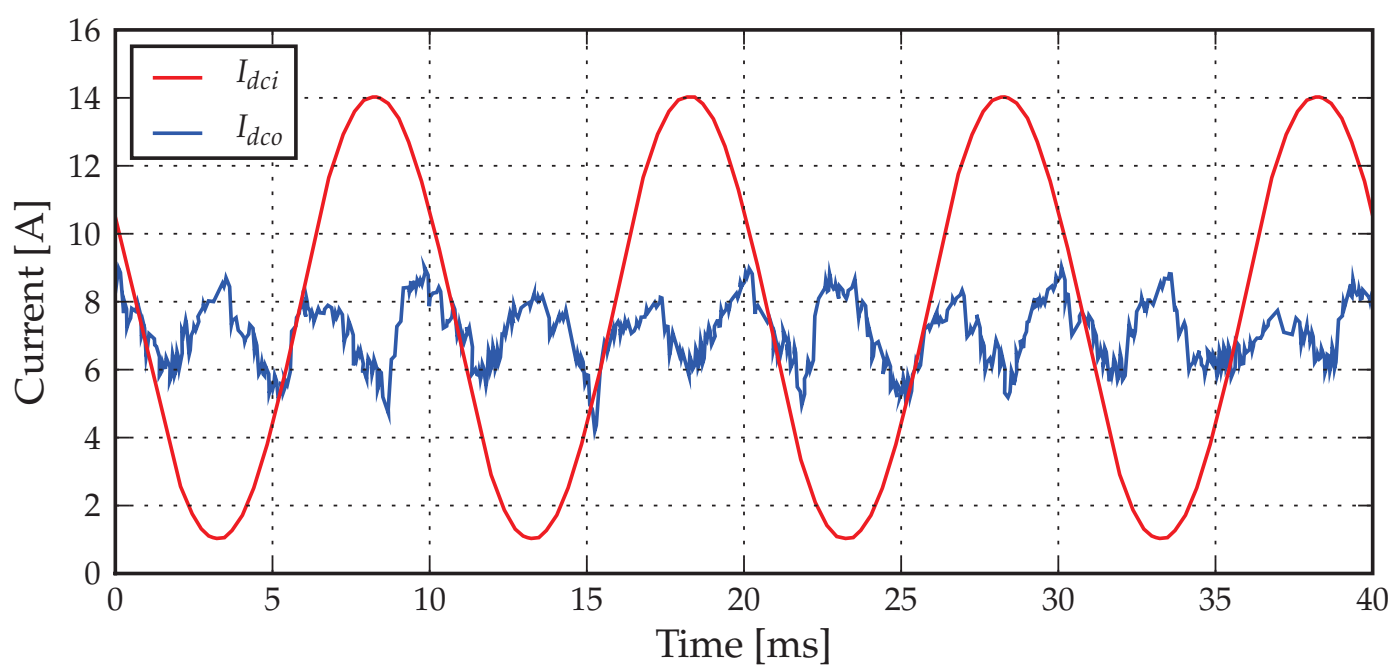

Figure 5.46: Verification (simulated) of current ripple due to three phase passive rectifier as input to bus.

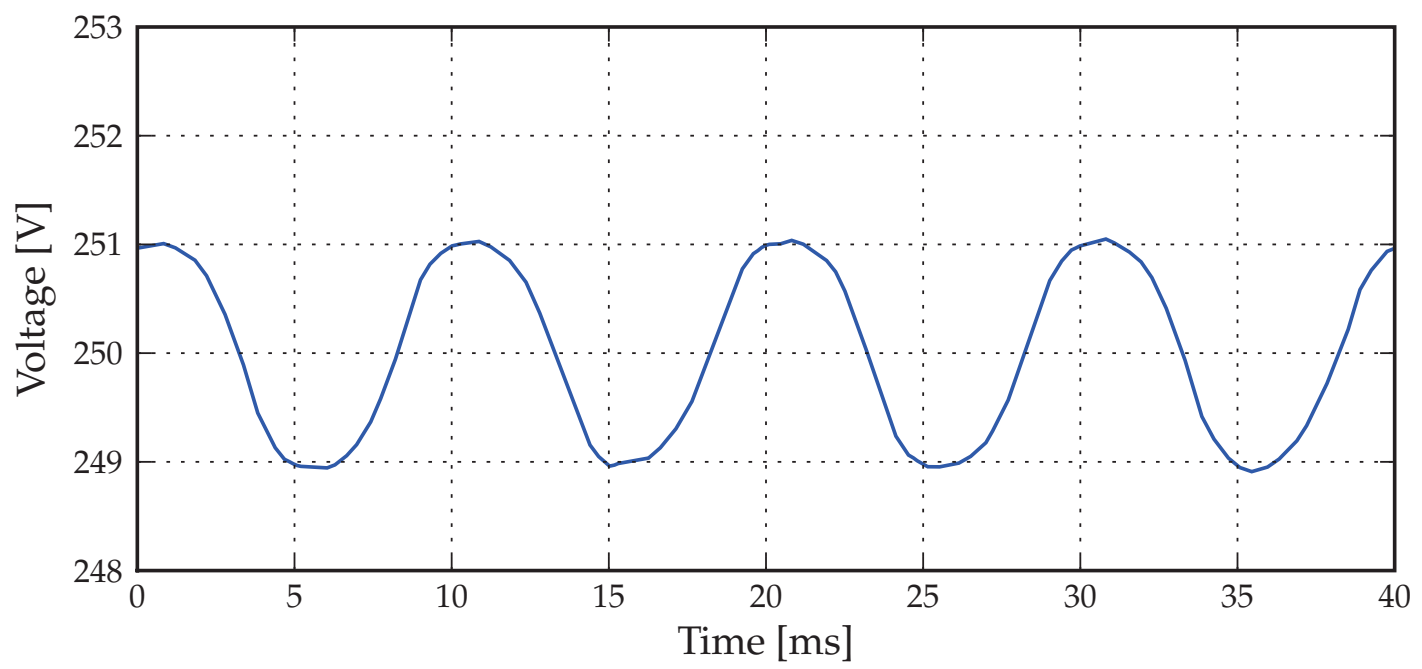

Figure 5.47: Simulated verification of the DC bus ripple due to the three phase passive rectifier as input to the bus. 
fore the value for $i_{\text {dref }}$ was not yet assigned before the inverter control started. $i_{\text {dref }}$ is limited as $15 \mathrm{~A}$ in both cases.

There is a slight delay in the measured result at the point where the inverter control takes over. This is because the contactor has a finite switching time. In both cases one can see that the bus voltage settles at the desired reference of $250 \mathrm{~V}$.

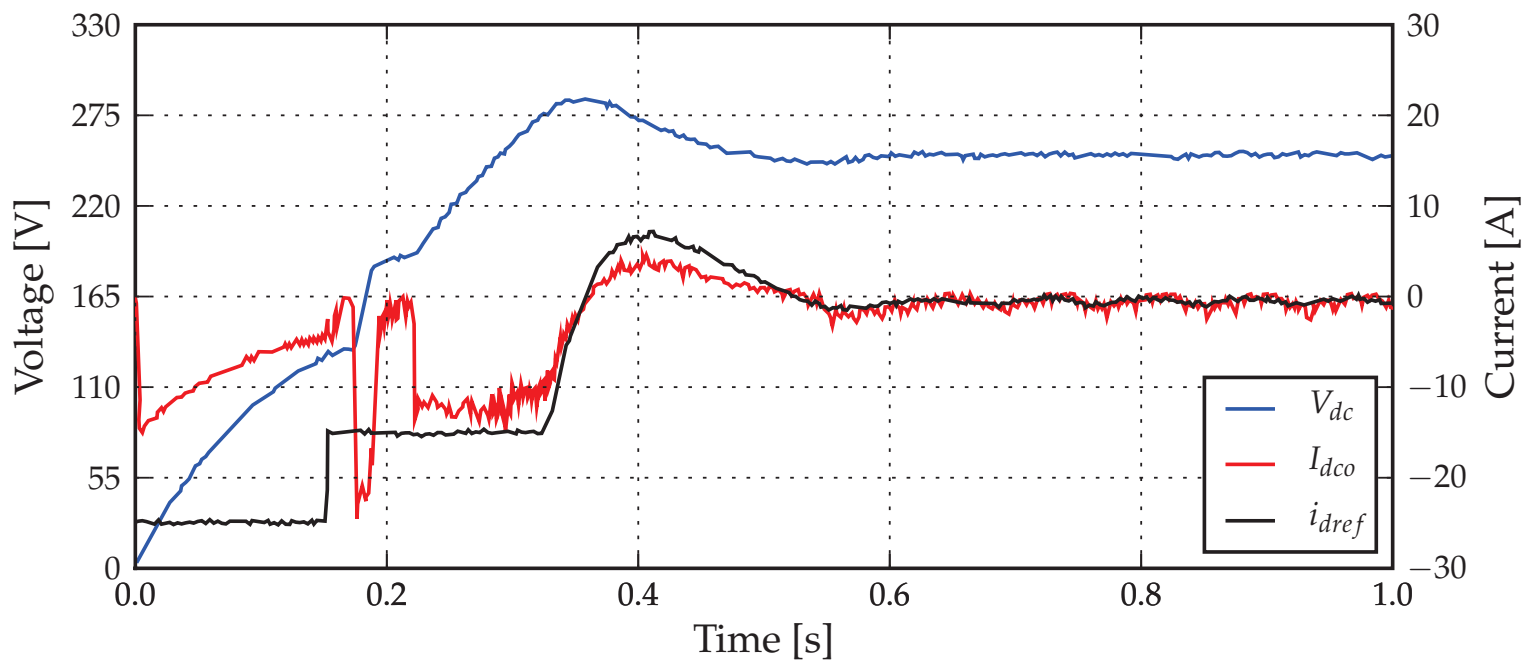

Figure 5.48: Measured transient signals at start up.

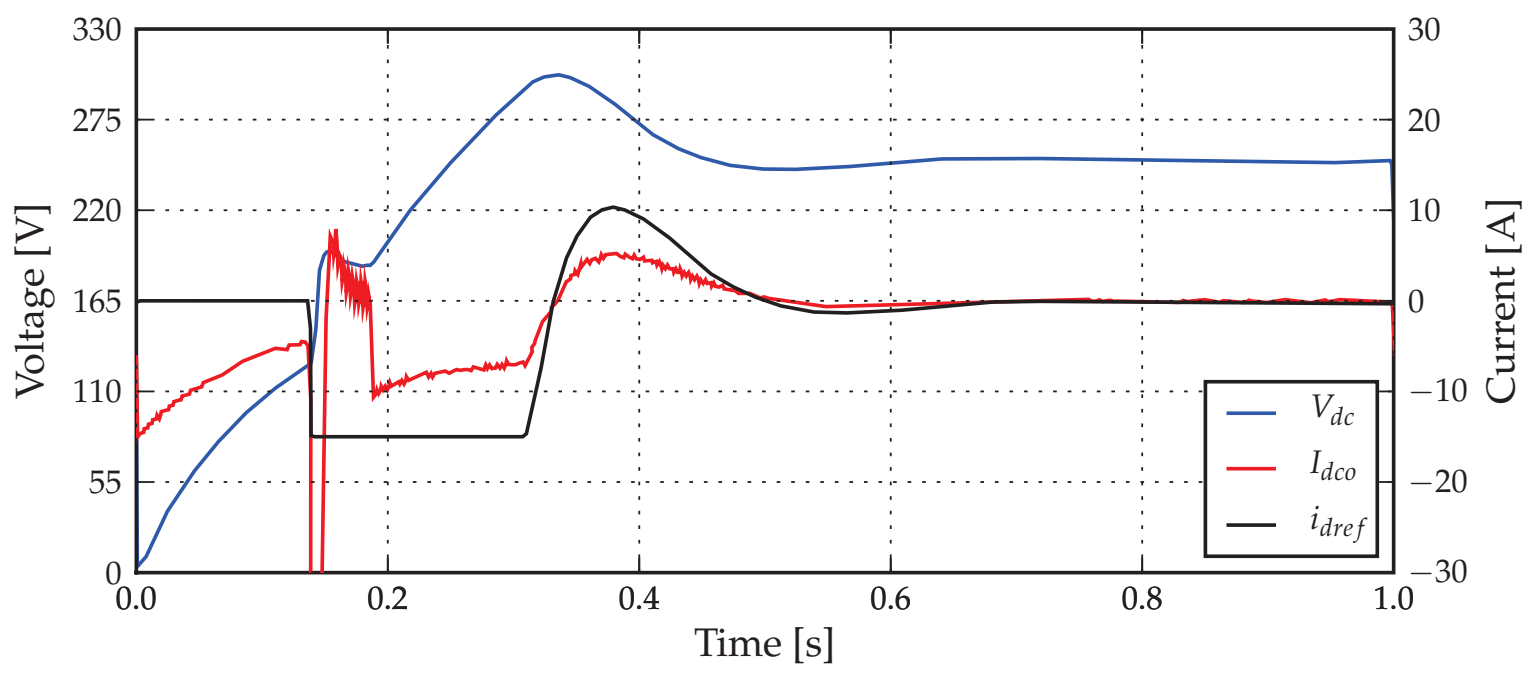

Figure 5.49: Simulated transient signals at start up.

\subsection{Conclusive remarks}

In this chapter the design and implementation of a $20 \mathrm{~kW}$ three-phase inverter was discussed. A simple PI controller was used to control the DC bus voltage at $250 \mathrm{~V}$. The rated bus voltage was designed to be $750 \mathrm{~V}$, but due to issues with the soft-start 
resistors, the anti-parallel diodes of the IGBTs failed. Therefore, the only test results available are those of the three times lower than rated tests which were done before components of the system failed.

A PI current control technique, using the $d q$ reference frame, was implemented. The duty cycles for the phase-arms were determined using space vector pulse width modulation (SVPWM). SVPWM was used due to its main advantage of being capable to operate with a bus voltage 15\% lower than compared to sinusoidal PWM. A major disadvantage of SVPWM is that it injects 7th order harmonics into the system. This was a big issue especially concerning tests that were done at one third of the rated design values. It is recommended that a different modulation scheme should be investigated when the control scheme is updated in the future, since the advantage of SVPWM named above is not of absolute importance in this case. 


\section{Chapter 6}

\section{Conclusion and recommendations}

Two of the most important aspects that a linear generator for Stirling engine applications must have are robustness and manufacturability. Tubular transverse flux (TF) linear generators are easier to manufacture than the tubular longitudinal (LF) generators which require wedge shaped laminations for manufacturing. The shape of tubular TF linear generators correspond better to the shape of free-piston Stirling engines than flat linear generators. This makes the tubular TF linear generator a more desirable option.

Tubular TF linear generators can be divided into several categories, two of which are extensively discussed in this project. The first one is the moving iron transverse flux permanent magnet (TFPM) linear generator and the second topology, which is the core of this thesis, is the moving magnet TFPM linear generator which is similar to the dualstator moving magnet topology described by Infinia Corporation. However, the dualstator generator faces challenges concerning the manufacturing of a magnet carrier due to the magnets being near the outside radius with two air gaps. While the moving magnet TFPM linear generator, which is a possible candidate for free-piston Stirling engines, have magnets mounted on the translator iron which results in only one air gap.

The moving magnet TFPM linear generator was geometrically optimised with the aim to maximise the power-to-weight ratio while maintaining preset power and efficiency levels. A $3 \mathrm{~kW}$ TFPM linear generator was successfully designed and built. The efficiency was designed to be $95 \%$ which was confirmed with the FE simulation, although a practical measurement of the efficiency could not be obtained. The efficiency of the dual-stator design described by Infinia Corporation is not revealed in literature.

Infinia Corporation claim that the dual stator moving magnet generator, which is a 3.1 
$\mathrm{kW}$ generator, has approximately half the mass of their previous $26 \mathrm{~kg} 1 \mathrm{~kW}$ moving iron generator they designed. This implies a power-to-weight ratio improvement of approximately six times.

The obtained total power-to-weight ratio of the moving magnet TFPM linear generator, discussed in this thesis, is approximately $0.124 \mathrm{~kW} / \mathrm{kg}$, which is a significant improvement on the total power-to-weight ratio of the moving iron topology described by Boldea and Nassar which is $0.058 \mathrm{~kW} / \mathrm{kg}$.

The only candidate for free-piston Stirling engine applications in the longitudinal flux linear generator group is the air-core linear generator due to the manufacturability advantage that it holds over the iron core LF linear generator that needs wedged shaped laminations. Therefore the moving magnet TFPM linear generator and the dual-stator design by Infinia Corporation are good candidates for free-piston Stirling engine applications. The only drawback is that there is very little information available on TF linear generators used for Stirling engine applications.

Regarding the moving magnet TFPM linear generator, there was difficulty aligning the moving magnet TFPM linear generator axle with the test bench, because the linear engineering plastic bearings are very sensitive to misalignment and that there are too many fixed points on the drive shaft which did not make the task any easier. The counterweight on the crank was not correctly balanced which contributed to the alignment issues. The alignment was fine-tuned with great effort to overcome this problem. Therefore one should consider using a linear test bench instead. Another option to overcome alignment issues is to use flexure bearings although great care should be taken due to the difficult design process.

Due to too much vibration on the test bench, the tests on the moving magnet TFPM linear generator were done at $10 \mathrm{~Hz}$ instead of the $50 \mathrm{~Hz}$ design specification. The vibrations of the test bench are a result of the conversion of rotational movement of an electrical motor being converted to a linear movement using a crank system. In future development of these generators a linear test bench should be considered as a possible alternative to the current test bench being used or rather test the generator in motor modus with a variable magnetic load.

Another option to improving the TFPM linear generator technology in general is to connect the moving magnet TFPM linear generator to the displacer piston instead of the power-piston. A dual-stator linear generator, introduced by Infinia Corporation can then be connected to the power-piston. The moving magnet TFPM linear generator will therefore have a lower power rating than the dual-stator linear generator, resulting in the moving magnet TFPM linear generator to be smaller in size than the dual-stator 
linear generator. In general the dual-stator linear generator has bigger inner diameter compared to the other TFPM linear generators. This allows the moving magnet TFPM linear generator to fit inside the inner diameter of the dual-stator linear generator. This will in effect combine two generators, i.e. the same steel laminations will be shared, but with different coils and magnets.

Even though only a selection of variables were chosen to be optimised the selection could be adjusted, i.e. adding freedom to variables in the z-direction.

The current control scheme of the rectifier needs to be improved to accommodate the fact that the emf of the generator cannot be measured directly during load operation. By resolving the measurement issue of the emf, much better results can be achieved regarding the energy transfer between the generator and the rectifier.

A three-phase $20 \mathrm{~kW}$ back-to-back converter was designed and implemented. Only two of the phase arms of the rectifier was used because the single phase moving magnet TFPM linear generator topology was connected to the input of the rectifier.

Predictive current control was successfully implemented and tested with a voltage supply connected to the input of the rectifier. A test was also done with the generator connected to the rectifier in order to evaluate a more practical approach. There was difficulty determining the emf of the generator operating under load conditions due to limited measuring techniques available. A simple PI controller was used to control the DC bus voltage at $250 \mathrm{~V}$, although the rated bus voltage was designed to be $750 \mathrm{~V}$. A PI current control technique, using the $d q$ reference frame, was implemented to control the output AC current of the inverter. The duty cycles for the phase-arms were determined using space vector pulse width modulation (SVPWM). A major disadvantage of SVPWM is that it injects 7th order harmonics into the system. This was discovered after the project was completed. It is recommended that a different modulation scheme should be investigated when the control scheme is updated in the future.

The following additional components were not implemented during the design of the back-to-back converter due to time constraints and should considered in order to improve the functionality of the converter:

- Deadtime compensation

- Compensation for the delay caused by the digital control scheme

- Ratings of the soft-start resistors

- Updating the digital control system which includes creating new non-generic PCBs for the digital control system 
- Enhanced soft-start procedure, i.e. control the DC bus voltage to a point which is higher than the maximum point that the electrical network can load the bus to through use of only the diodes. 


\section{Bibliography}

[1] C. M. Hargreaves, The Philips Stirling engine. The Philips Stirling engine. Elsevier Science Publishers B.V., 1991.

[2] G. T. Reader and C. Hooper, Stirling Engines. E. and F.N. Spon, 1983.

[3] G. Walker, Stirling Engines. Oxford University Press, 1980.

[4] W. T. Beale, "The free piston stirling engine: 20 years of development orlando, $\mathrm{fl}$," Proceedings of the 18th Intersociety Energy Conversion Engineering Conference, vol. vol. 2, pp. 689-693, August 1983.

[5] S. Qiu, D. L. Redinger, and J. E. Augenblick, "The next generation infinia freepiston stirling engine for micro-chp applications," Proceedings of the 12th International Stirling Engine Conference and Technology Exhibition, pp. 158-160, Sep. 2005.

[6] I. Boldea and S. A. Nasar., Linear Electric Actuators and Generators. Cambridge University Press, New York., 1997.

[7] W. M. Arshad, "A low-leakage linear transverse-flux machine for a free-piston generator." Ph.D. dissertation, Royal Institute of Technology, Stockholm, 2003. pp. 70-73.

[8] J. Schutte and J. Strauss, "Optimisation of a transverse flux linear pm generator using 3d finite element analysis," International Conference on Electrical Machines (ICEM), 2010.

[9] W. Arshad, P. Thelin, T. Bäckström, and C.Sadarangani, "Use of transverse-flux machines in a free-piston generator," IEEE Transactions on Industry Applications, vol. vol. 40, no. 4, pp. 1092-1100, July/August 2004.

[10] W. Arshad, T. Bäckström, P. Thelin, and C. Sadarangani, "Integrated free-piston generators: An overview," Electrical Vehicle Symposium, 2002.

[11] P. Zheng, A. Chen, P. Thelin, W. Arshad, and C. Sadarangani, "Research on a tubular longitudinal flux pm linear generator used for free-piston energy converter," IEEE Transactions on Magnetics, vol. vol. 43, no. 1, pp. 447-449, 2007. 
[12] L. Hultman and A. Jack, "Soft magnetic composites - materials and applications," International Electrical Machines and Drives Conference (IEMDC), vol. vol. 1, pp. 516 $-522,2003$.

[13] F. Kappel and A. V. Kuntsevich, "An implementation of shor's r-algorithm," Computational Optimisation and Applications 15, pp. 193-205, 2000.

[14] M. Wolf, "Design and implementation of a modular converter with application to a solid state transformer," Master's thesis, Univertity of Stellenbosch, 2009.

[15] M. Kazmierkowski and L. Malesani, "Current control techniques for three-phase voltage-source pwm converters: A survey," IEEE Transactions on Industrial Electronics, vol. vol. 45, no. 5, pp. 691-703, 1998.

[16] M. Ryan, W. Brumsickle, and R. Lorenz, "Control topology options for singlephase ups inverters," IEEE Transactions on Industry Applications, vol. vol. 33, no. 2, pp. 493-501, 1997.

[17] D. Bester, “Control of series compensator for power quality conditioner," Master's thesis, Univertity of Stellenbosch, 1999.

[18] I. K. Hobbs, "Evaluation and implementation methods for converter of antiislanding converter-fed distributed generation," Master's thesis, University of Stellenbosch, 2009.

[19] S. Buso and P. Mattavelli, Digital Control in Power Electronics, J. Hudgins, Ed. Morgan \& Claypool, 2006.

[20] T. Skvarenina, Ed., The Power Electronics Handbook. CRC Press, 2002. 


\section{Appendix A}

\section{Construction of prototypes}

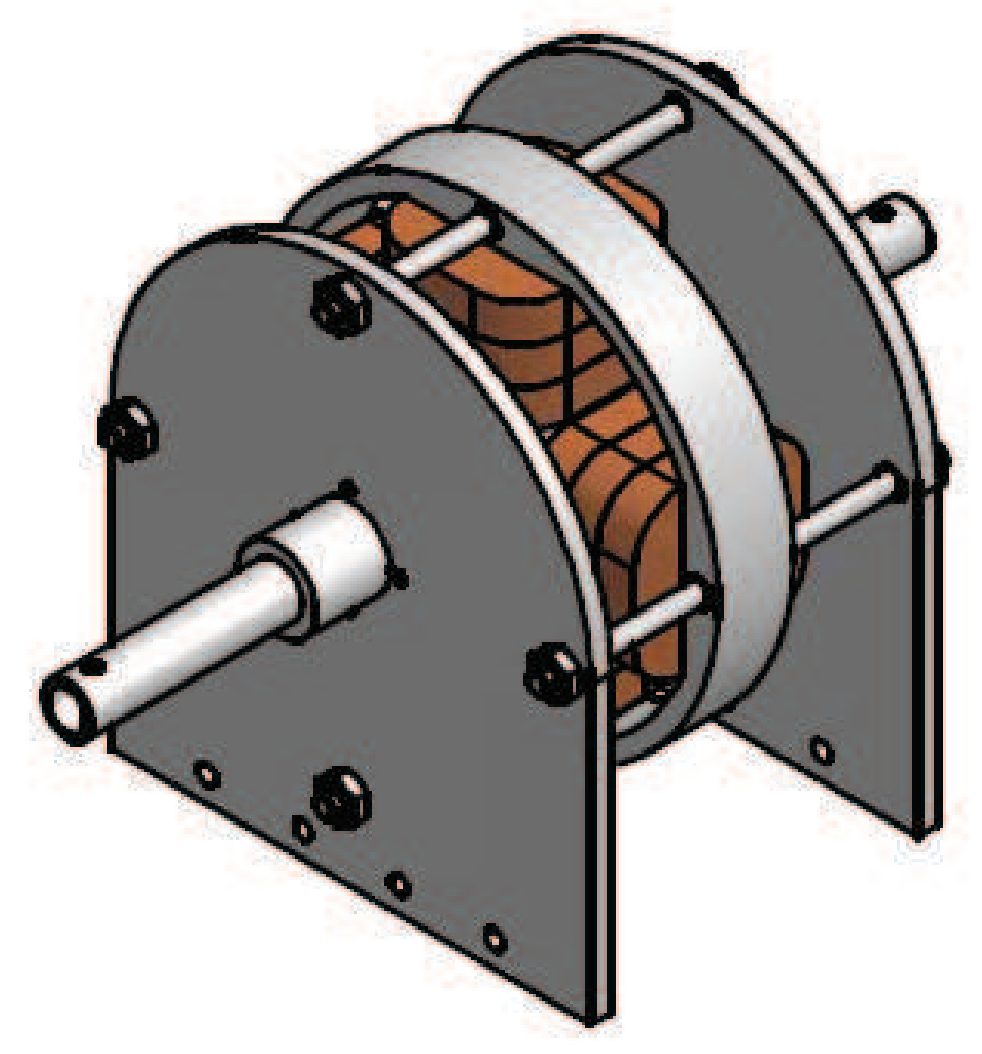

Figure A.1: Complete generetor as rendered in Inventor. 


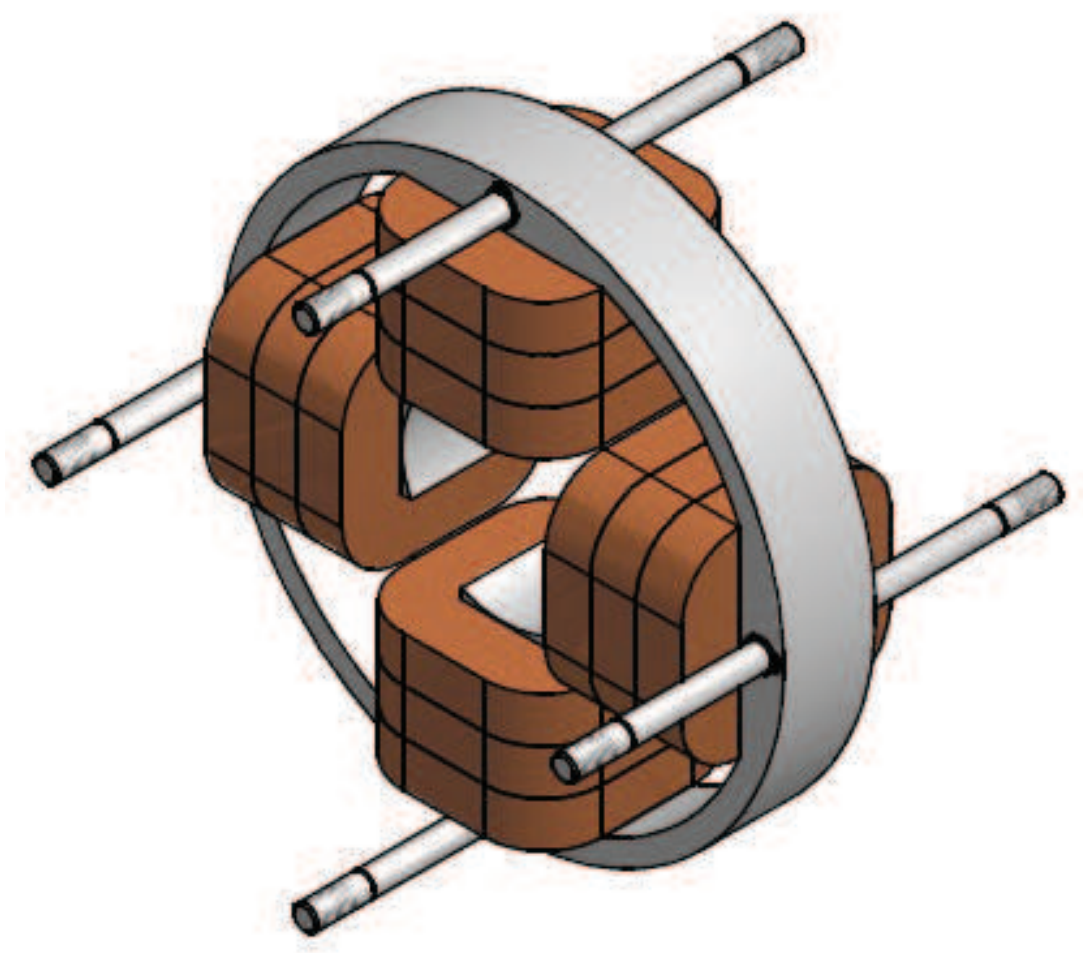

Figure A.2: Stator, coils and dowels unit of generator as rendered in Inventor.

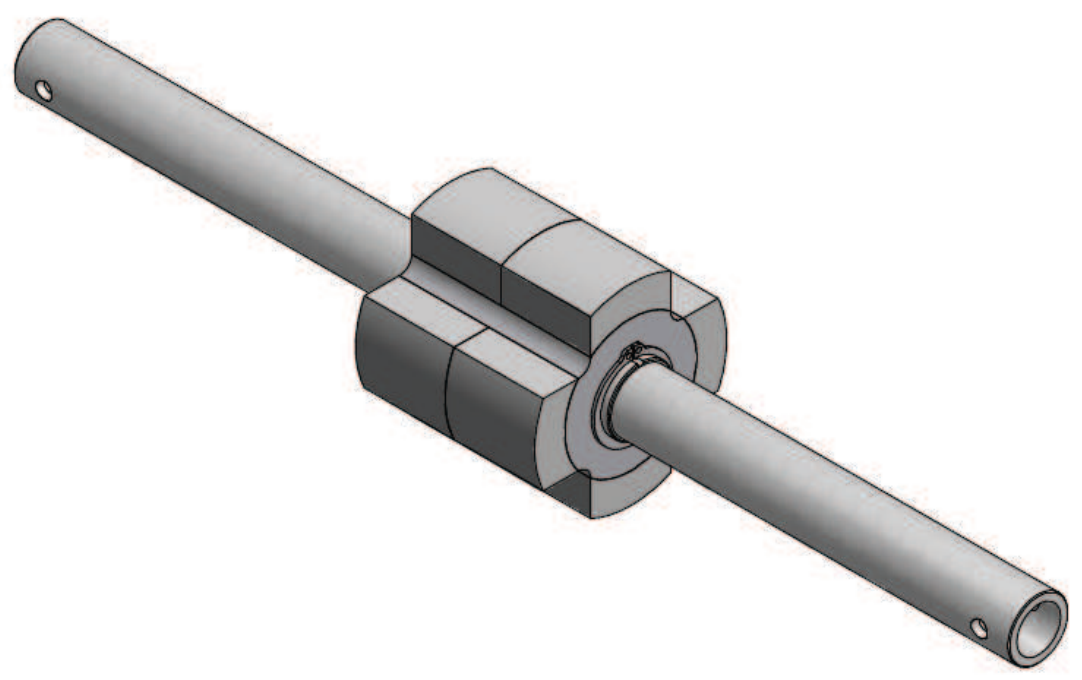

Figure A.3: Axle and magnets of generetor as rendered in Inventor. 


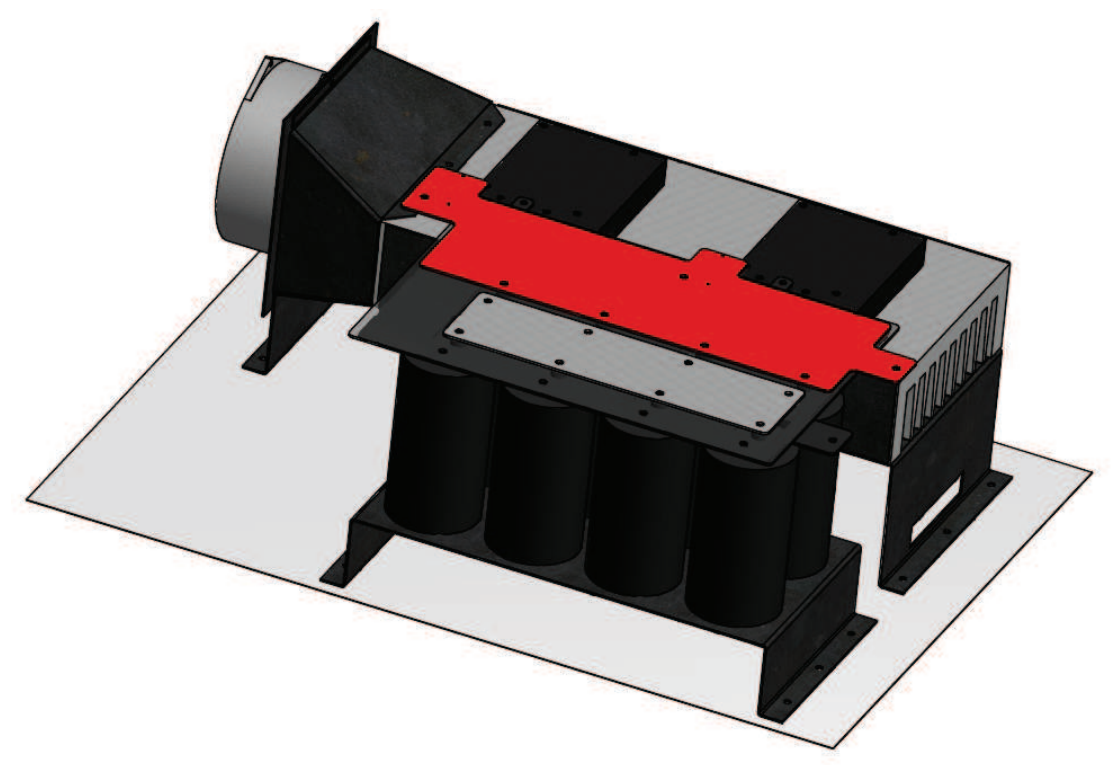

Figure A.4: Power electronic converter as rendered in Inventor.

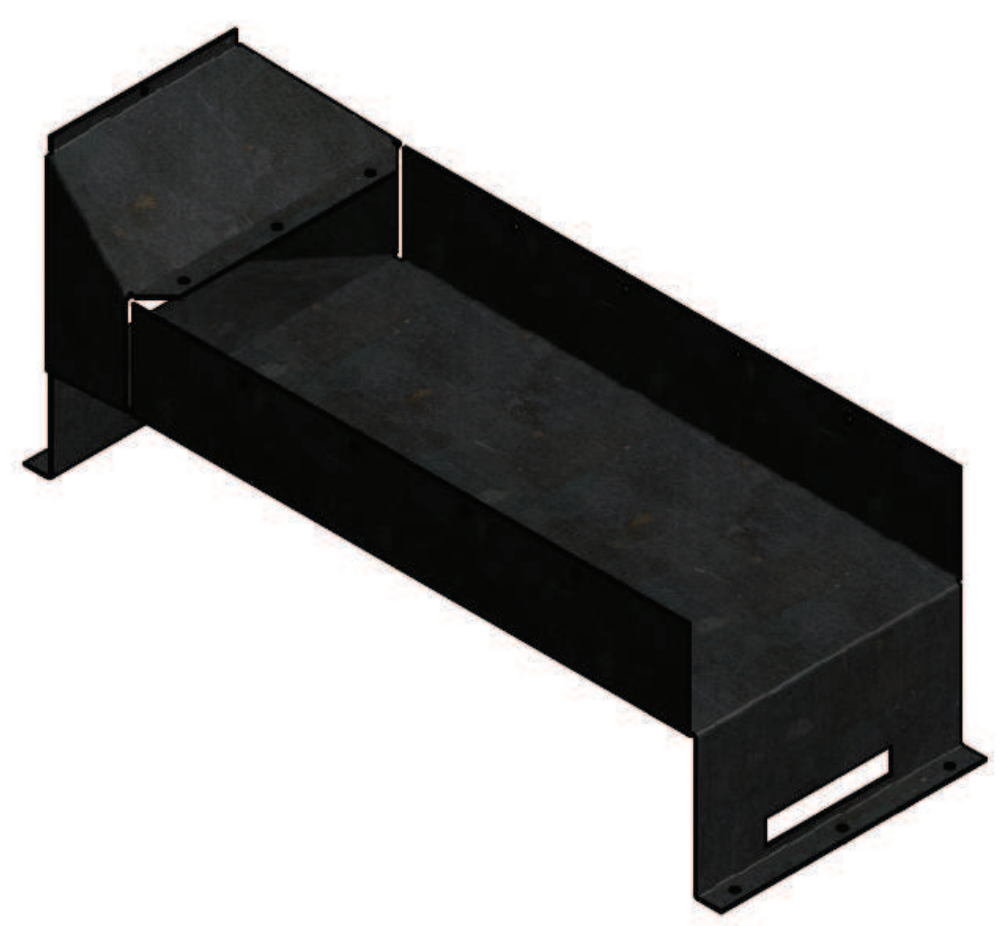

Figure A.5: Power electronic converter as rendered in Inventor. 


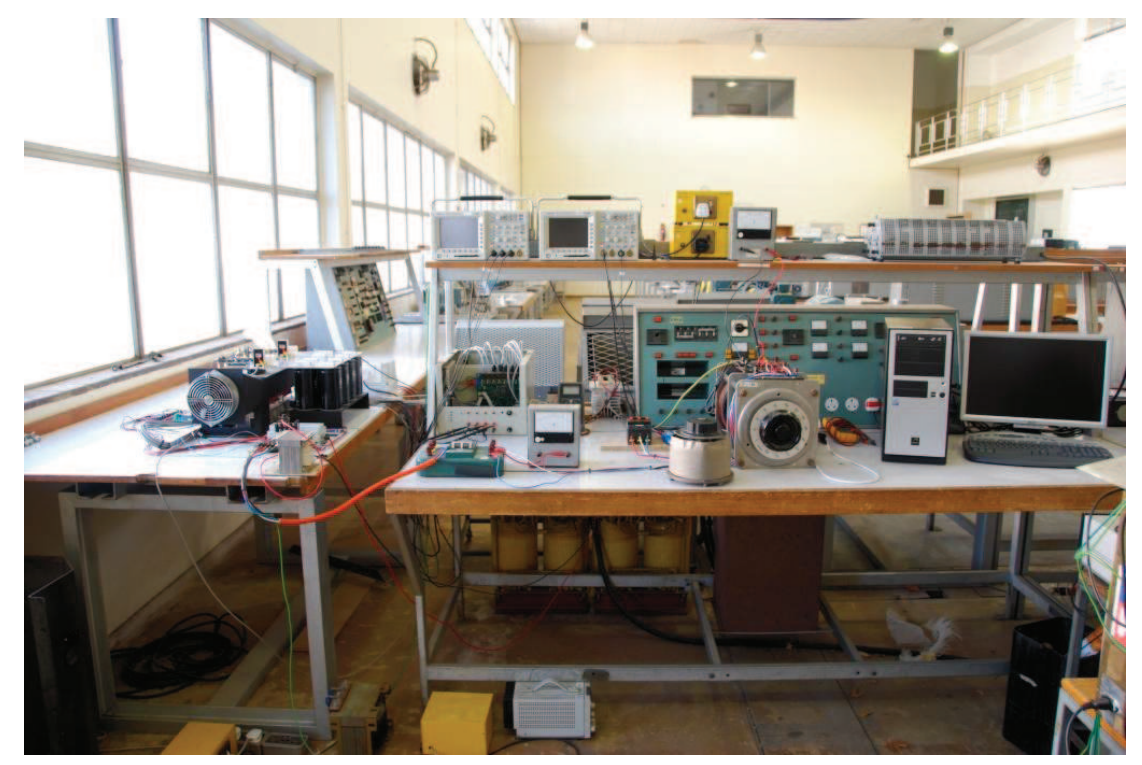

Figure A.6: Power electronic converter, switch gear, digital control hardware and measurement setup.

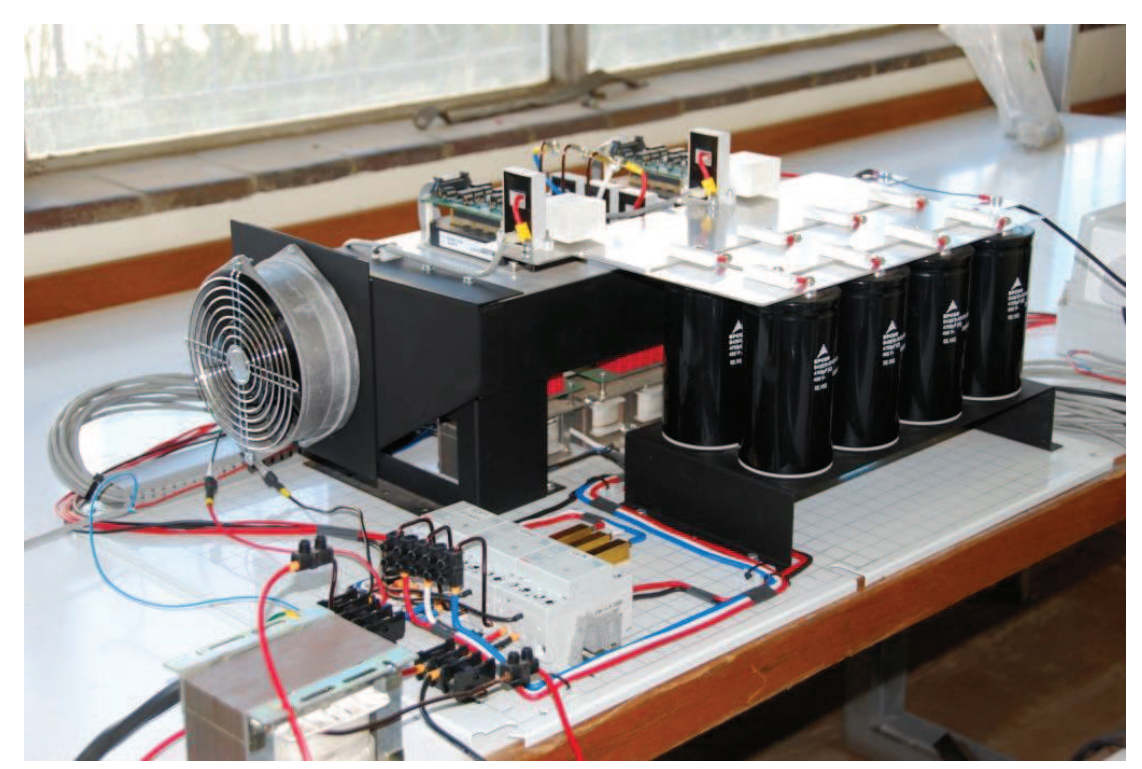

Figure A.7: Power electronic converter with inductors and filter capacitors visible. 


\section{Appendix B}

\section{Sallen-Key Filter}

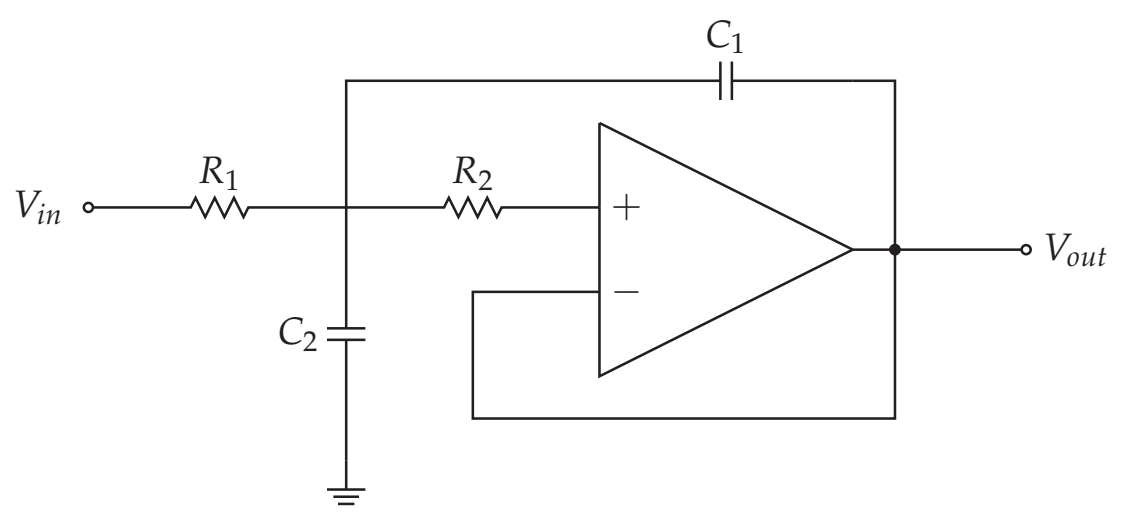

Figure B.1: Schematic diagram of a second order Sallen-Key LPF.

$$
f_{o}=\frac{1}{2 \pi \sqrt{R_{1} R_{2} C_{1} C_{2}}}
$$

where $f_{0}$ is the cut-off frequency chosen at $1 \mathrm{kHz}$ with $R_{1}$ and $R_{2}$ are chosen to be 16 $\mathrm{k} \Omega$ while $C_{1}$ and $C_{2}$ are chosen to be $0.01 \mu \mathrm{F}$. 